\title{
An Investigation of Learning and Experience Curves
}

Frank Krawiec John Thornton Michael Edesess
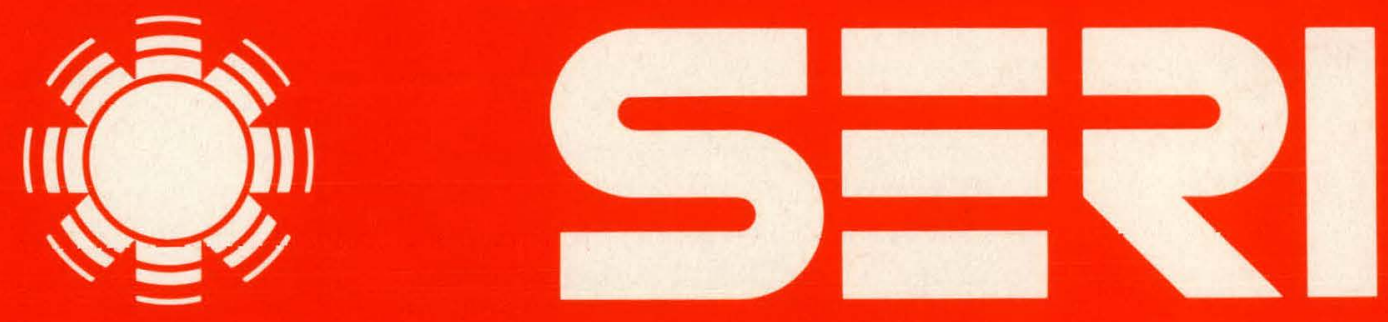

Solar Energy Research Institute

A Division of Midwest Research Institute

1617 Cole Boulevard

Golden, Colorado 80401

Operated for the U.S. Department of Energy under Contract No. EG-77-C-01-4042 


\section{DISCLAIMER}

This report was prepared as an account of work sponsored by an agency of the United States Government. Neither the United States Government nor any agency Thereof, nor any of their employees, makes any warranty, express or implied, or assumes any legal liability or responsibility for the accuracy, completeness, or usefulness of any information, apparatus, product, or process disclosed, or represents that its use would not infringe privately owned rights. Reference herein to any specific commercial product, process, or service by trade name, trademark, manufacturer, or otherwise does not necessarily constitute or imply its endorsement, recommendation, or favoring by the United States Government or any agency thereof. The views and opinions of authors expressed herein do not necessarily state or reflect those of the United States Government or any agency thereof. 


\section{DISCLAIMER}

Portions of this document may be illegible in electronic image products. Images are produced from the best available original document. 


\author{
Printed in the United States of America \\ Available from: \\ National Technical Information Service \\ U.S. Department of Commerce \\ 5285 Port Royal Road \\ Springfield, VA 22161 \\ Price: \\ Microfiche $\$ 3.00$ \\ Printed Copy $\$ 9.00$
}

\begin{abstract}
NOTICE
This report was prepared as an account of work sponsored by the United States Government. Neither the United States nor the United States Department of Energy, nor any of their employees, nor any of their contractors, subcontractors, or their employees, makes any warranty, express or implied, or assumes any legal liability or responsibility for the accuracy, completeness or usefulness of any information, apparatus, product or process disclosed, or represents that its use would not infringe privately owned rights.
\end{abstract}




\section{SERI/TR-353-459}

UC CATEGORIES: UC-62, 62a, 62b, $62 \mathrm{c}, 62 \mathrm{~d}, 62 \mathrm{e}$

\section{MASTER}

AN INVESTIGATION OF LEARNING AND EXPERIENCE CURVES

FRANK KRAWIEC JOHN THORNTON MICHAEL EDESESS

APRIL 1980

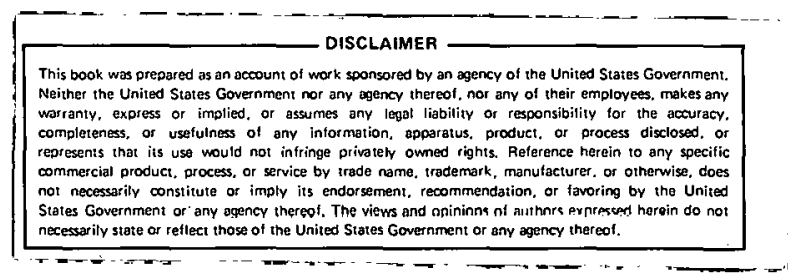

PREPARED UNDER TASK NO. 5227

\section{Solar Energy Research Institute}

1536 Cole Boulevard Golden, Colorado 80401

A Division of Midwest Research Institute

Prepared for the U.S. Department of Energy Contract No. EG.77.C.01.4042 


\title{
THIS PAGE
}

\section{WAS INTENTIONALLY}

\author{
LEFT BLANR
}




\section{PREPACE}

This final report was prepared for the Division of Energy Technology of the U.S. Department of Energy (DOE). It is the final product of the Investigation of Learning and Experience Curves, Solar Energy Research Institute (SERI) Task No. 5227, initiated in November 1979. The literature review was published in SERI Report RR-52-173, "Solar Cost Reduction through Technical Improvements: The Concepts of Learning and Experience." Arthur D. Little, Inc., under subcontract to SERI, prepared the final report on "Development of Surrogate Experience Curves for Costs Associated with the Production of Heliostats." J. H. Nourse of McDonnell Douglas Astronautics Company, under subcontract to SERI, prepared the final report on the "Prototype Heliostat Costing Scenario."

Primary SERI staff responsible for preparing this report were headed by Frank Krawiec, project leader and principal investigator. Michael Edesess and John Thornton wrote Sec. 6.0. Theresa Flaim was the major contributor to Report RR-52-173. Technical advice and support were provided by Dennis Costello, James Doane, Dennis Horgan, David Posner, Dennis Schiffel, Melvin Simmons, and John Thornton. Management assistance was given by Denn is Costello and Melvin Simmons.

The authors wish to express appreciation for the manuscript review and helpful suggestions of Gerald Bennington (MITRE Corp.); John Bigger (EPRI); Kirk Drumheller (Battelle); Steve Miller (Engineering and Public Policy, Carnegie Mellon University); and John Thornton (Systems Development Branch, SERI).

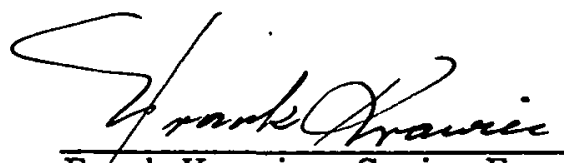

Frank Krawiec, Senior Econom ist Industrial Applications and Policy Branch

Approved for:

SOLAR ENERGY RESEARCH INSTITUTE
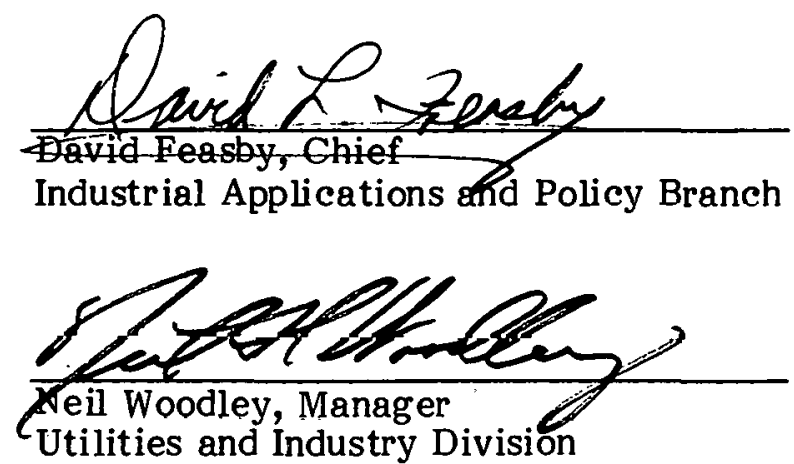
THIS PAGE

\section{WAS INTENTIONALLY LEFT BLANK}




\section{SUMMARY}

The applicability of the learning and experience curves to predict future costs of solar energy technologies here has as its major test case the production economics of heliostats. The literature review indica ted that the methods most of ten employed in past empirical studies to estimate and predict overall cost reduction in manufacturing new products are the "bottoms-up" engineering costs method, the engineering parametric approach, and aggregate cost estimation techniques. There are practical limitations to these methods when applied to predict cost reductions separately.

The unit cost estimated by application of the engineering bottoms-up cost method does not reflect an overall cost reduction due to labor learning, economies of scale, and technological change. Because of the dynamic nature of cost reduction in new products, generalized statements about specific cost data are meaningless. A thorough manufacturing cost analysis for a new system or product becomes complex when alternative techniques having their basis in the engineering bottoms-up cost approach are considered. In applying the engineering parametric approach, it is difficult to select a surrogate part relevant to a given product component in terms of configuration similarity, material correspondence, and fabrication congruency. Even if the surrogate parts or subassemblies are truly analogous, there are limitations inherent in the use of statistical inference.

In addition, cost histories on prior programs are imperfect indicators of future costs of a given design concept. The aggregate prediction of cost reductions in manufacturing new products involves a number of conceptual and analytical issues associated with relationships between changes in the costs of a firm and changes in its output: the cost function. Price theory gives most of its attention to two cost functions-the short-run and the long-run cost functions. Since price theory is based on the neoclassical theory of the firm, the short- and long-run cost functions can provide insights into economic and technical issues that influence the behavior of costs and prices over time. However, since neoclassical theory of the firm is a static, or at best a relatively static, depiction of behavior, it does not exhibit direct applicability of the short- and long-run cost functions to future cost reductions. The short-run cost function contains the assumption that the fixed costs, mainly those of the fixed plant and equipment, as well as the state of firm's technology, are constant.

Thus, the only short-run manufacturing cost reductions are those due to increasing labor productivity and improvement in management techniques. It is practically impossible to specify what the sources of short-run cost reduction will be for a new product. Therefore, in predicting cost reductions in manufacturing new products in the short-run, the learning curve based on bottoms-up engineering costs has been used as an approximation tool for future costs. The long-run cost function reflects unit cost changes due to the technology change and economies of scale.

Changes in scale, technology embodied in the fixed capital, and the inherent form of the product occur gradually over time. Consequently, the long-run cost function describes unit cost changes that are relatively smaller than those of the short-term. Although of great practical importance, it is not possible to estimate the relative proportions of total decrease in unit cost that are caused by changes in long-run cost reduction sources, or to characterize the manner in which unit-cost changes occur separately from changes in specified long-run cost reduction sources. It is not feasible to anticipate with any accuracy how and why the costs of a specific product are going to change in the future. In practice, the experience curve concept is applied as an aggregate tool to summarize cost 
changes resulting from a number of different long-run sources. This concept has been applied because it allows approximation of future manufacturing costs.

The most widely used definition of the learning concept refers to increased productivity of a direct single input (e.g., labor). In most industries, tooling changes, redesign of production methods, and improved management techniques are more important sources of cost reduction than direct labor learning. Broader definitions are too ambiguous to be used for cost estimation purposes. To reduce measurement problems, the learning concept could be applied to improvements in the production process which occur when the capital stock is fixed. Given these qualifications, the term learning curve is considered an aggregate to.ol that shows some empirical ability to summarize the sources of cost reductions in manufacturing new products within one particular process.

Although learning in the literal sense is restricted to improved productivity of direct labor input, the learning curve is an analytical tool applied to generalize the combined effects of both increased efficiency and management innovations. While the logic behind the learning concept does not suggest a particular functional form, the exponential function is the most widely used functional for $\mathrm{m}$. This for $\mathrm{m}$ is intuitively appealing because it reflects the fact that in some industries, progress is rapid during the early stages of production and continues at a decreasing rate.

The learning curve has been used as a basis for facilities and manpower scheduling, pacing assembly operations, and cost estimation. The use of learning curves for cost estimation is of primary interest. At the center of empirical studies is the concept of separating labor, materials, and overhead costs, the factors that make cost reductions and concomitant increases in quantity possible. An aggregated cost curve for direct application to different quantities of the end product can be developed by combining factors of labor, materials, and overhead.

The literature review indicated a greater, wider application of the learning curve model in labor-intensive production activities. There is a need for a greater application of the learning curve model in capital-intensive industries. Labor learning as defined here may be only a minor source of cost reduction in these types of production activities. However, the literature does not provide empirical evidence to question the applicability of the learning curve concept in capital-intensive industries.

Learning curves are subject to three important limitations.

- The learning curve is a method of estimating changes in labor productivity that occur after production operations begin. If substantial efforts are devoted to preproduction engineering and planning, and If labor pruduclivity is higher than it otherwise would have been, the learning curve will not reflect the progress that has been made.

- Learning rates vary substantially among industriès, products, und lyjes of work. A fundamental law of progress such as the $80 \%$ learning curve used in the aircraft industry does not exist. Analysts must choose an appropriate model and estimate the rate of progress for a particular product.

- The analyst must determine the runge of production over which progress will - occur. Empirical data show that progress does not continue indefinitely. The application of learning curves is based upon the assumption that progress in labor hours will be achieved over the range of production specified. 
Unlike learning that refers to the productivity of a single input, the experience concept has been used to describe changes in total cost as a function of cumulative production. The experience concept was developed from the observation that per-unit production costs declined in some industries as a direct, estimable proportion of cumulative production. Experience curves are similar to learning curves.

Unlike the concept of learning, the concept of experience is too ambiguous to be useful for cost estimation. There is no logical reason to believe that costs will decline purely as a function of cumulative production, and experience curves do not permit the analyst to identify logical sources of cost reduction directly. Using an experience curve to estimate future costs of new products will yield only tautological results. All that one can conclude from using an $80 \%$ experience curve to estimate costs is that if the cost of new products declines $20 \%$ each time cumulative production doubles, then new products will be $20 \%$ less expensive to produce each time cumulative production doubles. Clearly, better methods than experience curves should be used to estimate the future costs of new products. Empirical applications of learning and experience curves have been based upon products for which historical production data are available.

Solar energy supply systems represent emerging technologies with components and processes ranging from mature to untested prototypes, fabrication, assembly, and installation. Many solar technologies require significant amounts of on-site construction. Most learning and experience curves have been developed for manufactured products, rather than those assembled or constructed on-site. Since the solar industry is young, there is very little data on production economics. Learning or experience curves must be based on surrogate products, then, that resemble the new products or systems in configuration, materials, and production methods. The selection of appropriate surrogate products with available cost histories permits inferences regarding the probable cost of the new product. It is assumed that because of similarities of design, materials, fabrication, and assembly processes, the new product will undergo the same cost reduction pattern as the surrogate product.

The procedures for developing learning and experience curves for a given solar energy supply system or its component are:

- A conceptual breakdown of the new product or assembly into components, subassemblies, and processes;

- Identification of the surrogate part, subassembly, or assembly;

- Estimation of learning and experience curves for surrogate subassemblies; and

- Evaluation of learning and experience curves for surrogate products in order to determine whether the same rate of progress can reasonably be expected to occur in the new system or product.

Historical data collection for surrogates is the most difficult task, not because general information does not exist, but because detailed historical data concerning labor, labor costs, materials costs, and investment may not exist in some instances, may be extremely sensitive in others, or may be so interspersed with unrelated data as to be either unusable or uncollectable. Most of the data involved, except for regulated industries, are unavailable to the public. In some instances, published retail or wholesale data, broken down into approximate components, can be used. Once the data are obtained, the technological factors that caused specific changes or trends have to be identified. An analyst has to determine whether this development path would apply to the new system or 
product. This step utilizes past cost history by rationally projecting how it may be extended for the new product, eliminating those factors that cannot occur, or reducing the impact of those unlikely to occur. In addition, production volume effects have to be assessed. Surrogate product volumes probably will differ widely from one another and from projected volumes for the new product. These volume variations can have a significant cost impact and have to be standardized to produce realistic expectations. Based on all of the data gathered and developed, learning and aggregated cost curves can be estimated. This approach to development of learning and composite curves predicts overall cost reduction in manufacturing the MDAC and GE prototype heliostat designs, to project future costs for these designs using surrogate cost history and the learning curve conceptual and analytical framework.

The heliostat field represents the largest fraction of the cost of a solar central receiver system. The U.S. Department of Energy (DOE) has placed major emphasis on reducing heliostat cost through a variety of programs. The goal is to develop reliable costeffective heliostat designs amenable to mass production and meet strict performance standards. The current cost goal, established in 1975 , is to produce heliostats of $\$ 72 / \mathrm{m}^{2}$ $\left(\$ 7 / \mathrm{ft}^{2}\right)$ reflectivity. This goal is under review and will probably change to reflect newer cost estimates resulting from recent advances in heliostat design, as well as any innovations by large manufacturing companies interested in heliostats, such as General Motors or Ford Motor Company. To foster competition, DOE awarded contracts to five separate contractors to build prototypes. All of these prototypes will be of the glass-mirror design, because the requisite plastic technology is not yet sufficiently advanced to promote confidence in the plastic enclosure design. These low-cost prototypes are second-generation heliostats. Meanwhile, research and development of suitable plastic materials for use in the enclosed heliostat design will be continued.

While second-generation prototype heliostats are being built, work is proceeding toward a third-generation design. Twelve special studies are being performed on heliostat component design and maintenance. A new heliostat components solicitation was released in 1978. Resulting design improvements are planned to be incorporated into a thirdgeneration heliostat design in the early part of FY81. Second-generation glass-steel and inflated-bubble heliostat design concepts, developed by MDAC and GE, respectively, are described in some detail in this report.

Critical areas for cost reduction were identified for each generic design. For the "hard" (glass-steel) heliostat design, the highest cost elements are the drive unit, reflective unit, foundation, and site development. The elemental cost breakdown for the "soft" (plastic-bubble enclosed) heliostat indicated the critical areas for cost reductions to be the foundation and site preparation and structural support and protection units.

The fundamental requirement for estimating and predicting cost reduction is establishment of a detailed costing scenario. In this report, the costing scenarios were determined through description of the basic characteristics of market potential, the production and installation volume, and the general configuration of the manufacturing/ assembly facility module. Points in cumulative production volume where the effective, steady-state production process may be established, along with the associated first-unit cost for the steady-state scenario, are provided. Three main costing scenarios were presented: $25,000,250,000$, and 1,000,000 heliostats/yr production rates.

A rate of 25,000 units/yr was selected as the baseline production scenario for the MDAC and GE heliostat designs. This rate represents significant high-volume production situations, yet may be translated easily into higher or lower production rate scenarios. As a 
result, this scenario supports the development of a viable business approach and a strategy for capturing an important share of eventual markets.

Additionally, the design/production, installation, and operating plans derived for the 25,000 units/yr scenario support the DOE goal of $\$ 72 / \mathrm{m}^{2}$ reflectivity. The average unit cost is projected to be about $20 \%$ lower than that projected for the initial pilot production. The average unit cost for a $250,000 / y r$ production rate shows a significant reduction compared with its estimated value at the 25,000 heliostats/yr rate. In contrast, the average unit cost reduction for the $1,000,000 / \mathrm{yr}$ production rate is not as significant as for the 250,000 units/yr scenario.

Changing market growth and location, competition, basic design, available production technology and resources, and government and business policy affect the point in cumulative production volume where the effective, steady-state production process may be established along with the associated first-unit cost for the steady-state scenario. The manufacturing and installation of the MDAC prototype heliostat design was used as an example.

The MDAC prototype heliostat study implies that the 125,000 th unit is the cumulative volume where an effective, steady-state production process is established for the baseline scenario. The rationale for this assumption is that certain electronic components will not be available until 1985, and a market will not develop which will support a rate of 25,000 units/yr until 100,000 units have been produced. An additional plant start-up of 1-2 years or 25,000 units will stabilize production in the new plant. This is a conservative projection. It is possible that market or fiscal incentives or production alternatives could allow the facility to be installed well before 100,000 units are reached. Also, many elements (especially buy items procured from the industrial base) may essentially reach a steady state well before the first facility goes into operation. On the other hand, designs and production methods never fully stabilize and breakthroughs will continue long after the first 100,000 units are produced.

The production scenario progression was viewed in three parts: (1) test hardware to pilot plant; (2) pilot production to demonstration and early commercialization; and (3) continuation to Nth unit of production.

The point of steady-state production is defined as that point in cumulative production volume where the only design changes permitted are those that may modify a part for more effective production or performance, are for the primary purpose of cost reduction, and will maintain a stable interface with other part concepts and designs.

The prototype heliostat baseline production scenario is a steady-state scenario. As conceived, this scenario provides for the production and installation of 25,000 heliostats/yr, but by simply operating on a one-shift basis, reducing line speed somewhat and cutting the number of field crews in half, the identical facilities and equipment may be operated with a minimal and acceptable economic penalty at a rate of 10,000 heliostats/yr or less. It was concluded that the prototype baseline scenario, with minor modifications, also may be used to describe a steady-state production situation that could occur at a fairly early stage of cumulative production. A review of demand growth projected for the modified scenario indicated the following production requirements:

- By the end of 1982 , all suppliers will have produced 10,000 heliostats.

- During 1983 and 1984, an additional 10,000 heliostats will be supplied each year. 
- In 1985, all suppliers must produce an additional 20-25,000 units in order to meet demand projections.

- During 1986,1987 , and 1988, demand will approach 100,000, 150,000 and 300,000 heliostats, respectively.

Accepting this market projection, an aggresive supplier designing $40-50 \%$ of the market could plan its new facility initial operating capability in 1985, in time to produce its 15,000-and-first heliostat in accordance with the modified baseline scenario. Assuming approximately a 12-month startup during which 5,000 heliostats are produced, the actual steady-state will be achieved when the supplier has produced a cumulative total of 20,000 heliostats.

It was argued that if cost reduction efforts in preproduction, pilot, and demonstration programs were successful, by 1983 a manufacturer should be able to demonstrate that a move into basoline facilities will permit heliostat price quotes that are quite competitive with altemutive energy costs. As a result, an effective, steady-state production status for an aggressive and dominant supplier at the 20,000 th unit is not an unreasonable projection under the circumstances.

The steady-state unit cost for the modified prototype heliostat scenario was estimated. The two methods applied were a resource impact approach and cost reduction curves.

The development of learning and composite curves for the MDAC and GE prototype heliostat designs proceeded with (1) the selection of those subassemblies, assemblies, and processes that have significant potential cost reductions; (2) selection of surrogate components or processes that can provide a learning slope for the component of the heliostat designs; (3) collection evaluation of data for the selected surrogates; (4) derivation of learning and experience curves for surrogates; and (5) application to heliostat assembly. In selecting heliostat components that have significant potential cost reduction, emphasis was put on the reflective and drive units of both MDAC and GE heliostat designs.

Surrogates for cost analysis were chosen for selected components (e.g., reflectors, elevation actuator, drive controls, etc.) on the basis of the following criteria:

- The relative importance of the component to the contractor's design;

- The relative contribution of the component to the total cost of the design; and

- The likelihood of availability of a meaningful surrogate having a body of historical data.

The choice of surrogates was based largely on similarity of the manufacturing opcrations between the surrogate and the heliostat components and the availability of reliable cost data. All automotive-related surrogates had to be discarded because cost information could not be obtained. Moreover, specific components investigated for this study have varying degrees of validity as surrogates of their heliostat component counterparts, and varying levels of cost data quality.

For the overall product, no reliable surrogate data were available. The radio telescope antenna assembly represents the penultimate surrogate for a heliostat. Unfortunately, none were ever mass-produced. 
Surrogate products were identified and selected under the assumption that historical (relative) cost patterns exhibited by these products could be anticipated for the corresponding heliostat components as well. Also, in order to be applicable to the heliostat assembly, the relative cost behavior for each surrogate must be independent of ancillary conditions such as:

- years of production;

- annual production rates, and changes in rates;

- absolute unit costs of surrogate;

- economic factors;

- production volume, lot sizes, and sequence number used; and

- extraneous factors that might distort the constant rate of reduction in unit costs.

The data acquisition task proved formidable, and cost data were of limited quality. For the surrogate approach to be credible, it is imperative that accurate and reliable cost data be used, and that the manufacturing history of each component be well understood.

After all relevant data had been accumulated, unit costs and corresponding cumulative production quantities were calculated. In most cases, the average cost of producing the Nth unit was considered; however, a few cumulative cost curves were also generated, primarily for comparative purposes. A least-squares linear fit (on log-log scale) was performed using the BMDP Biomedical Computer Program subroutine BMDP1R, Multiple Linear Regression.

The effect of variability in slope estimates, as well as overall precision in the estimation techniques, was demonstrated. There were limitations in applying historical learning trends to related but different components. The following concerns are noted:

- Learning curve slope estimates are highly dependent on the particular surrogate selected; different surrogates intended to characterize the same heliostat component can yield vastly different estimates of learning effects.

- Identical surrogates (such as plywood) lead to widely varying estimates, depending on the data source, age of industry, and extraneous variables, such as geographical location.

- There is evidence that learning dampens out for mature industries, and therefore may not represent expected patterns for similar components with different system configurations and/or requirements.

- Estimated slopes appear to depend on units of measure, even in situations that should be invariant.

- Many of the surrogates used in this study indicated little or no measurable learning. This condition manifested itself in two ways: (1) the data did not appear to be linearly related as measured by standard goodness-of-fit test statistics, and/or (2) unit costs were constant, and apparently unrelated to quantity produced over the range of production units considered.

- Estimates for heliostat components are highly subjective, even if the surrogate cost/quantity data were reliable in all respects. 
- Historical raw cost data frequently are contaminated with hidden effects that only extraordinary and detailed investigation studies will uncover.

In view of unexpected and unavoidable difficulties encountered in acquiring reliable cost data for many surrogate products, it is recommended that the derived learning percentages be accepted with caution, and that absolute values and ranges be, considered illustrative rather than definitive.

The procedures for using learning and cost curves to predict cost reduction in manufacturing solar technologies provided that learning and cost curves were to have been derived and aggregated over labor, material, and overhead cost elements for each heliostat part. Since the data collected were not amenable to treatment at this level of detail, the conceptual framework was illustrated with total cost data only.

Composite cost curves were constructed for each heliostat design by aggregating at similar production quantity levels over the 11 individual component parts. The developed aggregate cost curves for the GE and MDAC heliostat designs indicate that the conceptual estimation technique examined in this study would almost certainly yield a nonlinear cost/quality for the overall assembly since slopes are not additive over components in a $\log -\log$ scale. The MDAC heliostat assembly composite unit cost curve starts out at approximately $94 \%$, changes to $96 \%$, and finally reaches $97 \%$. For the same production scenario, the GE heliostat assembly composite unit cost curve starts out at approximately $89 \%$, changes to $92 \%$ and $94 \%$, and finally reaches $99 \%$.

The analytical method described in this report was intended to yield a predictive cost/ quantity relationship that can be applied to the heliostat production program. In this context it should be recognized at the outset that the estimation of surrogate learning and experience curves to predict cost reductions for any new product or system is a difficult and complex process, particularly for a system designed to perform a unique function (such as the Solar-Electric Power Tower). The literature presents underlying theories, conjectures, and plausible explanations for many past programs in which estimated production costs deviated dramatically from what was actually experienced.

Although it is recognized that estimating production costs is an important and necessary element in program planning and evaluation, it is equally important to understand the inherent limitations and constraints of the estimation process itself. The value of the procedure illustrated in this report is essentially dependent upon the following key considerations:

- The validity of the relationship between surrogates and the actual heliostat components;

- The quality of unit cost data available for surrogate components;

- The applicability of relative unit cost reductions observed for surrogates to the heliostat components' counterparts;

- The ability to express, accurately and precisely, unit cost-quantity relationships in a mathematical form; and

- The understanding of manufacturing methods and technology related to the production of surrogates and heliostat components.

The surrogate concept of cost estimation used in this study combines qualitative steps that are highly subjective with quantitative techniques that require thorough knowledge 
and understanding to justify their use. As such, the results, interpretations, and inferences must be qualified by an understanding of the process through which they were developed.

The analysis conducted for this study indicates a learning effect that varies with production unit number of the heliostat assembly. Moreover, the learning effect is different for each of the two heliostat designs.

The method of surrogate learning curves had limitations in both the data acquisition and data analysis phases of activity. Improvements in the validity of cost data and in the tools used for this type of study are necessary to enhance the reliability of unit cost predictions resulting from this technique.

The task of analyzing solar energy systems' costs is made complex by considering alternative cost reduction techniques which have their basis in bottom-to-top costing. An approach that combines a neoclassical production function with a learning-by-doing hypothesis is needed to yield a cost relation compatible with both the learning curve frequently encountered in empirical studies and the traditional cost function of economic theory. Despite the popularity of each concept, there has been a remarkable lack of success in integrating the two approaches in empirical studies. Previous attempts to integrate learning with production theory have been more conceptual than analytical. An approach constructed from a neoclassical production function and a learning-by-doing hypothesis will generate better or more accurate information to address such issues as (1) establishment of research and development programs; (2) design and evaluation of government programs to accelerate the commercialization of solar energy; and (3) more accurate assessments of the potential market for solar energy. 


\section{THIS PAGE WAS INTENTIONALLY LEFT BLANK}


TABLE OF CONTENTS

Page

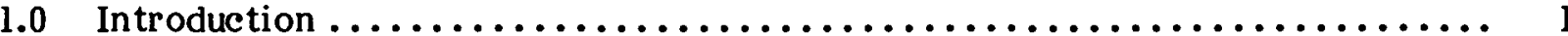

2.0 Methods for Predicting Cost Reductions in the Manufacture of

New Systems .....................................

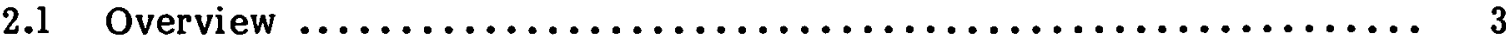

2.2 Engineering Bottoms-Up Cost Analysis $\ldots \ldots \ldots \ldots \ldots \ldots \ldots \ldots \ldots \ldots \ldots$

2.3 Engineering Parametric Approach ...................... 5

2.4 Aggregate Prediction of Cost Reduction.................. 5

3.0 Conceptual Foundation of Learning $\ldots \ldots \ldots \ldots \ldots \ldots \ldots \ldots \ldots \ldots \ldots \ldots$

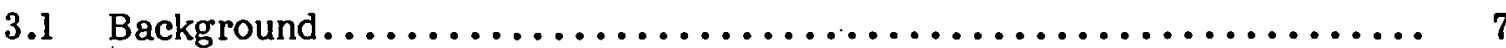

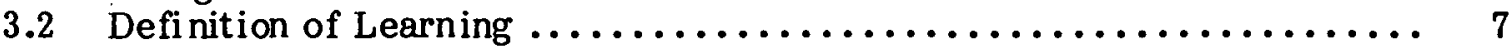

3.3 The Learning Curve $\ldots \ldots \ldots \ldots \ldots \ldots \ldots \ldots \ldots \ldots \ldots \ldots \ldots \ldots \ldots$

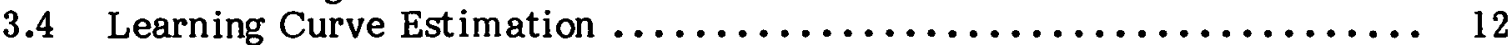

3.5 Empirical Applications of Learning Curves ................. 15

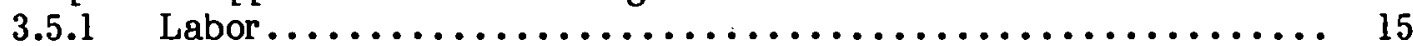

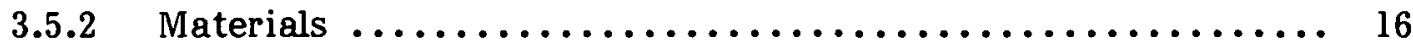

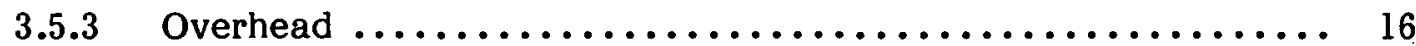

3.5.4 Obtaining Total Production Costs................. 16

3.6 Limitations of Learning Curves $\ldots \ldots \ldots \ldots \ldots \ldots \ldots \ldots \ldots \ldots \ldots \ldots \ldots \ldots$

4.0 The Concept of Experience $\ldots \ldots \ldots \ldots \ldots \ldots \ldots \ldots \ldots \ldots \ldots \ldots \ldots \ldots \ldots \ldots$

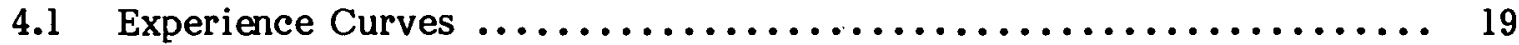

4.2 Applications of Experience Curves ...................... 20

4.3 Experience Curves and Cost Estimation $\ldots \ldots \ldots \ldots \ldots \ldots \ldots \ldots \ldots \ldots$

5.0 Development of Leaming and Experience Curves for Solar Energy

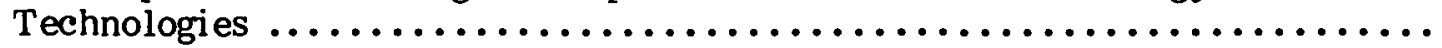

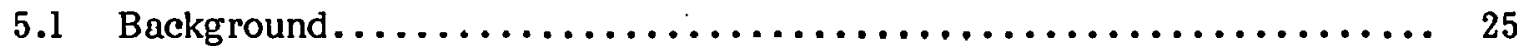

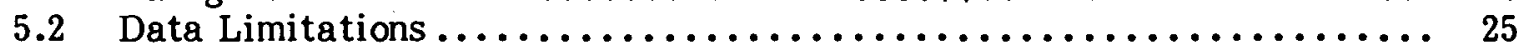

5.3 Estimating Learning and Experience Curves for Surrogate

Products or Syste ms ............................... 25

5.4 Estimating Experience Curves for Surrogate Products

or Systems .................................. 27

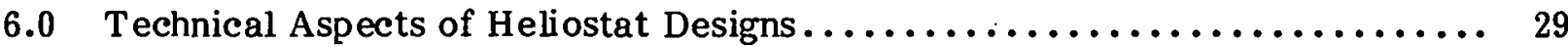

6.1 Basic Elements of a Solar Central Receiver System .............. 29

6.2 The DOE Heliostat Developm ent Program .................. 33

6.3 Descriptions of Generic Heliostat Designs .................. 34

6.3.1 The MeDonnell Douglas Prototype Heliostat Design ......... 34

6.3.2 The General Elec tr ic Prototype Heliostat Design .......... 43

6.4 Key Cost Factors in Heliostat Design ..................... 48 
TABLE OF CONTENTS (concluded)

Page

7.0 Prototype Heliostat Cost Scenarios ........................ 51

7.1 Introduction $\ldots \ldots \ldots \ldots \ldots \ldots \ldots \ldots \ldots \ldots \ldots \ldots \ldots \ldots \ldots \ldots \ldots \ldots \ldots$

7.2 Factors Influencing Cost Scenarios $\ldots \ldots \ldots \ldots \ldots \ldots \ldots \ldots \ldots \ldots \ldots \ldots$

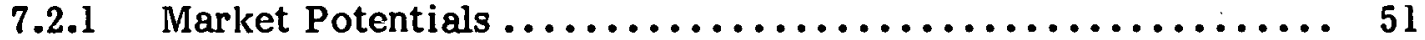

7.2 .2 Production Volume Progression.................... 52

7.2 .3 Design and Development Status ................... 54

7.2 .4 Plant and Equipment Impact .................... 54

7.2.5 Management Alternatives and Concern ................ 56

7.3 Deseriptions of the Buseline Production Scenario ............... 56

7.3.1 The McDonnell Douglas Prototype Holiastat Docign

Production Scenarlo ......................... 56

7.3.2 'I'he General Electric Prototype Heliostat Design

Prodiction Scenario ............................. 80

7.4 Steady-state Production Volume and Cost Variation............. 88

7.4.1 The MDAC Prototype Heliostat Design ................ 88

7.4.2 The Point of Steady-State Production $\ldots \ldots \ldots \ldots \ldots \ldots \ldots \ldots . . . \ldots 7$

8.0 Development of Learning and Composite Curves for Costs Associated

with Heliostat Production ................................ 105

8.1 Selection of Surrogates $\ldots \ldots \ldots \ldots \ldots \ldots \ldots \ldots \ldots \ldots \ldots \ldots \ldots \ldots \ldots \ldots$

8.2 Derivation of Learning and Experience Curves for Surrogates ........ 111

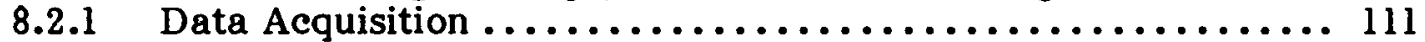

8.2.2 Surrogate Learning Curve Estimation ................ 113

8.3 Application to Heliostat Assembly ....................... 115

8.3.1 Unit Cost Estimates for Relevant Components ............ 115

8.3.2 Development of Heliostat Component Cost Curves............ 115

8.3.3 Aggregation of Costs ......................... 115

9.0 References $\ldots \ldots \ldots \ldots \ldots \ldots \ldots \ldots \ldots \ldots \ldots \ldots \ldots \ldots \ldots \ldots \ldots \ldots \ldots \ldots \ldots$

Appendix A. Summary of Data Acquired for Selected Surrogate Products

(Tables) .......................................... 125

Appendix B. Estimations of the Surrogate Learning Curve (Figures) $\ldots \ldots \ldots \ldots \ldots 143$

Appendix C. Cost Curves for the MDAC and GE Heliostat Designs

(Figures) 


\section{LIST OF FIGURES}

Page

3-1 Hypothetical Unit Learning Curve on Arithmetic Coordinates .......... 10

3-2 Hypothetical Unit Learning Curve on Logarithmic Coordinates ......... 10

3-3 Hypothetical Leaming Curve on Logarithmic Coordinates............. 11

6-1 Schema for a Typical Central Receiver System .................. 30

6-2 Heliostat Field and Central Power Tower ..................... 31

6-3 Cost Breakdown for a Typical Central Receiver Plant ............... 32

6-4 Typical Two-Axis Tracking Heliostat....................... 32

6-5 Generic Heliostat Development $\ldots \ldots \ldots \ldots \ldots \ldots \ldots \ldots \ldots \ldots \ldots \ldots \ldots \ldots \ldots$

6-6 MeDonnell Douglas Second-Generation Heliostat $\ldots \ldots \ldots \ldots \ldots \ldots \ldots \ldots$

$6-7$ Laminated Mirror Module Assembly $\ldots \ldots \ldots \ldots \ldots \ldots \ldots \ldots \ldots \ldots \ldots \ldots \ldots$

6-8 Reflector Support Structure Assembly $\ldots \ldots \ldots \ldots \ldots \ldots \ldots \ldots \ldots \ldots \ldots \ldots$.

6-9 General Electric Enclosed Heliostat $\ldots \ldots \ldots \ldots \ldots \ldots \ldots \ldots \ldots \ldots \ldots \ldots \ldots \ldots 44$

6-10 General Electric Heliostat Design $\ldots \ldots \ldots \ldots \ldots \ldots \ldots \ldots \ldots \ldots \ldots \ldots \ldots \ldots$

6 -11 Stretch Frame Reflector Subassembly $\ldots \ldots \ldots \ldots \ldots \ldots \ldots \ldots \ldots \ldots \ldots \ldots$

6-12 Support and Drive Assembly $\ldots \ldots \ldots \ldots \ldots \ldots \ldots \ldots \ldots \ldots \ldots \ldots \ldots \ldots \ldots \ldots$

7-1 Cumulative Heliostat Market Scenario $\ldots \ldots \ldots \ldots \ldots \ldots \ldots \ldots \ldots \ldots \ldots \ldots$

$7-2 \quad$ Present Value of Capital Equipment $\ldots \ldots \ldots \ldots \ldots \ldots \ldots \ldots \ldots \ldots \ldots \ldots \ldots$

$7-3 \quad$ Block Flow Plant Layout $\ldots \ldots \ldots \ldots \ldots \ldots \ldots \ldots \ldots \ldots \ldots \ldots \ldots \ldots \ldots \ldots \ldots \ldots \ldots \ldots \ldots$

7-4 Reflector Panel Assembly Manufacturing Flow ................... 66

7-5 Drive Assembly Manufacturing Flow $\ldots \ldots \ldots \ldots \ldots \ldots \ldots \ldots \ldots \ldots \ldots$

7-6 Final Assembly Joining Area Drive Unit to Pedestal. .............. 71

7-7 Heliostat Controller Manufacturing Flow Chart $\ldots \ldots \ldots \ldots \ldots \ldots \ldots \ldots \ldots \ldots$

7-8 Data Distribution Interface (DDI) Manufacturing Flow Chart ......... 72

7-9 Heliostat Control Harness Manufacturing Flow Chart .............. 73

$7-10$ Installation Task Sequence $\ldots \ldots \ldots \ldots \ldots \ldots \ldots \ldots \ldots \ldots \ldots \ldots \ldots \ldots \ldots$ 


\section{LIST OF FIGURES (concluded)}

Page

$7-11$ Drive Unit Installation Machine $\ldots \ldots \ldots \ldots \ldots \ldots \ldots \ldots \ldots \ldots \ldots \ldots \ldots \ldots$

$7-12$ Reflector Installation Equipment $\ldots \ldots \ldots \ldots \ldots \ldots \ldots \ldots \ldots \ldots \ldots \ldots \ldots \ldots$

7-13 Cost Elements of MDAC Heliostat $(25,000$ Units/Yr) $\ldots \ldots \ldots \ldots \ldots \ldots \ldots$

7-14 Cost Elements of MDAC Heliostat $(250,000$ Units/Yr $) \ldots \ldots \ldots \ldots \ldots \ldots$

7-15 Cost Elem ents of MDAC Helioștat $(1,0 n n, 0 n n$ Units $/ Y r) \ldots \ldots \ldots \ldots \ldots$

7-16 Cost Elements of GE Heliostat $(25,000$ Units/Yr $\ldots \ldots \ldots \ldots \ldots \ldots \ldots$

7-17 Cost Elem ents of GE Heliostat $(250,000$ Units/Yr $\ldots \ldots \ldots \ldots \ldots \ldots \ldots \ldots$

7-18 Cost Elements of GE Heliostat $(1,000,000$ Units/Yr $) \ldots \ldots \ldots \ldots \ldots \ldots \ldots$

7-19 Manuf acturing Facility for 25,000 Heliostats $/ Y r) \ldots \ldots \ldots \ldots \ldots \ldots \ldots$

7-20 Manufac turing Facility for 250,000 Heliostats/Yr) $\ldots \ldots \ldots \ldots \ldots \ldots \ldots$

7-21 Typical Heliostat Installation Sequence..................... 95

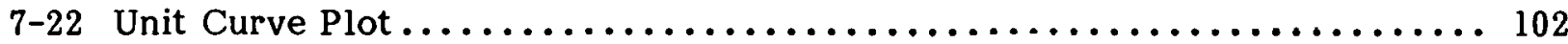

8-1 Heliostat Assembly Unit Cost Curve (GE) Design ................. 118

8-2 Heliostat Assembly Unit Cost Curve (MD) Design .................. 119 


\section{LST OF TABLES}

$\underline{\text { Page }}$

4-1 Experience Curves Identified by the Boston Consulting Group .......... 22

6-1 Technical Descriptions-Collector Subsystem $\ldots \ldots \ldots \ldots \ldots \ldots \ldots \ldots \ldots$

6-2 Drive Unit Requirements $\ldots \ldots \ldots \ldots \ldots \ldots \ldots \ldots \ldots \ldots \ldots \ldots \ldots \ldots \ldots \ldots \ldots$

6-3 General Electric Heliostat Weight Breakdown ................... 48

6-4 Design Parameters Aff ecting Heliostat Elemental Cost............. 49

$7-1$ Prototype Heliostat Hardware Tree ........................ 59

$7-2$ Installation Tasks and Crew Size $\ldots \ldots \ldots \ldots \ldots \ldots \ldots \ldots \ldots \ldots \ldots \ldots$

7-3 MDAC Prototype Heliostat Cost Breakdown ................... 81

7-4 GE Heliostat Cost Comparison $\ldots \ldots \ldots \ldots \ldots \ldots \ldots \ldots \ldots \ldots \ldots \ldots \ldots \ldots$

7-5 Projected Costs for GE Heliostat Design $\ldots \ldots \ldots \ldots \ldots \ldots \ldots \ldots \ldots \ldots \ldots$

7-6 10,000 Heliostats/Yr Steady-State Preliminary Cost Breakdown ......... 89

7-7 Steady-State Costs ............................... 100

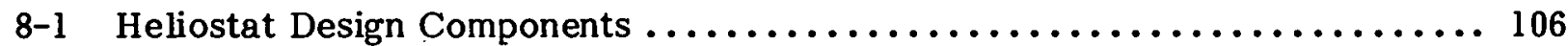

8-2 Choice of Surrogates for Heliostat Components ................. 107

8-3 Surrogates Used in the Study $\ldots \ldots \ldots \ldots \ldots \ldots \ldots \ldots \ldots \ldots \ldots \ldots \ldots$

8-4 Cost Estimate-25,000th Unit, GE Design................... 116

8-5 Cost Estimate-25,000th Unit, MDAC Design $\ldots \ldots \ldots \ldots \ldots \ldots \ldots \ldots \ldots \ldots$

8-6 Estimated Costs and Slopes for the MDAC Heliostat Design........... 120

8-7 Estimated Costs and Slopes for the GE Heliostat Design ............. 120 


\section{SECTION 1.0}

\section{INTRODUCTION}

A crucial issue in the commercial development of solar energy technologies concerns the cost of solar technologies and whether this cost can be reduced. Many solar technologies are now too expensive to be economically feasible. Some of these technologies may achieve substantial cost reductions with improved product design and production techniques.

An assessment of future solar energy costs* is necessary for several reasons. First, an assessment of solar technologies with the greatest potential for cost reductions would help establish research and development priorities. Second, such an assessment is useful for designing and evaluating government programs to accelerate the commercialization of solar energy. Finally, identifying possible reductions in costs leads to more accurate assessments of the potential market for solar energy.

Most of the U.S. Department of Energy (DOE) programs for estimating and predicting cost reductions in solar technology manufacturing have been through: (1) the low-cost Solar Array Project at the Jet Propulsion Laboratory (JPL) and (2) the Repowering Strategy Analysis Supply Task of the Solar Energy Research Institute (SERI).

JPL has been investigating possible sources of cost reductions in all aspects of the production and assembly of flat-plate photovoltaic cells, including extensive subcontracting for detailed design and engineering improvements in each step of the array production. process. This has led to refining a process to achieve the $\$ 2 / \mathrm{W}_{\mathrm{p}}$ goal. Work remains to be done in support of the $\$ 0.50 / \mathrm{W}_{\mathrm{p}}$ goal.

SERI has been analyzing the production economics of heliostats and investigating the effects of changes in production quantity and processes on heliostat cost. Some changes in design and manufacturing processes may be necessary to attain low-cost, high quality production. Also, SERI has been identifying significant cost components in heliostats and applying these to an investigation of new heliostat concepts to determine the value of the new designs. A thorough bottoms-up engineering cost analysis has been performed.

The methods most of ten employed in past empirical studies to estimate and predict overall cost reductions in manufacturing new products are: (1) engineering bottoms-up cost analysis; (2) engineering parametric approach; and (3) aggregate cost estimation techniques (short- and long-term cost functions, learning and experience curves based on bottoms-up engineering costs analysis, etc.). Cost estimates for solar energy technologies typically are made assuming a fixed production process characterized by standard capacity factors, overhead, and labor costs.

The concepts of learning and experience have been developed in the business management and industrial economics literature as ways to explain cost reductions observed in some industries; learning and experience curves were developed in order to estimate the magnitude of reduction in costs $[9,10,12,13]$. In the broadest sense, the concepts of learning and experience are based on the premise that, as people gain experience with methods of producing a particular product, improvements will be identified and implemented. Reductions in per-unit costs have been observed with such regularity in some

\footnotetext{
* Cost refers strictly to market cost in constant dollars, unless otherwise noted.
} 
industries that a number of authors believe that costs can be expected to decrease at some constant, estimable proportion of cumulative production $[26,27]$. Because the solar industry is relatively new, it could be argued that costs will decline as firms gain experience with different methods of producing solar energy equipment [9]. Consequently, the objective of this report is to assess the applicability of learning and experience curves for predicting the future costs of solar technologies. The major test case here is the production economics of heliostats.

A brief discussion of alternative methods for predicting cost reductions in the manufacture of new systems resulting from learning by doing, economies of scale, and technical change is summarized in Sec. 2.0. Learning concepts, including the factors affecting initial production costs, procedures for estimating learning curves and their empirical applications, and limitations of learning curves are presented in Sec. 3.0. Section 4.0 describc3 the coneepl of experience and its applicability to cost estimation. Procedures for developing learning and experience curves for solar energy technologies are outlined in Sec. 5.0. Section 6.0 summarizes the technical description of the McDuinell Douglas and General Electric heliostat designs and describes the basic elements of a solar central receiver system, the $\mathrm{D} D \mathrm{E}$ heliostat development program, generic heliostat designs, and key cost factors in heliostat designs. The factors influencing a costing scenario, a description of the baseline production scenario, and steady-state production volume and cost variations are provided in Sec. 7.0. Section 8.0 describes the selection of surrogates, derivation of learning and experience curves for surrogates, and application to heliostat assembly.

Appendix A contains a summary of the data acquired for the selected surrogate products. An example of surrogate learning curve estimations is presented in Appendix B. Figures illustrating the cost curves for the MDAC and GE heliostat designs are provided in Appendix C. 


\section{SECTION 2.0}

\section{METHODS FOR PREDICTNG COST REDUCTIONS IN THE MANUPACTURE OF NEW SYSTEMS}

\subsection{OVERVIEW}

The rapid pace of technology development since the end of World War II and improved analytical techniques are two of the reasons why analysts pay close attention to product costs.

Alternative methods for predicting cost reductions in the manufacture of new products include consideration of learning by doing; economies of scale; and technical change. The tools most often employed in past empirical studies to estimate and predict overall cost reductions in manufacturing are:

- engineering bottoms-up cost analysis;

- engineering parametric approach; and

- aggregate cost estimation techniques (short- and long-term cost functions, learning and experience curves based on bottoms-up engineering costs).

These methods, and the conceptual and analytical framework of learning and experience curves, are discussed in the following sections.

\subsection{ENGINEERING BOTTOMS-UP COST ANALYSIS}

The most widely used method to estimate cost in manufacturing a new product or system is the engineering bottoms-up costs approach. This method has been successfully used to estimate manufacturing costs for various solar hardware systems [1-4]. Its analytical framework is provided in detail in Ref. 1 and 2.

The hardware system design and performance specifications of the product, the production rates and schedules, and the location sites for facilities must be determined. First, equipment designs are evaluated to determine any potential manufacturing problems and to investigate the possibility of using less costly materials and processes. Make-versusbuy studies are conducted to determine availability and relative costs of outside sources for components or subassemblies and the level of in-plant integration is determined. Proper equipment, tooling fixtures and auxiliaries are specified and the necessary facilities are laid out, and environmental impact studies and marketing and distribution analyses are completed.

Once this initial capital equipment and facilities cost estimate effort is completed, initial engineering feasibility studies begin, followed by capital equipment and assessment facility cost. Capital equipment and facility costs are estimated by pricing manufacturing and testing equipment, floor space and building needs, and unique tooling systems outlined in specifications. This costing process uses standard equipment manufacturing catalogues, quotes, or estimates published in various manufacturing studies. The cost of highly specialized equipment and tools is usually determined from similar equipment costs. If necessary, escalation factors are applied to project these costs into the future. 
The next step is to estimate direct and indirect costs, including materials, labor, transportation, depreciation, and overhead.

Direct materials cost includes purchased parts, subassemblies, and all materials used to fabricate parts. The direct materials cost is stated in standard cost for parts manufacture. Material quantity standards are based on system/product specifications as to size, shape, appearance, desired performance characteristics, and tolerance limits. The detailed parts drawings and manufacturing specifications provide the required quantity for the various materials and parts that make up the finished product. Direct materials cost is based on market information. Reductions in direct material costs are estimated by analyzing available quantity and lot discount rates for the total materials bill. Direct material cost is also affected by visibility, scrap and rework, and fee. The cost of purchased parts and subassemblies is mainly determined from vendor quntes for parts and subassemblies and from catalog prices.

Estimates of direct labor cost begin with manufacturing specifications. They determine the operations to be performed on the fabricated part and the time required to man the factory equipment required to make the part. Industrial engineering methode (bascd on historic data obtained from similar products) and efficiency factors are applied to determine the person-hours required to complete each operation. Direct support hours for planning, tooling, and product support are estimated by application of standard factors. Time required for materials handling and supervision is usually covered within the applied burden rates. The direct labor cost is the product of person-hours in a given operation times pay rate. The sum of all the direct labor costs associated with each operation yields the total direct labor cost of producing a part. Hourly rates for labor are based on prevailing costs in similar industries for a particular region.

Indirect manufacturing costs include items such as supervision and clerical help, materials handling, operating supplies, maintenance, janitorial work, process engineering, transportation, hand tools, quality assurance not included in inspection operations, and spare parts.

Transportation cost is determined from obtaining transportation costs of firms located in the same region. Other indirect manufacturing expenses are included in the overhead rates. The amortization of the asset, return on investment, income taxes, property taxes, and capital repairs are included in the fixed-charge rate. The fixed-charge rate converts capitalized cost into a series of uniform end-of-year payments to repay the investment at the stated interest rate over the life of the asset.

Once this cost process is completed, the first unit cost of a given design concept, including material, labor, transportation, depreciation, and overhead, is estimated. Its practical value is limited to providing a solid base for application of the aggregated cost estimation techniques. The unit-cont estimate does not refleut un overall cost reduction due to labor learning, economies of scale, and technological change over time. Because of the dynamic nature of cost reductions in manufacturing new products, generalized statements about specific cost data are meaningless. A thorough manufacturing cost analysis for a particular new product becomes complex when alternative cost reduction techniques that have their basis in the engineering bottoms-up cost approach are considered. 


\subsection{ENGINEERING PARAMETRIC APPROACH}

The engineering parametric approach combines scaling laws, direct analogy, cost factors, and cost estimating relationships (CERs) to estimate and predict cost reductions in manufacturing new products. Various government studies show this approach applies to communications equipment and advanced weapon systems. The most fundamental component is the CERs. Based on engineering-economic theory basis and principles of statistics and econometrics, cost estimating relationships are quantitative expressions of cause and effect between cost, the dependent variable, and selected design and performance characteristics (e.g., weight, horsepower volume, material type, conversion efficiency) the independent variables. G. H. Fisher and R. L. Petrushel present a broad description of the derivation of cost estimating relationships $[5,6]$.

Detailed parametric costing relationships can be particularly useful for a new product during its early phases of planning and development when only mission and performance parameters are defined. These relationships can also be applied in evaluating many design options. During the early phases of a particular design concept, limited and uncertain physical and performance characteristics are available regarding new product development and manufacture. Therefore, relationships between aggregated components of product cost and the physical or performance parameters of the product are derived from cost histories on prior programs or from surrogate parts resembling the pieces to be manufactured in configuration, material, and production methods.

There are practical limitations to the engineering parametric approach. It is difficult to select a surrogate part relevant to a given product component in terms of configuration similarity, material correspondence, and fabrication congruency. Even if the analogous, surrogate parts or subassemblies are truly analogous there are limitations inherent in statistical inference. In addition, cost histories on prior programs are imperfect indicators of future costs of a given design concept.

\subsection{AGGREGATE PREDICTION OF COST REDUCTIONS}

The aggregate prediction of cost reductions in manufacturing new products involves a number of conceptual and analytical issues associated with relationships between changes in a firm's costs and changes in its output; the cost function. Economic theories of the production function of a firm and the prices it pays for its inputs determine the firm's cost function. Since a production function may have different forms, with either one, some, or all of the input variables, cost functions may also have different forms. Price theory gives most of its attention, however, to two cost functions-the short-run and the long-run. Since price theory is based on the neoclassical theory of the firm, the shortand long-run cost functions can provide insights into economic and technical issues that influence the behavior of costs and prices over time. However, since neoclassical theory of the firm is a static, or at best a relatively static depiction of behavior, it does not exhibit direct applicability of the short- and long-run cost functions to predict future cost reductions. The cost functions have been extensively used in empirical studies of production. Walters [7] provides a survey of applications of cost and production functions.

The simplest short-run relation between changes in the costs of a firm and changes in its output assumes that the fixed costs-those of the fixed plant and equipment, as well as the state of technology of the firm-are constant. The firm's decision in the short run involves only determining the optimal quantity to produce. In the short run, fixed costs are 
relatively high, since little is done to achieve economies of scale due to expanded plant capacity; improve economics of production technology and utilize optimum forms of current manufacturing techniques; introduce new production methods; and change the inherent form of the product. Therefore, the only short-run manufacturing cost reductions are those due to increasing labor productivity: (1) as workers repeat an operation, they learn, and the number of person-hours required per unit of production declines; and (2) management techniques such as planning, purchasing, control, and supervision improve. Other variable costs may also decline as production increases. For example, direct materials costs may be subject to volume discounts, more efficient purchasing, or reduction of rejects.

It is practically impossible to specify what the sources of short-run cost reduction will be for a new product. Therefore, in predicting cost reductions in manufarturing new products in the short-run, the learning curve based on bottoms-up engineering costs has been used as an approximation tool for future costs.

In the long run, all factors of production are assumed to be variable. The firm's production function has no fixed inputs; the firm has no fixed costs. Hence, the firm's longrun decision involves a simultaneous determination of the optimal level of output, as well as the optimal mix of factor inputs. Greater opportunities exist in the long run for a cost reduction in manufacturing of new products due to (1) technological change (i.e., substitution of more efficient production equipment, processes, or products for less efficient ones); and (2) economies of scale (i.e., expanded plant capacity, increased labor efficiency resulting from worker specialization, or more efficient combination of production factors). Changes in scale, technology embodied in the fixed capital, and the inherent form of the product occur gradually. Consequently, the long-run cost function reflects unit cost changes that are relatively smaller than those of the short term.

To estimate cost reductions in the manufacturing of a new product, the experience curve concept is applied as an aggregate tool to summarize cost changes resulting from a number of different long-run sources. This concept has been applied because it allows approximation of future manufacturing costs. Although of great practical importance, it is not possible to estimate the relative proportions of total decrease in unit cost that are caused by changes in long-run cost reduction sources, or to characterize the manner in which unit cost changes occur separately from changes in the specified long-run cost reduction sources. It is not feasible to anticipate with any real accuracy how or why the costs of any specific product are going to change in the future. 


\section{SECTION 3.0}

\section{THE CONCEPTUAL FOUNDATION OF LEARNING}

\subsection{BACKGROUND}

The learning curve is a generalization about the sources of short-run cost reductions. A literature survey of learning curve applications $[8,9,10]$ indicates that different authors have presented a wide variety of definitions of the sources of cost reduction in manufacturing new products that are generalized in this phenomenon. There is no consensus in the literature as to whether a given process innovation will result in a shift in the learning curve or a movement along the curve. This distinction is of critical importance for policy makers.

Any changes in variable inputs to the production process are defined as modifications of a given process and hence a movement along the leaming curve. Variable inputs are those production factors whose cost varies with short-term fluctuations of output. Any change in fixed inputs to the production process is defined as a switch in processes and, hence, a shift in the learning curve. Fixed inputs are production factors in which cost does not vary with short-term fluctuations of output. Thus, improvements in the efficiency or organization of the work forces, management, or other variable inputs are regarded as movements along the learning curve. Changes in scale or technology embodied in fixed capital are considered shifts in the learning curve. This definition makes movements along the learning curve analogous to short-run adjustments in traditional economic theory and shifts in the learning curve analogous to long-run adjustments. The separation of those sources causing shifts in the learning curve from those causing movements along the learning curve, allows a precise distinction to be made between the experience concept and the learning curve effect. Also, policy recommendations are made regarding optimal actions to take to ensure the achievement of cost goals.

The learning curve is considered here to be an aggregate tool that empirically summarizes the sources of cost reductions in manufacturing new products within one particular process.

The experience curve herein is restricted to the analytical tool that collectively generalizes the shifts in the learning curve that result from changes in scale or technology embodied in fixed capital.

This section extensively discusses the definition of learning, approximation function, procedures for estimating learning curves, empirical applications of learning curves, and limitations of learning curves, in addition to the conceptual foundation of learning.

\subsection{DEFINITION OF LEARNING}

The expression itself is borrowed from psychology, which has found through experimentation that humans and many animals learn at certain rates by repeated trials.

The conceptual foundation of learning observed for manufacturing operations originated around 1920 in the aircraft industry and was subsequently reported by $T$. P. Wright in 1936 [17]. Its basic concept, that the direct labor input required to produce each of a series of airframe orders for a particular plane model diminished at a uniform rate as the 
orders accumulated, is still accepted theory. During subsequent years, it was found that, once production on a plan commenced: the fourth plane required only $80 \%$ as much direct labor as the second; the sixteenth plane, only $80 \%$ as much as the eighth; the twentieth, only $80 \%$ as much as the tenth; and so on. Based on this uniform pattern, it was concluded that the rate of learning to assemble aircraft was approximately $80 \%$ between doubled quantities.

The learning concept, its properties and uses, has been the subject of extensive study and discussion [8-16] producing relevant data and theoretical knowledge of the subject. The learning concept, also called manufacturing progress function [8], is presently used to characterize an increasing labor efficiency: again, as workers repeat an operation, they learn, and the number of person-hours required per unit of production declines; the efficiency improvement is regular and predictable [11, p. 410]. This definition has been used in various empirical studies [8,9,11,14-16]. Conway and Schultz state that it "holds promise of providing a better basis for the budgeting of engineering and other efforts in cost reduction activities, for the budgeting of production vs, product engineering, and possibly for providing some objective indication of organizational achievements" [8, p. 39].

Variations of the preceding learning phenomenon definition used by a number of authors [12, pp. 25-27; 10, p. 24] are of relatively limited value because of the conceptual and empirical uncertainty involved $[9$, p. 4].

The defined concept of learning emphasizes an increased direct labor efficiency as the principle causal factor in short-run manufacturing cost reduction. Conway and Schultz believe that "operator learning in the true sense of performance of a fixed task is of negligible importance in most manufacturing progress" [8, p. 42], although it significantly influences the number of subsequent opportunities for cost reduction. In most industries tooling changes, redesign of production methods, and improved management techniques such as planning, purchasing control, and supervision are more important sources of cost reduction than direct labor learning. "Such changes are usually the result of management and engineering effort rather than operator learning in any sense" [ $, p, 42]$.

In this report, a learning concept is restricted to mean improved productivity of a direct single input (e.g., labor).

\subsection{THE LEARNING CURVE}

A curve depicting the learning curve concept "was worked up empirically from the two or three points which previous production experience of the same model in differing quantities made possible" [17, p. 122]. To represent the functional interdependencies between labor hours per unit of output and cumulative production, the following approximntion function is suggested $[8,16]$ :

$$
\mathrm{y}_{\mathrm{x}}=\mathrm{xa}^{-\mathrm{b}}
$$

where

$$
\begin{aligned}
\mathbf{y}_{\mathbf{x}} & =\text { labor hours required to produce the } \mathrm{xth} \text { unit of production; } \\
\mathbf{x} & =\text { cumulative production, between lst and } \mathrm{xth} \text { units; } \\
\mathbf{a} & =\text { estimated labor hours required to produce the lst unit; and }
\end{aligned}
$$


$\mathrm{b}=\mathrm{a}$ measure of the rate of reduction in labor hours as cumulative production increases.

Parameter $a$ is obtained by extrapolating the learning curve to $x=1$. If $x=1$ the numerical value of the parameter $a$ is given by:

$$
\mathrm{y}_{1}=\mathrm{a}(1)^{-\mathrm{b}}=\mathrm{a} \text {. }
$$

The numerical value of the parameter $b$ describes the rate of decrease in direct labor input only of a new product. Its past values have normally been in the range $-1<b<0$.

The logarithmic transformation of Eq. 1 is:

$$
\log y_{x}=\log a-b \log x
$$

which is a straight line when graphed on logarithmic coordinates. Figure 3-1 portrays a hypothetical learning curve on arithmetic coordinates; Fig. 3-2 illustrates the same curve on logarithmic coordinates $[9, \mathrm{p} .7]$.

The learning curve applies only to the range of production over which learning occurs $[8,15,16]$. In actual experience, a given operation eventually approaches a plateau or a steady-state phase, during which direct labor input remains constant as cumulative production increases $[8,16]$. This is of ten encountered with large output volume. In practice, this phase should be estimated independently [16, pp. 330-331]. The start-up and steady-sta te phases are illustrated in Fig. 3-1 and 3-2.

In practice, the rate of reduction in labor hours is often replaced by the learning-curve slope, that is, "the percent of learning that occurs each time output is doubled" [16, p. 330]. The learning-curve slope is often called the progress (PI) $[16, \mathrm{p} .330]$. Its mathematical expression is defined as follows:

$$
\begin{aligned}
& \text { if } \mathrm{x}_{1} \text { and } \mathrm{x}_{2} \text { are two points in production and } \mathrm{x}_{2}=2 \mathrm{x}_{1} \text {, } \\
& \text { then } \mathrm{PI}=\frac{\mathrm{y}_{2}}{\mathrm{y}_{1}}=\frac{a \mathrm{x}_{2}^{-\mathrm{b}}}{a \mathrm{x}_{1}^{-\mathrm{b}}}=2^{-\mathrm{b}} \\
& \text { or } \mathrm{b}=\log \mathrm{PI} / \log 2
\end{aligned}
$$

The rate of reduction is usually described by giving the complement of the reduction that occurs when the production quantity is doubled. This is equal to the $\mathrm{PI}=2^{-\mathrm{b}}$ Hence, in an estimated learning curve with $b$ equal to -0.322 , its PI would be $80 \%\left(2^{-0.322}=0.80\right)$, indicating that each time production output doubled the direct labor input would be reduced to $80 \%$ of its former value.

The learning curve defined by Eq. 1 is called a unit curve. In practice, a cumulative average curve is of ten applied $[8,16,18]$. 


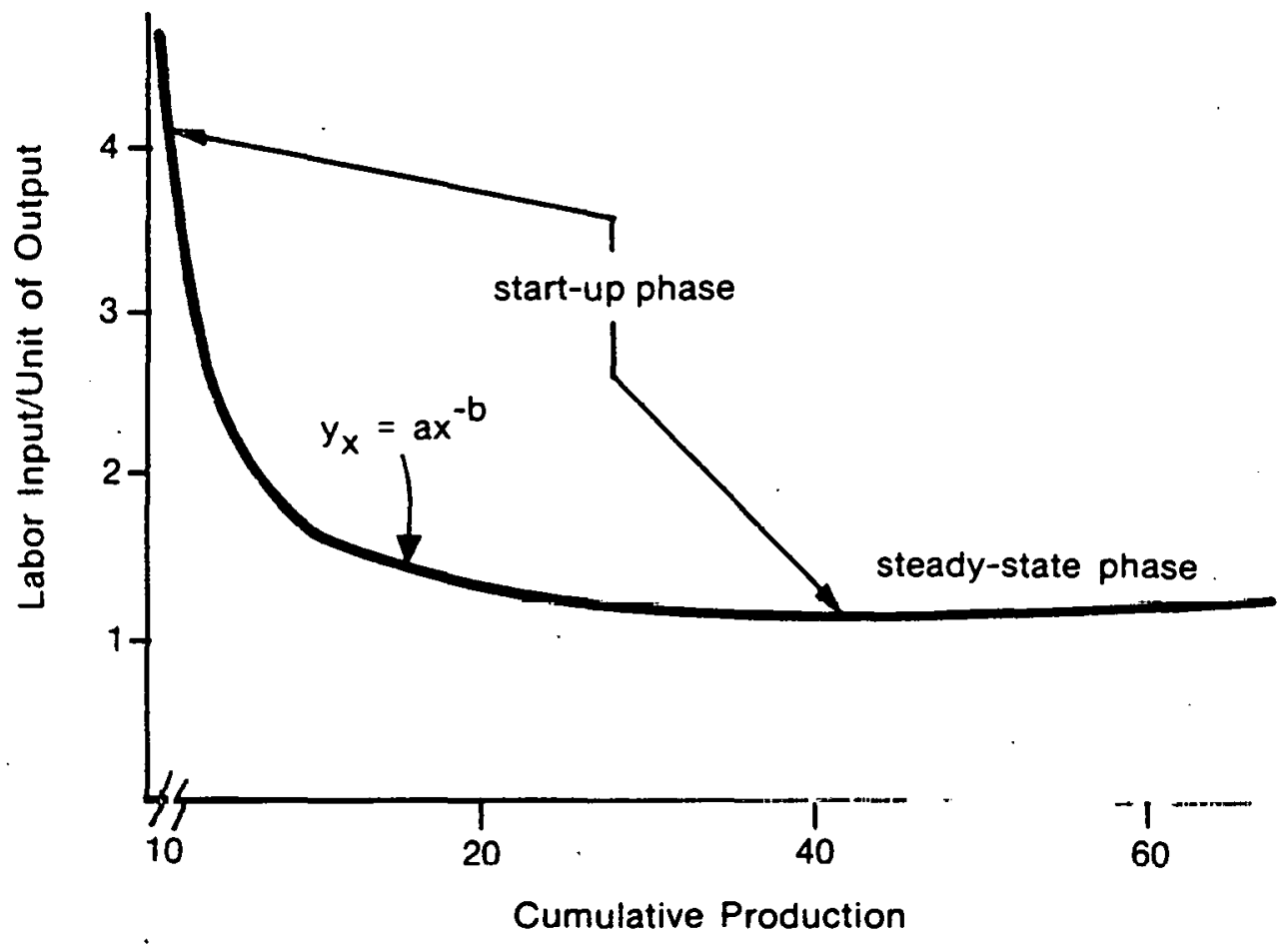

Figure 3-1. Hypothetical Unit Learning Curve on Arithmetic Coordinates

Krawiec and Flaim $(9$, p. 7$)$.

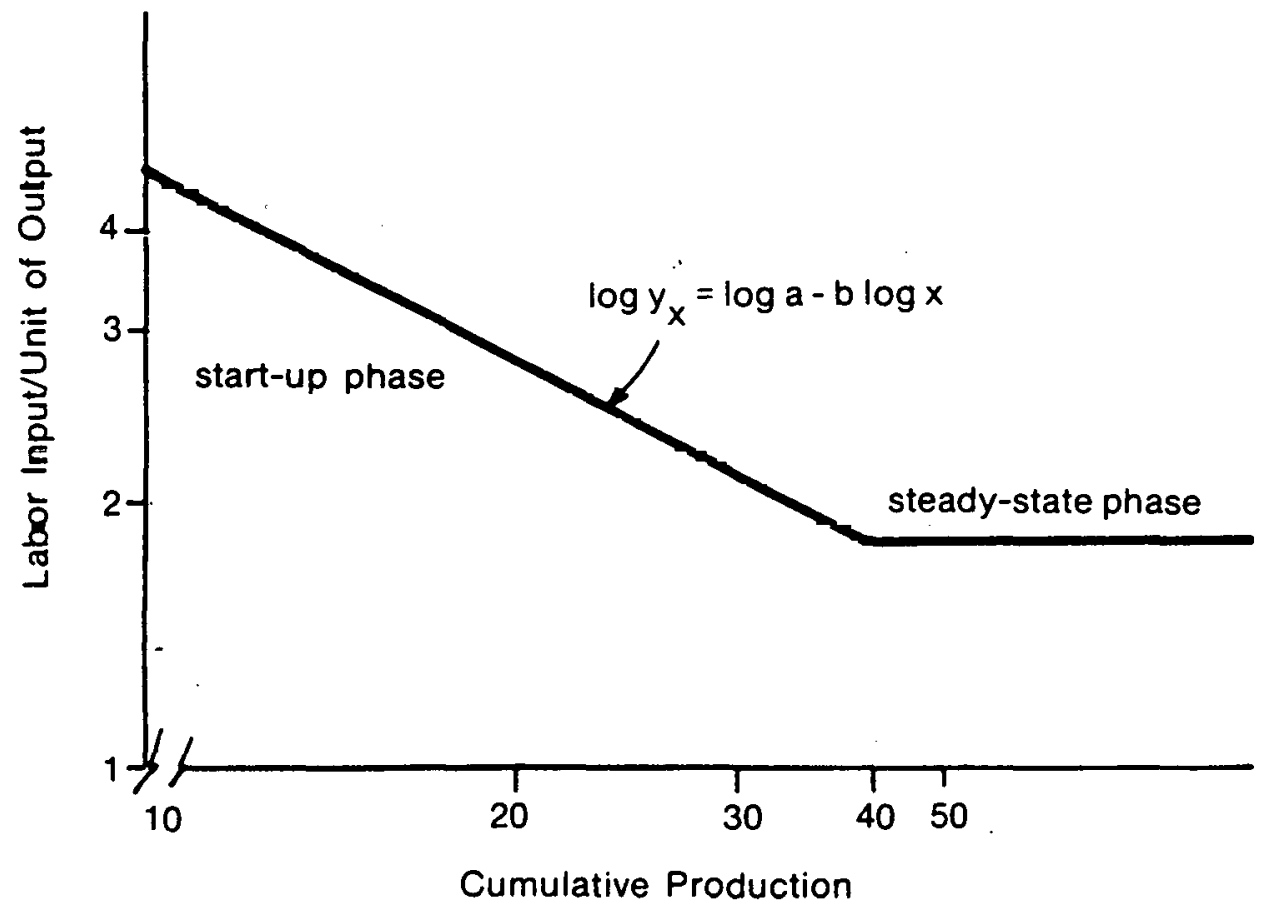

Figure 3-2. Hypothetical Unit Learning Curve on Logarithmic Coordinates

Krawiec and Flaim (9, p. 7). 


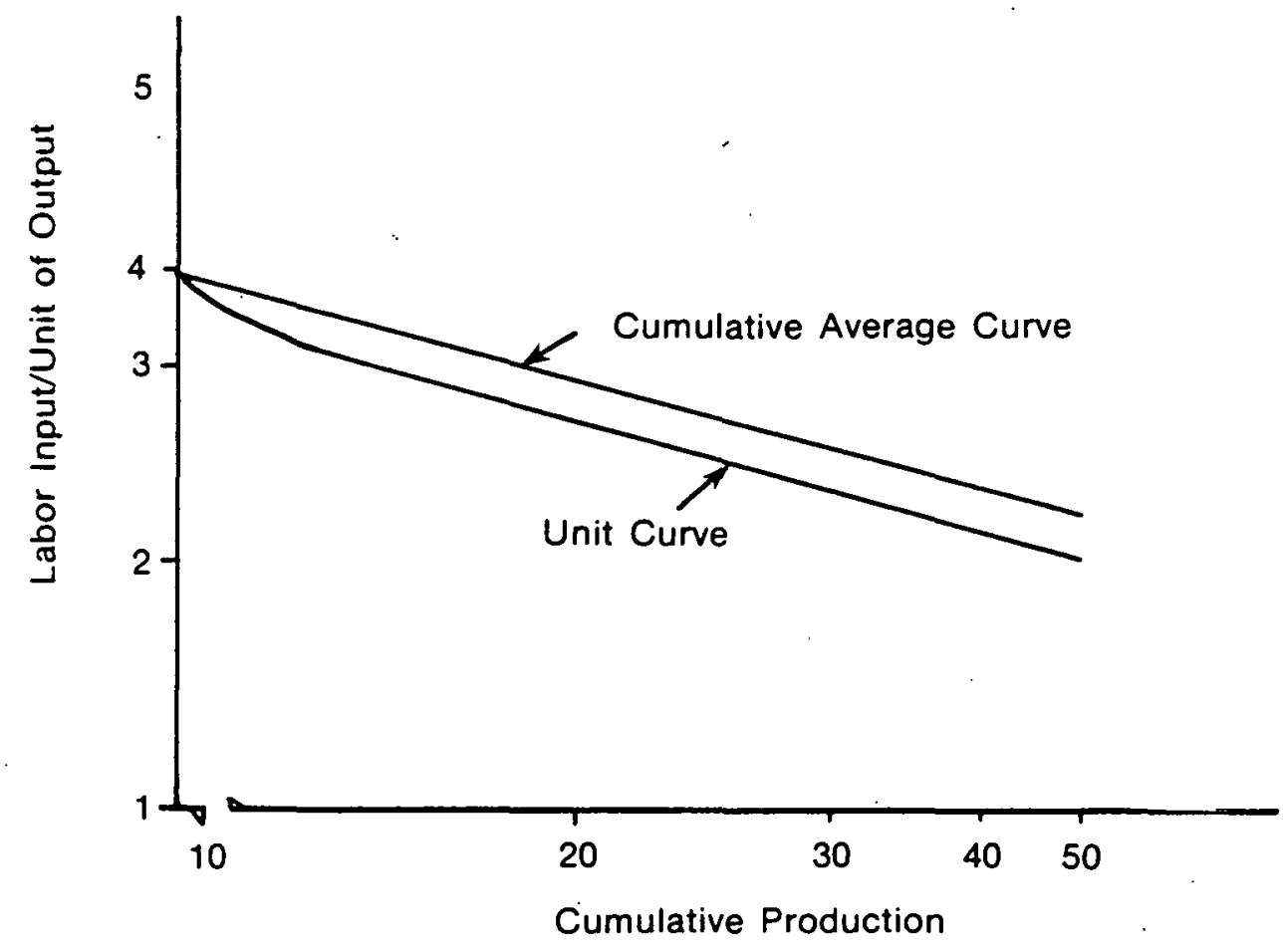

Figure 3-3. Hypothetical Learning Curve on Logarithmic Coordinates 
It is characterized by the following approximation function [8, p. 40]:

$$
\bar{y}_{x}=\frac{a}{N} \sum_{n=1}^{N} x^{-b}
$$

where

$$
\begin{aligned}
\bar{y}_{x}= & \text { cumulative average labor input per unit, averaged over all units of produc- } \\
& \text { tion from the first to the } X \text { th. } \\
\mathrm{x}= & \text { the production count }(\mathrm{x}=1,2, \ldots, \mathrm{X}) \\
\mathrm{N}= & \text { cumulative production between the lst and Nth unit. }
\end{aligned}
$$

All other symbols are the same as in Fq. I.

For values of $\mathrm{N}$ greater than 100, Eq. 4 can be approximated by [12, p. 40]:

$$
\bar{y}_{x}=\frac{a x^{-b}}{1-b}
$$

where all symbols are the same as in Eq. 4.

The various empirical studies [19-22] report substantial difficulties in determining the pragmatic superiority of the preceding curves by logic and empirical evidence. Conway and Schultz observed that "the choice in usage has been largely a matter of computational convenience; when the unit curve is of primary interest and use, the first model is selected; when the cumulative average curve is primary, the alternative model is used. Since in either case the two curves are parallel for large quantities of production the difference is important only during the initial stages of production and hence for many applications, not crucial" [8, p. 41]. Figure 3-3 illustra tes two hypothetical curves drawn on logarithmic coordinates. The upper curve shows the cumulative average curve, while the lower line represents the unit curve.

In applying the cumulative average curve, an analyst should keep in mind that "the averaging process has tremendous power to smooth the data and enhance the appearance if not substance of the curve" $[8, \mathrm{p} .41]$.

Although learning in the literal sense here is restricter to improved productivity of direct labor input, the learning curve is an analytical tool applied to generalize the rombined effects of both increased efficiency of workers and management innovations [15, p. 89].

\subsection{LEARNING CURVE ESTIMATION}

The method used to estimate the learning curve structural parameters depends upon the nature and format of the data required. The use of the learning curve as a predictor requires some clear definition of the quantitative measures relating to the variables used in estimating its structural parameters. The variables used in estimating learning curve 
structural parameters (i.e., the estimated direct labor input required to produce the first unit and the rate of reduction in direct labor input) are: direct labor hours required to produce the $x$ th unit of production and cumulative production between the first and $x$ th unit.

It is imperative that accurate, reliable, and properly aggregated data be used for each variable. Conway and Schultz summarize the difficulties encountered in obtaining the production count. The most important are [8, pp. 43-44]:

- Varying lot sizes, lead times, and schedules make it difficult to associate specific costs with specific production quantities of the end product.

- Some components are produced in relatively large volume in initial lots and later are split in production.

- Actual labor times are seldom accurately recorded; considerable doubt exists as to the validity of operator times charged to direct vs. indirect labor accounts.

- Actual product costs in terms of dollars or labor time are, in many cases, unobtainable.

- Design and model changes make it difficult to judge if a change is significant enough to justify treatment of the product as a new model, and when it should be treated as normal progress with the current model.

- Definition of individual operations is not constant over time; a particular portion of the work that must be performed on each unit often shifts from one operation to another.

Some of these difficulties can be eliminated through the process of aggregation of the parts manufacture operations and subassembly and final assembly operations. Conway and Schultz state that "considering the sum of two operations the data are unaffected by work transferred between these two operations (assuming the times for elements are additive). Considering the product as a whole, redefinition of operations does not affect the data. ". . . in considering groups of operations we are in effect considering the sums of a number of chance variables. In general such sums are much better behaved than the individual change variable" [8, p. 43-44]. However, they indicate that the aggregation process applies only to those operations that have basically the same cause-and-effect patterns [8, p. 44$\rceil$. Thus, each operation, part, subassembly, and assembly that has different cause-and-effect patterns is subject to its own learning curve.

Once the selection and aggregation process is complete, quantitative measures relating to the cumulative production count and the direct labor input required to produce the $x$ th unit of production should be determined. The three quantitative measures that an analyst can develop, based on sufficient data, are:

- The sequential production units and corresponding actual direct labor input for any particular unit.

- Production lot sizes released and corresponding costs accumulated on a production lot basis. The mean of a lot and corresponding average direct labor input is calculated. An average direct labor input is weighed by the amount of production it represents.

- An annual cumulative production and corresponding cumulative average direct labor input, averaged over all units of production. 
After these measures are established, the learning curve can be developed either graphically or mathematically. In applying the former process, the log paper is used to plot a direct labor input per unit against cumulative output. The line that connects these points is the learning curve for the units produced. The slope of the line indicates the percentage of direct labor input reduction achieved as the number of units produced is doubled. Alternatively, mathematical curve fitting procedures are applied to estimate which equation best fits the data points collected. In applying this approach, the exponential approximation function is assumed. On the basis of the empirical data, an analyst estimates the function's structural parameters by application of the ordinary least squares method.

Although the exponential function is the most widely used functional for $\mathrm{m}$, it has not yet been logically or mathematically related to manufacturing procedures in terms of quantitative cause and effect. This form is intuitively appealing because it reflects the fact that, in some industries, progress is rapid during the early stages of production and continues at a decreasing rate [15, p. 89]. Several authors proposed alternative approximation functions such as log-quadratic. Orsini summarizes this debate, the results of which have been inconclusive [13, pp, 24-30]. Krawiec and Flaim state that "since the logic behind the learning concept does not suggest a particular functional form, analysts should specify an equation which best summarizes the data" $[9, \mathrm{p} .10]$.

Perhaps the most difficult problem associated with estimating learning curves is aggregation. The production of a given product is not a single process, but rather a summation of fabrication, processing, subassembly, final assembly, installation, and testing, subject to its own learning curve. The aggregated learning curve for a given product is the vertical sum of the individual unit learning curves. The process of aggregation of the individual unit learning curves rests on a strong assumption that the exponential approximation function (which is linear in logs) holds for each manufacture, subassembly, and final assembly operation as well as for the completed product. It is difficult to justify assuming such linearity. Conway and Schultz indicate the implications involved by considering the sum of two unit learning curves for a series of two components of a given end product:

$$
\begin{aligned}
& y_{1 x}=a_{1} x^{-b_{1}} \\
& y_{2 x}=a_{2} x^{-b_{2}} .
\end{aligned}
$$

The sum is $\left(y_{1}+y_{2}\right)_{x}=a_{1} x^{-b_{1}}+a_{2} x^{-b_{2}}$.

a plot of $\left(\mathrm{y}_{1}+\mathrm{y}_{2}\right)_{\mathrm{x}}$ against $\mathrm{x}$ on $\log$ coordinates is a convex curve whose shape depends on the values $\left(a_{1}, a_{2}, b_{1}\right.$, and $\left.b_{2}\right)$. The ulut will be slruight if and only if $b_{1}=b_{2}=b$ $[8$, p. 41$]$. This indicates that the rate of learning is the same for both components, which will not generally be the case. Theoretically, the exponential learning curve can at best apply to only one level [8, p. 4l]. Krawiec and Flaim indicate that "from a practical point of view, aggregating learning curves for processes involves complex calculations. If analysts decide to use the exponential function for each suboperation and then the sum for convenience, they should realize that doing so will result in errors in computation" $[9$, p. 11$]$.

An alternative approach is to calculate the actual cost of the first unit "as a basis for extrapolation and use of a uniform $80 \%$ characteristic to define slope" [8, p. 44]. The 
first unit cost, the basic parameter to locate the function, may be defined in a number of ways depending on the perspective of the analyst. In a development firm, it may be viewed as the cost of the first test article with or without a nonrecurring engineering allocation or as a synthetic value extended from industrial engineering standards that have been determined at, say, the 100th unit of production. Development of the first unit cost can be accomplished employing the engineering build-up cost method "on the basis of some implicit conception of stabilized production volume and conditions peculiar to the firm and its environment" [8, p. 44]. The applicability of this approach to estimate numerical values of the structural parameters of the function is questionable. Although the approach is widely used in the aircraft industry, Conway and Schultz do not recommend its application because "There is no such thing as a fundamental law of progress such as the ' $80 \%$ learning curve'. . . No particular slope is universal, and probably there is not even a common model" $[8$, p. 53].

Despite the various difficulties and unsolved problems mentioned, the structural parameters of the specified approximation function can be estimated either graphically or mathematically.

\subsection{EMPIRICAL APPLICATIONS OF LEARNING CURVES}

The learning curve was developed as a managerial planning tool. It has been used as a basis for facilities and manpower scheduling, pacing assembly operations, and cost estimation [8, p. 50]. Cost estimates obtained through learning curves have been used as the basis for contract negotiations in the aircraft industry, and for a variety of pricing, buying, and financing decisions [15, pp. 91-95].

Estimated learning curves can be useful tools for predicting manufacturing costs. At the center of empirical studies is the concept of separating labor, materials, and overhead costs, the factors that make possible both cost reductions and concomitant increases in quantities produced. Prediction of labor costs will be discussed first. Next, the estimation of the parameters of the curve for materials and overhead costs will be considered. Then, procedures for obtaining total product costs will be outlined. Finally, the limitations of learning curves will be addressed.

\subsubsection{Labor}

A learning curve indicates the relationship between labor input (measured in labor hours per unit of output) and cumulative production. ' In order to determine labor costs, labor hours must be multiplied by appropriate wage rates. Even though some authors have used learning curves to predict labor costs directly [13,14], labor hours and wage rates should be calculated separately for several reasons.

First, economic theory suggests that as the productivity of an input increases, its wage rate should also increase [23, pp. 293-307]. Second, for some of the industries examined, Conway and Schultz found that progress in labor hours was roughly offset by rising hourly wages and that labor costs were less predictable than hours [8, p. 49]. They state:

Use of labor hour or a machine hour base has been found to be much more illuminating than dollar costs. Where dollar costs are desired they may be used as a multiplier, but price changes serve to mask production progress in terms of fundamental resource consumption. [8, p. 53] 
Finally, labor hours can be reduced by substituting more skilled and more expensive labor for less skilled workers. However, reducing labor hours could cause higher labor costs $[15$, p. 90]. For these reasons, labor hours and wage rates must be calculated separately to avoid errors in labor cost predictions.

\subsubsection{Materials}

Material generally decreases in cost as the quantity of output increases. Although the estimation of the parameters of the curve for materials costs has been of significant concern, little has been written concerning reduction in the materials component of product cost. Only a few authors have examined materials cost reductions due to volume discounts, more efficient purchasing, or reduction of rejects $[17,18,20,24]$. Conway and Schultz believe that "there is no reason why one could not quantify past experience and use it to predict reduction in materials cost. Lacking such information, one would probably neglect progress in this area except for obvious economics associated with quantity" $[8$, p. 51$]$.

\subsubsection{Overhead}

Some empirical studies indicate that amount of overhead varies, within limits, with quantity of output. Overhead is usually expressed as a percentage of direct labor costs that results in a log-linear relationship for overhead costs. Overhead costs fluctuate greatly in different cases depending, for example, on structural components (i.e., taxes, depreciation, executive salaries) or when a particular factory is engaged in the manufacture of one or many types of products [17,24].

\subsubsection{Obtaining Total Production Costs}

An aggregated cost curve for direct application to different quantities of the end product can be developed by combining factors of labor, material, and overhead. Wright pointed out that the shape of a total cost curve developed by this method in the aircraft industry "will start out at $83 \%$, then change to $87 \%$, and finally reach $90 \%$. This change in slope is an indication of the relatively greater importance of material to labor as quantity increases" $^{\prime \prime}$ 17, p. 126]. This cost estimation procedure is distinctly different from using experience curves to predict total unit costs directly.

\subsection{IMITATIONS OF LEARNING CURVES}

Learning curvc3 can bc uscful tools for estimating changes in production costs. They have been applied successfully in aerospace and related defense industries [8,15-17]. The relevance of the learning curve in labor extensive manufacture-automobile assembly, apparel manufacture, and the production of large musical instruments-was found by Baloff. The studied products, modes of manufacture, and industries differed significantly from each other and from the aerospace industry to suggest a greater, wider application of the learning curve model in labor-intensive production activities [16, p. 339]. There is need for a greater generalization for and application of the learning curve model in capital-intensive industries. Labor learning as defined here may only be a minor source of cost reduction in these types of production activities. However, the literature $[8,14-17,24]$ does not provide empirical evidence questioning the applicability of the 
learning curve concept in capital-intensive industries. These learning curves are subject to three important limitations.

First, the learning curve is a method of estimating changes in labor productivity which occur af ter production operations begin. If substantial efforts are devoted to preproduction engineering and planning and if labor productivity is higher than it otherwise would have been, the learning curve will not capture the progress that has been made.

Second, learning rates vary substantially among industries, firms, products, and types of work $[8,14,16]$. Again, Conway and Schultz conclude:

There is no such thing as the fundamental law of progress such as the " $80 \%$ learning curve"* used in the aircraft industry. No particular slope is universal, and probably there is not even a common model. The contention that such exists is most difficult to defend either logically or empirically. $[8$, p. 53]

Analysts must choose the appropriate model and estimate the rate of progress for that product.

Third, the analyst must determine the range of production over which progress will occur. Empirical data show that progress does not continue indefinitely $[8,16,26]$ : The application of learning curves is based on the assumption that progress in labor hours will be achieved over the range of production specified.

*The "80\% learning curve" is identical to the progress index. 
SERI 


\section{SECTION 4.0}

\section{THE CONCEPT OF EXPERIENCE*}

Like the leaming concept, the experience concept was developed from the observation that per-unit production costs declined in some industries as a direct, estimable proportion of cumulative production [26-28]. Unlike learning that refers to the productivity of a single input, the experience concept has been used to describe changes in total cost as a function of cumulative production.

According to the Boston Consulting Group, which claims to have originated the concept, "The experience... effect ... encompasses all costs (including capital, administrative, research, and marketing) and traces them through technological displacement and product evolution" $[27$, p. 6]. They state from their observations of various industries that "Costs appear to go down ...20\% to 30\% every time total product experience doubles for the industry as a whole, as well as for individual producers" [27, p. 12]. The experience concept applies to long-term improvements in production processes and includes cost reduction from every conceivable source, including technical improvements, input substitution, economies of scale, new product design, and changing input prices.

\subsection{EXPERIENCE CURVES}

Experience curves are similar to learning curves and are calculated as follows:

$$
c_{\mathbf{x}}=\mathbf{a x}
$$

where

$$
\begin{aligned}
\mathbf{c}_{\mathbf{x}} & =\text { the cost of producing the } \mathrm{xth} \text { unit of output; } \\
\mathbf{x} & =\text { cumulative production; } \\
\mathbf{a} & =\text { estimated cost of producing the lst unit; and } \\
\mathbf{b} & =\text { parameter measuring the change in total cost (normally, }-1<b<0 \text { is } \\
& \text { assumed). }
\end{aligned}
$$

In practice, the experience curve usually refers to the percentage reduction in cost that occurs when cumulative production is doubled. It is calculated the same way that the progress index is calculated for learning curves:

$$
\text { for } \mathrm{x}_{2}=2 \mathrm{x}_{1}, \frac{\mathrm{C}_{1}}{\mathrm{C}_{2}}=\frac{\mathrm{ax}_{2}^{-b}}{\mathrm{ax}_{1}^{-b}}=2^{-\mathrm{b}} \text {. }
$$

An $80 \%$ experience curve would indicate that if cumulative production doubles, per-unit production cost would decline to $80 \%$ of its level prior to doubling [28, p. 53].

*This section originally appears, in essence, in Krawiec and Flaim [9]. 


\subsection{APPLICATIONS OF EXPERIENCE CURVES}

The Boston Consulting Group (BCG) examined historical data for 24 products and found that price reductions* were strongly correlated with cumulative production $[27, \mathrm{pp} .69-$ 101]. Their results were summarized by Costello et al. [10] and are presented in Table 4-1. Similar data were compiled by Hirschman [26] and cited by Bodde [28].

These experience curves were not estimated by the BCG to be used directly for cost estimation purposes. Rather, the BCG and other au thors cite experience curves as evidence that costs can decline as the result of many factors; they recommend that managers be aware of cost reduction possibilities when designing product-market strategies [26-28].

\subsection{BXPERIENCE CURVES AND COST ESTIMATION}

Even though cost prediction was not the goal of the Boston Consulting Group, some analysts have attempted to use experience curves to predict the future costs of solar technologies [24, pp. xiv-xv, 159-161]. Despite the statistical evidence that costs have declined in some industries, there are serious problems with using experience curves to predict cost reduction.

One problem is that there is no logical reason to believe that costs should decline as a function of cumulative production per se. In other words, there is no a priori reason to believe that the parameter $b$ in the experience curve will have a negative sign. It is quite possible that costs may be increasing for a particular product. Long-run costs could increase due to rising input prices, government regulations requiring higher cost production methods, or firms adopting new production methods that result in higher production costs.**

A second problem is that there is no way to separate cost changes due to technical progress from those due to falling input prices, because the experience curve describes cost changes as a function of cumulative production. Declining input prices clearly influenced cost changes for at least 9 of the 24 products cited by the BCG: electricity and the 8 petroleum-based products.I Experience curves necessarily reflect the combined effects of both progress and declining input prices, and cannot be interpreted as measures of progress alone.

* Cost data were unavailable; price data were used as proxies for costs. Price changes were measured in constant dollars. In general, prices are inadequate measures of cost because prices are determined by both supply and demand conditions.

**Firms might adopt higher-cost (less optimal) production methods because of imperfect infor mation or uncertainty. In addition, if markets are not price competitive, firms may pursue goals other than côst minimization, which could result in higher production costs $[30]$. However, these factors are beyond the scope of this report.

ICrude oil prices in constant dollars generally declined from 1950 to 1972 (see Table 4-1). Crude oil is an input to petroleum products; fuels derived from crude oil are used in electricity generation. 
Separating the influence of technical progress from that of changing input prices is further complicated by the fact that both affect improvements in production processes $[31$, p. 23]. Thus, if a change in the production process is made in order to substitute a cheaper input for a more expensive input, that improvement cannot be expected to apply to a solar technology unless the solar firm faces the same relative input prices.

The third problem involves source identification and analysis. Even though the experience concept as defined by BCG [27] and Bodde [28] includes cost reductions from logical sources such as: technical improvements, sources of cost reduction must be identified separately and their impacts on costs must be analyzed directly. There is no other way to evaluate whether cost reduction sources and their impact on costs can be expected to apply to the production of solar technologies. Without careful analysis of these separate sources, experience curves that are estimated from other product histories and used to predict the future costs of solar technologies will yield arbitrary and perhaps misleading cost estimates.

Analysts using experience curves to predict future costs of solar technologies should heed the advice of the Boston Consulting Group, who originated the concept:

As a practical matter experience curves should be considered only as a means of understanding relationships, not as a measuring device. There are inherently too many difficulties in definition and factor measurement. This applies particularly to the definitions of product and cost as well as measuring accumulated experience. [27, p. 63. Emphasis added] 
Table 4-1. EXPERIENCE CURVES IDENTIFIED BY THE BOSTON CONSULTING GROUP ${ }^{\mathrm{a}}$

(Cumulative Industry Production vs. Price)

\begin{tabular}{|c|c|c|}
\hline $\begin{array}{l}\text { Process or } \\
\text { Industry }\end{array}$ & $\begin{array}{c}\text { Experience Curve } \\
\text { Slope } \\
\text { (Constant Dollars) }\end{array}$ & $\begin{array}{c}\text { Data } \\
\text { Comments }\end{array}$ \\
\hline $\begin{array}{l}\text { Germanium Transistors } \\
\text { Industry }\end{array}$ & $\begin{array}{l}90 \%(1954-1960) \\
70 \%(1960-1968)\end{array}$ & $\begin{array}{l}1954-1968 \\
1954-1969\end{array}$ \\
\hline Silicon Transistors Industry & $\begin{array}{l}90 \%(1954-1959) \\
70 \%(1960-1965) \\
80 \%(1965-1969)\end{array}$ & $1954-1969$ \\
\hline Germanium Diodes & $\begin{array}{l}90 \%(1955-1959) \\
70 x(1960-1968)\end{array}$ & $1955-1968$ \\
\hline Silicon Diodes & $\begin{array}{l}90 \%(1955-1959) \\
70 \%(1960-1968)\end{array}$ & $1955-1968$ \\
\hline Integrated Circuits & 7096 & $\begin{array}{l}1964-1968 \text { (1965 \& } \\
1966 \text { monthly data) }\end{array}$ \\
\hline Crude Oil & $\begin{array}{l}\text { Increasing prices } \\
(1946-1948) \\
90 \%(1948-1958) \\
70 \%(1958-1968)\end{array}$ & $\begin{array}{l}1946-1968 \\
\text { real prices } \\
\text { increased from } \\
1946-1948\end{array}$ \\
\hline Motor Gasoline & $\begin{array}{l}\text { Prices increased } \\
(1946-1949) \\
90 \%(1949-1957) \\
75 \%(1957-1968)\end{array}$ & $\begin{array}{l}\text { 1946-1968 } \\
\text { (average price/ } \\
\text { gal. excluding } \\
\text { Cálifornia) } \\
\text { U.B. du tu only }\end{array}$ \\
\hline Ethylene & $\begin{array}{r}100 \%(1953-1963) \\
70 \%(1963-1968)\end{array}$ & $\begin{array}{l}1953-1968 \\
\text { U.S. tariff price } \\
\text { vs. U.S. data only }\end{array}$ \\
\hline Benzene & $\begin{array}{l}70 \%(1953-1963) \\
90 \%(1963-1968)\end{array}$ & $\begin{array}{l}1952-1968 \\
\text { U.S. da ta only }\end{array}$ \\
\hline Paraxylene & $\begin{array}{l}90 \%(1957-1961) \\
70 \%(1961-1968)\end{array}$ & $1957-1968$ \\
\hline Low Density I'olyethylene & $\begin{array}{l}90 \%(1952-1959) \\
70 \%(1960-1968)\end{array}$ & $1952-1968$ \\
\hline Polypropylene & $\begin{array}{l}90 \%(1959-1961) \\
80 \%(1961-1968)\end{array}$ & $1959-1968$ \\
\hline $\begin{array}{l}\text { Polystyrene (General Purpose } \\
\text { Molding and Extrusion Resin) }\end{array}$ & $\begin{array}{l}90 \%(1943-1954) \\
70 \%(1954-1968)\end{array}$ & $1943-1968$ \\
\hline Polyvinylchloride & $\begin{array}{l}90 \%(1946-1955) \\
70 \%(1955-1961) \\
80 \%(1961-1968)\end{array}$ & $1946-1968$ \\
\hline
\end{tabular}


Table 4-1. EXPERIENCE CURVES IDENTIFIED BY THE BOSTON CONSULTING GROUP ${ }^{a}$ (concluded)

(Cumulative Industry Production vs. Price)

\begin{tabular}{|c|c|c|}
\hline $\begin{array}{l}\text { Process or } \\
\text { Industry }\end{array}$ & $\begin{array}{c}\text { Experience Curve } \\
\text { Slope } \\
\text { (Constant Dollars) }\end{array}$ & $\begin{array}{c}\text { Data } \\
\text { Comments }\end{array}$ \\
\hline Primary Aluminum & $\begin{array}{l}80 \%(1929-1939) \\
70 \%(1939-1948) \\
\text { no trend }(1961-1968)\end{array}$ & $1929-1968$ \\
\hline Primary Magnesium & $80-90 \%$ & $\begin{array}{l}1929-1968 \\
\text { significant } \\
\text { deviations in trend }\end{array}$ \\
\hline Titanium Sponge & $\begin{array}{r}100 \%(1950-1954) \\
70 \%(1954-1968)\end{array}$ & $\begin{array}{l}1950-1968 \\
\text { strong deviation } \\
\text { between 1958-1968 }\end{array}$ \\
\hline $\begin{array}{l}\text { Monochrome Television } \\
\text { Receivers }\end{array}$ & $\begin{array}{l}90 \%(1947-1954) \\
70 \%(1954-1968)\end{array}$ & $1947-1968$ \\
\hline $\begin{array}{l}\text { Total Freestanding } \\
\text { Gas Ranges }\end{array}$ & $\begin{array}{r}100 \%(1946-1950) \\
70 \%(1951-1967)\end{array}$ & $\begin{array}{l}1946-1967 \\
\text { average wholesale } \\
\text { price }\end{array}$ \\
\hline $\begin{array}{l}\text { Total Freestanding } \\
\text { Elec tric Ranges }\end{array}$ & $\begin{array}{l}90 \%(1946-1957) \\
70 \%(1957-1967)\end{array}$ & $1946-1967$ \\
\hline Facial Tissue & $\begin{array}{l}90 \%(1933-1945) \\
\text { increases }(1945-1948) \\
90 \%(1948-1966)\end{array}$ & $1933-1966$ \\
\hline Japanese Beer & $80-90 \%$ & $\begin{array}{l}1951-1968 \\
\text { retail price } \\
\text { minus indirect tax }\end{array}$ \\
\hline Electric Power & $\begin{array}{l}70 \%(1939-1943) \\
80 \%(1943-1968)\end{array}$ & $1930-1968$ \\
\hline Refined Cane Sugar & $70 \%$ & $\begin{array}{l}1935-1968 \\
\text { very wide fluc- } \\
\text { tuations in data }\end{array}$ \\
\hline
\end{tabular}


S=Pl 


\section{SECTION 5.0}

\section{DEVELOPMENT OF LEARNING AND EXPERIENCE CURVES FOR SOLAR ENERGY TECHNOLOGIES}

\subsection{BACKGROUND}

The crucial issue in the commercial development of solar energy technologies is: "How will the cost of solar technologies change over time?" Many current solar technologies are too expensive to be economically feasible. Some of these technologies may achieve substantial cost reductions from improvements in product design and production techniques. These cost reductions are usually estimated or predicted on the basis of rough comparisons in dollars/lb or by comparing similar products. While such predictions may indicate a general cost range, they are of little value in making investment decisions at either the public or private levels in identifying specific areas needing improvement.

A brief and simple method for predicting the effect of future changes in design, materials, or production methods of solar technologies is essential to optimum development and planning.

An analyst can estimate future normal costs of a given technology or product if he understands their basic relationship to learning and experience. Such a relationship can be quantitatively expressed by the application of learning and experience curves.

\subsection{DATA LMITATIONS}

Empirical applications of learning and experience curves have been based upon products for which production data are available $[8,12-14,16,17,26,27]$. However, solar energy supply systems represent emerging technologies with both mature components and processes and untested prototype parts, assembly methods, and installation processes. Many solar technologies require significant amounts of on-site construction. Most learning and experience curves have been developed for the products that were manufactured, rather than constructed on-site.

Since the solar industry is young, few data are available on production economics and hardly any basis exists for estimating a particular learning or experience curve slope. In such situations, learning and experience curves must be based on surrogate products or systems resembling solar products in configuration, materials, and production methods. The selection of an appropriate surrogate product or system with an available cost history allows inferences to be made regarding the cost of the new product. It is assumed that because of these similarities, the new product will undergo the same cost reduction pattern as the surrogate product. Procedures for developing learning and experience curves for new products or systems using surrogate data follow.

\subsection{ESTIMATING LEARNING AND EXPERIENCE CURVES POR SURROGATE PRODUCTS OR SYSTEMS}

The procedure begins with the conceptual disaggregation of the new product or system assembly into components, subassemblies, and processes. This disaggregation depends upon the analyst's concept of availability of relevant surrogate components, subassemblies, and processes. 
The surrogate part or subassembly should then be identified. A number of selected surrogates might later be eliminated because of special circumstances in their commercial development, the fact that some entered the market fully developed, and the lack of reliable historical cost data.

The third step is to collect historical data on the costs of each of the surrogate parts or subassemblies and to break down these costs according to labor, materials, and overhead. Labor input should be measured in person-hours per unit of output, multiplied by appropriate wage rates, in order to determine labor costs. Economic theory suggests that as the productivity of a labor input increases, its wage rate should also increase [23, pp. 293-307]. For some of the industries examined, Conway and Schultz found that progress in labor hours was roughly offset by rising hourly wages and that labor costs were less predictable than labor hours [8, p. 49]. Labor hours can be reduced by substituting more skilled and more expensive labor for less skilled workers; however, by reducing labor hours, a firm could face higher labor costs [15, p. 90]. "For these reasons, labor hours and wage rates must be culculated separately to avoid errors in labor cost predictlons" [9, p. 13]. Material inputs should be measured in both physical units and dollar-cost-per-unit. Unit overhead cost should be expressed in dollars, and individual elements of the costs generated should be corrected to eliminate the effects of inflation. Production volume for surrogate parts and subassembly should also be determined.

Historical data collection for surrogates is the most difficult task, not because general information does not exist, but because detailed data concerning labor, labor costs, material costs, and investment on a historical basis may not exist in some instances, may be extremely sensitive in others, or may be so interspersed with other unrelated data as to be either unusable or uncollectable. Most of the data involved, except for regulated industries, are usually unavailable to the public. But it is not always necessary to use current or recent proprietary data sources to establish trends. An analyst can use published retail or wholesale manufacturing data to break down information into its costspecific components. He can then juxtapose specific technological improvements made in particular industries with new data. However, this process requires tremendous amounts of time and effort.

Once the data are obtained, an analyst has to identify the technological factors that caused specific manufacturing changes or trends for the selected surrogates and determine how this development would or would not apply to the new product or system. This step rationally projects how past cost history may be extended for the new proposed product or system. In addition to carefully examining technological factors that caused specific changes in manufacturing the surrogates, an analyst should assess production volume eff ects. Surrogate product volumes probably will differ widely from one another and from the projected volumes for the new product. These volume variations can have a significant cost impact and have to be standardized to produce realistic predictions. Based on the developed data, learning curves can be estimated using the procedures outlined in Sec. 3.6 of this report.

Finally, learning curves for surrogate products should be evaluated in order to determine whether the same rate of progress can reasonably be expected to occur in the new product or system. The surrogate learning curves can then be used to estimate labor requirements for each part, subassembly, assembly, and process involved in the product. Significant materials cost reductions in the surrogate product's history should be estimated. In order to calculate total costs for each process, labor costs must be added to materials, capital, and overhead costs [9, p. 25]. A composite product or system cost 
curve can be calculated by aggregating total cost estimates for each operation in the production process.

\subsection{ESTHMATING EXPERIENCE CURVES FOR SURROGATE PRODUCTS OR SYSTEMS}

An experience curve can be estimated on the basis of production experience for related products or systems. The selected surrogate should be similar in configuration, materials, and processes of manufacture and installation to those that are anticipated for the proposed new product or system.

Once an appropriate surrogate product has been selected, historical data on costs (including capital, administrative, research, and marketing), production rate, and volume must be collected, examined, and traced through technological displacement and product evolution. The procedure for estimating experience curves is outlined in Sec. 4.1.

If the experience curve that is developed for the surrogate product is judged applicable, it can be used to predict an overall cost reduction for the new product. It should be noted that such prediction can be used only to provide a rough estimate of long-term changes in the cost of the proposed new product. 
SER1 


\section{SECTION 6.0}

\section{TECHNICAL ASPECTS OF HELIOSTAT DESIGNS}

This section summarizes technical aspects of McDonnell Douglas and General Electric heliostat designs. Included here are basic elements of a solar central receiver system, $a$ description of the DOE heliostat development program, some generic heliostat designs, and key cost factors in heliostat designs.

\subsection{BASIC ELEMENTS OF A SOLAR CENTRAL RECEIVER SYSTEM}

The point focus central receiver system, commonly known as the "power tower," is a concept in which reflected sunlight is concentrated on a heat absorbing receiver mounted on a tower. This absorbed energy is used to heat a fluid (such as steam, air, salt, or sodium) which in turn can be used directly as a heat source for processes, to provide heat for operation of a turbine, or can be stored for la ter use. Figure 6-1 conceptually shows a typical central receiver for power generation using conventional steam technology [3].

As sunlight strikes the heliostat, it is reflected to the receiver/boiler that absorbs the energy and turns water to steam. The steam is then directed to a conventional turbine generator where electrical power is produced. When excess steam is produced, the heat is extracted and stored for later use when sunlight is not available. Then, the steam is cooled and condensed so that it can be pumped back to the receiver. Either a conventional wet cooling tower or a drying cooling tower can be used to cool the exhaust steam.

Several options exist in the selection of the thermodynamic cycle and coolant: closed or open-cycle air, or closed helium Brayton cycles, as well as the conventional steam Rankine cycle. The central receiver designs are characterized by high temperatures and high pressures in comparison with other solar technologies. Turbine inlet temperatures in excess of $800 \mathrm{~K}\left(980^{\circ} \mathrm{F}\right)$ and pressures of $7 \mathrm{MPa}(1,015 \mathrm{psia})$ are typical design values for steam Rankine cycles. The closed-cycle helium systems reportedly will utilize inlet temperatures as high as $1,088 \mathrm{~K}\left(1,500^{\circ} \mathrm{F}\right)$; open-cycle Brayton will utilize inlet temperatures of $1,250 \mathrm{~K}\left(1,800^{\circ} \mathrm{F}\right)[32]$.

The heat to the elevated receiver is supplied by a field of tracking collectors called heliostats. Various designs are being considered for the placement of the tower in relation to the heliostat field, depending upon plant capacity. A typical field layout for a plant with a capacity greater than $10 \mathrm{MW}$ is shown in Fig. 6-2 [34]. The tower is not placed in the center of the field, but is slightly to the south of center to obtain the best annual optical efficiency from the entire field.

The collector field is usually the most expensive element in a central receiver system, of ten accounting for more than 50\% of the plant cost (Fig. 6-3) [33]. The collector field consists of a large group of two-axis tracking heliostats (Fig. 6-4), each of which independently tracks the sun in a manner such that the sunlight is directed onto the towermounted receiver [36]. The field of heliostats is generally controlled by a centralized computer that sends sun position data to each heliostat. Small microprocessors located at each heliostat then translate those signals into azimuth and elevation angles for the particular heliostat and direct it to the correct position. A centralized computer is also used to supply common commands to the entire field during emergency or maintenance operations. 


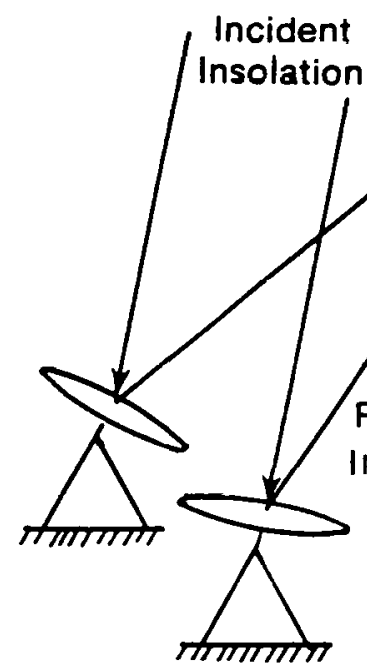

Tracking Heliostats
Heal

Recoiver

Tower

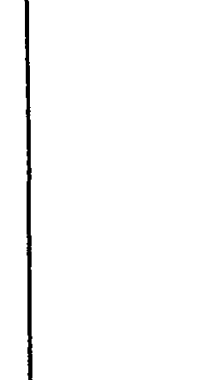

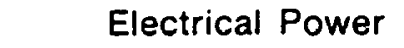

Transmission

+ Network<smiles>C1CCC1</smiles><smiles>CCCC</smiles><smiles>CCC(C)C(C)C</smiles>

Reflected Insolation

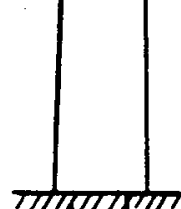

minkm
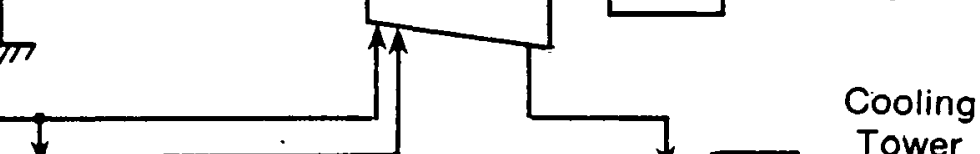

Thermal

Storage

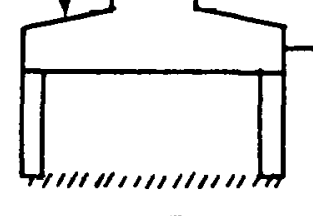

Electric Generator

Figure 6-1. Schema for a Typical Central Receiver System 


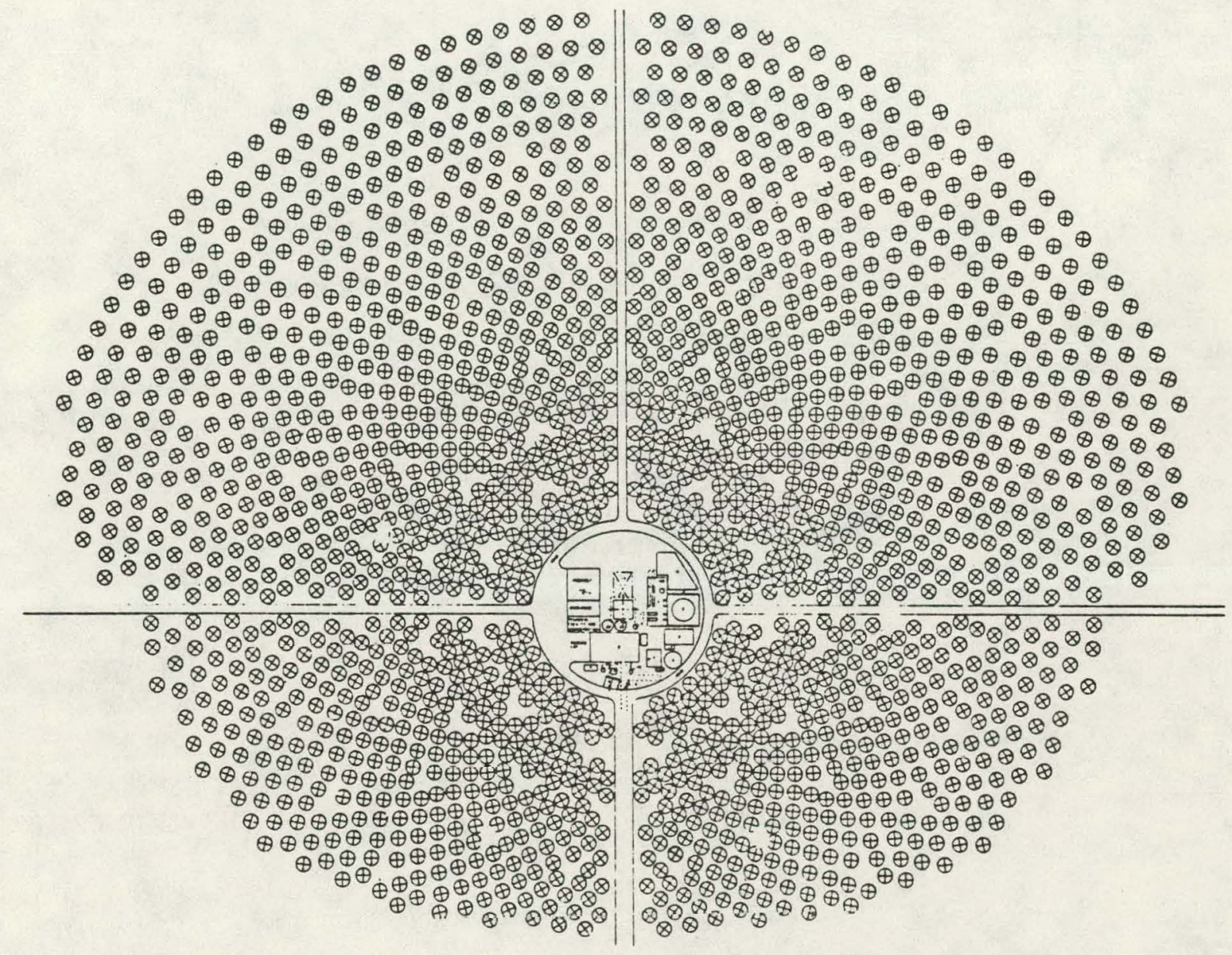

Figure 6-2. Heliostat Field and Central Power Tower 


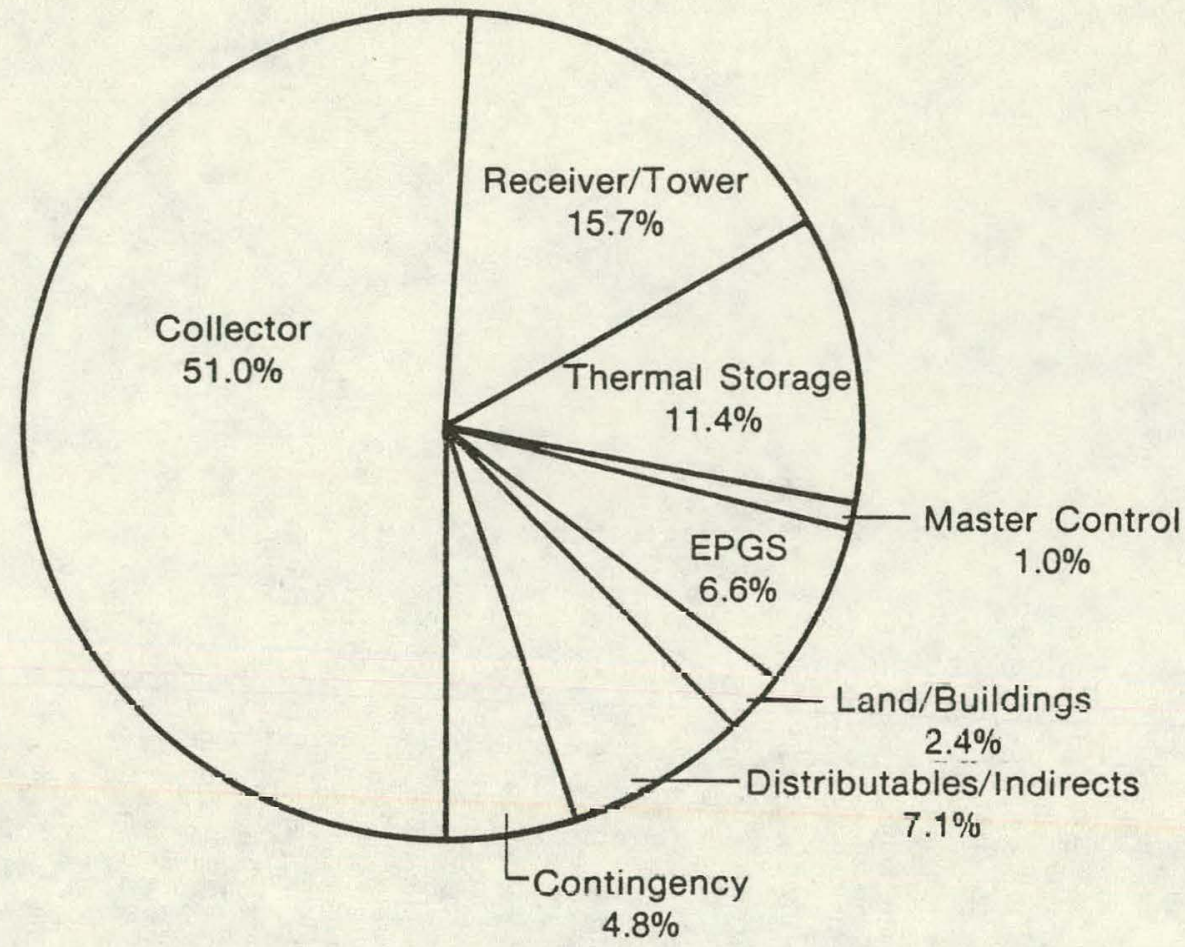

Figure 6-3. Cost Breakdown for a Typical Central Receiver Plant

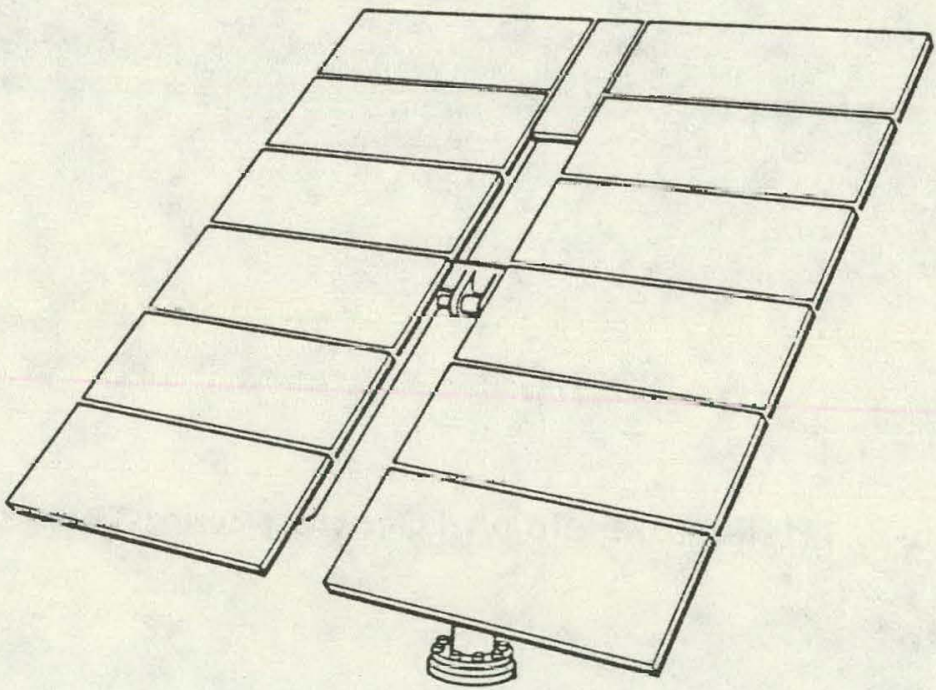

Figure 6-4. Typical Two-Axis Tracking Heliostat 
In a large plant, several thousand heliostats may be used. For example, a recent design of an advanced $100-\mathrm{MW}_{\mathrm{e}}$ central receiver plant was sized for a capacity factor of about 0.7 , which corresponds to an annual average of approximately 8 hours of storage per day. To achieve this, 15,177 heliostats, each with reflective areas of $40 \mathrm{~m}^{2}\left(431 \mathrm{ft}^{2}\right)$ were assumed [35].

Since each heliostat in a large field is identical, significant cost reductions through mass production and the use of commercially available, standard components are possible. Moreover, further cost reductions can be expected through normal engineering development. Current estimates by contractors and laboratories range as low as $\$ 42 / \mathrm{m}^{2}(\$ 3.90 /$ $\mathrm{ft}^{2}$ ) reflectivity for quantities of 250,000 heliostats/yr [36], a potential reduction of $10-$ 20 times over the costs of early prototype units.

\subsection{THE DOE HEIMOSTAT DEVELOPMENT PROGRAM}

The heliostat field represents the largest fraction of the cost of a solar central receiver system. Accordingly, DOE has placed major emphasis on reducing heliostat cost through several programs. The goal is to develop reliable cost-effective heliostat designs that are amenable to mass production and meet strict performance standards. The current cost goal, established in 1975 , is to produce heliostats at $\$ 72 / \mathrm{m}^{2}\left(\$ 7 / \mathrm{ft}^{2}\right)$ reflectivity. This goal is under review, however, and will probably change to reflect newer cost estimates resulting from recent advances in heliostat design, as well as interest shown by large manufacturing companies such as General Motors and Ford.

Various central receiver concepts have been studied during this century, notably by the United States, Russia, Italy, and France. The modern power tower concept had its inception in the United States in 1969-70 when Hildebrant and others conceived a 500- $\mathrm{MW}_{\text {th }}$ system to drive an MHD generator for a hydrogen production system. A proposal for a similar system, to genera te steam to drive a conventional turbine, was presented to NSF/ Rand in 1972, who funded a series of studies between 1973 and 1975 to develop systems and components. One of these contracts, awarded to Martin Marietta, resulted in the construction of a $1 \mathrm{MW}_{\text {th }}$ cavity receiver and its subsequent successful test at the French solar facility at Odiello.*

The first major funding of this concept occurred in 1975, with the award of four contracts by the Energy Research and Development Administration (ERDA). Three of these contracts (Martin Marietta, McDonnell Douglas Astronautics Company, and Honeywell Inc.) included preliminary designs of a first-generation $10-\mathrm{MW}$ system, while the fourth (Boeing Company) was for heliostat development only. All four contracts included the design, construction, and testing of four prototype heliostats. Testing was completed in 1977 by all four contractors; design and test data were subsequently published.

Also in 1975, proposals were submitted to ERDA for the design and construction of heliostats for the Solar Thermal Test Facility (STTF). The contract, which was awarded to Martin Marietta in 1976, resulted in the installation of 222 heliostats at the STTF site near Albuquerque, New Mexico. The system was operational by 1978 and data on the performance of the individual heliostats, as well as the entire field, have been gathered.

*An informative and detailed discussion of early work on the central receiver concept can be found in Ref. 37. 
Preliminary results also have been published [38]. Although the STTF was intended to be a research and test facility and the heliostats were designed to meet stricter performance plans, considerable insight and experience into large-scale production was obtained.

The goals and approach of the heliostat development program are described in some detail in Ref. 39. Heliostat design has already progressed through several generations, as shown in Fig. 6-5, [41, p. 7] starting with the original National Science Foundation heliostat and progressing to the prototype heliostat design. Additional paper/test hardware generations are expected.

In 1977, a solicitation was released to design low-cost prototype heliostats. ERDA awarded contracts to McDonnell Douglas, General Electric, Boeing, and Solaramics. The McDonnell Douglas and Solaramics heliostat designs use glass mirrors and a steel structure. The General Electric and Boeing designs involve less rigid, cheaper heliostat mirrors encased in inflated plastic enclosures. The plastic enclosure designs result in both lower mirror costs and lower reflectivity. One major cause of reflectivity loss is because of transmission losses through the plastic enclosure.

The MeDonnell Douglas low-cost prototype design was selected as most promising at the beginning of FY78. To foster competition, contracts were awarded to five separate contractors to build prototypes. All of these prototypes will use the glass-mirror design, because the requisite plastics technology is not advanced enough to inspire confidence in the plastic enclosure design. These low-cost prototypes are referred to as secondgeneration heliostats. While the glass-metal prototypes are constructed, research on development of suitable plastic materials for use in the enclosed heliostat design will be continued.

While second-generation prototype heliostats are being built, work is proceeding on a third-generation design. Twelve special studies are being performed on heliostat component design and maintenance. A new heliostat components solicitation was released in 1978. Resulting design improvements are planned to be incorporated into a thirdgeneration heliostat design in the early part of FY81.

Two second-generation designs discussed here are those proposed by McDonnell Douglas Astronautics Company (MDAC) and General Electric (GE). They represent the two generic heliostat concepts already described.

\subsection{DESCRIPTIONS OF GENERIC HELIOSTAT DESIGNS}

Two generic heliostat concepts are being studied by several contractors: the glass-steel and inflated plastic bubble concepts, now best represented by the designs of MDAC and $\mathrm{GE}$, respectively. The following describes the design, manufacturing, and installation of these designs $[3,34]$.

\subsubsection{The MeDonnell Douglas Prototype Heliostat Design}

The prototype heliostat design portrayed in Fig. 6-6 and Table 6-1 summarizes the technical characteristics of this design. The heliostat is divided into four subassemblies. These subassemblies are the reflector panel (one-half of the reflective unit), the drive unit (including the pedestal), the foundation, and the heliostat electronics (including controllers and control sensors). 


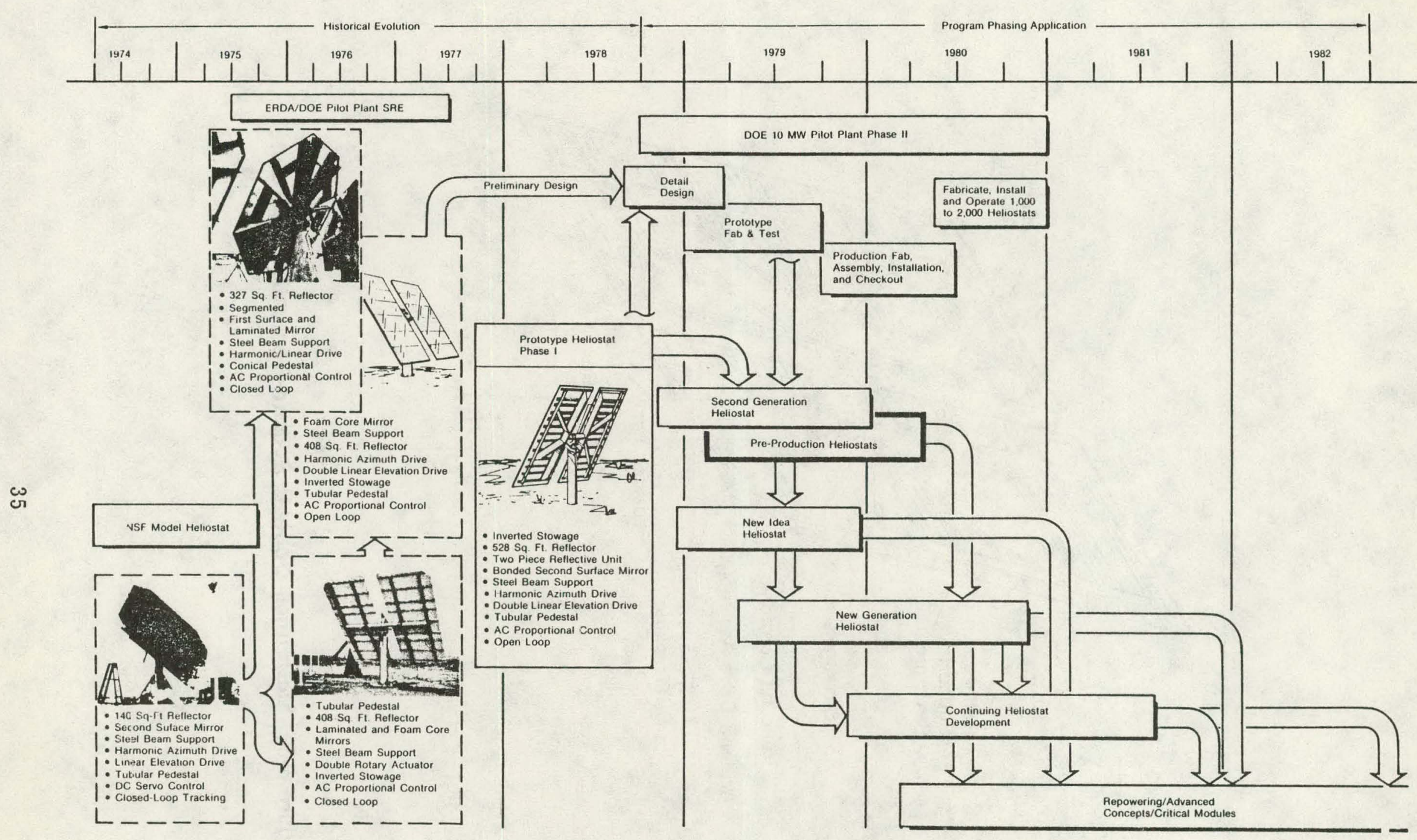

Figure 6-5. Generic Heliostat Development 


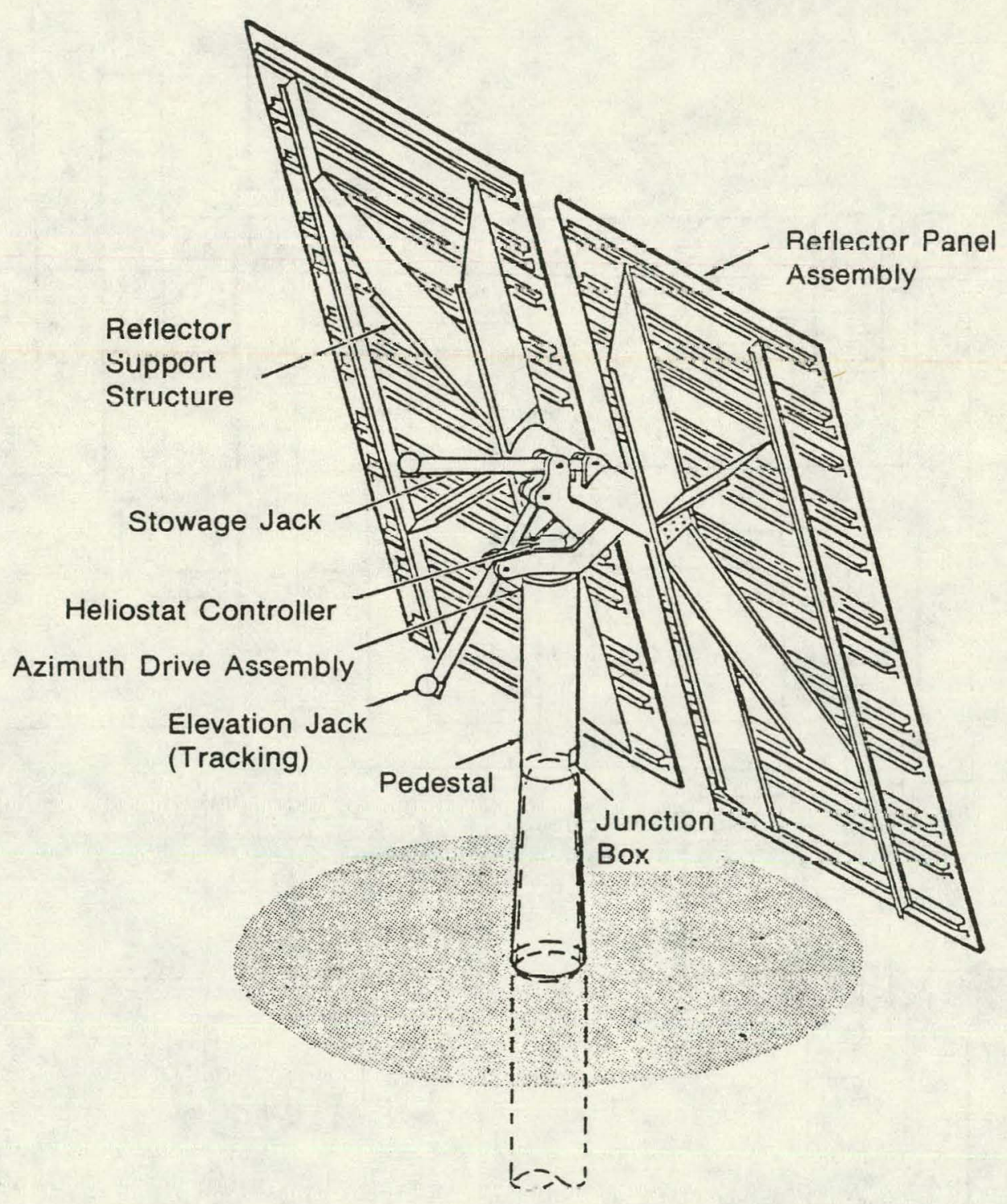

Figure 6-6. McDonnell Douglas Second-Generation Heliostat 
Table 6-1. TECHNICAL DESCRIPTION-COLLECTOR SUBSYSTEM

- Reflector-6 laminated reflector mirrors bonded to the reflec tor support structure.

- Reflective Surface Reflective Surface Area

Second Surface Mirror Glass Back Lite

$787 \mathrm{~kg}(1734 \mathrm{lb})$

$49.05 \mathrm{~m}^{2}\left(528 \mathrm{f}^{\mathrm{t} 2}\right)$

$1.5 \mathrm{~mm}\left(0.060^{\prime \prime}\right)$

$4.8 \mathrm{~mm}\left(0.1875^{\prime \prime}\right)$

- Mirror Backing Struc ture

IMBD Cross Beam 14 Gage

OUTBD Cross Beam 18 Gage

Diagonal Beam 14 Gage

Hats 16 Gage

$469 \mathrm{~kg}$ (1034 lb)

$173^{\prime \prime}-27^{\prime \prime}$ deep

$173^{\prime \prime}-11^{\prime \prime}$ deep

$112^{\prime \prime}-26^{\prime \prime}$ deep

$130^{\prime \prime}-6^{\prime \prime}$

- Drive-Consists of a rotary azimuth drive,a double

jack elevation drive, center main beam, and pedestal.

$578 \mathrm{~kg}$ (1273 lb)

Center Main Beam

Tube

Flange

$122 \mathrm{Kg}(268 \mathrm{lb})$

$81^{\text {" }} 16^{\text {" dia. }}$

$18^{\text {" square }}$

Elevation Drive

Jacks

$102 \mathrm{~kg}(225 \mathrm{lb})$

5 ton ball screw (63

$\mathrm{kg}, 139 \mathrm{lb}$ )

Motor (Two)

Drag Link-Weldment

1/4 hp; 480 VAC $(9.5$

kg., $21 \mathrm{lb)}$

Azimuth Drive

Housing-Weldment

Drive Unit (Retainer)

Helicon Input

Harmonic Output

$29.4 \mathrm{~kg}(65 \mathrm{lb})$

$185 \mathrm{~kg}$ (407 lb)

$108 \mathrm{~kg}(238 \mathrm{lb})$

$68 \mathrm{~kg}(150 \mathrm{lb})$

162:1

242:1

Final Drive Ratio

$39,204: 1$

Motor

Pedestal

Power Distribution Equipment and Wiring

l/2 hp; 480 VAC (8.6

$\mathrm{kg}, 19 \mathrm{lb})$

$169 \mathrm{~kg}(373 \mathrm{lb}$

Step Down Transformers

4160 VAC, 3-Phase

480 VAC, 3-Phase

Position Indicators

Incremental Encoder-Motor Turn Feedback

Hall effect sensors

- Control/Instrumentation Equipment

1985 readiness

Data Distribution Interface

78 per field of 25,000

Digital Microprocessor

Communication Interface

Heliostat Controller

Digital Microprocessor

1 per heliostat

Drive Motor Controller

Control Sensors

Communication Interface 
Table 6-1. TECHNICAL DESCRIPTION-COLLECTOR SUBSYSTEM (concluded)

Signal Distribution Equipment

Fiber Optic Transmission Cable

- Foundation

Concrete

Steel Reinforcement

Steel Form
Included in power

cable

$5478 \mathrm{~kg}$ (12076 lb)

$194 \mathrm{~kg}(428 \mathrm{lb})$

$34 \mathrm{~kg}$ (75 lb) 
Reflector. Each reflector panel is composed of six mirror modules and a support frame. The mirror modules (Fig. 6-7) [3] are 1.22 by $3.35 \mathrm{~m}$ (48 by 132 in.) and made of a $1.5 \mathrm{~mm}$ (0.060 in.) second surface mirror laminated to a $4.8 \mathrm{~mm}(0.1875$ in.) glass back panel. The clean reflectivity is estimated to be from 0.92 to 0.95 , depending on the thickness and chemical state of the glass.

The mirror assembly support structure is shown in Fig. 6-8 [3]. Each of the laminated mirror modules is stiffened with a pair of hat-section stringers which are part of the support structure assembly and are bonded to the glass when the reflector is assembled.

The 12 hat-section stiffeners are attached to the two cross beams that run the long distance of the reflector assembly. The deep, inboard cross beam is a 14-gage galvanized steel sheet, $0.476 \mathrm{~m}(18-3 / 4$ in.) deep and $7.62 \mathrm{~cm}(3.0 \mathrm{in.})$ wide. The shallow outboard cross beam is 18-gage galvanized steel, $12.7 \mathrm{~cm}(5.0 \mathrm{in.})$ deep and $5.72 \mathrm{~cm}(2-1 / 4 \mathrm{in.})$ wide. This cross beam is attached to the main beam by diagonal frames (beams) which tie into this cross beam at two points that are $4.62 \mathrm{~m}$ (167.9 in.) apart. These diagonal beams are $6.35 \mathrm{~cm}(2.5$ in.) wide with $1.91 \mathrm{~cm}(3 / 4$ in.) return flanges.

Drive Unit. The drive unit is composed of a rotary azimuth drive, a double screw jack elevation drive, and a pedestal. All drive motors are three-phase, 480-volt AC. The function of the drive unit assembly is to rotate the heliostat mirror about the azimuth and elevation axes. The drive unit will be operated for solar tracking, emergency slewing, stowage, and maintenance activities. Major performance requirements are described in Table 6-2.

The design life of the drive unit is 30 years. The drive unit is required to move the mirror from a stowed position to acquire the sun, track the sun during the day, and return the mirror to its stowed position at the end of the day. This lifetime is planned to be achieved without any scheduled maintenance activity.

The pedestal is a vertical tube $3.18 \mathrm{~m}$ (125 in.) high. At the top, the drive unit is welded to the pedestal; at the bottom, the lower $1.12 \mathrm{~m}$ (44 in.) is expanded to give a slight taper for slip-joint attachment to the rigid foundation.

The central torque tube main beam connects the two reflector panels (the reflective unit) together and ties the reflector to the elevation hinge and the elevating jacks at the top of the drive unit assembly. The main beam carries all the airloads and dead weight loads from the reflec tor to the pedestal.

Heliostat Electronies. The heliostat controller is located in a housing on the top of the drive unit. The controller receives and transmits commands from the collector controller and responds to requests for data. A microprocessor calculates the motor revolutions required to maintain tracking and activates the motor controllers. The motor controllers switch the motor on and off to produce the required motion. The motor revolution sensors detect motor revolution and direction, and the controller maintains a count of accumulated revolutions. A nonvolatile memory retains motor counts and alignment data in the event of a loss of power. The field wiring terminates at a junction box located on the pedestal. Data are routed to the heliostat controller, decoded, and relayed to the next heliostat in the link if not addressed to the receiving heliostat. Acknowledgment of receipt of a message and status are also transmitted. 


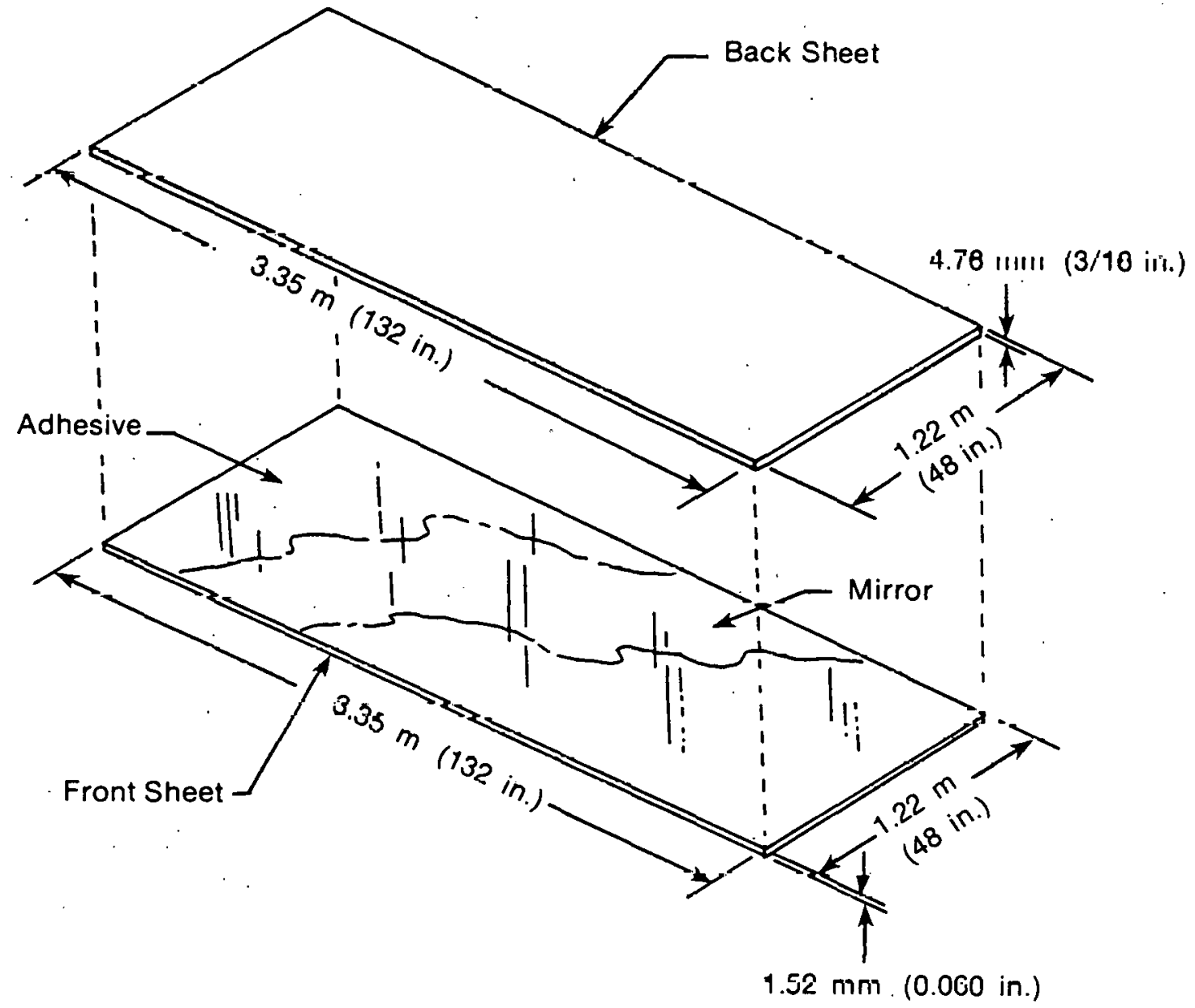

Figure 6-7. Laminated Mirror Module Assembly 


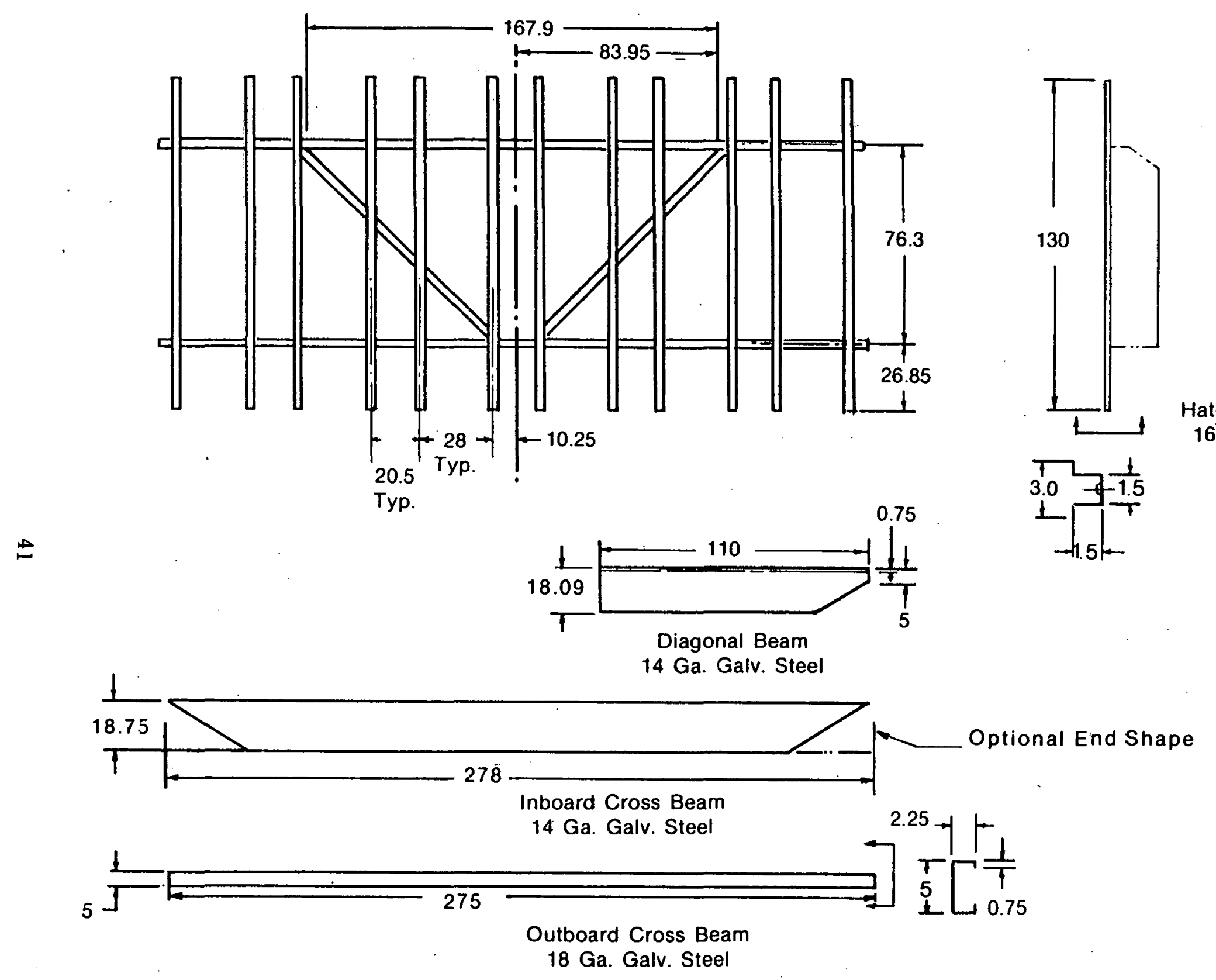

Note: All Dimensions in Inches

Figure 6-8. Reflector Support Structure Assembly 
Table 6-2. DRIVE UNIT REQUIREMENTS

\begin{tabular}{|c|c|c|}
\hline Requirement & Azimuth & Elevation \\
\hline Travel & $+270^{\circ}$ & 0 to $-180^{\circ}$ \\
\hline Maximum Travel Time Under Load & $180^{\circ}$ in 15 minutes & \\
\hline Maximum Static Load & $\begin{array}{l}9830 \mathrm{~N}-\mathrm{m} \\
(87,000 \text { in. } 1 \mathrm{~b})\end{array}$ & $\begin{array}{c}-32,650 \mathrm{~N}-\mathrm{m} \\
-289,000 \text { in.-1b) } \\
=0^{\circ}\end{array}$ \\
\hline Maximum Starting Load & $\begin{array}{l}10,050 \mathrm{~N}-\mathrm{m} \\
(\mathrm{x} \dot{y}, \mathrm{ill} \text { iñ. }-1 \mathrm{~B})\end{array}$ & $\begin{array}{c}+13,890 \mathrm{~N}-\mathrm{m} \\
+122,900 \mathrm{ln} .-1 \mathrm{~b}) \\
=-50^{\circ}\end{array}$ \\
\hline Maximum Running Load & $\begin{array}{l}10,050 \mathrm{~N}-\mathrm{m} \\
(89,000 \text { in. }-1 \mathrm{~b})\end{array}$ & $\begin{array}{c}+26 ; 790 \mathrm{~N}-\mathrm{m} \\
+237,100 \mathrm{in.} .1 \mathrm{~b}) \\
=-50^{\circ}\end{array}$ \\
\hline Maximum Overturning Moment & $\begin{array}{l}42,140 \mathrm{~N}-\mathrm{m} \\
(373,000 \text { in. }-1 \mathrm{~b})\end{array}$ & \\
\hline Backlash/Hysteresis & $1 \mathrm{mrad}$ & $1.6 \mathrm{mrad}$ \\
\hline Back Drive & None & None \\
\hline Life & 30 years & 30 years \\
\hline Minimum Stiff eners & $\begin{array}{l}1.13 \times 10^{6} \mathrm{~N}-\mathrm{m} / \mathrm{rad} \\
1.0 \times 10^{7} \mathrm{in.}-\mathrm{lb} / \mathrm{rad}\end{array}$ & $\begin{array}{l}1.516 \times 10^{6} \mathrm{~N}-\mathrm{m} / \mathrm{rad} \\
\left.1.342 \times 10^{7} \mathrm{in} . \mathrm{-l} / \mathrm{rad}\right)\end{array}$ \\
\hline
\end{tabular}


Foundation. The foundation is a drilled pier, $0.6 \mathrm{~m}$ (24 in.) in diameter. The pier extends about $1.2 \mathrm{~m}(4 \mathrm{ft})$ above grade and $6 \mathrm{~m}(20 \mathrm{ft})$ below. A tapered steel shell secures the mounting surface to the pedestal and serves as a form for the protruding end of the pier.

Heliostat Weight. Weights for the various heliostat components are given in Table 6-3.

\subsubsection{The General Electric Prototype Heliostat Design}

The enclosed heliostat (Fig. 6-9 and 6-10) [34] consists of an aluminized film reflector deployed on a lightweight, eight-strut frame mounted on a single pipe pedestal. Azimuth and elevation drives are also mounted on the pedestal. The entire assembly is housed in an air-supported enclosure. An open-loop control system directs centrally computed sunangle steering commands to all heliostats in the field.

Reflector. The reflector is a $55-\mathrm{m}^{2}$ octagonal surface of metalized polyester film held in place and tensioned by eight tubular compression struts and tension wires. These are supported by a reinforced structural plastic hub with a spring-loaded tensioning device. The reflector assembly is illustrated in Fig. 6-11. The principal parts of the assembly are: reflector surface, reflector corner beams, struts, tensioning wires, hub assembly, and tensioning device.

Support and Drive Assembly. The heliostat support and drive unit (Fig. 6-12) is a lightweight dual axis (azimuth and elevation) pedestal that provides the structural support and interface for the reflector assembly. The support and drive structure consists of the following major components or assemblies: elevation axis, yoke/pedestal assembly, elevation and azimuth drives, and lower support and foundation. The foundation pipe is an 11 $\mathrm{cm}$ (4.5 in.) diameter pipe embedded to a depth of at least $1.5 \mathrm{~m}(60 \mathrm{in.}$.).

Enclosure. The enclosure is an air-supported, transparent plastic structure that arrives at the site in three zippered sections. These sections can easily be attached to each other and to the plastic bag foundation ring.

The plastic bag foundation ring is a U-shaped bag that is buried in the ground and filled with earth to form an anchorage for the inflated enclosure. It has an outside diameter of $9.23 \mathrm{~m}(27.0 \mathrm{ft})$.

A ground cloth is used to cover the earth within the enclosure. It acts as a vapor barrier and also suppresses vegetation growth and dust movement. To form a complete seal, the ground cloth will be zippered to the foundation bag.

The enclosure is kept inflated by a blower which draws $15 \mathrm{~W}$ of electric power.

Weight Breakdown. Estimated weight for the various components of the prototype heliostat are given in Table 6-3 [34]. 
SEP

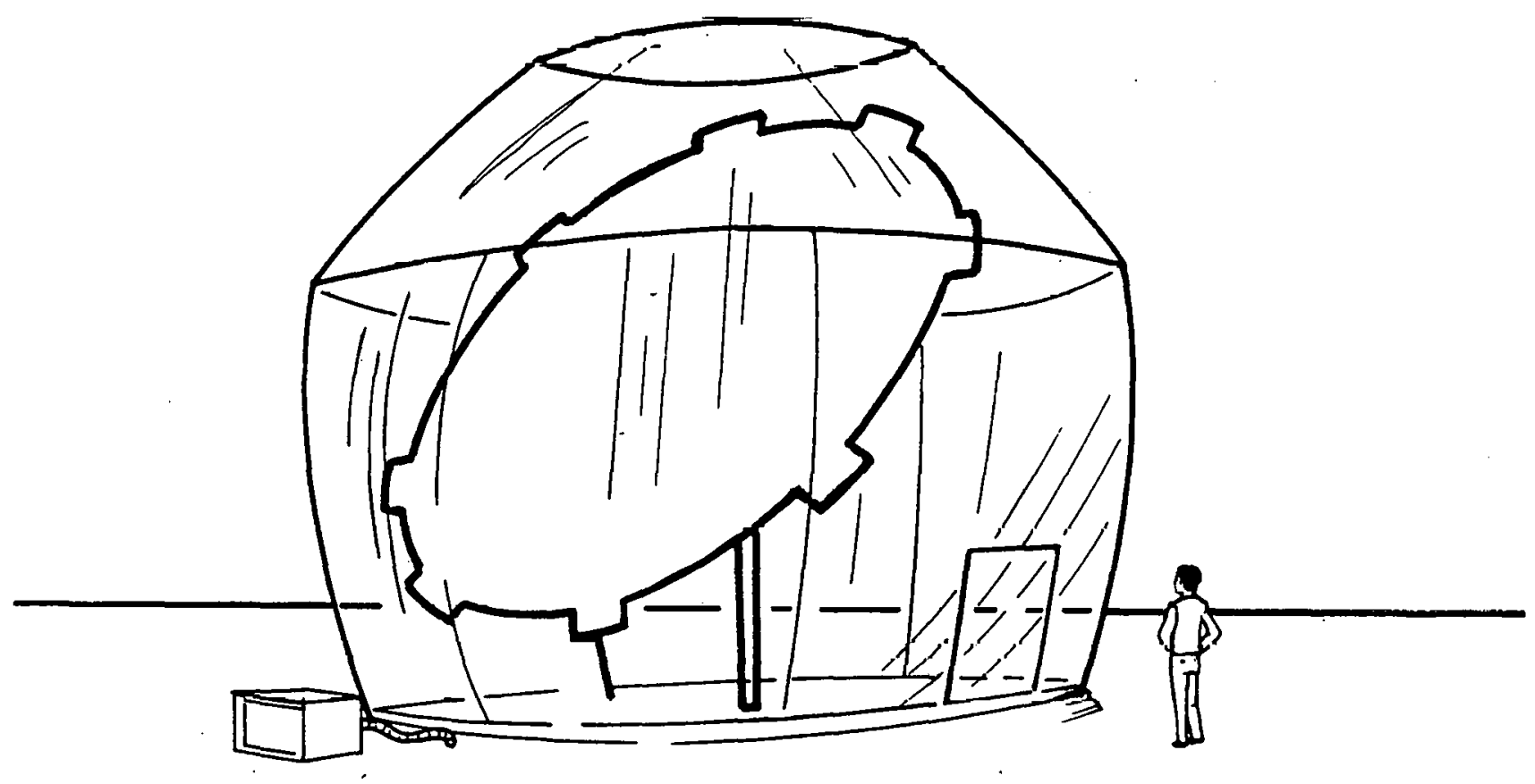

Figure 6-9. General Electric Enclosed Heliostat 


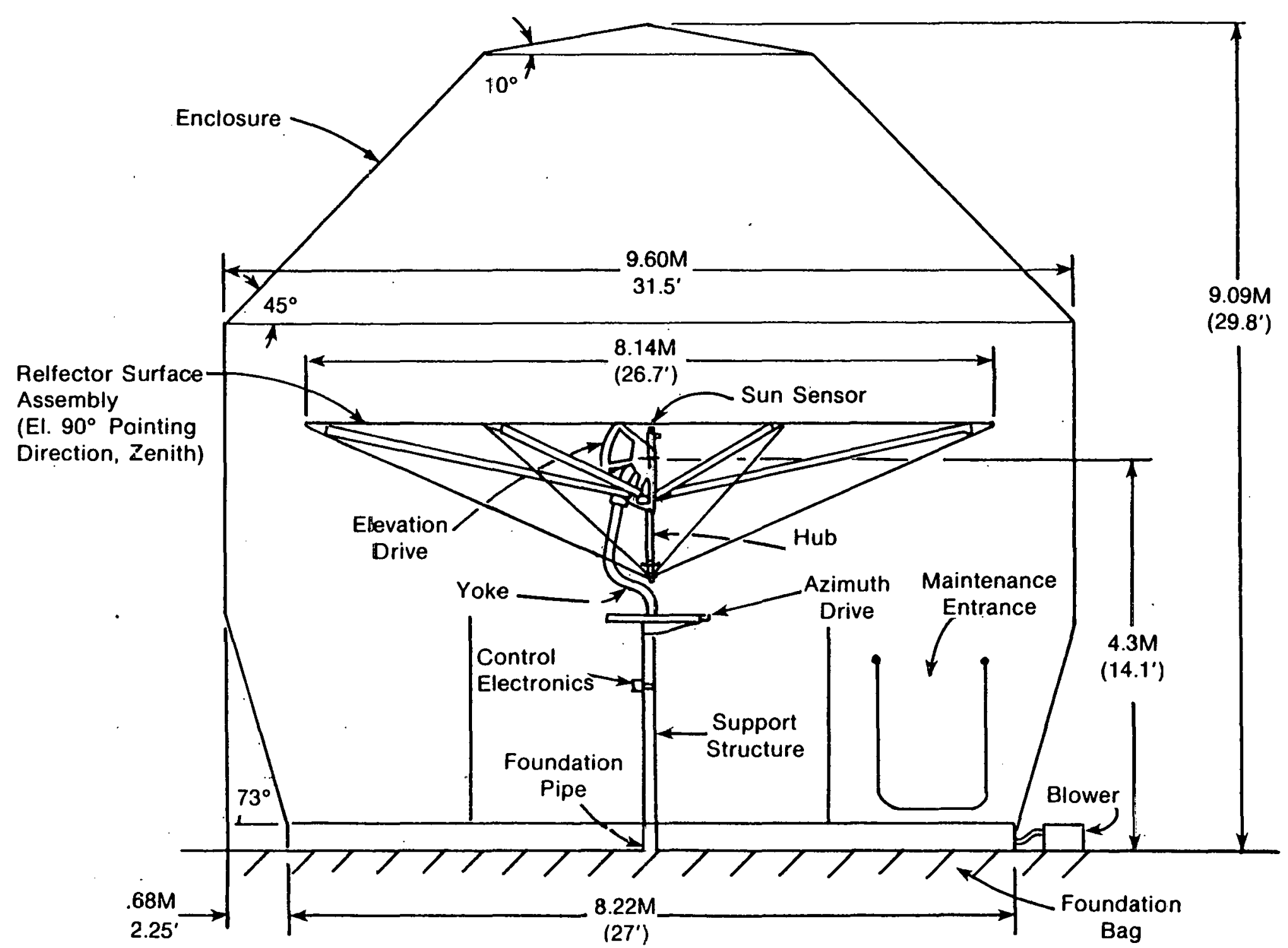

Figure 6-10. General Electric Heliostat Design 

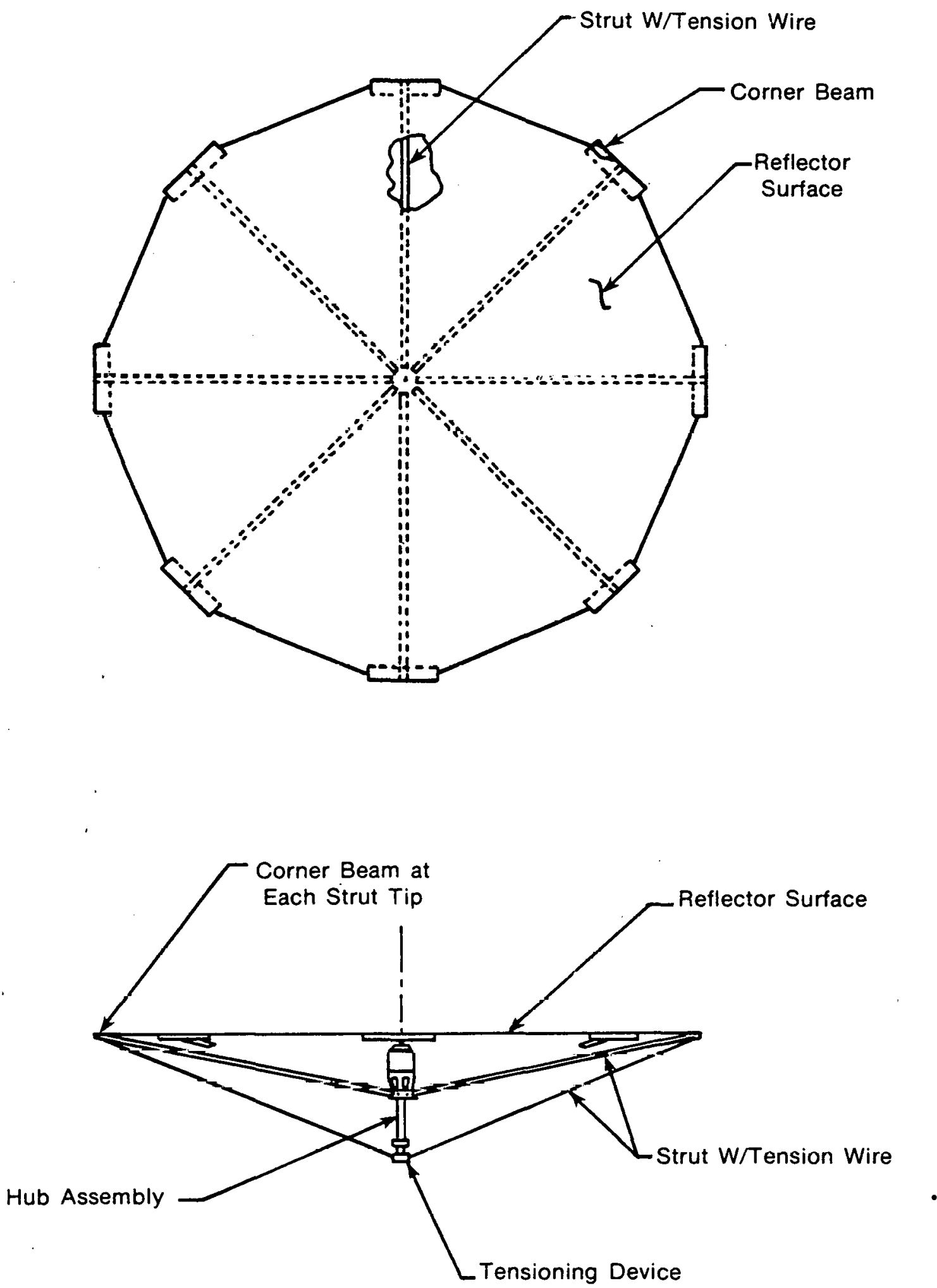

Figure 6-11. Stretch Frame Reflector Subassembly 


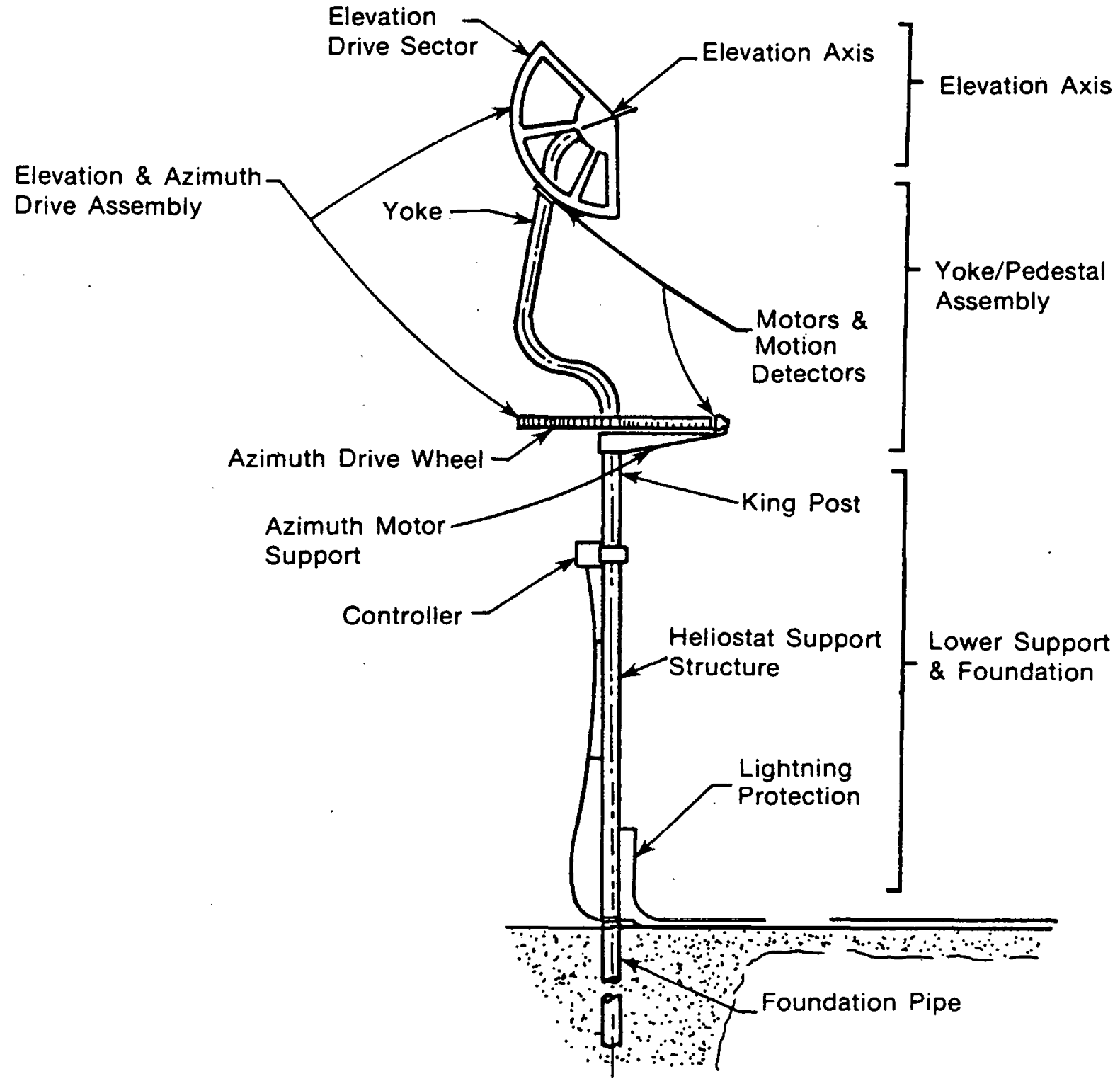

Figure 6-12. Support and Drive Assembly. 
Table 6-3. GENERAL ELECTRIC HELIOSTAT WEIGHT BREAKDOWN

\begin{tabular}{lr}
\hline \multicolumn{1}{c}{ Assembly } & Weight, kg (lb) \\
\hline Reflector & $31.3(69)$ \\
Support Structure and Driver & $16.3(36)$ \\
Controls & $14.5(32)$ \\
Enclosure & $166.0(366)$ \\
Foundation & $76.2(168)$ \\
Installation (Packaging) & $6.8(15)$ \\
\hline
\end{tabular}

\subsection{KEY COST FACTORS IN HEIIOSTAT DESIGN}

A significant factor in all heliostat designs is the total allowable error allocation. System performance is based up on a high percentage of reflected sunlight hitting the receiver, and accumulated error from all sources affecting a heliostat is considered part of the total field efficiency. Errors occur either from wind- or gravity-induced deflections of the structure, mechanical failures in the various heliostat subassemblies, foundation misalignment, thermal deformation of components such as mirror modules, and positional uncertainties in the control and instrumentation system.

Design of the various subassemblies or components depends on compromises between cost factors and performance standards; the goal is to produce the lowest overall installed field cost. A heliostat, therefore, has to meet requirements derived from total annual system performance requirements.

Certain factors aff ect particular elements of a heliostat. 'I'able 6-4 identifies those design parameters that significantly affect cost.

The highest costs in the "hard" (glass/steel) heliostat design involve the drive unit and the reflective unit. The drive unit must be able to withstand the full torque induced on the structure by the highest winds encountered during operations or emergency stow conditions. These loads may exceed $30,000 \mathrm{~N}-\mathrm{m}(289,000 \mathrm{in} .-\mathrm{lb})$ at certain times; the drive must be able to withstand these loads without permanent deformation or breakage.

In addition, the drive unit (which includes position indicators such as encoders) must track with great precision in order to assure that the reflected beam intercepts the receiver. The allowable backlash on a typical drive mechanism is $1 \mathrm{mrad}(3.3$ arc- $\mathrm{min}$ ) for azimuth and $1.6 \mathrm{mrad}(5.3 \mathrm{arc}-\mathrm{min})$ for elevation. This degree of backlash is more stringent than that usually encountered in commercial applications.

The glass mirror accounts for only a small fraction of the cost of the reflective unit. The majority of the cost lies in the assembly of individual mirror modules.

The third major cost element for a hard heliostat is the foundation and site preparation, which accounts for more than $20 \%$ of the total installed cost. The costs of the foundation are largely determined by the allowable error in heliostat alignment and deflections 
Table 6-4. DESIGN PARAMETERS AFFECTING HEIIOSTAT ELEMENTAL COST

\begin{tabular}{ll}
\hline \multicolumn{1}{c}{ Component } & \multicolumn{1}{c}{ Significant Design Parameters } \\
\hline Struc ture & Reflective area, operation wind loads, error budget \\
Drive Mechanisms & Operational wind loads, slew speed, error budget \\
Electronic/Electrical & Operational modes, motor power, error budget \\
Foundation & Site characteristics, error budget \\
Installation and Assembly & Labor costs, adaptability to tooling \\
Control & Operational and safety requirements, error budget \\
Reflective Surface & Spectral reflectivity, reflective area, wind loads, \\
& thermal deformation \\
\hline
\end{tabular}

and by soil characteristics at the site. Many desert soils contain large quantities of materials like (e.g., or bentonite) that are subject to long-term shifting. Accordingly, they require more preparation and a larger foundation.

The foundation, in addition to supporting the weight of a heliostat, must be sufficiently strong to withstand overturning by the wind without permanent deflection in either the pedestal or the soil. For the MDAC design, this overturning point may reach as high as $42,140 \mathrm{~N}-\mathrm{m}(373,000 \mathrm{in} .-\mathrm{lb})$.

The elemental cost breakdown for the "soft" or plastic bubble enclosed heliostat is slightly different. Because of the protection afforded by the plastic enclosure, wind loads are less; as a consequence, costs of the drive unit and reflective unit are less. The fraction of cost attributed to the structure, however, increases because of the cost of the plastic enclosure. Foundation and site costs constitute a slightly higher proportion of the total cost than for a hard heliostat.

Critical areas for cost reductions can be identified for each generic design. For the glass/steel heliostats, major emphasis should be placed upon the drive units, the reflective unit (including structure), foundations, and site development. The more equal distribution of costs in the enclosed bubble design dictate that all elements receive closer attention. Major emphasis should be placed up on the foundation, site preparation, and the heliostat structural support and protection. 


\section{SझPI눙}




\section{SECTION 7.0}

\section{PROTOTY PE HELIOSTAT COST SCENARIOS*}

\subsection{INTRODUCTION}

Establishing an adequately detailed costing scenario is the fundamental requirement for estimating and predicting cost reductions. This section presents the costing scenarios through description of the basic characteristics of market potential, production and installation volume, and the general configuration of the manufacturing/assembly facility module. This section also indicates the points in cumulative production volume where an effective, steady-state production process may be established along with the associated first-unit cost for the steady-state scenario.

The scenario presented in this section represents only one of many possible scenarios. Variations in market growth and location, competition, basic design, available production technology and resources, and government and business policy may have a significant impact on the scenario and cost-reduction rate.

The term production here includes factory procurement, fabrication, assembly, and checkout; transportation and handling required to ship the hardware to the installation site; and field procurement, fabrication, assembly installation, and final checkout of the hardware.

\subsection{FACTORS INFLUENCING COST SCENARIOS}

In developing cost scenarios for a prototype heliostat, the following factors have been considered: (1) market projections, (2) the implied growth of volume, (3) design and development status, (4) plant and equipment impacts, and (5) management alternatives and concerns.

\subsubsection{Market Potentials}

The market for heliostats is tied to the cost and availability of alternate energy products. The basic economic trade is the annual cost, including maintenance, per Btu of the incremental capital employed in collecting solar energy versus the annual cost per Btu of alternative fuels and other energy sources. For some potential solar energy users, this issue has been marked by considerable uncertainty about the future price of fuels and the capital needed for solar applications. Some analysts believe that the market is generally unfavorable for centralized solar systems, but concern about the future availability and cost of alternative sources of energy and the intrigue of a free and renewable energy source keep interest high.

These circumstances have made it difficult to identify a broad market based on current economic analysis, although the price trends of oil and gas and cost inefficiencies associated with using coal or nuclear power for intermediate-sized plants certainly suggest a market potential, especially with incentives. As a result, market forecasts have been

*This section was written with the assistance of J. H. Nourse of McDonnell Douglas Astroniaulies Company [41]. 
based on a penetration analysis given an absolute energy demand, expected growth in service by alternative energy sources, energy short-falls, and "target" solar energy costs.

Sandia Laboratories specified that Prototype Heliostat Study Contractors consider design and production scenarios that would be appropriate at rate production heliostat outputs of $25,000,250,000$, and 1 million units per year. In addition, a one-time pilot production of 2,500 units was to be analyzed. Sandia also indicated that the design and production scenario be conceived so that costs associated with the higher production rates are consistent with the DOE goal of $\$ 72 / \mathrm{m}^{2}$ reflectivity. Other than stating that the market cover eight Southwestern states in the 1990s, no other market description was indicated. Sandia's main purpose was to determine the costs that could be expected under certain and steady market conditions.

It is, however, necessary only to characterize and shape the growth of the market in general for purposes of cost reduction analysis and technology readiness considerations. Figure 7-1 shows one possible matket situation [3]. Although the details may be outdated, they are representative of the general aspects of a market plan considered at the time of the study. Both the total market and an assumed share for one producer are indicated, as weil as a possible gap in 1986 between overall demund for energy und this particular market scenario.

The illustration may be considered in phases. The first is a period of governmentsupported development projects requiring limited heliostat production capacity. At any given time, demand for an individual supplier's product may range from the total market to none. Then, a period of transition is expected where eventual users may begin to deploy the concept on a limited basis provided that any economic disparities with competitive energy sources are balanced by incentives. This is perhaps the most critical period to the survival of the concept, and costs must not exceed gaals. Of course, the final phase is the most unpredictable; it depends on the relative success of the intermediate phase, as well as on the cost and availability of alternative energy. It could be the period in which both the technology and the relative cost of solar energy have received users' acceptance. If expectations about energy shortages prove true, the potential demand for and production of heliostats could be great.

\subsubsection{Production Volume Progression}

As indicated, the volume scenario established for the McDonnell Douglas Prototype Heliostat Study [3] calls for 25,000 heliostats/yr at the lowest commercial rate. For the study, it was assumed that the baseline plant $(25,000$ units/yr) will initiate operations at the 100,000 th unit and continue production for 500,000 units over the next 20 years. At this period, production and installation capacity increases to 250,000 units/yr; an additional 5 million units will be produced at this rate. After 15-18 years of operation in these facilities, capacity increases to 1 million heliostats/yr and continues for unolher 20 years.

This scenario provides three important variables-cumulative volume, annual rates of production and installation, and rate of volume growth. While cumulative volume may be the primary cost-reduction curve variable, quality and quantities of production and growth rates had a much more significant impact on the production and installation scenarios devised for the Prototype Heliostat Study. The study assumes a steady production rate where productive resources may be selected and geared in just the right balance to economically achieve required output over the expected production period. 


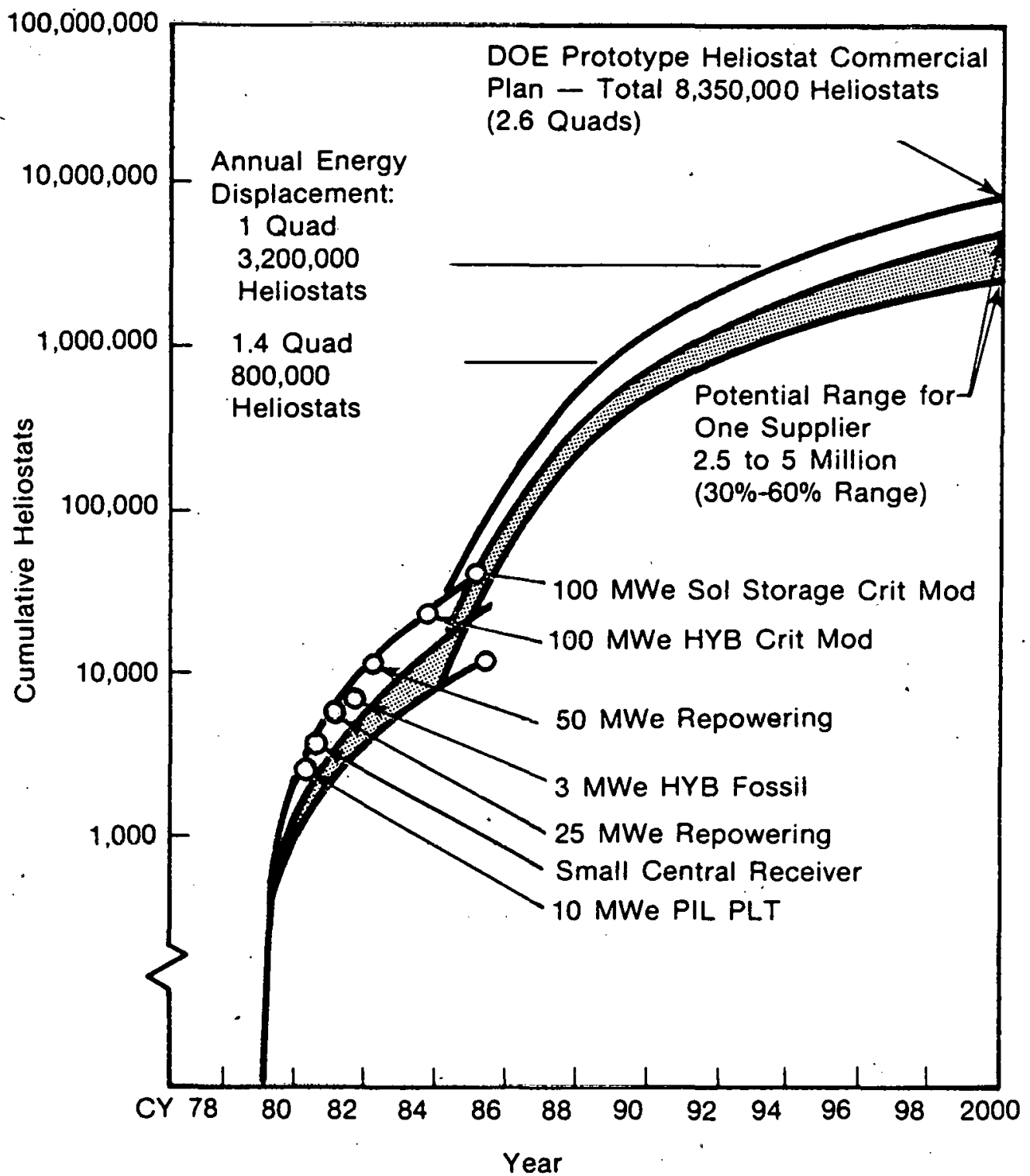

Figure 7-1. Cumulative Heliostat Market Scenario 
The expected rate and quality of growth further influences the timing and degree of capital employment. Capacity growth, although potentially rapid in the first 5-10 years, is expected to be intermittent following the nature of demand. This could delay installation of the baseline rate production facilities, or cause it to be staggered until a steady 25,000-unit/yr output appears maintainable. As indicated, growth in capacity from this point has been portrayed in the study as a series of 20-yr steps extending approximately 50-60 years to about the year 2045. If this is true it could lead to a somewhat slackened rate of innovation and the actual growth will probably occur in more frequent steps with a modular approach to capacity expansion.

\subsubsection{Design and Development Status}

The status of design, development, test, and evaluation (DDT\&E) is of interest from a number of perspectives. The issue is not just whether a design is proven, but also whether it is producible and cost effective, will have future technological impact, and the extent to which the innovation may be implemented within current schedules or must be programmed into the future. From a cost reduction viewpoint, very little improvement occurs in actual hardware cost while the design is stili in a state of change. However, parallel design-to-cost studies may identify and project "paper" improvements leading to rapid cost reductions as advance design-to-cost configurations and plans can be incorporated.

The baseline 25,000/yr scenario represents plans for a well conceived, advanced design, although the production plans for early supply assume that many specific design or production innovations will not be immediately available for technological or economic reasons. Heliostat design has already progressed through several generations, as shown in Fig. 6-5, starting with the original National Science Foundation heliostat and progressing as far as the prototype heliostat design. Additional paper/test hardware generations are expected.

A considerable amount of heliostat development effort will have been expended in research experiments such as the Barstow plant, and in second-generation, preproduction hardware. Also, there will be some final production design involved in the first prototype pilot production purchase. However, once the design has been established, further design eff ort is self-supporting; i.e., only design changes that will result in net design/hardware cost reductions will be incorporated.

\subsubsection{Plant and Equipment Impact}

A fourth major consideration is the impact of prudent use of plants and equipment. Figure 7-2 shows the importance of finding the right combination. The figure indicates the approximate break-even investment associated with a savings, using an existing method, of 1 person-minute on each heliostat produced, transported, and installed in a $20-y r$ period, at various annual production rates. In the example, any investment that costs less than $\$ 264$ thousand would result in a savings at a production rate of 30,000 heliostats/yr. Given this incentive, the objective is to identify cost-saving equipment/ processes and plant arrangements; influence the design to permit desirable alternatives; and balance the use of plant and equipment resources with respect to desired output and other management considerations. 
At Savings of 1 Man-minute of labor Per Heliostat (Dollars in Millions)

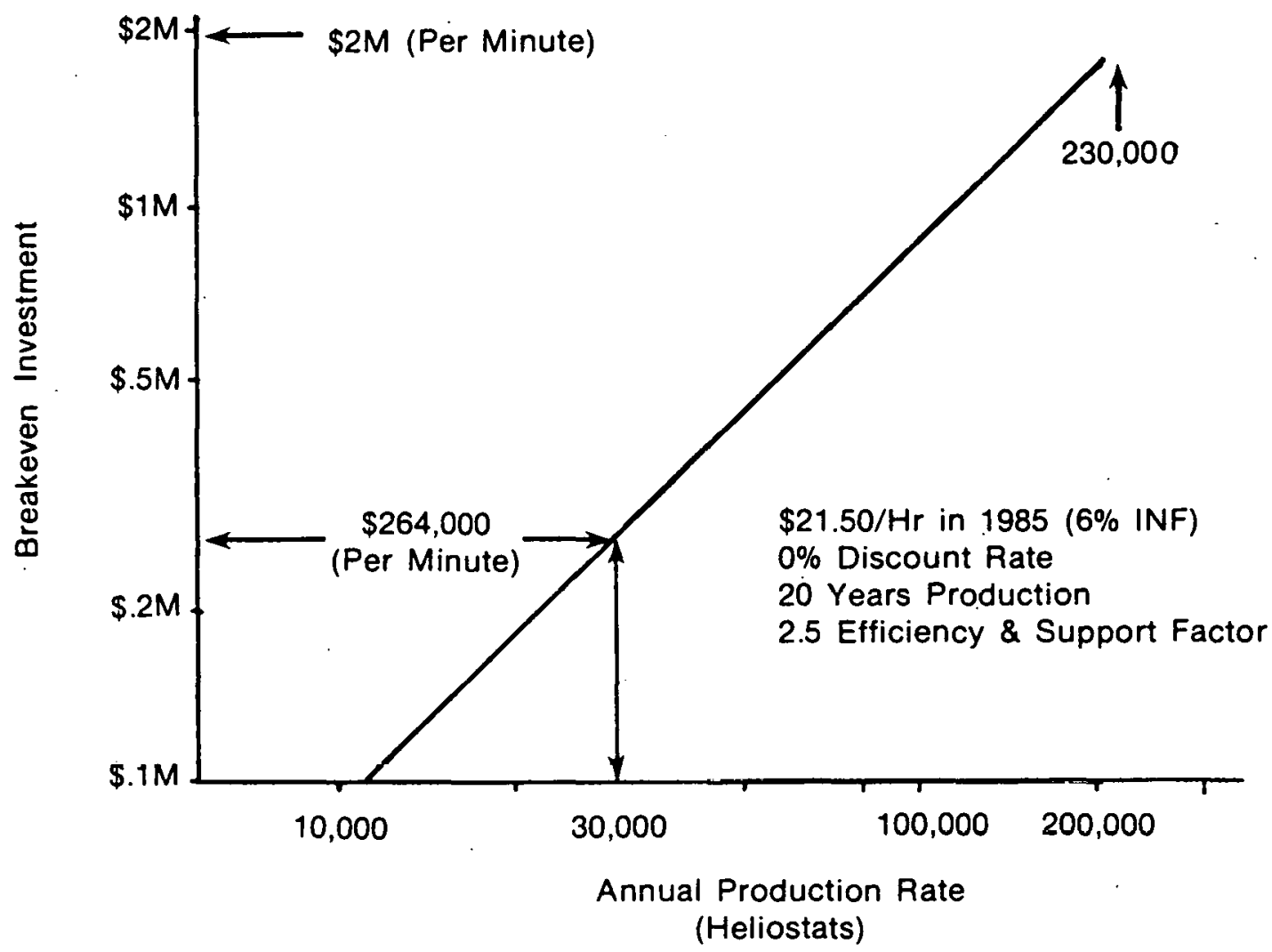

Figure 7-2. Present Value of Capital Equipment 


\subsubsection{Management Alternatives and Concern}

Management concerns generally relate to a specific firm's policy, traditions, practices, and fiscal constraints. They affect decisions about market approach, resource sharing, allocation and balance, make-or-buy resolutions, organizational structure, labor and other industrial relations, and choice of technology. The firm must also consider availability of funds, labor, and other resources; the impact of outside influences such as government, unions, and special interest groups; the flexibility of their business approach and the technical requirements/acceptability of their product in the face of market characteristics and competition; and finally, the acceptable risk exposure and return on investment. The result of these considerations sets the ultimate course of the production scenario and the overall business approach in a manner intended to assure the firm's financial success and meet market requirements.

\subsection{DEECRIPTIONE OF THE BASEINNE PRODUCTION SCENARIO}

The baseline production scenario for the MDAC and GE heliostat design describes production at a rate of 25,000 units/yr. Thus, the 25,000 units/yr rate has been studied in greater depth than other production rates. This rate represents significant high-volume production situations, yet may be easily translated into higher or lower production-rate scenarios. As a result, this scenario effects a viable business approach that meets early business constraints and simultaneously attempts to capture an important share of future markets. A summary of the baseline production scenario and changes in the scenario for higher production rates for each of the heliostat designs follow [3,34]. More detailed discussion of the production concepts is found in the cited references. Additional information on high-production heliostat manufacture can be found in Ref. 1 .

\subsubsection{The MeDonnell Douglas Prototype Heliostat Design Production Scenario}

In developing the baseline production scenario for MDAC prototype heliostat design, the overall approach has been to minimize hand labor and achieve quality through mechanization, with as much flexibility and as little risk as possible.

\subsubsection{Equipment}

Equipment has been designed to reduce hand labor and to assure continuously acceptable production performance. Wherever practical, automatic handling equipment has been used to keep operator handling time to a minimum, especially where operation cycles involve manual loading or unloading. Reflective unit equipment used for fabrication, transfer, and installation has been mechanized to address special problems in handling glass and to minimize potential damage.

Assemblies are automatically checked out with special equipment in the factory to reduce field problems. Pre-assembled units are installed with equipment designed to correlate time, crew size, and proficiency with equipment capabilities rather than human capabilities, and final alignment and checkout is largely automated. Thus tools and equipment are designed mainly for automatic production, according to specifications and to production rates. 


\subsubsection{Quality Assurance}

The quality assurance approach calls for verification of hardware through control of incoming parts and materials and attention to the quality of tooling and equipment. The quality of incoming materials and parts is controlled through careful supplier selection and source inspections for critical items. Inspection at the Receiving phase is carried out for identification, certification, and any damage. Tooling and equipment are designed within specified tolerances; an automatic "out of spec" trend warning triggers the necessary tool adjustments. Automated end-item inspections and alignments are used for the reflector panels and at checkout stations for the pedestal/drive/electronics unit and power distribution modules. A special test van is used in conjunction with digital image radiometers and master control support to automatically check and align an installed heliostat.

\subsubsection{Transportation to Installation Site}

Transportation covers the transportation of final assemblies to sites, and delivery of installation equipment. In addition to the foundation and field wiring materials, only three end-products must be delivered-reflector panels, drive/pedestal/electronics units, and power distribution modules. Special reusable open containers are designed for ease of access and handling. Placement and removal will be automatic for these containers, using robot-like controls. Equipment is transported from factory to site by a manufacturer-owned truck fleet.

\subsubsection{Installation Equipment Ownership}

Another important provision in the overall approach is that the heliostat manufacturer will control (through ownership or sale/leaseback) the special equipment used to transport, install, and check the heliostats. The manufacturer will provide the equipment to each installation on a cost-sharing basis, and assure that an efficient, uniform plan is available to any installation. This equipment is important to the installation scenario at all volume levels and probably should be made available as early as the pilot production.

\subsubsection{Fexibility}

Flexibility has been considered in both macro- and micro-modularity characteristics of the facility. The plant may be thought of as a production module that may be more than tripled in capacity by adding shifts, extending the work week, or adding automation equipment simultaneously in a few critical areas. When production capacity is reached, or design technology and competition dictate, a new, upgraded module may be added in the most desirable location. Assemblies such as the drive, electronics, and panels may also be moved into their own facilities. Fairly low production rates, at a greater cost per unit, may be accommodated by eliminating a shift, deferring purchase of certain equipment, or by increased use of the industrial base. In effect, the scenario permits a logical extension of pilot facilities.

Such flexibility allows a manufacturer to take some financial risk in proportion to product demand and at the same time remain reasonably current in production and design technology. In addition, use of the industrial base for production of tubes and beams, glass, chips, drives, and other components reduces capital equipment requirements. 'This 
approach permits a firm to expand according to market conditions, available resources, product acceptability, and profitability.

\subsubsection{Make Or Buy Plan}

The make-or-buy plan is shown in Table 7-1, and indicates whether finished parts and materials are made in the heliostat production facility or are procured from outside sources. Generally, if an item is commercially available from several sources, and acquisition of specialized capability is required, purchase of the items is likely. Make ite ms, typically, are specially designed and are critical to schedule, cost, or process. Obviously, this plan is a fundamental variable in sizing a facility.

\subsubsection{The Heliostat Factory}

Figure 7-3 provides a schematic of the prototype heliostat production plant. The plant is $62,500 \mathrm{ft}^{2}$, located in the Southwest, and has access to rail lines and adequa te roads. The locality also provides a work force of less than 300 predominantly unskilled factory employees. The level of workers' skills permits low average labor wages, while the factory burden and direct support typically reflect an operating stand-alone plant limited to one product line. Annually, the factory produces 50,000 reflector panels, 25,000 drive/ pedestal/elec tronic assemblies, and 25,000 foundation caps. The plant operates on a twoshift basis, 5 days per week, 240 days a year.

\section{Reflector Panel}

Figure 7-4 provides a pictorial schematic of the reflector panel fabrication and assembly line. A total of 52 assemblers, handlers, and operators are required to run this line as follows:

\begin{tabular}{lc} 
Hardware Element & Workers \\
\cline { 2 - 2 } Mirror Modules & 16 \\
Support Structure & 18 \\
Assemble and Bond & $\frac{18}{52}$
\end{tabular}

The two glass lites are stacked on a reusable A-frame, and automatically loaded on conveyors using vacuum cups. From that point, the mirror modules are fabricated, treated with adhesive, and lined up on the bonding tables. Each of the facets on the bonding tables is curved and canted individually so that each mirror module will rest in its appropriate position relative to the other five modules.

The beams and hat sections for the support structures are delivered from the rolling mill, formed, and palletized for assembly. The details are purchased, formed, and palletized, and then delivered to the fabrication area after inspection. The inboard, outboard, and diagonal beams are loaded into separate punch presses that automatically punch the bolt holes. The parts then proceed on an overboard monorail to a weld and drill station where they are lowered into a floor-mounted fixture and secured. Spot welding of the inboard and outboard areas is accomplished simultaneously. After welding, the bolt holes for attachment to the drive units are jig-bored. 
Table 7-l. PROTOTY PE HELIOSTAT HARDWARE TREE

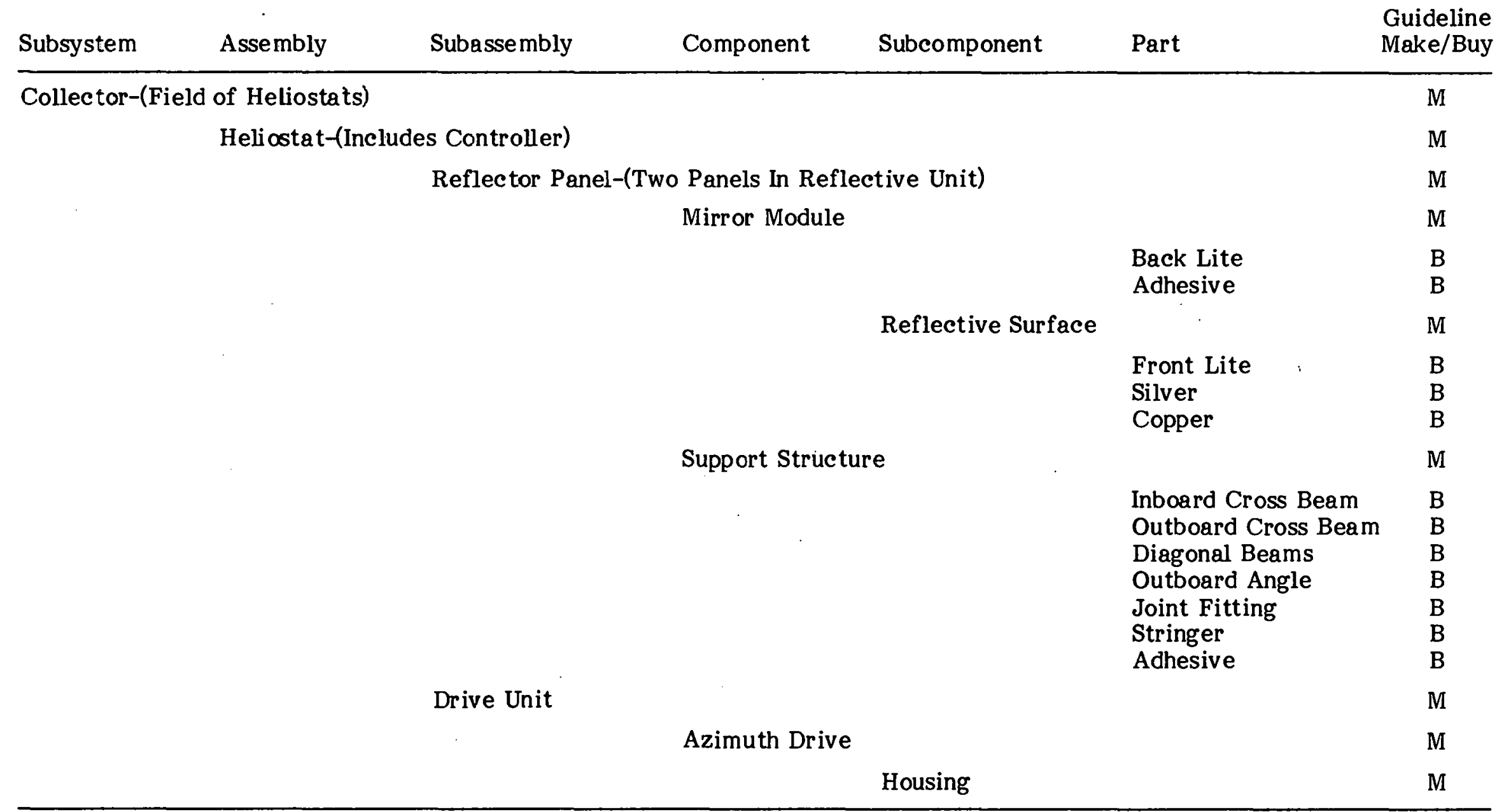


Table 7-1. PROTOTY PE HEIIOSTAT HARDWARE TREE (continued)

\begin{tabular}{|c|c|c|c|c|c|c|}
\hline Subsystem & Assembly & Subassembly & Component & Subcomponent & Part & $\begin{array}{l}\text { Guideline } \\
\text { Make/Buy }\end{array}$ \\
\hline \multirow{7}{*}{8} & & & & & $\begin{array}{l}\text { Shell } \\
\text { Retainer } \\
\text { Cover } \\
\text { Bolt } \\
\text { Oil } \\
\text { Seal } \\
\text { Bushing } \\
\text { Ball } \\
\text { Base Plate } \\
\text { Stand Pipe } \\
\text { Bearing } \\
\text { Bearing Race }\end{array}$ & $\begin{array}{l}\text { M } \\
\text { M } \\
\text { M } \\
\text { B } \\
\text { B } \\
\text { B } \\
\text { B } \\
\text { B } \\
\text { B } \\
\text { B } \\
\text { B } \\
\text { B }\end{array}$ \\
\hline & & & & Circular Sp̈ine & & M \\
\hline & & & & Flexspline & & M \\
\hline & & & . & & $\begin{array}{l}\text { Membrane } \\
\text { Tube } \\
\text { Spline } \\
\text { Doubler }\end{array}$ & $\begin{array}{l}\text { B } \\
\text { B } \\
\text { B } \\
\text { B }\end{array}$ \\
\hline & & & & Wave Generation & & M \\
\hline & & & & & $\begin{array}{l}\text { Plug } \\
\text { Bearing } \\
\text { Drive Shaft }\end{array}$ & $\begin{array}{l}M \\
B \\
M\end{array}$ \\
\hline & & & & Motor (Typical) & & B \\
\hline
\end{tabular}


Table 7-1. PROTOTY PE HEIIOSTAT HARDWARE TREE (continued)

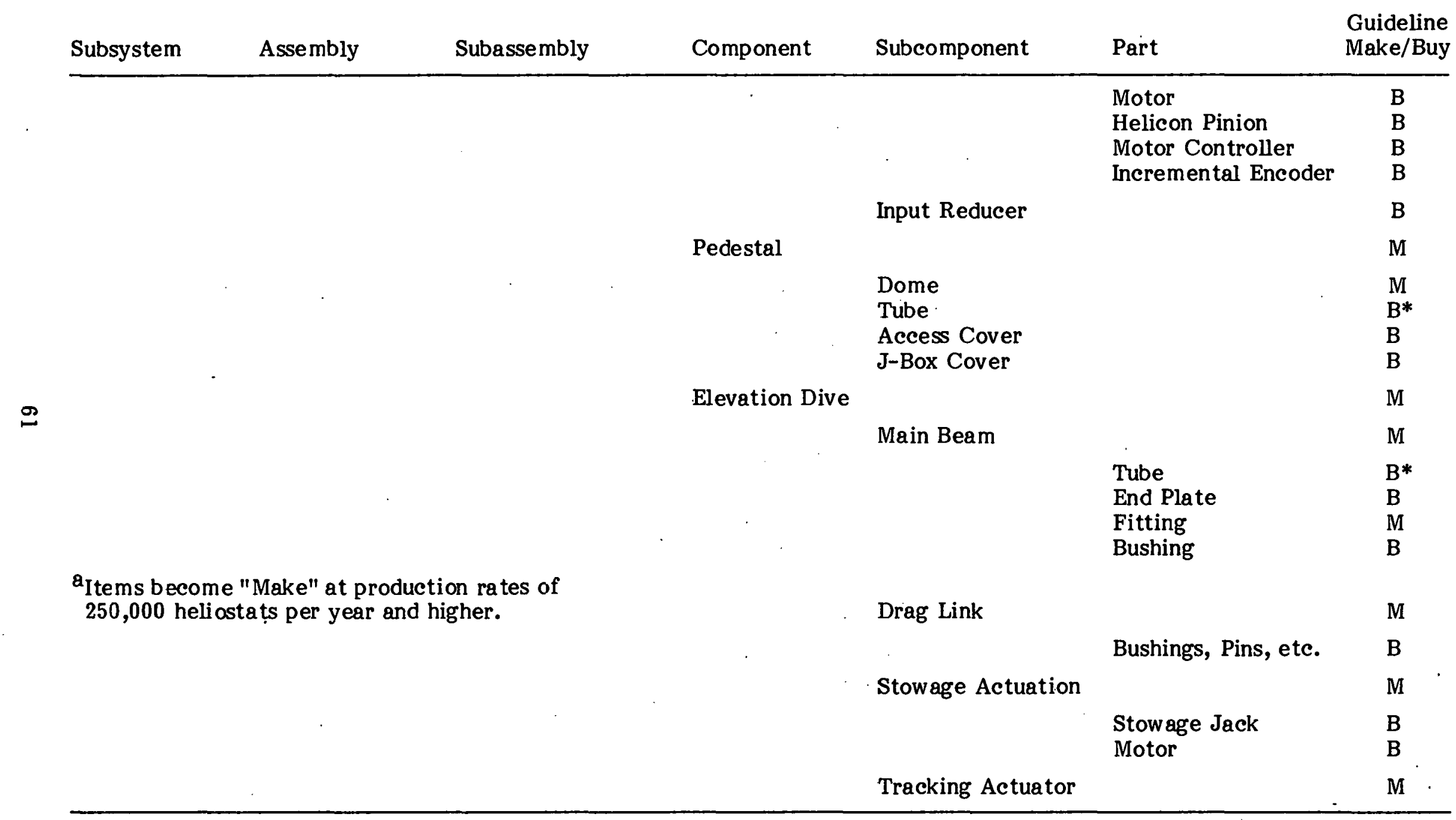


Table 7-1. PROTOTYPE HELIOSTAT HARDWARE TREE (continued)

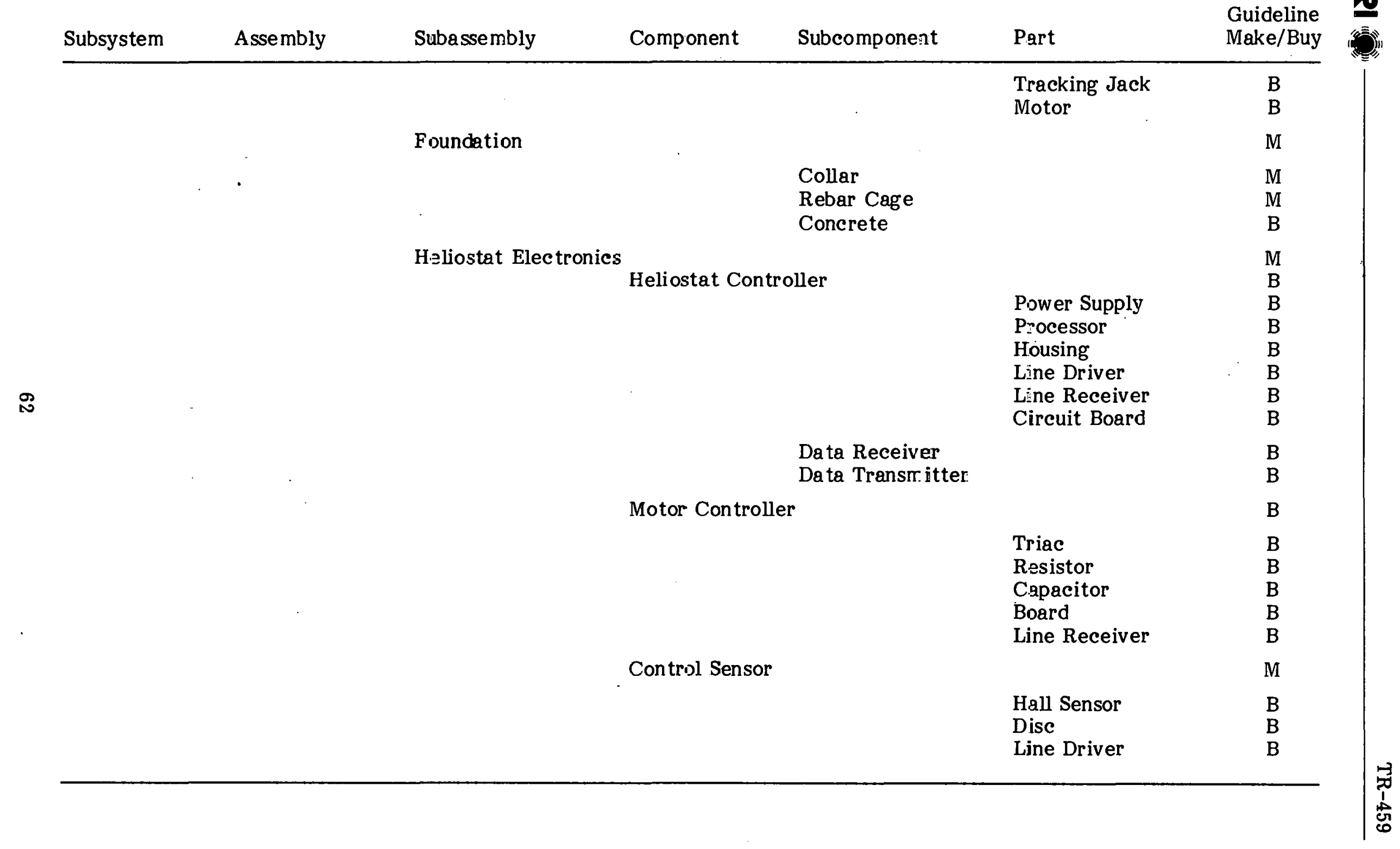


Table 7-1. PROTOTY PE HEIOSTAT HARDWARE TREE (continued)

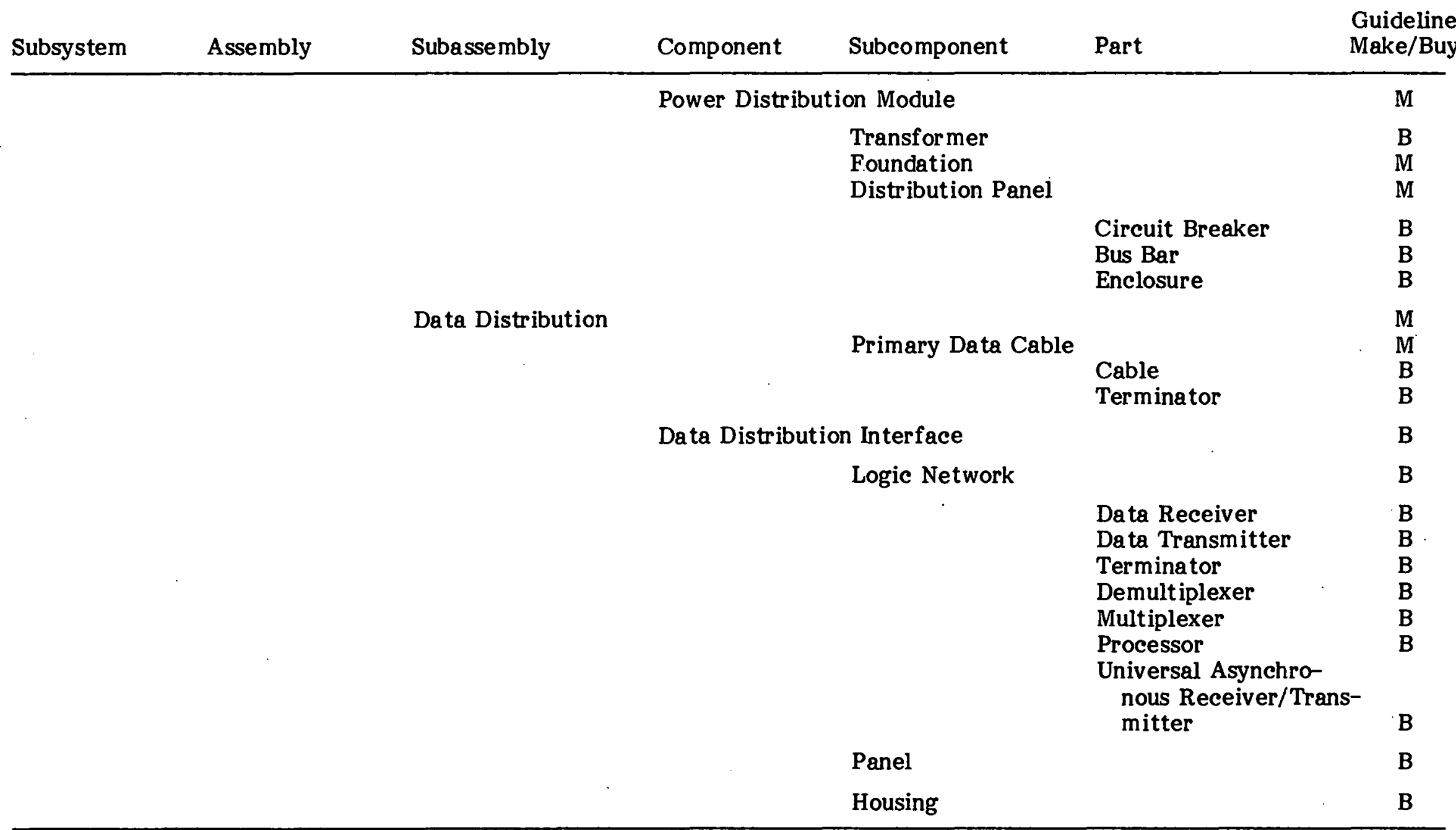


Table 7-1. PROTOTY PE HELIOSTAT HARDWARE TREE (concluded)

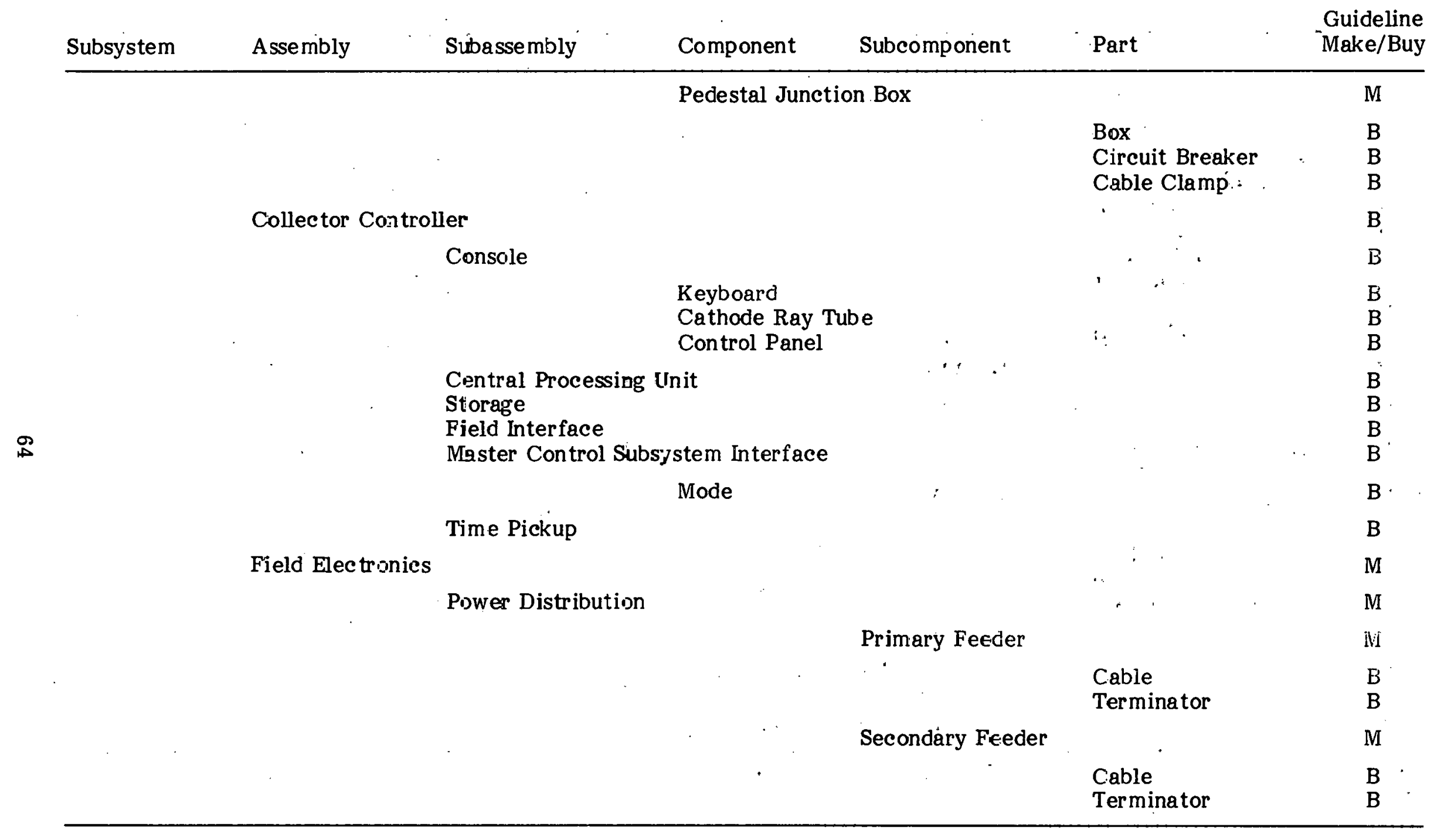




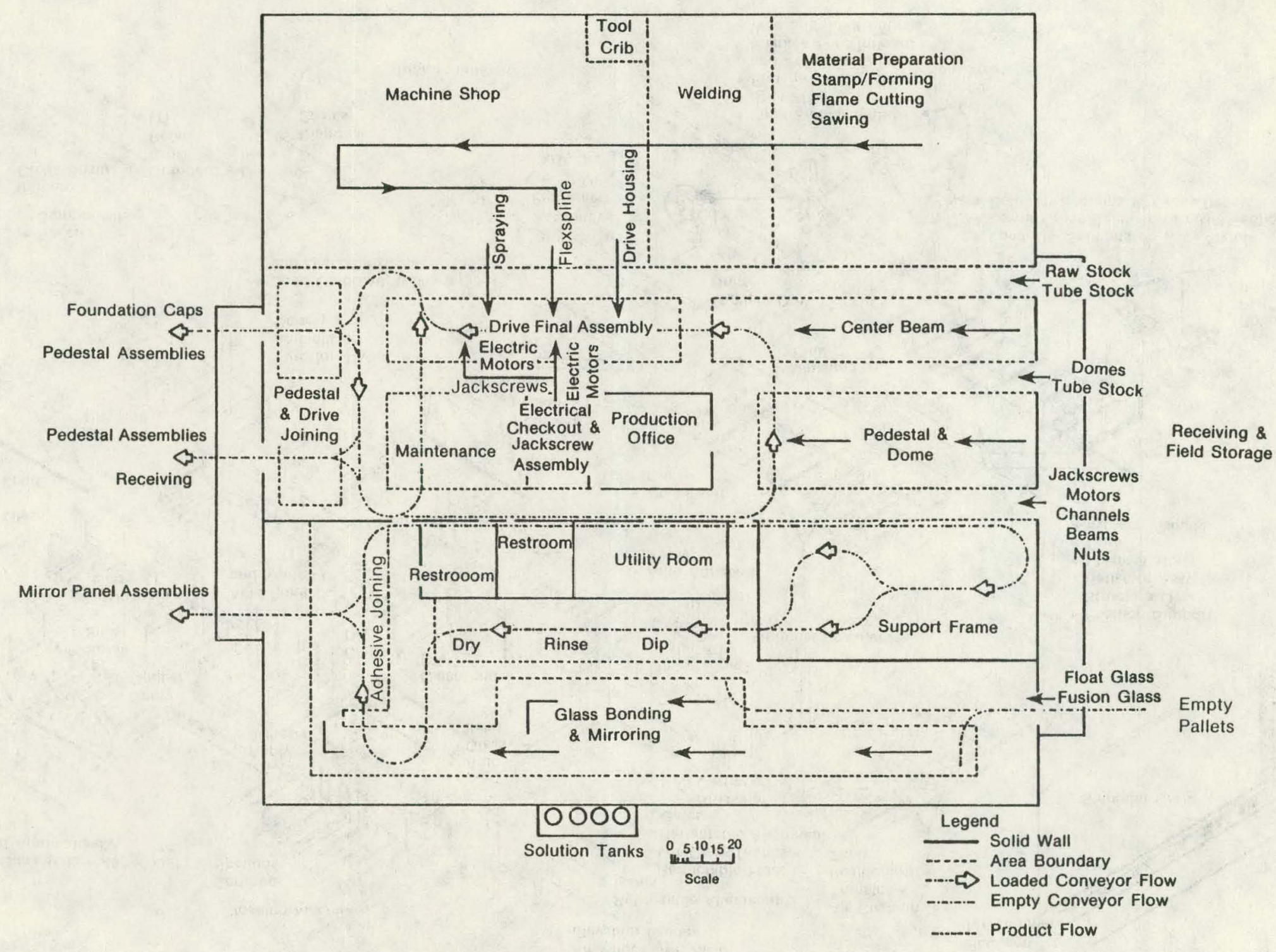

Figure 7-3. Block Flow Plant Layout 


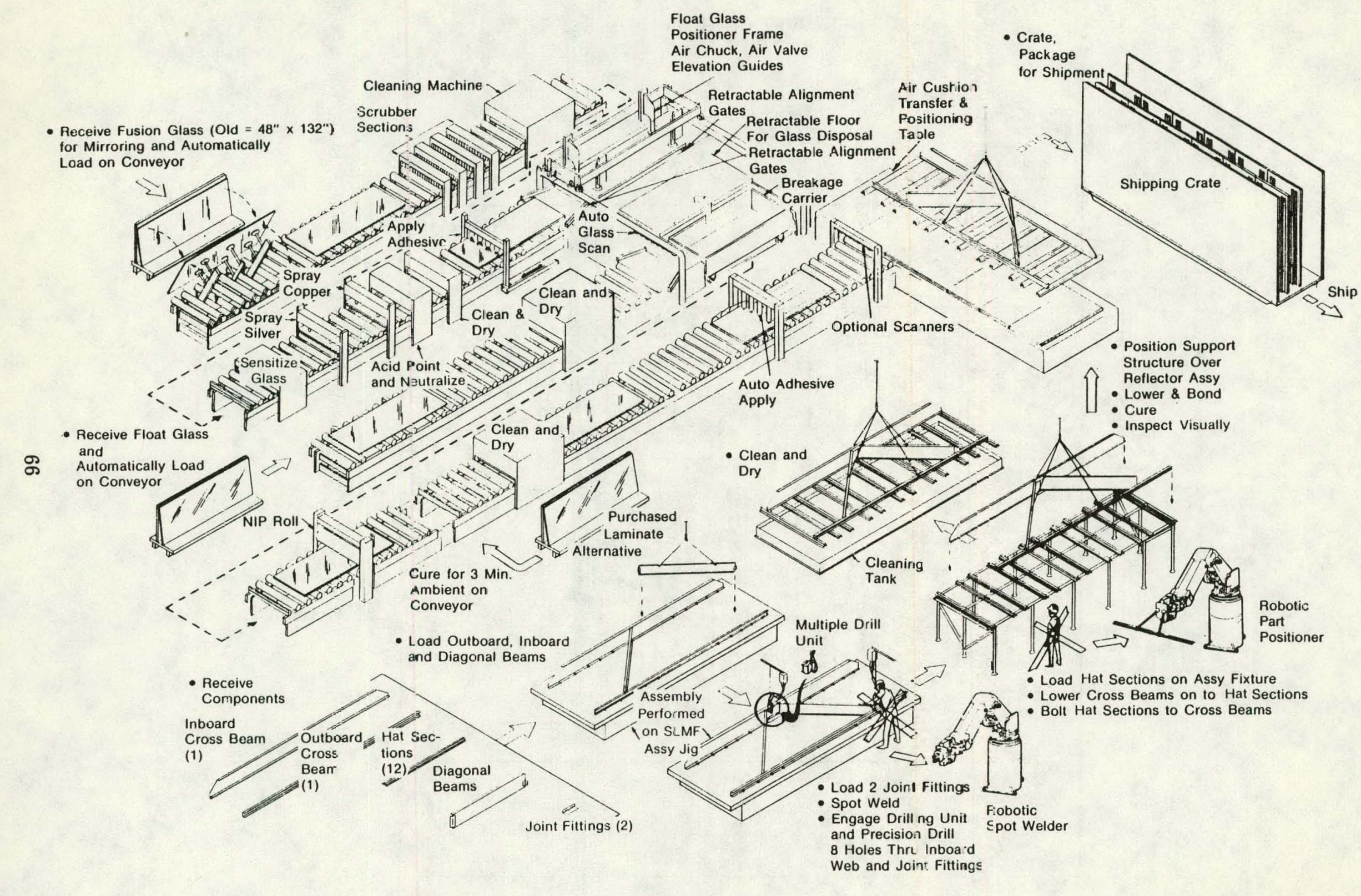

- Receive Fusion Glass (Old = 48" $\left.\times 132^{\prime \prime}\right)$ Sections Apply Air Chuck, Air Valve

Air Custion Transter : Tale Load on Conveyor

loat Glas

\section{1} Cure for $3 \mathrm{M}$
Ambient on

Load Outboard, Inboard Unit

Figure 7-4. Reflector Panel Assembly Manufacturing Flow 
The welded structure is removed from the weld fixture and proceeds on a monorail to two stringer attach stations. The 12 stringers are loaded and clamped in position in the assembly fixture, and the welded structure is lowered onto the stringers, clamped in place, and bolted.

The structure is then removed from the tool and is moved by monorail to a dip-clean, rinse, and air-dry station prior to bonding the structure to the mirror modules. At this point, the structure is lifted from an adjacent conveyor by a fixture that places the structure so that the hat sections rest on the two bond material lines that have been applied to each mirror module. The fixture holds the drive unit interface in correct alignment with respect to the mirror module surfaces. The mirror module curve and cant, and the hat section interface imperfections, are taken up in the thickness of the bond line.

The reflector panel is ambient-curved and vacuum-lifted from the assembly line and placed on shipping racks for transfer to the site. Special exhaust systems will remove vapors emitted by the acids, solvents, and adhesives. The exhaust systems may require scrubbers before the exhaust is released to the outside environment.

Special attention has been given to glass handling and transfer through the production lines. Glass handling equipment will be completely automatic and include unstacking machines for removing large sheets of glass from vertical storage and placing them on a horizontal production-line conveyor. Air float tables are used for transfer. Additional handling equipment includes a $90^{\circ}$ conveyorized transfer unit.

Drive and Pedestal Fabrication and Assembly. Drive and pedestal fabrication and assembly comprises a series of relatively standard equipment lines for metal forming, joining, removal, and assembly that utilize automatic feed and clear features and are interconnected by conveyors, hoists, drive assembly carriers, and other handling devices. For example, shuttle-type loaders allow machining while hardware is being loaded and unloaded on the numerical control machining centers and vertical turret lathes. This also allows individual operators to service more than one machining activity. Automatic positioners and gravity-fed conveyors allow the large, bulky items like the main beam and pedestal to roll to their next station rather than be handled between stations. Where items required several positions for assembly, such as on the azimuth drive, specialized equipment permits multiple part orientation by individual operators. The type of handling equipment and tooling used reduces the cost of major machine tool investment. Figure 7-5 shows the drive assembly flow and lists possible purchased materials and parts. The basic equipment required is:

\section{$\underline{\text { Major Equipment }}$}

Flame cutter

G\&L vertical turret lathe

Numerical control lathe

Automatic lathe

Hydrosize machine

Punch press line with coil straight

Hydraulic press (300-ton)

Deep draw press

Small press

Multi-drill station

Numerical control milling machine center K\&T
Number

Required 


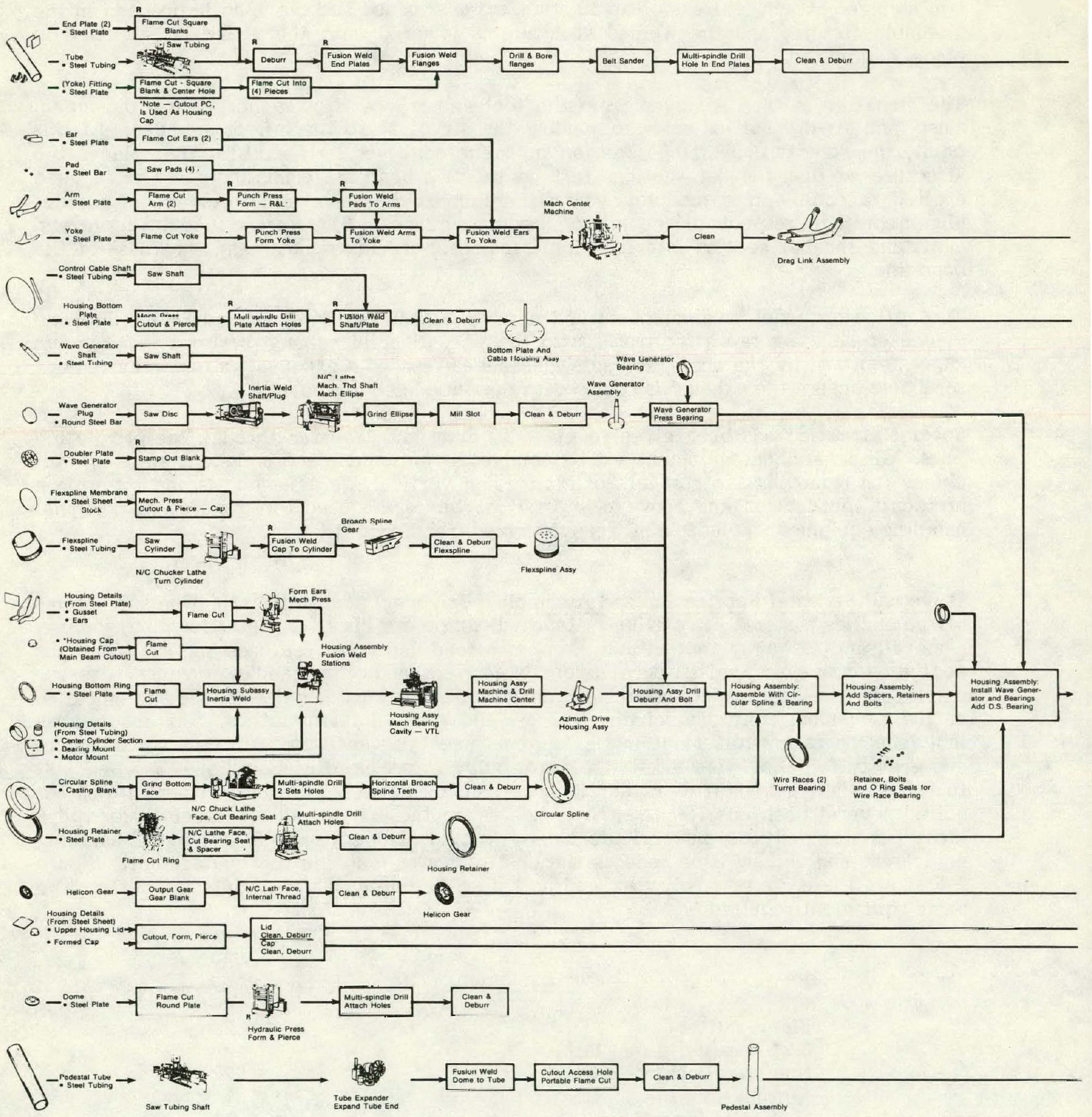




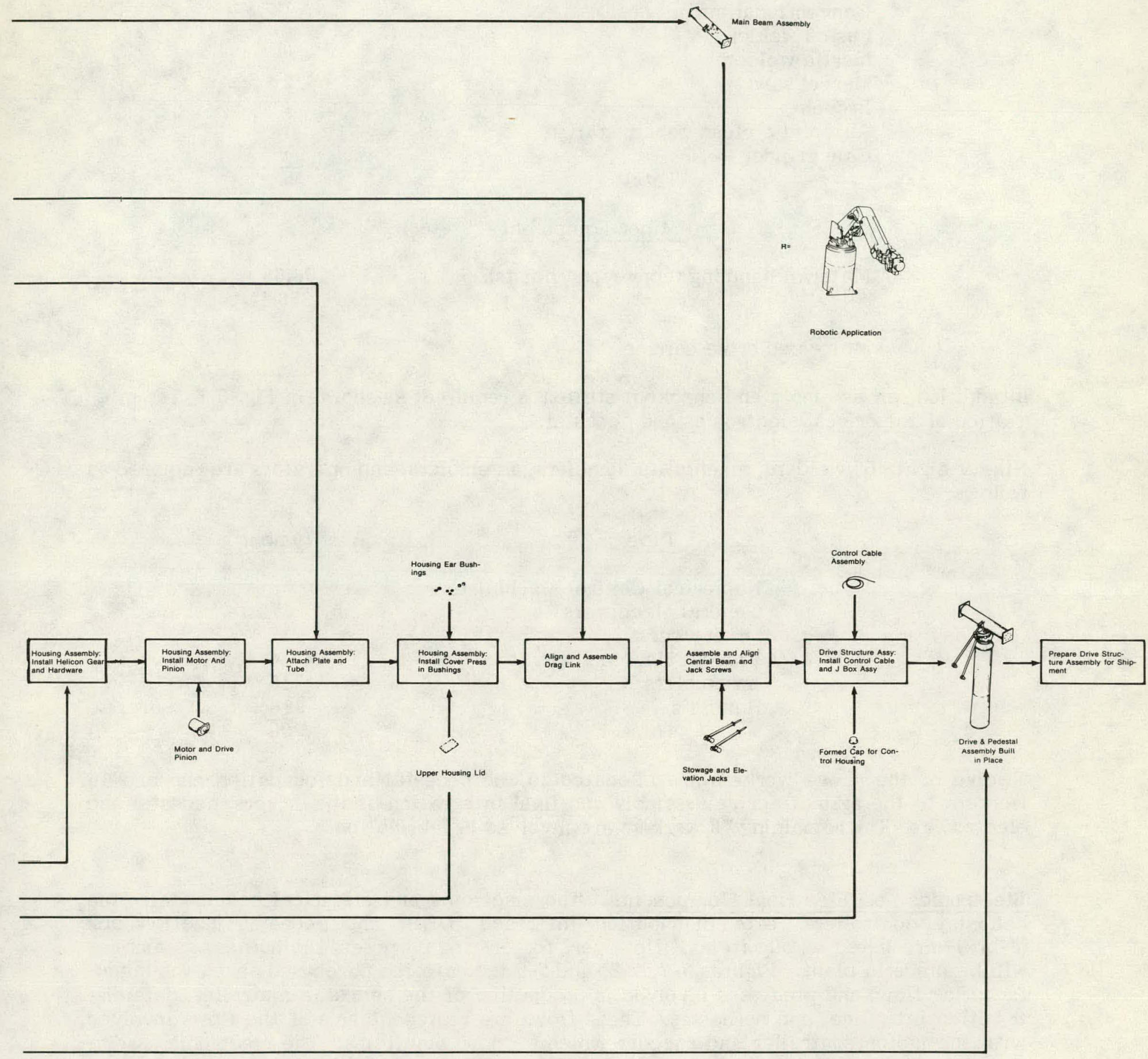




\section{Major Equipment}

Conventional mill

Fusion welder

Inertia welder

Marvel saw

Broach

Automatic clean deburr station

Cam grinder

Total

Minor Equipment

Ma terial handling (conveyors, hoists)

Motorized drive carrier
Number

Required

$\begin{array}{r}1 \\ 6 \\ 2 \\ 2 \\ 1 \\ 1 \\ 1 \\ \hline 36\end{array}$

$106.68 \mathrm{~m}$

$(350 \mathrm{ft})$

5

In addition, an assembly and checkout station is required, as shown in Fig. 7-6, for integration of the drives, electronics and pedestal.

Ninety-eight "B" welders, machinists, handlers, assemblers, and operators are required as follows:

$\underline{\text { Type }}$

Numerical Control Machinists

General Machinists

"B" Welders

Process Machine Operators

Assemblers

Handlers

Total
Number

$\begin{array}{r}8 \\ 37 \\ 17 \\ 4 \\ 16 \\ 16 \\ \hline 98\end{array}$

Twelve of the above workers are allocated to the pedestal and foundation cap and 16 workers to the azimuth drive assembly and final integration of the drivers, pedestal and electronics. The remaining 70 workers are involved in fabrication.

Electronics and Electrical Components. The electronic and electrical components-the heliostat controllers, data distribution interface (DDI), and pedestal junction box (J-box)-are listed as buy items. However, for costing purposes, the harness assemblies will be made in-plant. Figurss 7 7, 7-8, and 7-9 indica te the purchased parts, the manufacturing flow, and processes involved in production of the heliostat controller, data distribution interface, and harnesses. These flows are representative of the flows involved with the motor controller and encoder which are also buy items. The electronic assemblies will be procured from sources that have programmable automatic sequencer and insertion equipment. The flow solder technique is employed to complete the circuits, and a functional test and burn-in is accomplished prior to installation in the housing. Commercial-grade components produced to military specifications will be employed. 


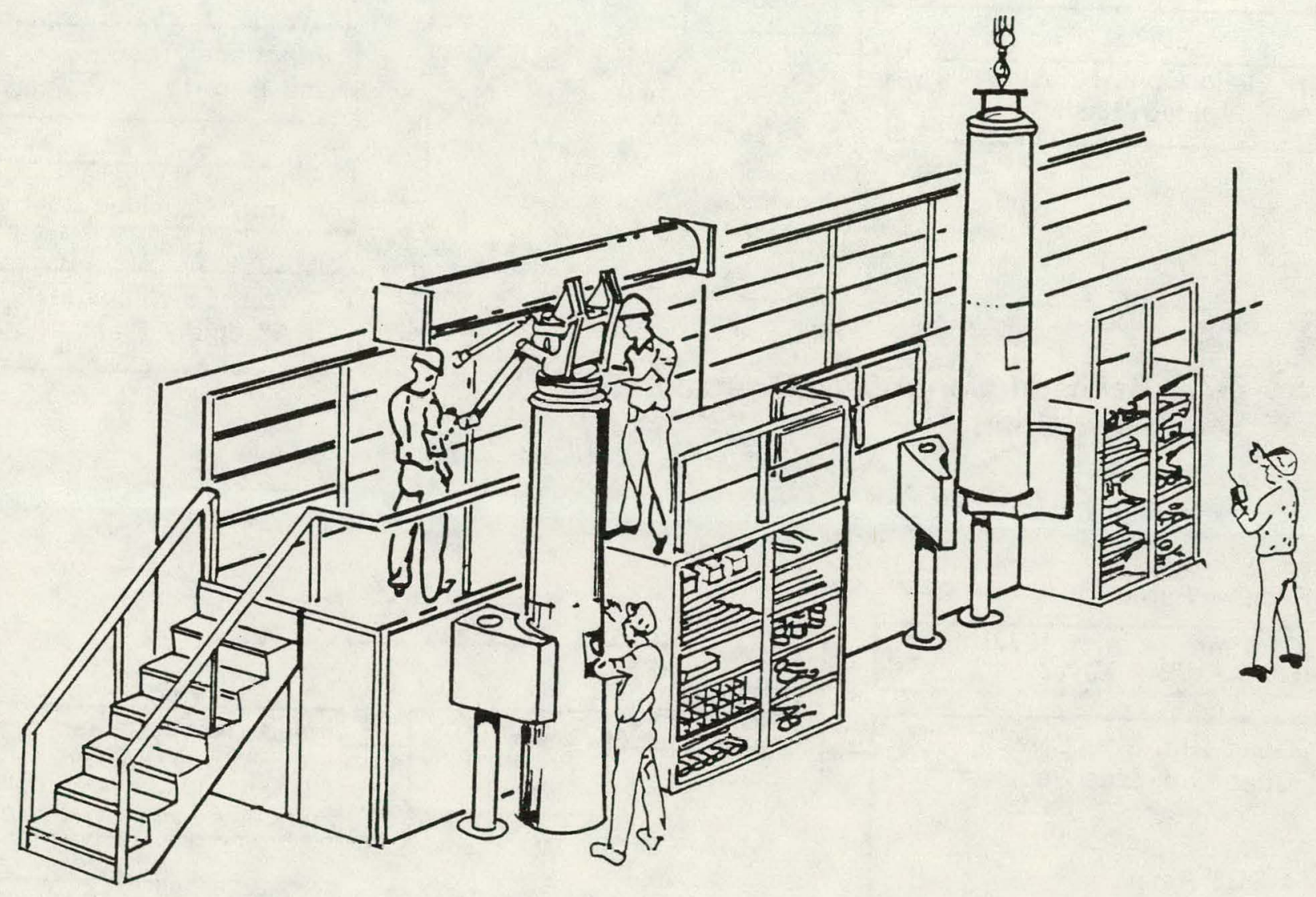

Figure 7-6. Final Assembly Joining Area Drive Unit Pedestal 
Receive Parts

(1) $101.6 \mathrm{~mm} \mathrm{(4} \mathrm{in} \mathrm{)} \times 127.0 \mathrm{~mm}$

(5 in) PWB - 2 Layer

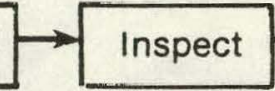

(1) $\mu$ Computer

(3) Diff. Line Drivers

(2) Quad. Diff. Line Receiver

(3) Hex D- $\mu$ IN Flop

(3) 0.1 yf $50 \mathrm{~V}$ Ceramic Caps

(1) 5 V PWR Supply

(1) Board Connector

(1) Fiber Optic Transmitter/Receiver

(1) Helio Cont. Housing Molded Plastic

\section{Inspect}

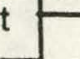
Figure 7-7. Heliostat Controller Manufacturing
Flow Chart

Receive Parts

(2) $101.6 \mathrm{~mm}(4 \mathrm{in}) \times 127.0 \mathrm{~mm}$ (5 in) PWB 2 Layer

Inspect

(4) Quad Diff. Line Driver

(4) Quad Diff. Line Receiver

(2) $\mu$ Computer

(2) Transceiver

(8) 4 PDT Relay

(4) 0.1 yf $50 \mathrm{~V}$ Ceramic Caps

(2) 5 V PWR Supply

(2) Board Connector

(1) D.D.I. Housing Moulded Plastic

\section{Inspect}

\begin{tabular}{|ll|}
\hline (1) & D.D.I. Housing \\
& Moulded Plastic
\end{tabular}

Set Up For Automatic Insert

Ship To Heliostat Assembly Plant

Insert Components into PWB Trim and Clench Leads - All Automatically

Tape Controlled
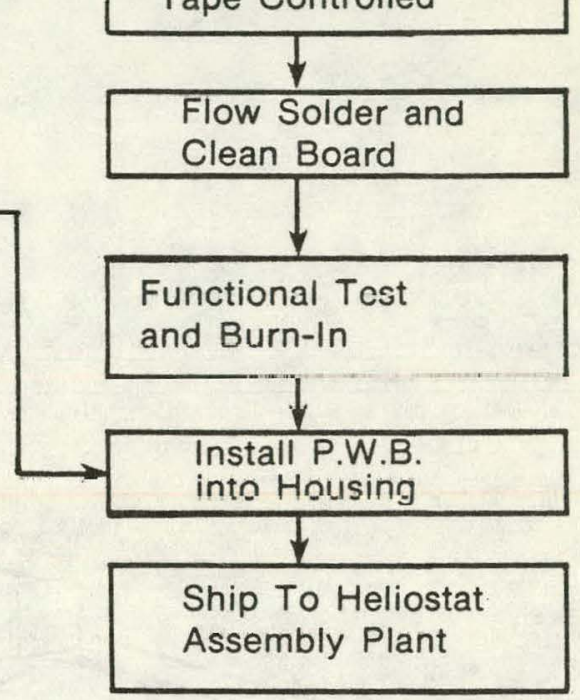

Functional Test and Burn-In

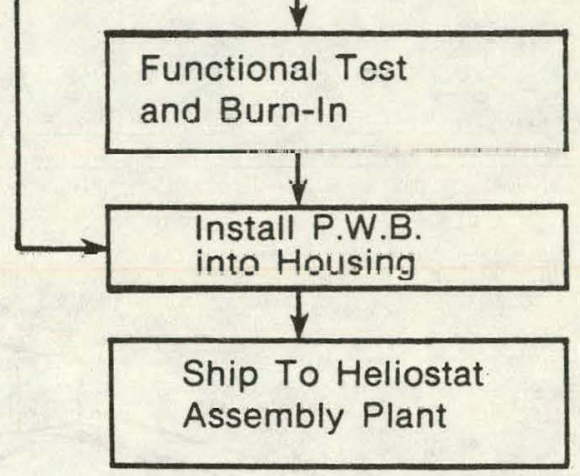

\section{Figure 7-8. Data Distribution Interface (DDI) Manufacturing Flow Chart}

Ship To Heliostat Assembly Plant 
Receive Parts (Control Box to Motors)

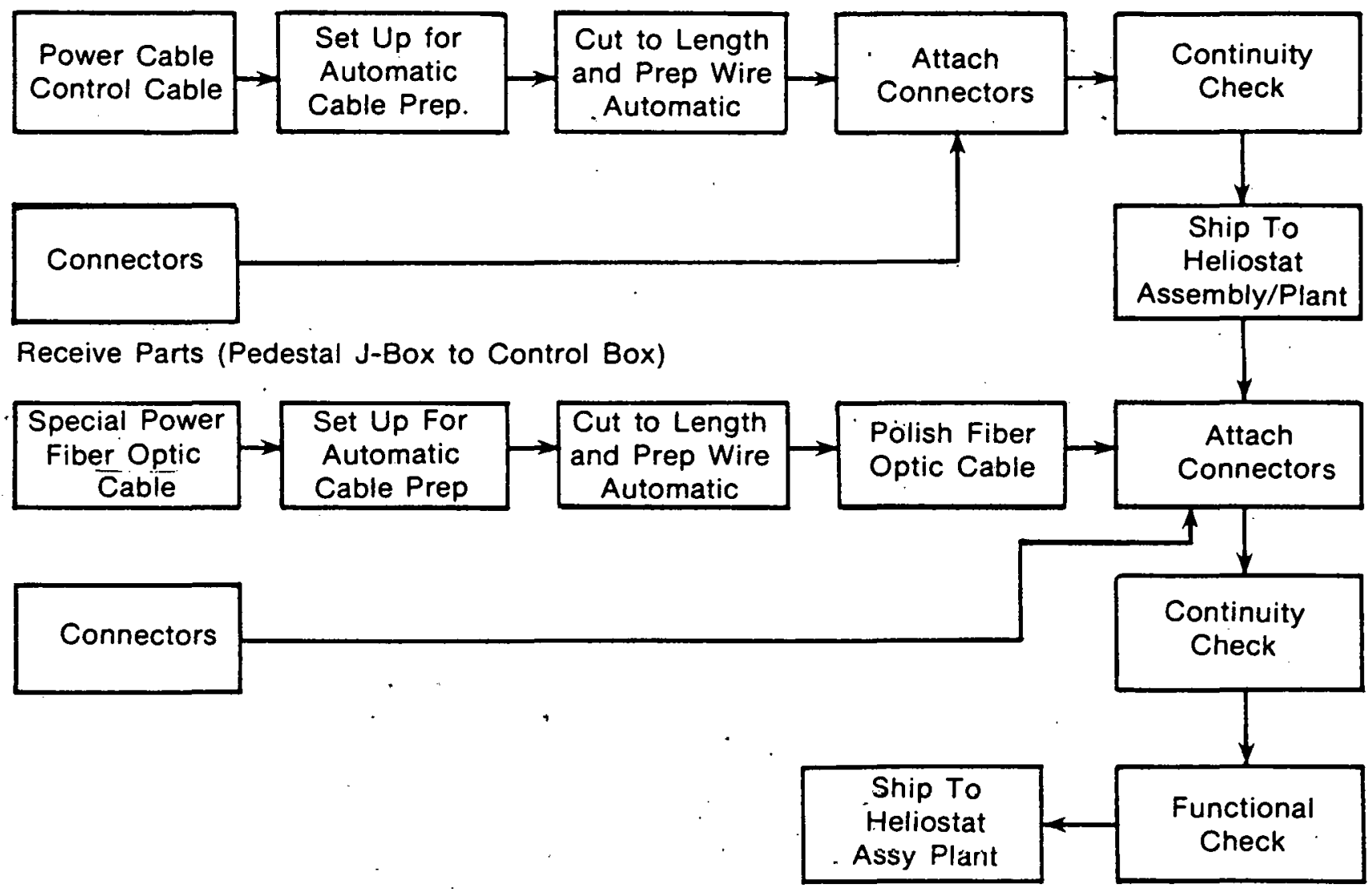

Figure 7-9. Heliostat Control Harness Manufacturing Flow Chart 
A total of 32 assemblers, technicians, handlers, operators, inspectors, electricians and mechanics are required, as follows:

Element

Controller and DDI

Motor controller and encoder

Harness

Motor Test

Total
Workers

12

9

9

$\frac{2}{32}$

\subsubsection{Installation}

The heliostat is assembled in the field from basic component subassemblies that have been checked in the factory. This simplifies field operations by reducing the number and complexity of tasks performed in the field. The installation is mainly achieved by trade labor supplemented with specially trained operators and technical personnel. The labor force is supervised by the heliostat manufacturer. Figure 7-10 provides the sequence of installation events; time and resource requirements for one crew are shown in Table 7-2.

Foundation. Standard construction techniques are employed for foundation installation, and a number of methods could be employed. For the baseline method, rebar cages are fabricated in a site-located shop with the foundation cap welded to the top. At the same time, pier holes are drilled using a high-powered auger. The completed cages are trucked to location and placed in the hole with light lifting equipment such that the cap extends above grade. Concrete obtained from a local batch plant and trucked to the area is pumped and vibrated through the top of the cap, filling both the hole and the cap extension.

Labor is required as follows:

\begin{tabular}{lcc} 
Element & \multicolumn{2}{c}{ Workers } \\
\cline { 2 - 3 } & Crew & Total \\
\cline { 2 - 3 } Cage Fabrication & 7 & 35 \\
Survey and Auger & 8 & 40 \\
Installation & $\frac{14}{29}$ & $\frac{70}{145}$ \\
Total & $\frac{14}{2}$ &
\end{tabular}

These 145 workers are capable of installing 25,000 foundations in 25 weeks, including lost time for start-up/shutdown, personal time, fatigue shortages, inclement weather, and lost eificiency. However, the numbers shown exclude concrete truck drivers and batch plant laborers, who are covered in the concrete price.

Reflector and Drive/Control Unit. The reflector panels and drive/control units are installed using the equipment depicted in Fig. 7-11 and 7-12. The drive/control installation equipment is used to lift the unit from the flatbed trailer, rotate it to a vertical position, and place the pedestal section over the tapered foundation cap. The drive unit is then oriented to true north, and downward pressure and vibration are applied to seat the unit on the foundation. Once this is completed, the drive is filled with oil. 


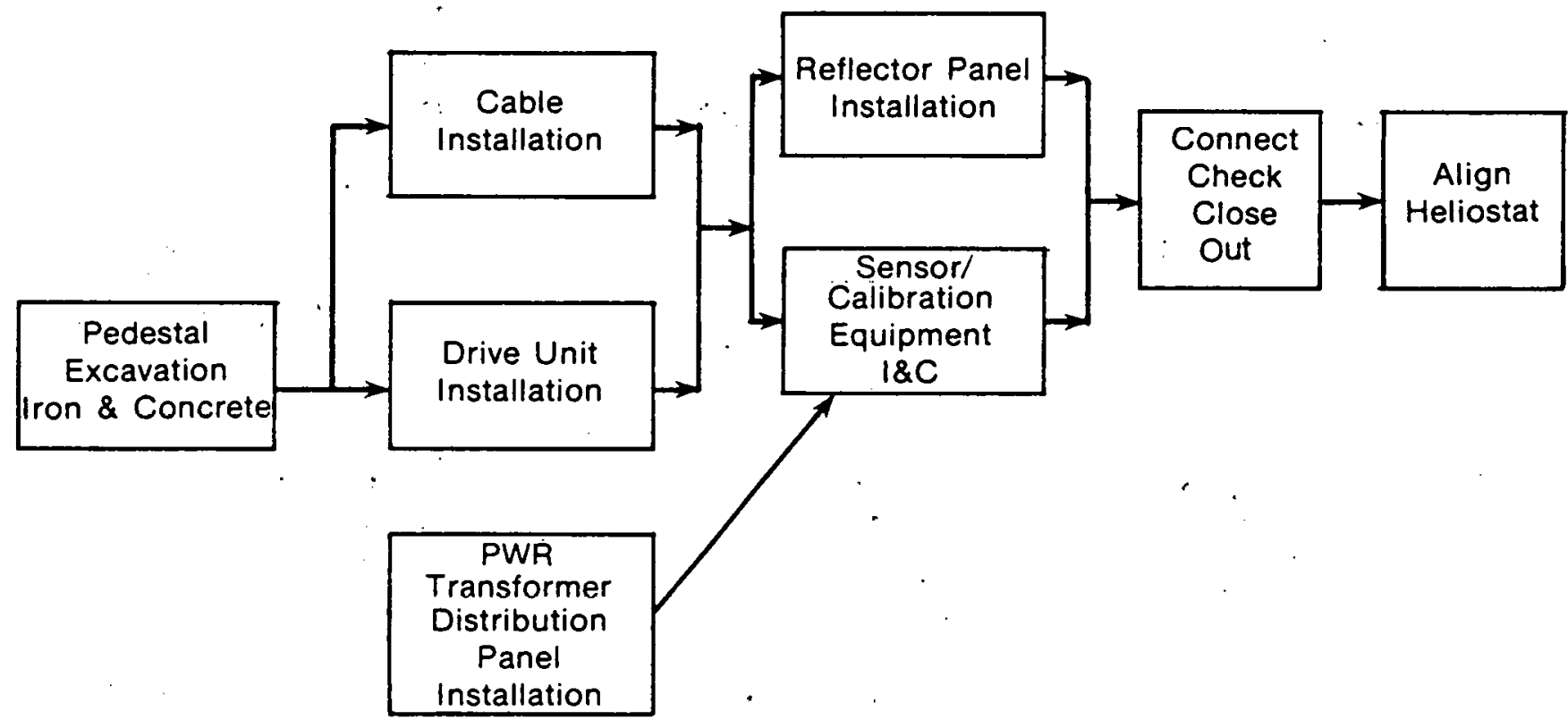

Figure 7-10. Installation Task Sequence

Note: Task Descriptions

Are Given in Table 7-2 
Table 7-2. INSTALLATION TASKS AND CREW SIZE

\begin{tabular}{|c|c|c|}
\hline Task Number & Time/Heliostat & Crew and Equipment Allocations \\
\hline $\begin{array}{l}\text { 1. Pedestal Excavation } \\
\text { Iron Work and Concrete }\end{array}$ & $30 \mathrm{~min} /$ heliostat & $\begin{aligned} 4 & \text { Trucks } \\
2 & \text { Hydraulic Cranes } \\
1 & \text { Auger Rigs } \\
3 & \text { Equipment Operators } \\
4 & \text { Truck Drivers } \\
2 & \text { Surveyors (part-time) } \\
2 & \text { Oilers } \\
2 & \text { Iron Workers } \\
4 & \text { Rodmen } \\
12 & \text { Laborers }\end{aligned}$ \\
\hline 2. Cable Installation & $18 \mathrm{~min} /$ heliostat & $\begin{array}{l}1 \text { Cable Plow } \\
1 \text { Cable Plow Opera tor } \\
2 \text { Laborers }\end{array}$ \\
\hline 3. Drive Unit Installation & $18 \mathrm{~min} /$ heliostat & $\begin{array}{l}1 \text { Pedestal/Drive Assembly } \\
\text { Installation Equipment } \\
1 \text { Installation Equipment } \\
\text { Operator } \\
1 \text { Millright } \\
1 \text { Laborer }\end{array}$ \\
\hline $\begin{array}{l}\text { 4. Power Transformer/ } \\
\text { Distribution Panel } \\
\text { Installation }\end{array}$ & $\begin{array}{l}90 \mathrm{~min} / 312 \text { helio- } \\
\text { stats }\end{array}$ & $\begin{array}{ll}1 & \text { Millwright } \\
2 & \text { Laborers } \\
1 & \text { Truck } \\
1 & \text { Forklift } \\
1 & \text { Truck Driver }\end{array}$ \\
\hline $\begin{array}{l}\text { 5. Reflector Panel } \\
\text { Instailation }\end{array}$ & $21 \mathrm{~min} /$ heliostat & $\begin{array}{ll}1 & \text { Reflector Panel Assembly } \\
\text { Instaliation Equipment } \\
1 \text { Installation Equipment } \\
\text { Operator } \\
2 \text { Hi-Lift Forklifts } \\
2 \text { Forklift Operators } \\
2 \text { Millwrights } \\
2 \text { Lnborcrn }\end{array}$ \\
\hline $\begin{array}{l}\text { 6. Sensor/Calibration } \\
\text { Equipment I\&C }\end{array}$ & $8 \mathrm{hrs} / 3,000$ heliostats & $\begin{array}{ll}1 & \text { Field Engineer } \\
1 & \text { Electrician } \\
1 & \text { Volt-Ohm Metèr } \\
1 & \text { Oscilloscope }\end{array}$ \\
\hline $\begin{array}{l}\text { 7. Connect, Check and } \\
\text { Close Out }\end{array}$ & $15 \mathrm{~min} /$ heliostat & $\begin{array}{ll}1 & \text { Electrician } \\
1 & \text { Laborer } \\
1 & \text { Test Set }\end{array}$ \\
\hline 8. Align Heliostat & $10 \mathrm{~min} /$ heliostat & $\begin{array}{ll}1 & \text { Field Engineer } \\
2 & \text { Technicians } \\
1 & \text { Mobile Field Test } \\
& \text { Station }\end{array}$ \\
\hline
\end{tabular}




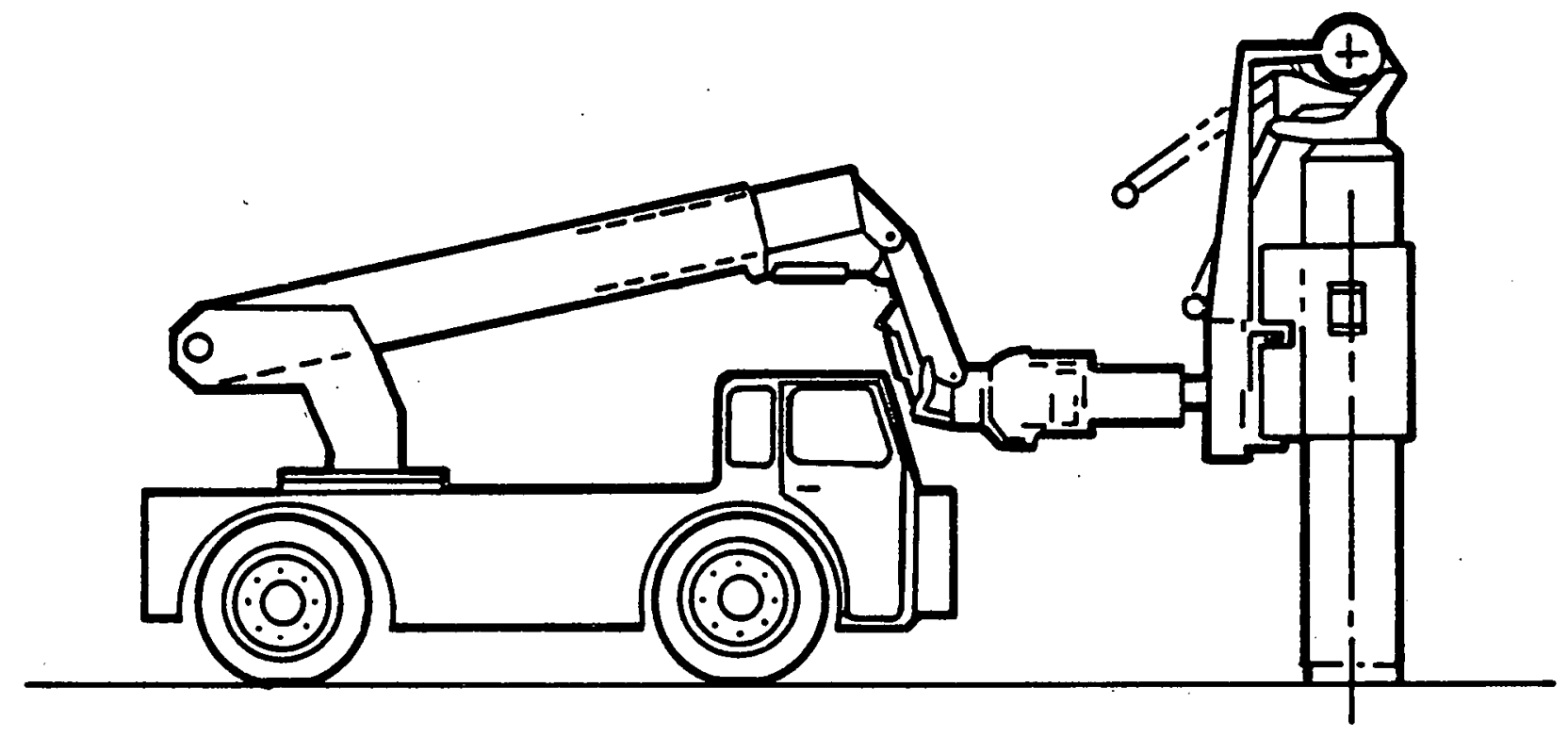

Figure 7-11. Drive Unit Installation Machine
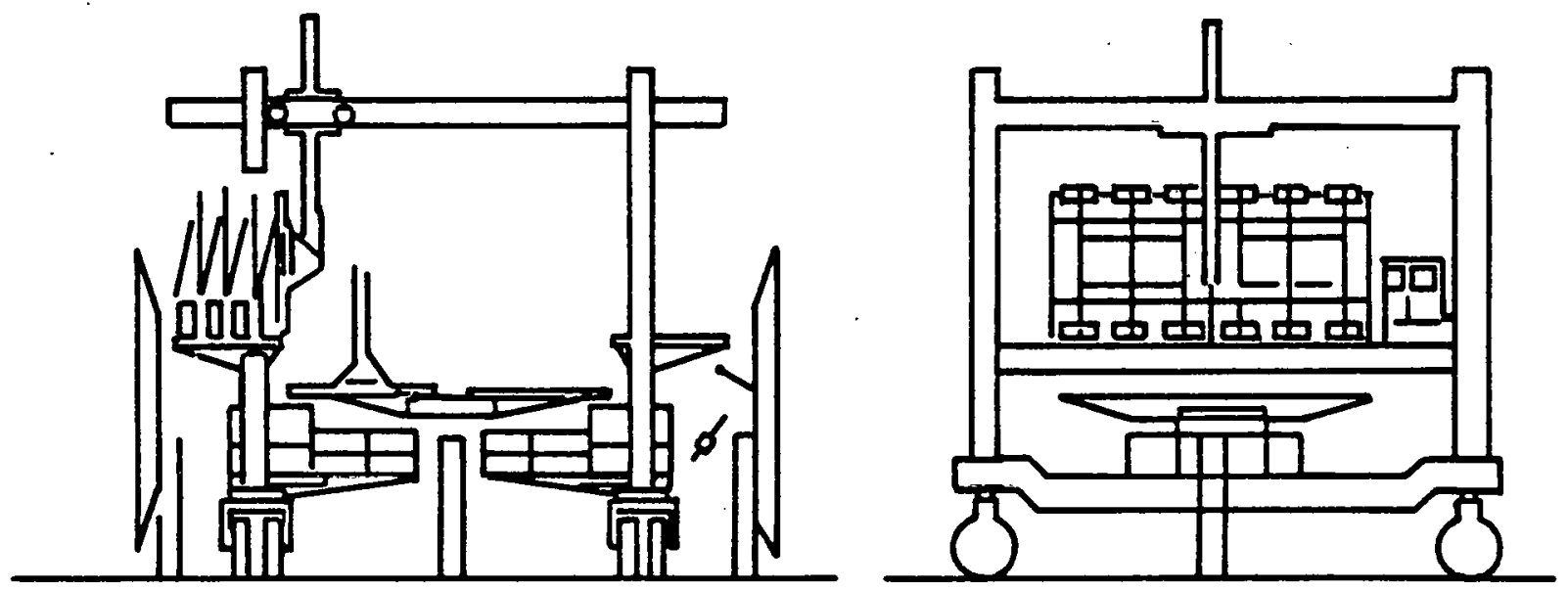

Figure 7-12. Reflector Installation Equipment 
The reflector installation equipment is designed to simultaneously position two panels next to the drive unit and provide convenient access for bolting the panels to the drive unit. First, one pallet containing four reflector panels is loaded on each side of the installation equipment using a high-lift forklift. The equipment is then driven over the drive, and a manipulator arm on each side (only one is shown in the drawing) engages a panel. The arms move the panel to positions where they may be connected to the drive using 8 bolts for each panel. The equipment is disengaged and moved over the next drive.

The work force employed is:

\begin{tabular}{lcc}
\multicolumn{1}{c}{ Element } & \multicolumn{3}{c}{ Workers } \\
Drive/Control & & Total \\
Reflector Panels. & $\frac{6}{9}$ & $\frac{30}{45}$
\end{tabular}

These crews are sufficient to install 25,000 reflector and drive/control units in 39 weeks, with allowances for lost time.

Power Distribution and Sensor/Calibration Units. Installation of these elements includes burying $88,350 \mathrm{~m}$ of branch circuit cable and placing and checking 79 power distribution modules and 8 digital image radiometers. The cable is "plowed in" using a standard cable plow that slices a V-groove in the soil to a .61-m depth and feeds cable into the bottom of the groove at a rate of $76 \mathrm{~m} / \mathrm{hr}$. As the cable is placed, the plow guides the soil back into the groove. At each point where power is required or distributed, the plow stops and a large loop is allowed to form in the cable before the plow moves on.

Installation of the power distribution modules is basically a matter of pouring a small foundation at each position and setting the equipment. A field engineer must further inspect the 8 digital image radiometers using a volt-ohm meter and an oscillossope in the final alignment of the heliostats.

Labor is employed for these tasks as follows:

Element

Lay Cable

Power Distribution Modules

Digital Image Radiometer

Connect, Check, and Closeout

Total

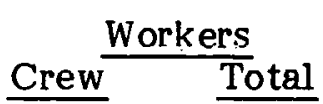

\begin{tabular}{cr}
3 & 9 \\
4 & 4 \\
2 & 2 \\
2 & 8 \\
\hline N/A & $\frac{23}{23}$
\end{tabular}

Plowing in the cable and the connections requires 39 weeks. Only 3 weeks are required for the power distribution modules and a little over 1 week is required to install the digital image radiometers.

Alignment and Checkout. A final tracking alignment and checkout are accomplished using a control van, the digital image radiometer, and the plant master control. No mechanical adjustments are required for the heliostat after installation. The alignment 
is done by establishing and adjusting position relationships in the heliostat controller to reflect the differences between the programmed placement of the heliostat and the actual position of the unit. New position information is required on the first alignment, and a subsequent alignment compensates for vertical errors.

The control van is connected into the data distribution interface once for 24 heliostats as the heliostats read positioning information from a common optical data bus. The group of heliostats is then activated, moved to standby positions, and established on track. At this point, the activities of the alignment branch into two categories: interacting manmachine alignment in the northern half of the field, and automatic search in the southern half.

In the interacting alignment, a sighting mirror is placed on the reflector edge, and the installer views the position of the image with respect to an alignment target on the tower. A verbal command is then given to the alignment operator in the control van that brings the spot on the target. Once the spot is on target, the digital image radiometer is used to establish the exact position and provide updated position information.

An automatic search technique will be used in the southern portion of the field because the heliostats will be in a nearly horizontal position during much of the day. It is therefore inconvenient to attach a sighting mirror and observe the solar image. In the automatic search, the heliostat is moved in an expanding spiral search pattern until the target is intercepted. Afterward, the digital image radiometer is used to set the exact position and ipdate it as in the interacting technique.

In conjunction with these activities, the heliostat will be checked for tracking, a satisfactory image quality, correct data and power transmission, and lack of lubrication leaks or installation damages. The labor required for this task is three 3-person crews over a 39-week period.

\subsubsection{Changes in the Scenario for Higher Production Rates}

Three main changes have been made in the 250,000 heliostats/yr costing scenario. First, material weights have been reduced to their theoretical minimum for the mirror backing structure and integrated drive unit structure. Second, parts have been eliminated in the drive housing by assuming a welded flexspine/housing assembly. Third, au tomated assembly equipment has been deemed capable of eliminating $90 \%$ of hand labor and its additional use is assumed. However, production plant adjustments necessary to assimilate automation assume that a lot of direct labor support is still required to maintain and provide basic direction to the automated equipment. Two types of industrial "robots" were considered: one produced by Unimation, Inc., which is used in numerous automobile production situations, and a highly flexible one produced by Cincinnati Milacron. These machines are capable of performing almost any assembly, machine loading, welding, or handling operation. One other change assumed is that foundation installation will become more mechanized. Also, overhead is assumed constant (i.e., reduced fringe costs will be balanced by increased equipment cost and fringe rates), so that overhead rates increase, dramatically. Additional changes, such as improved line flow, integration, and increased supplier control, are considered through the operation of the cost reduction curve.

The 1 million units/yr scenario assumes further that production facilities will be more func tionally specialized; that designs, materials, and processes will continue to improve; and that greater control over supply will be achieved. It also may become feasible to 
vertically integrate the production of certain basic materials. All such changes have been given effect through adjustments along the cost reduction curve to reflect costs at the 15 millionth unit.

\subsubsection{Production Volume Impact on Average Unit Cost}

The MDAC heliostat cost comparison is presented in Table 7-3. Figures 7-13, 7-14 and 7-15 describe cost elements of the MDAC heliostat based on production rates.

The design/production, installation, and operating plans derived for the 25,000 units/yr scenario support the belief that the DOE goal of $\$ 72 / \mathrm{m}^{2}$ reflectivity is obtainable. For the rate of 25,000 units/yr, the average unit cost is projected to be about $20 \%$ lower than that projected for the initial pilot production. Large cost reductions are projected for all elements except foundation and site preparation. However, the constly foundatinn prnposed for this design/production scenario permits important cost reductions in other areas by (1) supporting a larger heliostat, and (2) contributing to a simplified field assembly and checkout procedure. . Perhaps the largest cost reduction is projected in the drive unit, which has been simplified in such areas as the housing, bearings, jackscrews, and various azimuth components. In general, projected cost reductions are associated with the introduction of automated assembly and material transfer; numerically controlled machines; automatic electronic component insertion; and wave soldering.

The average unit cost for a $250,000 / \mathrm{yr}$ production rate shows a significant reduction compared with its estimated value at the 25,000 heliostats/yr rate. This cost reduction is supported by:

- Reduction of the material weights to their theoretical minimum for the mirror backing structure and integrated drive unit structure.

- Elimination of the parts in the drive housing by assuming a welded flexspine/ housing assembly.

- Introduction of automation (industrial robots) capable of eliminating $90 \%$ of hand labor positions.

- Mechanization of the foundation installation.

- Improved line flow, integration, and increased supplier control.

The average unit cost reduction for the 1 million/yr production rate is not as significant as for the 250,000 units/yr scenario. It is assumed that further cost reductions will be caused by continued improvement of the design, materials, and processes; further functional specialization of the production facilities; greater control over supply; and vertical integration of the production of certain basic materials.

\subsubsection{The General Electric Prototype Heliostat Design Production Scenario}

This subsection briefly summarizes the facilities, equipment, tooling, manpower, new materials, materials handling, quality control, and cost requirements needed to produce 2,500 heliostats as a one-time purchase, and steady-state production levels needed for $25,000,250,000$ and 1 million heliostats/yr. Detailed information on the manufacturing design for this heliostat is in Ref. 34 . 
Table 7-3. MDAC PROTOTY PE HELIOSTAT COST COMPARISON

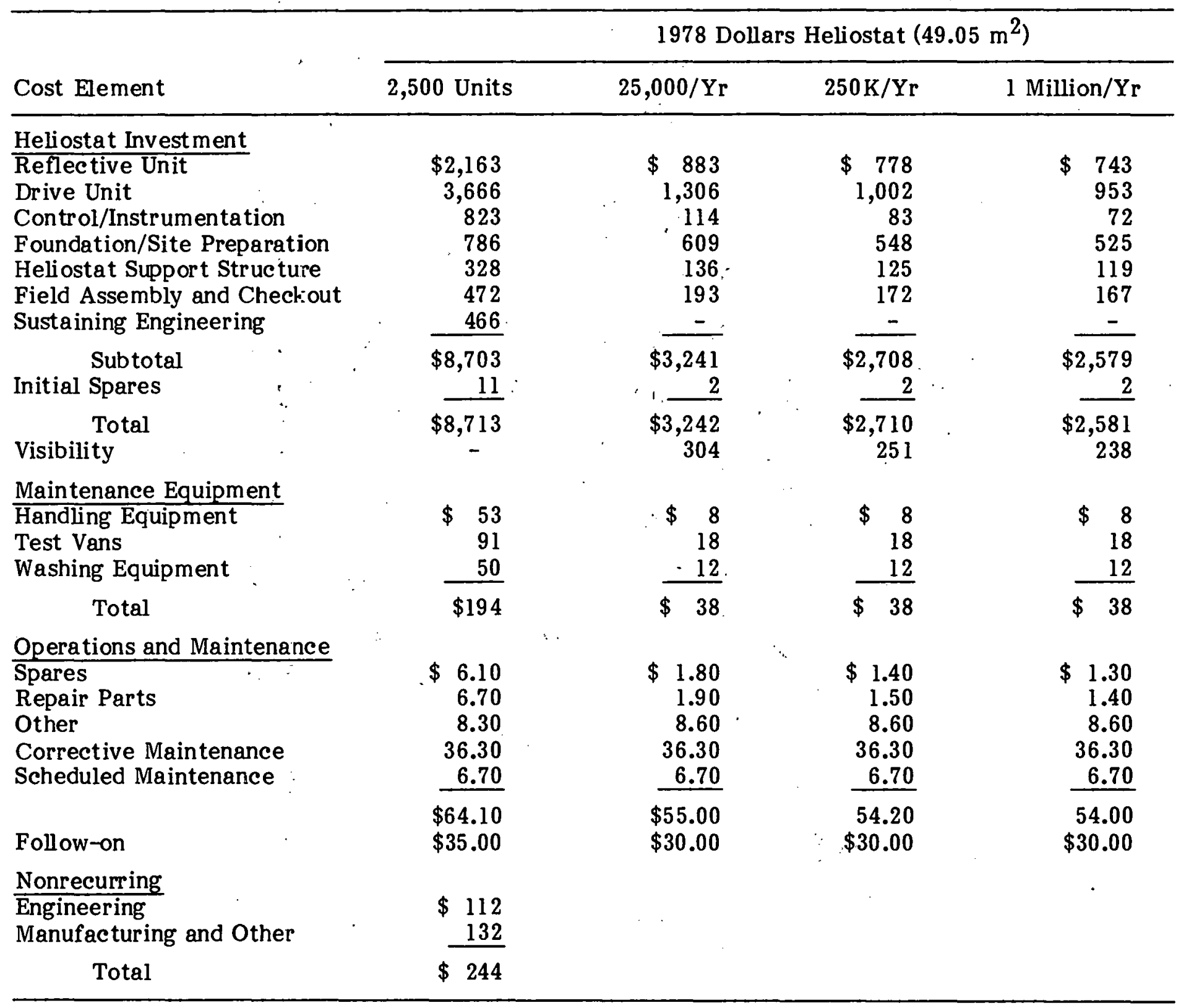




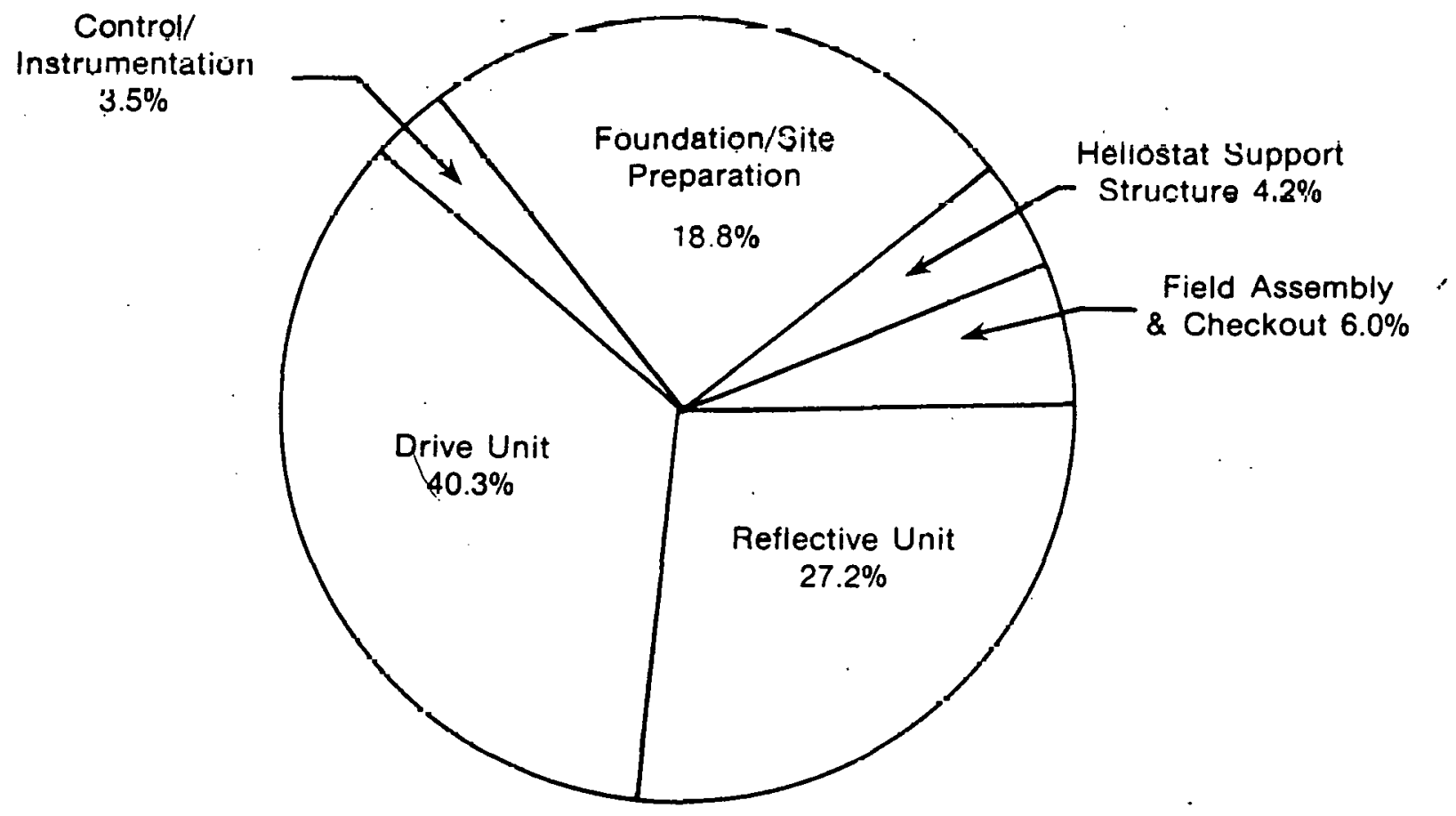

Figure 7-13. Cost Elements of MDAC Heliostat (Based on Production of 25,000 Units/Yr) 


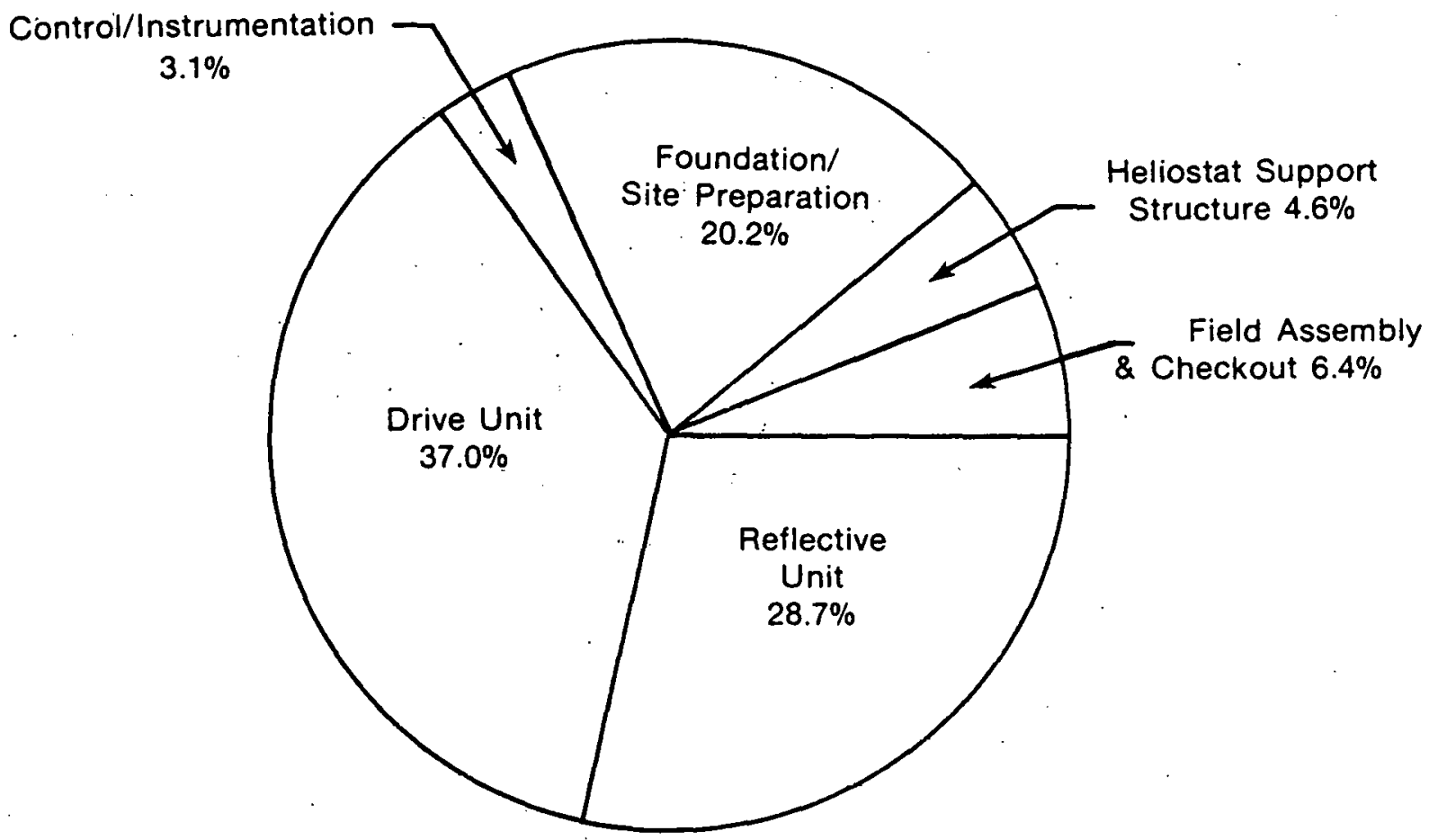

Figure 7-14. Cost Elements of MDAC Heliostat (Based on Production Rate of 250,000 Units/Yr) 


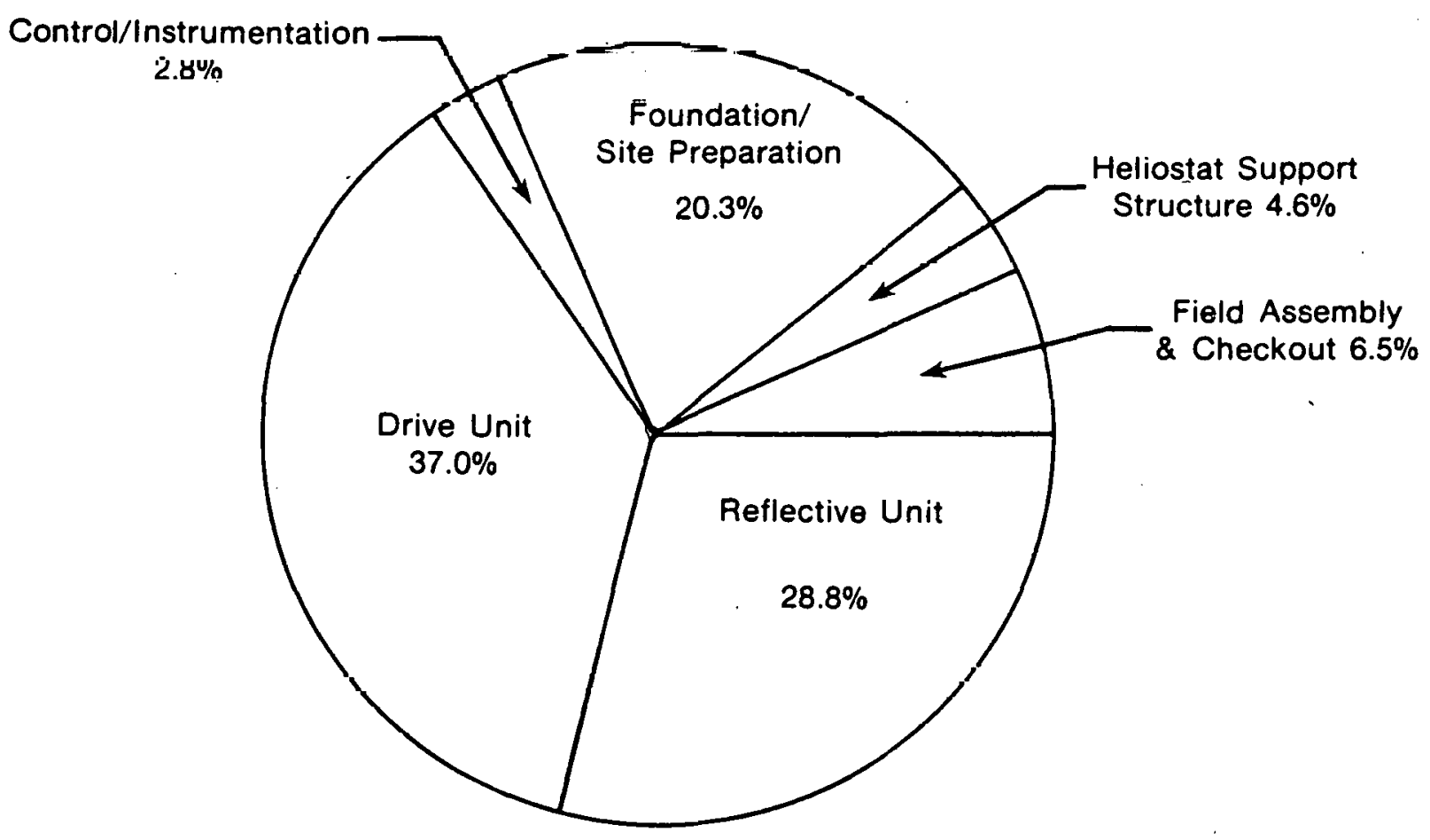

Figure 7-15. Cost Elements of MDAC Heliostat (Based on Production Rate of 1,000,000 Units/Yr) 
The 25,000 units/yr rate has been applied to develop a baseline production scenario for the GE prototype heliostat design. The overall approach for developing a costing scenario is similar to that applied for the MDAC prototype design.

Tables 7-4, 7-5, and 7-6 illustrate the production volume progression on the average unit cost while Fig. 7-16, 7-17, and 7-18 portray the relative changes in structural cost components of the GE heliostat based on production rates under consideration here.

\subsubsection{Baseline Production Concept for 25,000 Heliostats/Yr}

The facility concept for the production of 25,000 heliostats/yr is shown in Fig. 7-19. The plant occupies $3,700 \mathrm{~m}^{2}\left(39,812 \mathrm{ft}^{2}\right)$ and is operated on a 5-day, 2-shift basis using $43 \mathrm{di}$ rect labor personnel. The degree of automation is low.

The average unit cost for an annual production rate of 25,000 is estimated to be $\$ 81.09 / \mathrm{m}^{2}$ reflectivity, a decrease in cost of nearly $55 \%$. Cost improvements range from 40-65\% over those of the pilot 2,500. Major improvements in the cost of the reflective unit, and field assembly and checkout, resulted in decreases of $57 \%$ and $63 \%$, respectively.

\subsubsection{Production Concepts for 250,000 and 1,000,000 Heliostats/Yr}

Tables 7-4 and 7-5 illustrate some effects of increased production rates, plant characteristics, and heliostat cost. As higher levels of production are reached, the degree of both automation and vertical integration increases sharply. The manufacturing facility for 250,000 heliostats/yr is presented in Fig. 7-20.

Production of 250,000 heliostats/yr. necessitates a highly automated facility, divided between two buildings to accommodate expansion. There are 151 direct labor personnel in this plant, representing 1,656 heliostats per person, compared with 581 heliostats per person at a $25,000 / \mathrm{yr}$ production output. At that level of production, an additional 279 people would be required if the automation level remained the same as for a 25,000 heliostat/yr production. However, automation could be greatly increased for 250,000 units/yr.

The 250,000/yr capacity of this facility would be limited only by the areas available for die casting, final assembly, reflector fabrication, and ground cloth fabrication. Through the addition of overtime and/or a limited third shift in these areas, the plant output could be increased to 300,000 heliostats/yr without affecting other areas or operations.

For an increase in production from 25,000 to 250,000 units/yr, the average unit cost decreased another $44 \%$, to $\$ 45.39 / \mathrm{m}^{2}$ reflectivity, primarily because of automation. The reflective unit and the heliostat support and protection subsystem showed the best cost improvements, i.e., decreases of $58 \%$ and $74 \%$, respectively. The drive unit showed a $37 \%$ decrease. The remaining major elements showed cost improvement of $25 \%$ to $33 \%$.

The GE 1,000,000 units/yr production facility consists of multiples of the 250,000 heliostats/yr plant with an appropriate adjustment in film making capability. Two full lines of film machinery would be required as well as additional materials handling equipment. 
Vacuum metalizing of plastic film is now limited to 2.4-m (7.87-ft) widths based on equipment size; the technology has no known limit. Therefore, vacuum metalizing 8.53-m (28- $\mathrm{ft}$ ) widths is possible. Equipment based on the present technology (placing the whole material roll and the take-up reel in the vacuum tank) is expensive. Technology is now emerging that will eliminate the need for these reels to be in the tank, which will greatly reduce the cost of such equipment. The manufacturing plan contains the vacuum metalization of a one-piece reflector only at $1,000,000$ units/yr, and contains vacuum metalizing equipment to handle $2.13-\mathrm{m}(7-\mathrm{ft})$ material at $250,000 / \mathrm{yr}$.

Cutting the reflector to shape can be readily accomplished by a numerically controlled, multiheaded water knife or a tracer-controlled water jet which delivers a high pressure stream of water $.13 \mathrm{~mm}$ (.005 in.) wide. The cutting would be performed while the film is held in place on a vacuum table and a chemically treated swab removes the aluminum at the reflector center. The reflector would then be moved via belt conveyor to another table where adhesive loadstraps would automatically be transported from their fabricating lines by overhead rubber suction devices and placed under the edges nf the reflentor. Pressure would be applied until the adhesive quickly cured; the reflector would be rolled up on protected tynes and slipped into a compartment in the shipping container.

Cost improvements for increases in annual production, from 250,000 to $1,000,000$ units, were not as dramatic as in earlier increases. Average estimated unit cost dropped only $6 \%$, to $\$ 42.88 / \mathrm{m}^{2}$ reflectivity. The most noteworthy cost improvements were in the control and instrumentation and the support and protection subsystems, with decreases of $12-15 \%$. Cost decreases for other subsystems ranged between $2 \%$ and $6 \%$. The small decrease indicates that automated manufacturing techniques may reach a maximum use level, and demonstrates that heliostat costs have here nearly reached a plateau on the learning curve, unless further technical advances are made.

Installation. The typical installation sequence is illustrated in Fig. 7-21. Several of the initial steps in this process are performed by a device called the Automatic Foundation Machine (AFM). The AFM performs the following functions:

- Accurately surveys and locates the center hole for mounting the heliostat;

- Trenches and buries the power distribution cable and lightning grid wire between heliostat stations;

- Drills the heliostat support pipe foundation into the ground; and

- Trenches, inserts plastic, fills with excavated soil, and closes the ring bag enclosure foundation.

After these steps are completed, workmen place a cloth over the ground within the ring bag, zip together the enclosure and foundation bag, inflate the enclosure, and assemble the heliostat within it.

Weight Breakdown. Estimated weight for the various components of the prototype heliostat are the same as those shown in Table 6-3.

Cost Breakdown. Estimated costs for the prototype heliostat at production levels are given in Table 7-5 [34]. 
Table 7-4. GE HELIOSTAT COST COMPARISON

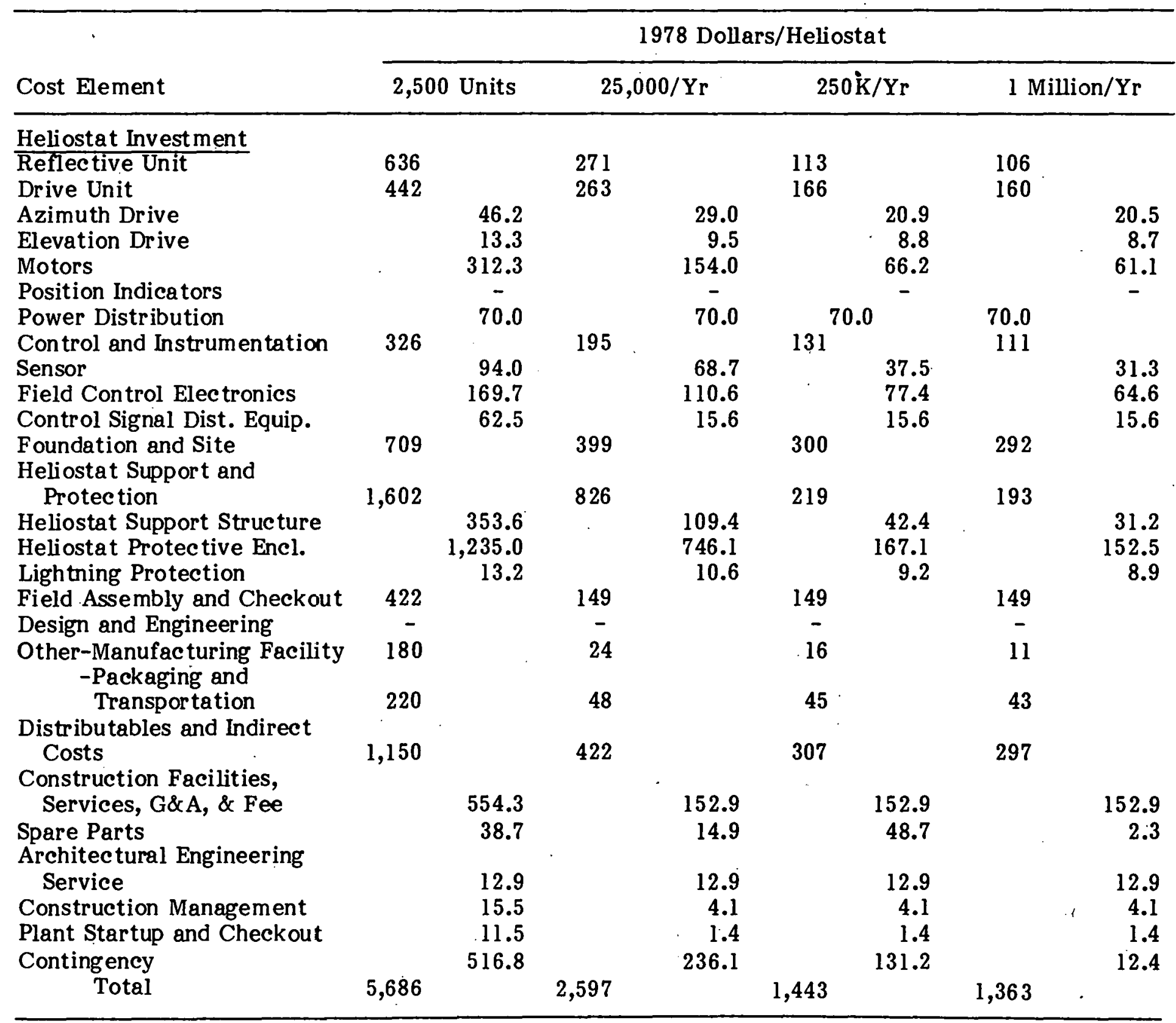


Table 7-5. PROJECTED COSTS FOR GE HELIOSTAT DESIGN (1978\$)

\begin{tabular}{rcccc}
\hline $\begin{array}{c}\text { Production } \\
\text { Level }\end{array}$ & $\begin{array}{c}\text { Installed Equipment } \\
\text { Investment Costs } \\
\text { (in thousands of dollars) }\end{array}$ & $\begin{array}{c}\text { Operation and } \\
\text { Maintenançe } \\
\text { Costs } \$ / \mathrm{m}^{2}\end{array}$ & $\begin{array}{c}\text { Heliostat } \\
\text { Installed } \\
\text { Cost }\end{array}$ & $\begin{array}{c}\text { Heliostat } \\
\text { Cost } \\
\$ / \mathrm{m}^{2}-\mathrm{R}\end{array}$ \\
\hline $1,000,000$ & 171,619 & 26.77 & $\$ 1,363$ & 42.88 \\
250,000 & 64,254 & 27.24 & $\$ 1,443$ & 45.39 \\
25,000 & 13,351 & 50.48 & $\$ 2,597$ & 81.09 \\
2,500 & 1,264 & 79.73 & $\$ 5,686$ & 178.83 \\
\hline
\end{tabular}

\subsection{STEADY-STATE PRODUCTION VOLUME AND COST VARIATION}

Although the information presented in previous sections provides an accurate summary of the design and baseline production scenario for each of the heliostat designs, it should be recognized that it represents only one of many possible scenarios. This subsection demonstrates how changing market growth and location, competition, basic design, available production technology and resources, and government and business policy affect the establishment of an effective, steady-state production process in cumulative production along with the associated first-unit cost for the steady-state scenario. The manufacturing and installation of the MDAC prototype heliostat design is an example.

\subsubsection{The MDAC Prototype Heliostat Design}

The prototype heliostat study implied that the 125 thousandth unit is the cumulative volume point at which an effective, steady-state production process is established for the baseline scenario. The rationale for this assumption is that certain electronic components will not be available until 1985, and a market will not develop that will support a rate of $25,000 / y r$ until 100,000 units have been produced. An additional plant startup of one to two years or 25,000 units will stabilize production in the new plant. On the whole, this is a conservative projection. It is passible that because of market or fiscal incentives or production alternatives, the facility could be installed well before 100,000 units are reached. Also, many elements (especially buy items procured from the industrial base) may reach a steady state well before the first facility goes into operation. On the other hand, designs and production methods never fully stabilize and breakthroughs will continue long after the first 100,000 units of production. These aspects may be illustrated through a brief overview of expected developments in heliostat design, production methods, and cost from early test programs to the installation of the baseline 25,000 units/yr facility.

\subsubsection{Production Scenario Progression}

Changes in the production scenario are viewed in three parts: (1) test hardware to pilot plant, (2) pilot production to demonstration and early commercialization, and (3) continuation to Nth unit of production. 
Table 7-6. 10,000 HELIOSTATS/YR STEADY-STATE

PREIIMIN ARY COST BREAKDOWN

(1978\$)

\begin{tabular}{|c|c|c|c|c|}
\hline \multirow[b]{2}{*}{ Cost Element } & \multirow{2}{*}{$\begin{array}{l}\text { Labor } \\
\text { Dollars }\end{array}$} & \multicolumn{2}{|c|}{ Material Dollars } & \multirow[b]{2}{*}{ Total } \\
\hline & & Parts & Raw Material & \\
\hline Reflective Unit & $\$ 129$ & $\$ 856$ & $\$ 103$ & $\$ 1,088$ \\
\hline Drive Unit & 233 & 1,088 & 284 & 1,605 \\
\hline Control & 74 & 160 & - & 234 \\
\hline Foundations/Site Prep & 532 & 187 & 112 & 831 \\
\hline $\begin{array}{l}\text { Heliostat Support } \\
\text { Struc ture }\end{array}$ & 32 & 1 & 132 & 165 \\
\hline Field Assembly and $\mathrm{C} / \mathrm{O}$ & 300 & 1 & - & 301 \\
\hline Total & $\$ 1,300$ & $\$ 2,293$ & $\$ 631$ & $\$ 4,224$ \\
\hline $\begin{array}{l}\text { Adjustments: } \\
\text { Reflective Units } \\
\text { Foundation }\end{array}$ & $\overline{-}$ & $\begin{array}{l}(856) \\
(187)\end{array}$ & $\begin{array}{l}856 \\
187\end{array}$ & - \\
\hline Adjusted Total & $\$ 1,300$ & $\$ 1,250$ & $\$ 1,674$ & $\$ 4,224$ \\
\hline
\end{tabular}




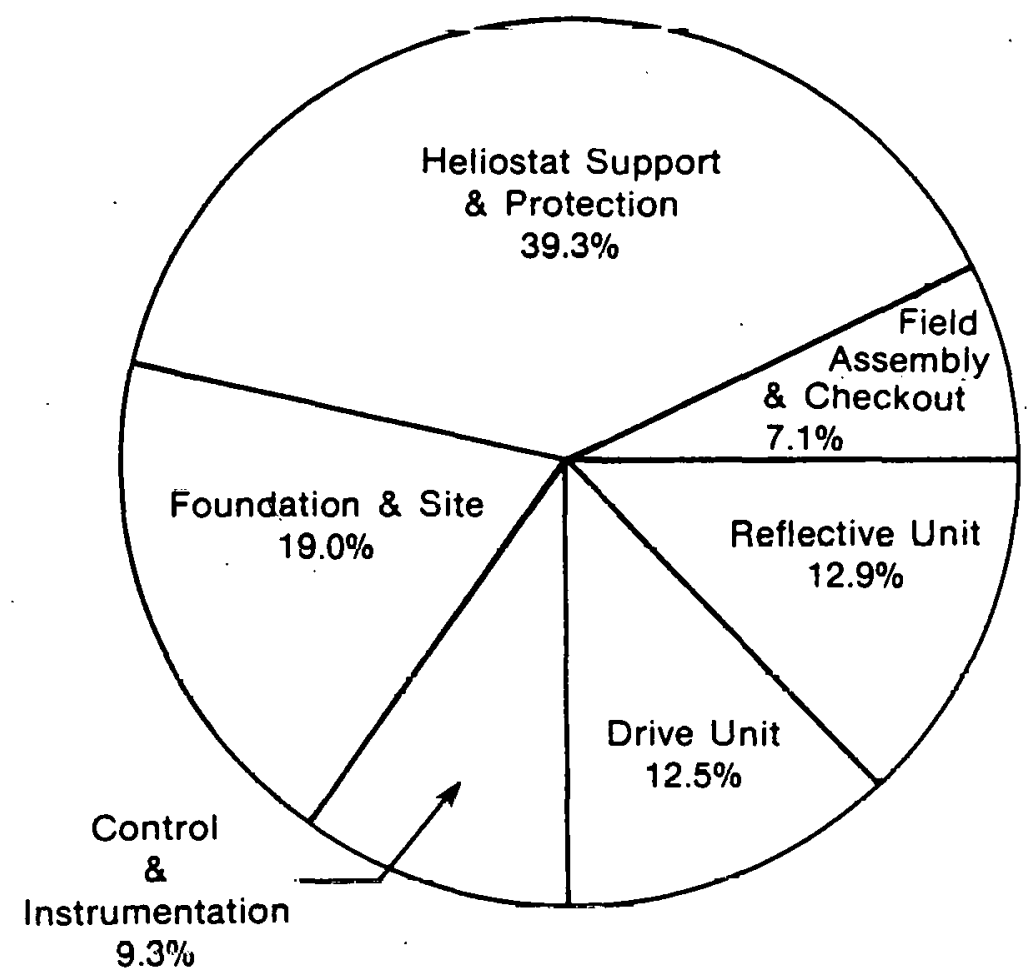

Figure 7-16. Cost Elements of GE Heliostat (Based on Production Rate of 25,000 Units/Yr) 


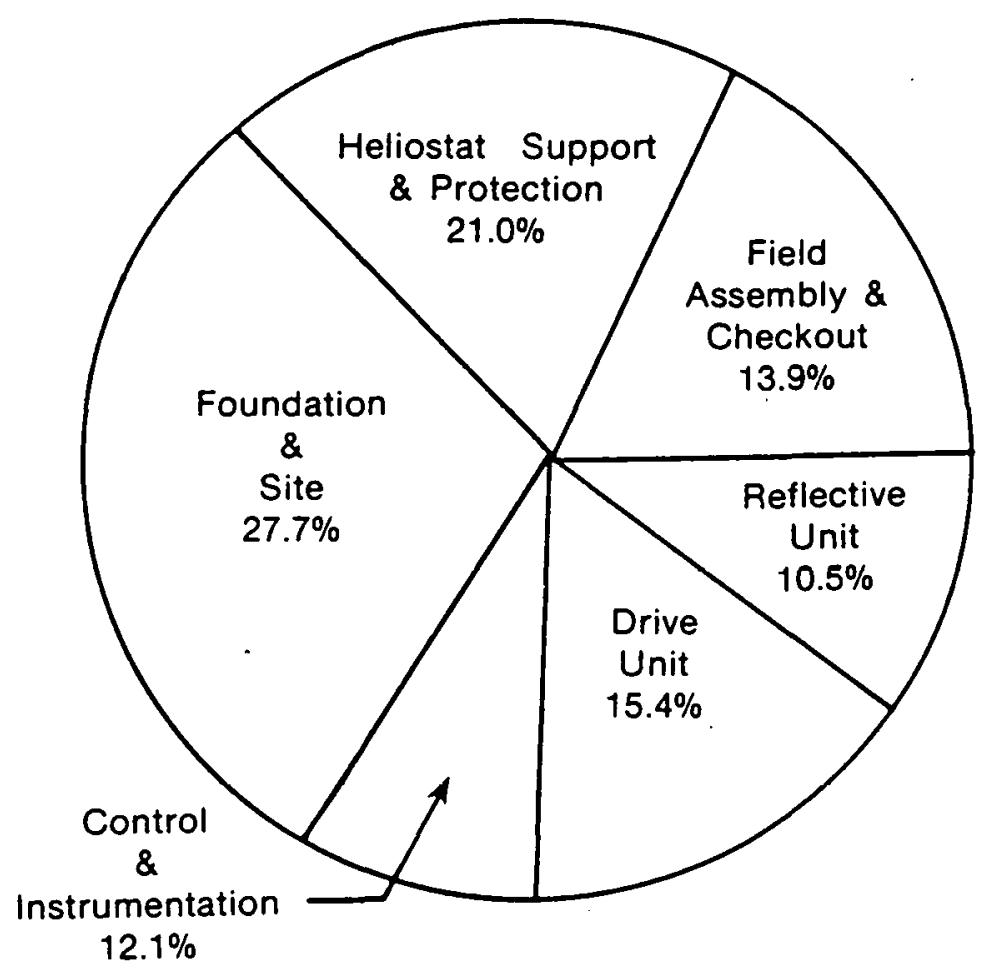

Figure 7-17. Cost Elements of GE Heliostat (Based on Production Rate of 250,000 Units/Yr) 


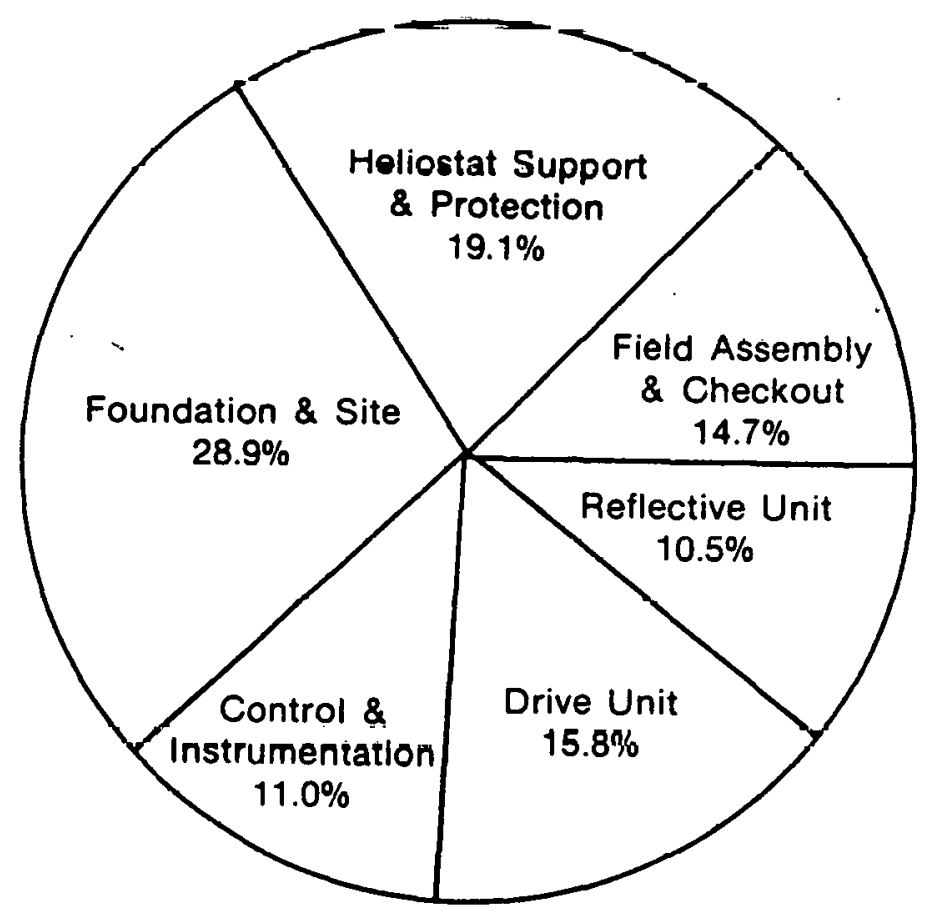

Figure 7-18. Cost Elements of GE Heliostat (Based on Production Rate of $1,000,000$ Units $/ \mathrm{Yr}$ ) 


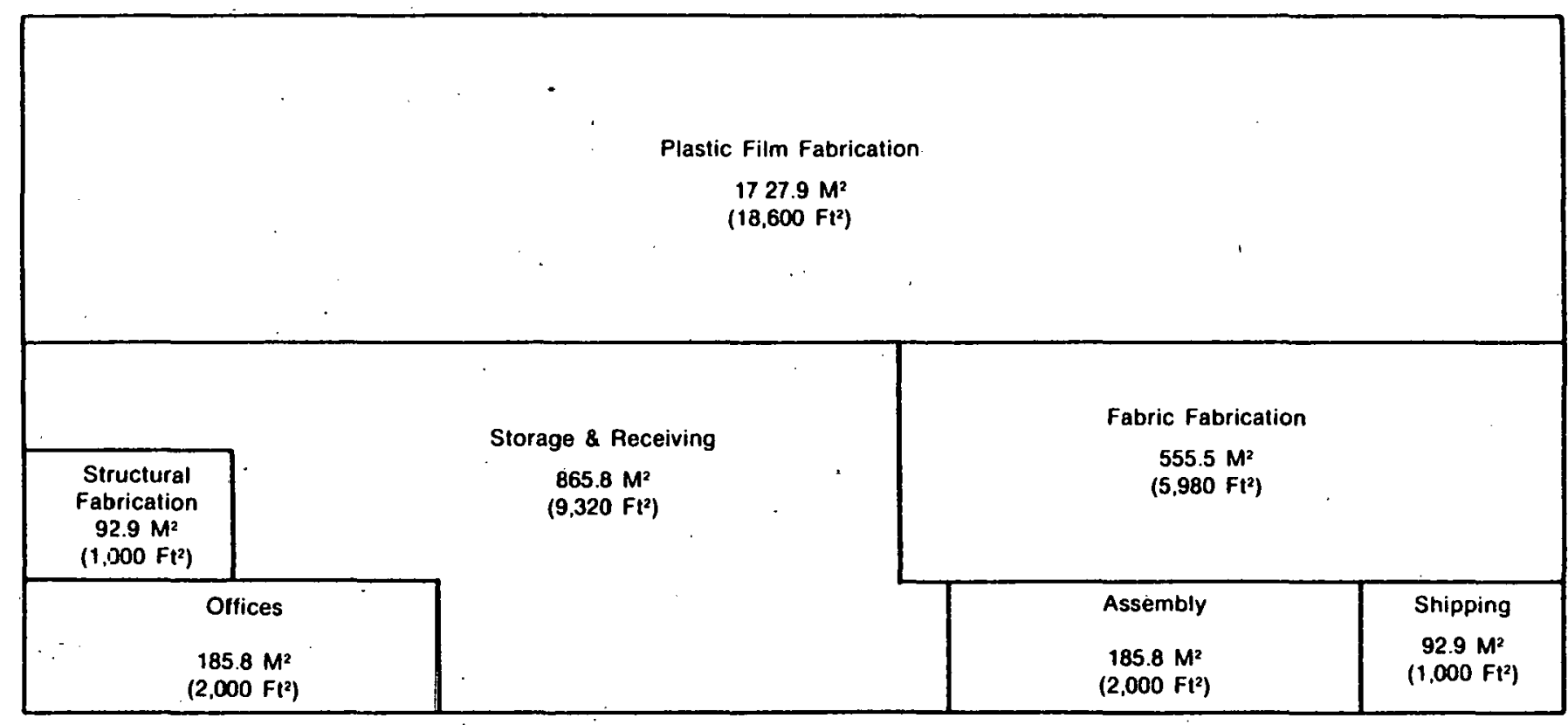

$3706.6 \mathrm{M}^{2}$ $\left(39,900 \mathrm{Ft}^{2}\right)$

Scale

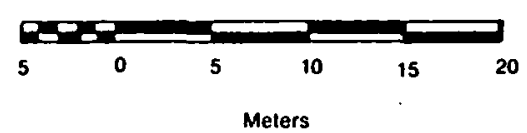

Figure 7-19. Manufacturing Facility for 25,000 Heliostats/Yr 

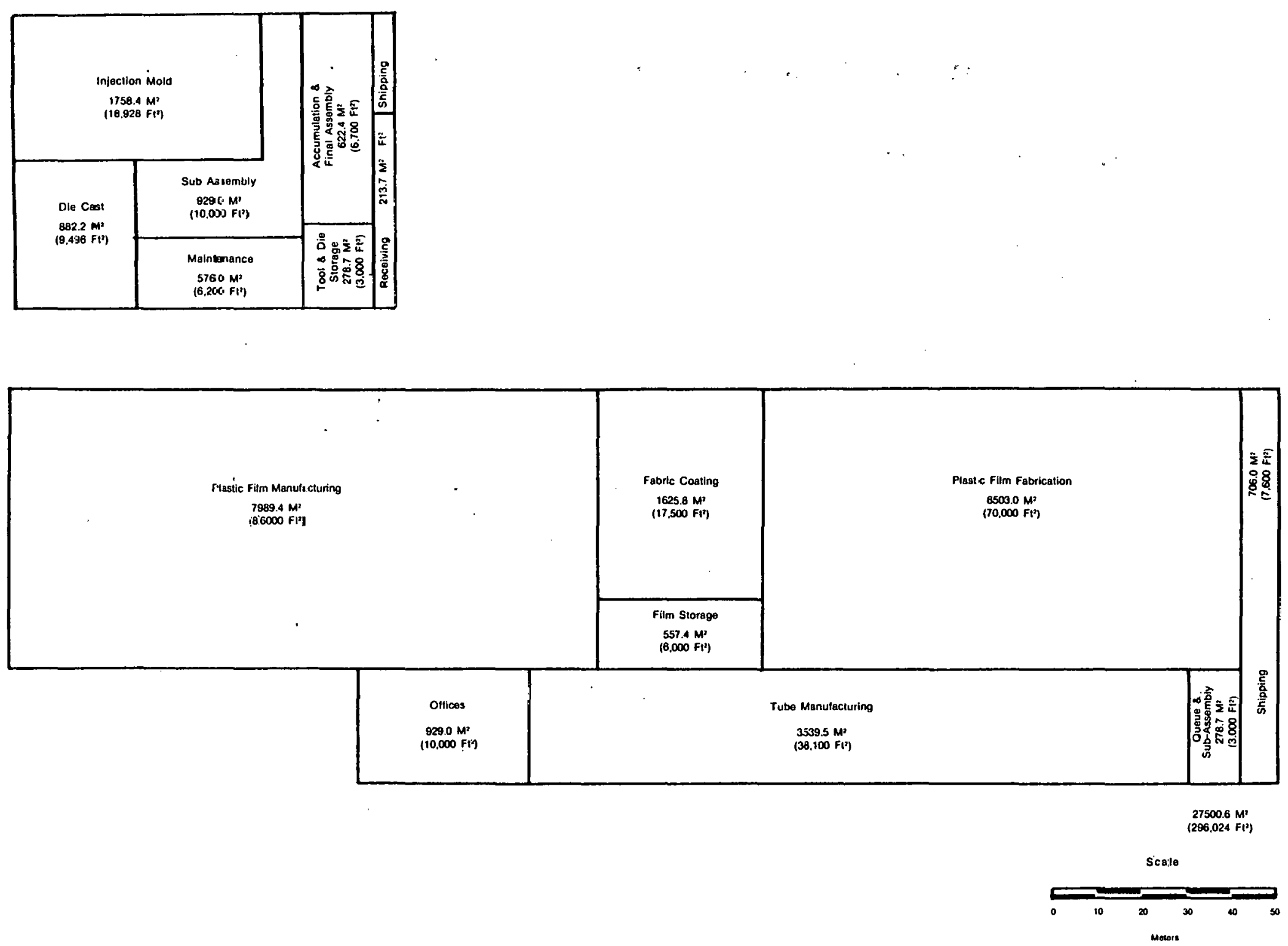

Figure 7-20. Manufacturing Facility for 250,000 Heliostats/Yr 


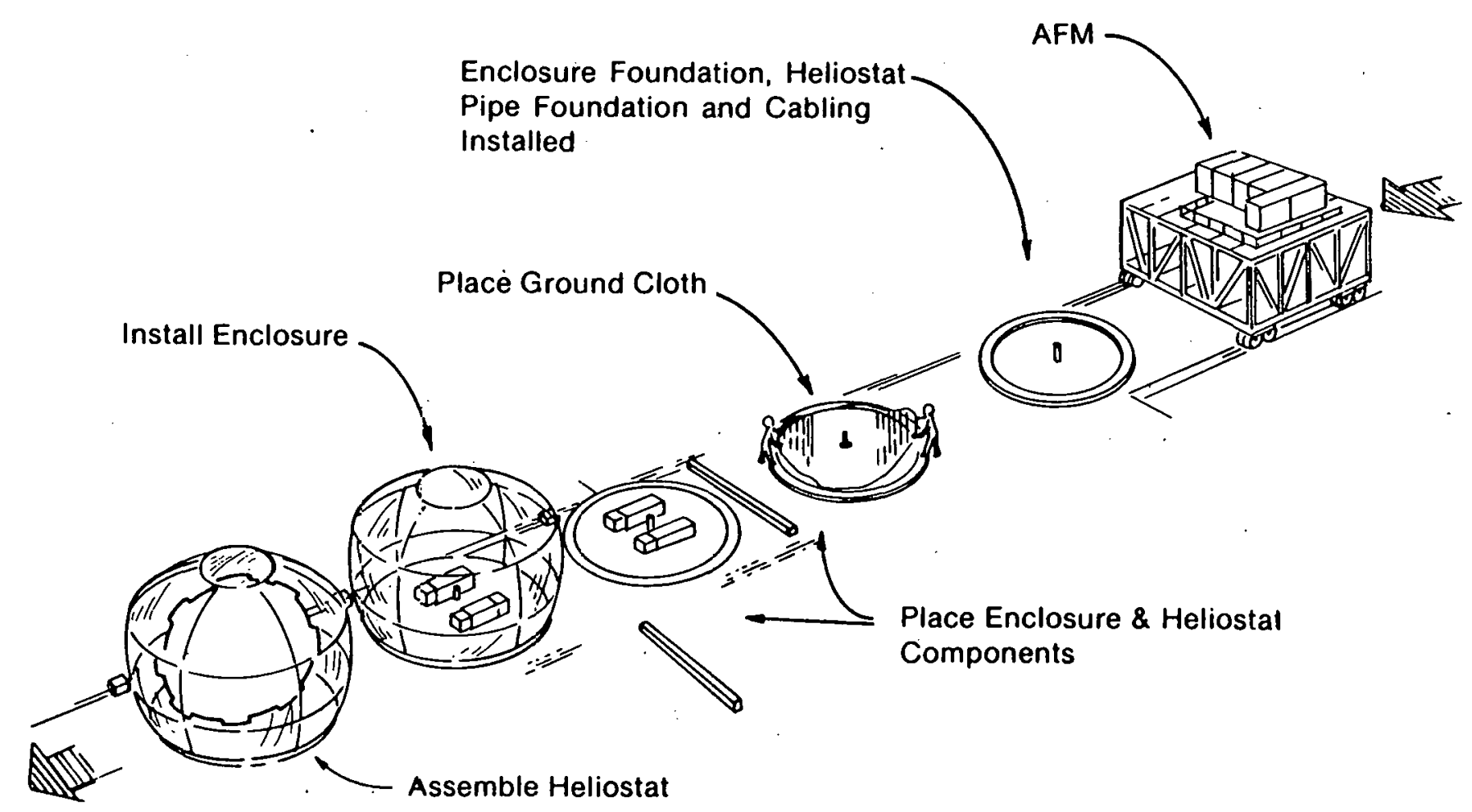

Figure 7-21. Typical Heliostat Installation Sequence 
Test Hardware to Pilot Plant. The National Science Foundation heliostat, the Subsystem Research Experiment (SRE) hardware, and other future preproduction articles (i.e., hardware constructed in small quantities in order to verify design/production feasibility) have been or will be produced in a typical way for test hardware using soft tools (nonpermanent) and experiencing all the usual delays and first-time production problems. The nature of test hardware construction, if not trial and error, is at least one of a close, informal, and exacting association between engineers and manufacturing personnel.

Further, materials may not be delivered on time, they may be overprocured, or they may come in totally "out of spec," and setup times and vendor tools must be allocated over only a few units. Often, items must be reworked, causing additional setup or changes in tooling. Finally, a great deal of time may be spent in working out specific methods for actually accomplishing particular manufacturing operations. As a result, labor and overhead are typically 5-15 times the cost of material, and materials are 4 or 5 times what they might cost for a pilot procurement.

The first major breakthrough in cost reduction will occur in the Barstow pilot plant heliostat production. A production design is available and the quantities allow hard tooling, procurement discounts, scale economies, and standardized processes and balanced production flows typical of a working operation. It is difficult to project a true first-unit cost for such a scenario for comparison with test-unit cost because material costs are based on vendor quotes for entire quantities, while labor hours are based on industrial engineering standards for a working production line. However, a synthetic first-unit cost, developed by extending unit pilot-plant costs on typical cost reduction curves, would be only a quarter to a third the actual test article unit cost. Overall, labor and overhead costs for pilot production will nearly equal materials costs and the average unit hours of labor will be about $10 \%$ of the unit hours for the test articles.

Further cost reductions may occur in follow-on pilot production as a result of design-tocost analysis. However, since ever-changing designs tend to inhibit cost reduction, much of the potential will be latent, with changes apparent only where costs are immediately designed out (e.g., elimination of inversion or of the site assembly facilities). Otherwise, the basic production facilities will change very little and each design variation will require essentially a restart of production for the aff ected assemblies.

Pilot Production to Demonstration and Early Commercialization. As a result of preproduction and pilot production programs, a relatively firm design that will be suitable for commercial production is expected to evolve. The prototype heliostat is representative of such a design, although several changes have already been examined since completion of the study. This design allows considerable flexibility as to where and how the major assemblies are fabricated and assembled.

I'he potential for strong but intermittent and uncertain growth in demand for any manufacturer's product may give $r$ ise to a conservative attitude toward expansion. A rational expansion scenario suggests that modifying and expanding existing pilot facilities, in conjunction with added shifts and overboarding, and taking advantage of available capacity in other facilities, are necessary. Continued extensive procurement from other industries will limit expansion pressures on resources, allowing much of the expansion to be industrially financed. As a result, many of the purchased parts will have reached an established production status at this point. 
Cost-effective changes in the plant will reflect labor learning and management learning-about organizational requirements, production line flows, and so for th. As volume expands, the manufacturer will be in a better bargaining position with suppliers, scale benefits will become apparent, and it may become necessary or cost-effective to add or upgrade some equipment. Also, cost-effective design improvements that develop or were planned as part of the prototype scenario but deferred until available, proven, or volume justified may be incorporated on a part-by-part basis. In sum, although this is a cautious, "make-do" period of expansion, a considerable cost reduction potential exists.

Early Commercialization to Nth Unit of Production. The primary issue during this period is when and how the change-over to a large-scale, independent production facility should occur. At least two possibilities exist. The first is to continually expand an existing facility with added and upgraded equipment until a steady $25,000 / \mathrm{yr}$ production rate is achieved. This could cause some market share to be lost if cost reduction oppor tunities are delayed or capacity is reached before the new facility is completed.

The other possibility is to make the move when less than half of the $25,000 / \mathrm{yr}$ rate is reached. This could occur as early as the demonstration/early commercial period. As already indicated, the facility may be operated on a one-shift basis at reduced capacity with deferred purchase of some equipment. The most likely candidates would be cer tain au to matic transfer equipment, or similar equipment (such as a bonding table).

Although the per-heliostat cost of the facility may double in the short run, the increment may be small compared with the savings potential of the new facility. It is likely that the increase would be more than compensated by a reduction in average labor rate, reduced hand labor headcount (i.e., "hands-on" workers producing hardware either directly or through operation of equipment), reduced overhead, and increased productivity caused by increased output per shift. As volume increases, the deferred equipment may be added along with the second shift, contributing further to productivity and scale benefits. In addition, further procurement advantages will become apparent as suppliers recognize both increasing volume and the growing stature of the program.

\subsubsection{The Point of Steady-State Production}

The point of steady-state production may be defined as that point in cumulative production volume where the only design changes permitted are those that may modify a part for more cff ective production or performance, are for the primary purpose of cost reduction, and will maintain a stable interface with other part concepts and designs. Similarly, the production process is a working, "debugged" operation representative of the eventual rate production plan. Generally, changes will be logical extentions of or improvements up on existing processes, made only if the change permits a favorable rate of return and involves an acceptable risk.

This definition does not exclude changes, but it is clear that research experiments, preproduction, and even pilot heliostat production facilities do not qualify because of their uncertainties. It is equally clear that the prototype heliostat baseline production scenario would qualify because it is a steady-state scenario by definition. As conceived, this scenario provides for the production and installation of 25,000 heliostats/yr, but by operating on a one-shift basis, somewhat reducing line speed, and cutting the number of field crews in half, identical facilities and equipment may be operated with a minimal, acceptable economic penalty at a rate of 10,000 heliostats/yr, or less. Thus, the prototype 
baseline scenario, with minor modification, also may be used to describe a steady-state production situation that could occur at a fairly early stage of cumulative production.

Accepting the modified scenario, the issue becomes a matter of determining how early an aggressive and dominant producer would plan initial operations in a new facility capable of producing approximately 10,000 heliostats/yr. In other words, at what point may the new production plant's initial operating capability (IOC) be aligned with the producer's cumulative sales volume expectations? Prior to this point in a producer's cumulative volume, it may be assumed that the production scenario is in an unstable state where designs and production plans are still subject to important changes. It follows that the determination of this point should provide the earliest stage in cumulative production volume, where it would be feasible to initiate operations under the defined steady-state production scenario.

Relative to a market projection, this point of interest may be further defined as the earliest point in cumulative demand for a dominant producer's product, after which further demand is able to absorb all the producer's future output at or greater than the steadystate production rate. A review of demand growth projections reveals the following production requirements:

- By the end of 1982 , all suppliers will have produced 10,000 heliostats.

- During 1983 and 1984, an additional 10,000 heliostats will be supplied each year.

- In 1985, all suppliers must produce an additional 20-25,000 units in order to meet demand projections.

- During 1986, 1987, and 1988, demand will approach 100,000, 150,000, and 300,000 heliostats, respectively.

- Demand will continue to expand from 1988 through the turn of the century.

Accepting this market projection, an aggressive supplier desiring $40-50 \%$ of the market could plan its new facility IOC in 1985, in time to produce its 15,00 lst heliostat in accordance with the modified baseline scenario. This corresponds to the electronics technology readiness date, and all other part configuration and production processes described as part of the prototype heliostat baseline production scenario. Assuming a 12month startup, during which 5,000 heliostats are produced, the actual steady-state status will be achieved when the supplier has produced a cumulative total of 20,000 heliostats15,000 of other designs in other facilities and 5,000 of the prototype heliostat design.

Whether or not this occurs in the manner described depends on how the individual firm ac tually views the strength of the market and associated risks. Of course, the strength of the market depends on the quoted price of heliostats relative to alternative energy costs, and the extent of incentives for both suppliers and users. These variables are still unknown. However, if successful cost reduction results in preproduction, pilot, and demonstration programs, by 1983 a manufacturer should be able to demonstrate to its own satisfaction that a move into baseline facilities will permit heliostat price quotes that are quite competitive with alternate energy costs. As a result, an effective, steadystate production status for an aggressive, dominant supplier at the 20,000th unit is not an unreasonable projection under the circumstances. 


\subsubsection{First-Unit Costs}

First-unit cost may be defined in a number of ways, depending on the perspective of the analyst. In a development firm, it may be the cost of the first test article with or without a nonrecurring engineering allocation, or a synthetic value extended from industrial engineering standards that have been determined at, say, the 100 th unit of production.

A materials buyer for a new product may see the first-unit cost of a procured item as the average cost of the first lot in the door. The seller of the same item may see the price charged as that which the market will bear in order to recover a margin plus the average cost to produce the item during the current year. The true first-unit cost for the item may be some unknown amount that occurred many years earlier. In a steady-state case such as this, the analyst is likely to consider the first unit cost as the sum of the cost per unit at the steady-state production rate plus an allocation of the incremental startup costs that may be associated with introduction of a new model, introduction of new production equipment, or the initiation of a new production facility.

A marketer may be interested in developing a synthetic first-unit cost for use as a reference in formulating downline pricing strategy. For this purpose, a product's current cost experience must be aligned with a unit of cumulative sales volume, as suggested in the previous subsection, and the cost extended back on a historically representative cost reduction slope to arrive at the synthetic first-unit cost. The resulting cost is synthetic because it represents a situation that usually is only hypothetically implied by current production characteristics and the slope of the applied cost reduction curve. The relationships between these definitions for the modified scenario will become more apparent when the steady-state cost is quantified.

\subsubsection{Development of Steady-State Unit Costs}

The steady-state unit cost for the modified prototype heliostat scenario is developed using two different methods. Both methods adjust the detail costing results presented in the prototype heliostat study final report for the 25,000-unit production rate. The first method uses an aggregate resource impact approach, while the second employs cost reduction curves applied to each detail line item. Both approaches arrive essentially at the same total price at unit 20,000. Labor and overhead, however, are somewhat higher in cost for the resource impact approach.

The results of the first method are shown in the steady-state cost column of Table 7-7. They address the four basic cost categories: factory labor, raw materials, purchased parts, and field labor. The concept is to develop a logical adjustment reflecting the changes in the scenario that permit reduced annual output. Since facilities and equipment remain the same, factory and field labor per unit stay essentially the same since total labor would be cut in half in going from two shifts to one. However, to produce 10,000 units/yr, line speed must be reduced $20 \%$, which is assumed to increase hand labor $25 \%$. As a result of reduced use of the plant, the scale effect must be considered so that overhead is assumed to be $50 \%$ higher. Capital cost per unit will be somewhat more than double, while fringe benefits and a large share of other overhead items will vary more directly with labor hours per unit. Direct support-including items such as sustaining tooling, industrial engineering, quality assurance, and manufacturing engineering-are also assumed to increase $50 \%$ for reasons of scale. 
Table 7-7. STEADY-STATE COSTS

\begin{tabular}{|c|c|c|c|c|}
\hline \multirow[b]{2}{*}{ Element } & \multirow[b]{2}{*}{$\mathrm{CRC}$} & \multicolumn{3}{|c|}{ Costs $(1978 \$)$} \\
\hline & & $\begin{array}{l}\text { Steady-State } \\
\text { Costs at } 20,000\end{array}$ & $\begin{array}{l}\text { Synthetic } \\
\text { lst Unit }\end{array}$ & $\begin{array}{l}\text { Effec tive } \\
\text { lst at } 500\end{array}$ \\
\hline Factory Labor & $89 \%$ & $\$ 468$ & $\$ 2,973$ & $\$ 870$ \\
\hline Raw Material & $98 \%$ & 1,674 & 2,301 & 1,864 \\
\hline $\begin{array}{l}\text { Purchased } \\
\text { Parts }\end{array}$ & $92 \%$ & 1,250 & 4,667 & 1,948 \\
\hline Field Labor & $98 \%$ & 832 & 1,152 & 933 \\
\hline Total & $94 \%$ & $\$ 4,224$ & $\$ 11,103$ & $\$ 5,615$ \\
\hline
\end{tabular}


These adjustments have been applied to the labor and overhead costs at the prototype heliostat's resource loaded peg point-the 125,000th unit. Costs were adjusted down a learning curve from this point to the 350,000th unit, and are thus slightly lower than costs used for the adjustments described previously. Use of the costs at the peg point provides a more direct connection to the actual manloads developed for the prototype heliostat report.

Materials costs were adjusted to include discounts. These costs were quoted by suppliers at rates of 25,000 units/yr over several years and reflect suppliers' discounts for fairly large quantities. At $40 \%$ of these quantities, the discounts will be less. The changes in discount are assumed as follows:

\begin{tabular}{lccc} 
& \multicolumn{2}{c}{$\%$ Discount } & $\begin{array}{c}\text { Price } \\
\text { Impact }\end{array}$ \\
\cline { 2 - 3 } & 10,000 & $\underline{25,000}$ & \\
Raw Materials & $15 \%$ & $25 \%$ & 1.13 \\
Installation & $26 \%$ & $40 \%$ & 1.23
\end{tabular}

The discount factors are based on cost analysis judgment, and the price impact shows the increase applied to materials prices. For this analysis, all reflector unit and foundation materials costs were treated as raw materials, although the prototype heliostat final report classified some of these elements (such as the sheet steel beams) as purchased parts.

The cost-reduction curve method extends the costs shown in the prototype heliostat report from the 350,000 th unit (i.e., the midpoint unit in the 25,000 th unit/yr scenario) back to the 20,000th unit. The same curves have been used that were employed to extend the midpoint cost of the $25,000 / \mathrm{yr}$ baseline out to the midpoint cost projected for the 250,000 unit/yr scenario. If labor increases approximately $10 \%$ a cost breakout is provided that ties in with results determined using the resource impact approach.

Table 7-7 also shows the results of adjusting the steady-state cost column, using the cost reduction curves shown, to reflect a synthetic first-unit cost and the effective cost at plant startup. The latter is calculated as the synthetic cost of the five hundredth unit, and is based on the determination that 500 units of equivalent experience are applicable to a calculation of plant startup costs.

Figure 7-22 shows these costs plotted in a log-log relationship. Translating a steadystate cost to an actual point on a cost-reduction curve can cause controversy. It is clear that the cost should not be plotted as a first-unit cost, if only because the second unit would be expected to be significantly less costly, while the average change in cost between units in steady-state production will be very small. Similarly, it is probably not preferable to plot the cost at even several thousand units further out in cumulative volume. A point is finally reached, however, where such empirical arguments fade, so that the alignment of the steady-state cost and a point on a cost-reduction curve finally must be based on a feel for circumstances, some logic, and no small amount of judgment.

The steady-state cost is plotted at the 20,000th unit reflecting the attitude that the steady-state cost actually represents costs associated with one heliostat's worth of resources and production time where the employment of resources is exactly as described, and the 20,000 th unit is the earliest probable point where this situation exists exactly as defined. Prior to this point, the producer will not have deployed and utilized this set of resources as defined because of market conditions, technological conditions, and startup problems. After the steady-state is reached, as defined, the resources and the manner of 


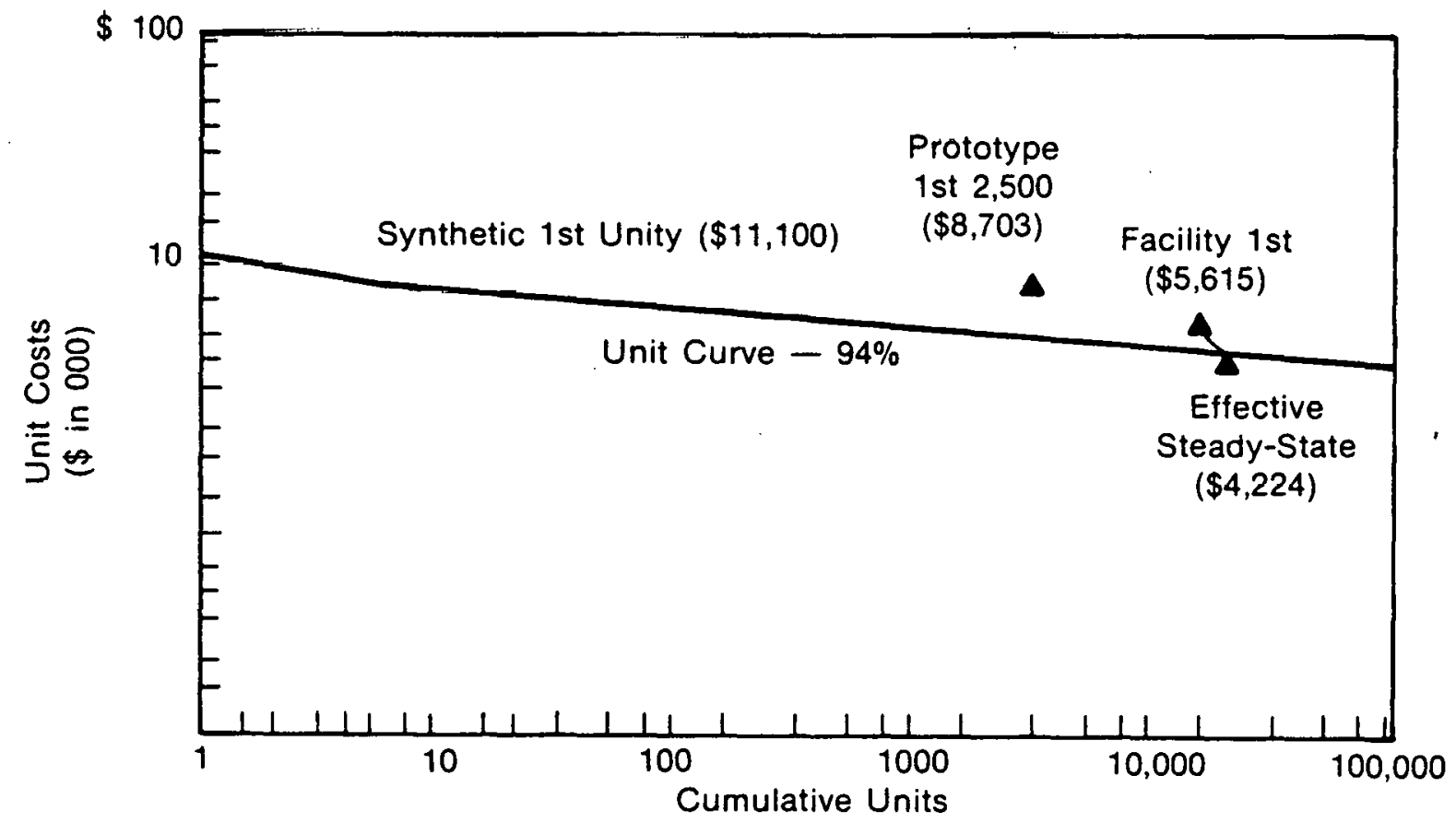

Figure 7-22. Unit Curve Plot 
their employment will immediately start to change in response to market growth, innovation in product, process, equipment and manufacturing flows, influence on suppliers, and similar cost reduction issues. Obviously, there is a margin of expectation in this analysis, so that the projection must be carefully considered.

The synthetic first-unit cost, as defined earlier, is also plotted along with the effective first cost after plant startup using the data shown in Table 7-7. The plant startup cost is plotted at unit 15,000 and shows a rapid drop to the steady-state cost as prior heliostat experience is used and production schedules and plans are brought to rate production definition. These points are presented more to illustrate the concepts than as basic parameters since they will vary around the steady-state projection, depending on the way a firm conducts its business and responds to market conditions.

The cost reported in the prototype heliostat study for the first 2,500 units is also plotted for purposes of comparison. This cost reflects the prototype heliostat design but not the steady-state production scenario. These heliostats are assumed produced in a pilotplant-like production facility geared to a lower rate of production. The projected cost is approximately $75 \%$ greater than the unit cost curve at 2,500 units, which is about what is expected for this scenario since labor and overhead rates nearly double, production equipment is much less sophisticated, procurement is apparent for only 2,500 units rather than 10,000 units/yr, and many production uncertainties still exist.

These projections have been developed using relatively general cost analysis methods that could be accomplished within the scope of the study. A more complete analysis would obtain vendor quotes for each item of material at the production rates involved. Also, the impact on overhead and direct support labor would be examined in greater depth, and hand labor would be reviewed in detail in order to carefully screen the impact of line speed and double- to single-shift adjustments. Although a fair amount of revision of the detail costs might be necessary if a more comprehensive analysis were needed, aggregate costs are probably within a reasonable range of accuracy. Even so, the main intention of this analysis has been to provide sufficient credible data so that the expectations presented in this report may be adjusted to fit any variation in production circumstances that might be considered. Above all, it should be recognized that the market and production scenarios, logic, and costs that have been presented here represent only one of many ever-changing alternatives to the design, production, and marketing of heliostats. 


\section{SEPr}




\section{SECTION 8.0}

\section{DEVELOPMENT OF LEARNING AND COMPOSITE CURVES POR COSTS ASSOCIATED WITH HELIOSTAT PRODUCTION*}

The development of learning and composite curves, outlined in Sec. 3.0, can help predict overall cost reduction in manufacturing the MDAC and GE prototype heliostat designs. The objective here is to project future costs for these designs using surrogate cost history and the learning curve conceptual and analytical framework. First, selection of surrogates will be discussed, followed by estimations of the learning and cost curves for surrogate products, and applications to heliostat assembly.

\subsection{SELECTION OF SURROGATES}

Each of the two heliostat designs has been broken down into its components for purposes of cost analysis by both McDonnell Douglas Company and General Electric. The components are designated by WBS name and number as shown in Table 8-1.

Not all of the components and subassemblies are applicable to both contractors' designs. Surrogates for cost analysis have been chosen for selected components on the basis of the following criteria:

- The relative impor tance of the component to the contractor's design;

- The relative contribution of the component to the total cost of the design; and

- The likelihood of availability of a meaningful surrogate having a body of historical data.

The initial choice of components and surrogates to be analyzed and the design to which they are applicable is given in Table 8-2. As the study proceeded through the data collection phase, it became evident that other surrogate selections should be considered in addition to or instead of those originally specified. An expanded listing of surrogates used for this study is shown in Table 8-3.

The surrogates that were finally used for this study were chosen because manufacturing operations between the surrogate and the heliostat components were close and reliable cost data were available. In several instances, the first surrogate chosen had to be changed. to another because of a lack of historical cost data. In other instances, as the study progressed, more appropriate surrogate parts with cost data became available. The changes made to the list of surrogates can be seen by comparing the surrogate selections in Tables 8-2 and 8-3.

*This section summarizes material presented in the report, "Development of Surrogate Experience Curves for Custs Associated with the Production of Heliostats," prepared by Arthur D. Little, Inc., for SERI. 
Table 8-1. HETIOSTAT DESIGN COMPONENTS

\begin{tabular}{|c|c|}
\hline WBS Number & Part or Subassembly Name \\
\hline $\begin{array}{l}4410 \\
4411 \\
4412 \\
4413\end{array}$ & $\begin{array}{l}\text { Reflective Unit } \\
\text { Reflective Surface } \\
\text { Mirror Back Structure } \\
\text { Assembly and Bonding }\end{array}$ \\
\hline $\begin{array}{l}4420 \\
4421 \\
4422 \\
4423 \\
4424 \\
4425 \\
4426\end{array}$ & $\begin{array}{l}\text { Drive Unit } \\
\text { Azimuth } \\
\text { Elevation } \\
\text { Motors } \\
\text { Positiun Indleutors } \\
\text { Power Distribution } \\
\text { Assembly of Drive and Pedestal }\end{array}$ \\
\hline $\begin{array}{r}4430 \\
4431 \\
4432 \\
4433\end{array}$ & $\begin{array}{l}\text { Control and Instrumentation } \\
\text { Sensor } \\
\text { Field Control Electronics } \\
\text { Control Signal Equipment }\end{array}$ \\
\hline $\begin{array}{r}4440 \\
4441 \\
4442\end{array}$ & $\begin{array}{l}\text { Foundation and Site Preparation } \\
\text { Foundation } \\
\text { Site Preparation }\end{array}$ \\
\hline $\begin{array}{l}4450 \\
4451 \\
4452 \\
4453\end{array}$ & $\begin{array}{l}\text { Heliostat Support and Protection } \\
\text { Heliostat Support Structure } \\
\text { Heliostat Protective Enclosure } \\
\text { Lightning Protection }\end{array}$ \\
\hline $\begin{array}{l}4460 \\
4461 \\
4462 \\
4463 \\
4464 \\
4465 \\
4466\end{array}$ & $\begin{array}{l}\text { Field Assembly and Checkout } \\
\text { Heliostat } \\
\text { Sonsor Calibration Equipment } \\
\text { Electrical Power Distribution } \\
\text { Alignment of Heliostats } \\
\text { Field Support } \\
\text { Packaging and Transportation }\end{array}$ \\
\hline
\end{tabular}


Table 8-2. CHOICE OF SURROGATES FOR HELIOSTAT COMPONENTS

\begin{tabular}{|c|c|c|c|}
\hline & Heliostat Component & Surrogates & $\begin{array}{c}\text { Design } \\
\text { Applicability }\end{array}$ \\
\hline & Reflectors & $\begin{array}{l}\text { Laminated Mirrors } \\
\text { Ply wood Production }\end{array}$ & $\begin{array}{l}\text { McDonnell Douglas and } \\
\text { General Electric }\end{array}$ \\
\hline 2. & Elevation Actuator & Machine Ball Screws & $\begin{array}{l}\text { McDonnell Douglas and } \\
\text { General Electric }\end{array}$ \\
\hline & Drive Controls & $\begin{array}{l}\text { Solid State Power } \\
\text { Controls and Condition- } \\
\text { ing }\end{array}$ & $\begin{array}{l}\text { MeDonnell Douglas and } \\
\text { General Electric }\end{array}$ \\
\hline 4. & Pedestal & $\begin{array}{l}\text { Corrugated Tube } \\
\text { Welded Tubing }\end{array}$ & $\begin{array}{l}\text { McDonnell Douglas and } \\
\text { General Electric }\end{array}$ \\
\hline 5. & Reflector Supports & $\begin{array}{l}\text { Conduit Raceway } \\
\text { Door Mullions }\end{array}$ & MeDonnell Douglas \\
\hline 6. & Azimuth Gear Box & $\begin{array}{l}\text { Automative Gear Boxes } \\
\text { Variable Pitch Prop. } \\
\text { Boxes }\end{array}$ & McDonnell Douglas \\
\hline & Azimuth Drive Hub & $\begin{array}{l}\text { Surveyors Wheels } \\
\text { Bus/Truck Steering } \\
\text { Wheels } \\
\text { Complex Precision } \\
\text { Plastic Mold }\end{array}$ & General Electric \\
\hline 8. & Reflector Yoke & Automobile Exhaust Tube & $\begin{array}{l}\text { MeDonnell Douglas } \\
\text { and General Electric }\end{array}$ \\
\hline & Reflector Enclosure & $\begin{array}{l}\text { Swimming Pool Liners } \\
\text { Weather Balloons } \\
\text { Blow Molded Bottles }\end{array}$ & General Electric \\
\hline
\end{tabular}


Table 8-3. SURROGATES USED IN THE STUDY

\begin{tabular}{|c|c|c|c|c|}
\hline & Component Part & Surrogate & $\begin{array}{c}\text { Design } \\
\text { Applicability }\end{array}$ & Status $^{\mathbf{a}}$ \\
\hline 1. & Reflectors & $\begin{array}{l}\text { A. Plywood } \\
\text { 1. Total } \\
\text { 2. Southern (New } \\
\text { Industry) } \\
\text { 3. Western (Old } \\
\text { Industry) } \\
\text { 4. Plywood and } \\
\text { Veneer } \\
\text { 5. Plywood } \\
\text { Manufacturer } \\
\text { B. Aircraft Windshield } \\
\text { C. Laminated Mirrors }\end{array}$ & $\begin{array}{l}\text { McDonnell } \\
\text { Douglas and } \\
\text { General } \\
\text { Electric }\end{array}$ & $\begin{array}{l}+ \\
+\end{array}$ \\
\hline 2. & $\begin{array}{l}\text { Elevation } \\
\text { Actuator }\end{array}$ & $\begin{array}{l}\text { A. Aircraft Landing Gear } \\
\text { B. Machine Ball Screws }\end{array}$ & $\begin{array}{l}\text { MeDonnell } \\
\text { Douglas and } \\
\text { General } \\
\text { Electric }\end{array}$ & - \\
\hline 3. & Drive Controls (Si & $\begin{array}{l}\text { Microprocessor) } \\
\text { A. Personal Electronic } \\
\text { Caleulatul's } \\
\text { B. Solid State Calcula- } \\
\text { tors }\end{array}$ & $\begin{array}{l}\text { McDonnell } \\
\text { Douglas and } \\
\text { General } \\
\text { Electric }\end{array}$ & + \\
\hline 1. & Pcdestal & $\begin{array}{l}\text { A. 3teel Pipes und Tubes } \\
\text { B. Corrugated Tube } \\
\text { C. Welded Tubing }\end{array}$ & $\begin{array}{l}\text { MeDonnell } \\
\text { Douglas and } \\
\text { General } \\
\text { Electric }\end{array}$ & $\begin{array}{l}+ \\
- \\
-\end{array}$ \\
\hline 5. & $\begin{array}{l}\text { Reflector } \\
\text { Supports }\end{array}$ & $\begin{array}{l}\text { A. Steel Wall Sturds } \\
\text { B. Metal Door Sash and } \\
\text { Trim } \\
\text { C. Metal Household } \\
\text { Furniture } \\
\text { D. Conduit Raceway } \\
\text { E. Door Mullions }\end{array}$ & $\begin{array}{l}\text { MeDonnell } \\
\text { Douglas }\end{array}$ & $\begin{array}{l}+ \\
+ \\
+ \\
-\end{array}$ \\
\hline 6. & $\begin{array}{l}\text { Azimuth Gear } \\
\text { Box }\end{array}$ & $\begin{array}{l}\text { A. Drive Wheel Trans- } \\
\text { mission } \\
\text { B. Automotive Gear Boxes } \\
\text { C. Variable Pitch Prop. }\end{array}$ & $\begin{array}{l}\text { McDonnell } \\
\text { Douglas }\end{array}$ & $\begin{array}{l}+ \\
- \\
-\end{array}$ \\
\hline
\end{tabular}

$a_{+}$Da ta have been obtained; - Da ta cannot be obtained. 
Table 8-3. SURROGATES USED (concluded)

\begin{tabular}{|c|c|c|c|}
\hline Component Part & $\begin{array}{l}\text { Design } \\
\text { Surrogate }\end{array}$ & Applicability & Status ${ }^{a}$ \\
\hline $\begin{array}{l}\text { 7. Azimuth Drive } \\
\text { Hub }\end{array}$ & $\begin{array}{l}\text { A. Steering Wheel Bus, } \\
\text { Truck } \\
\text { B. Harmonic Drive Wheel } \\
\text { C. Surveyors Wheels } \\
\text { D. Complex Precision } \\
\text { Plastic Mold }\end{array}$ & General Electric & $\begin{array}{l}- \\
- \\
- \\
-\end{array}$ \\
\hline 8. Reflector Yoke & $\begin{array}{l}\text { A. Automobile Exhaust } \\
\text { Tubing } \\
\text { B. Metal Household } \\
\text { Furniture } \\
\text { C. Steel Pipes and Tubes } \\
\text { D. Fabricated Pipes and } \\
\text { Fittings }\end{array}$ & $\begin{array}{l}\text { MeDonnell } \\
\text { Douglas } \\
\text { and } \\
\text { General } \\
\text { Electric }\end{array}$ & $\begin{array}{l}+ \\
+\end{array}$ \\
\hline $\begin{array}{l}\text { 9. Reflector } \\
\text { Enclosure }\end{array}$ & $\begin{array}{l}\text { A. Swimming Pool Enclo- } \\
\text { sure } \\
\text { B. Aircraft Canopy } \\
\text { C. Blow Molded Bottles } \\
\text { D. Weather Balloons } \\
\text { E. Helicopter Blade } \\
\text { Liners } \\
\text { F. Inflatable Shelters }\end{array}$ & $\begin{array}{l}\text { General } \\
\text { Electric }\end{array}$ & $\begin{array}{l}- \\
+ \\
- \\
+ \\
+\end{array}$ \\
\hline 10. Assembly & $\begin{array}{l}\text { A. Truck/Bus Bodies } \\
\text { B. Wing Struc ture }\end{array}$ & $\begin{array}{l}\text { McDonnell } \\
\text { Douglas } \\
\text { and General } \\
\text { Electric }\end{array}$ & $\begin{array}{l}+ \\
+\end{array}$ \\
\hline 11. Overall Product & $\begin{array}{l}\text { A. Motor Vchicles } \\
\text { B. Radio Telescope }\end{array}$ & $\begin{array}{l}\text { McDonnell } \\
\text { Douglas } \\
\text { and General } \\
\text { Electric }\end{array}$ & $\begin{array}{l}+ \\
-\end{array}$ \\
\hline
\end{tabular}

$a_{+D a t a}$ have been obtained; -Data cannot be obtained. 
All automotive-rela ted surroga tes (e.g., cxhaust tubes, differentials, steering wheels) had to be discarded because of the automotive industry did not release enough cost information. Despite several efforts, including those of a leading automotive industry consultant, no more definitive data than selling prices of automotive parts could be obtained.

During the course of the study, an exceptionally appropriate surrogate for the entire heliostat assembly was discovered in work sponsored by the U. S. Air Force at Hanscom Field, Mass. in 1962 [40]. The project involved the construction of a radio telescope design to function in the same manner as the heliostats and tower. A multiplicity of individually oriented flat screen antennae were used to reflect radio waves emanating from a distant source to a central receiver mounted in the tower. The plan was to use several thousand antennae in an engineering installation. Unfortunately, only about 500 were built and no mass production techniques were used. However, there were several design cycles for cost improvement that were completed within the coursc of the program.

The specific surrogates that were investigated for this study (see Table 8-3) have varying degrees of validity for heliostat component counterparts and varying levels of cost data quality. Surrogate validity and data fidelity cannot be measured quantitatively. Some inferences regarding the quality of the data, however can be drawn statistically. A qualitative judgment can be made regarding the validity of the surrogate as an analogue.

The use of aircraft windshields and laminated mirrors for surrogates of heliostat reflectors represents a very close match of materials and manufacturing processes. The use of plywood as an analogue of the reflector is less directly related in terms of material but similar in terms of manufacturing processes. Plywood manufacturing requires the bonding of friable, delicate laminates in to a continuous, multilayered structure. Although plywood manufacturing is an old, well established industry, there are segments (such as the southern plywood industry) that are relatively new. Learning effects would probably be more prevalent in such new industries.

The elevation actuator is an electromechanical positioning system. While the machine ball-screw mechanism is a very close surrogate, no cost data were available for it. The aircraft landing gear is a similar electrohydraulic mechanical system which requires fine mechanical design, careful machining and assembly, and a high level of reliability. Although the landing gear surrogate is probably more complex than the elevation actuator, the configuration, materials, and manufacturing operations are probably quite similar to the elevation actuator component.

The drive controls and their costs are dominated by the microprocessor or control component. The other components of the control system are necessary to the design but are generally purchased elsewhere and assembled. The electronic calculator is a reasonable surrogate in that its cost is also dominated by a single chip microproccrinr, despite $\&$ need for other electrunic and struc tural components.

The pedestal is a difficult component for which to find surrogates with meaningful historical cost data. Steel pipes and tubes (welded or seamless) are manufactured using an old technology. Early cost data are virtually lost, and resent data would exhibit little (if any) learning effect. We have nevertheless included these because of the dearth of information related to any other potential surrogates. Furthermore, the fact that manufacturing of tubular components is a well developed technology indicates that if manufacturers skilled in the art are used, the learning effect in manufacturing these components would be minimal. 
Several surrogates are available for the reflector supports. The least realistic are the fabricated pipes and fittings. However, the rolled steel sheet shapes used in steel wall studs and metal door sashes are completely analogous to the steel channel configuration of the reflector supports. These surrogate industries are well developed and mature. Learning effects, however, are probably not evident. Of course, there may also be little learning in fabricating as simple a structure as the reflector supports.

The surrogates for the azimuth gear box were chosen because they represent medium precision gear trains that were produced in medium volumes of tens of thousands per year. The only choice including manufacturing cost da ta involved the transaxle transmission of an off-the-road vehicle such as a tractor. The data is given for a completely new design, from its inception four years ago to the present. The results indicate that, while learning ocurs, the design and fabrication of transmissions by people skilled in the art will avoid most of the early costs associated with new designs.

Data for the azimuth drive hub was not available for any of the selected surrogates. Manufacturers of automotive steering wheels and harmonic drives would not release cost data. Other sources such as industry associations and plastic parts suppliers also proved to be of no help. For this study, it was conservatively assumed that the current manufac tured estimated cost by General Electric would not change much.

The surrogates for the reflector yoke resulted in much the same data as the pedestal surrogates. No data were directly available from manufacturers or manufacturers' associations. The data available at this time are weak. However, because of the nature of these parts, significant learning should not be expected.

Several surrogates yielded good quality data for the reflector enclosure. The aircraft canopy, helicopter blade liners, and inflatable shelter provided valid cost data. The helicopter blade liners and inflatable shelter are closer in manufacturing process and material to the processes used for the reflector enclosure.

Originally, no surrogate was selected to represent the assembly operation. Essentially, the heliostat is a mechanical configuration requiring assembly of structural components. The aircraft wing structure assembly operation is an excellent analogue for which valid cost data are available from the manufacturer. The learning effect is typical of what may be anticipated for the assembly of the heliostat units.

For the overall product no reliable surrogate data were available. As previously discussed, the radio telescope antenna assembly represents the penultimate surrogate for a heliostat. Unfor tunately, none were ever mass-produced.

\subsection{DERIVATION OF LEARNING AND EXPERIENCE CURVES FOR SURROGATES}

\subsubsection{Data Acquisition}

As noted previously, surrogate products were identified and selected under the assumption that historical (relative) cost patterns exhibited by these products could apply to corresponding heliostat components as well. Furthermore, in order to be applicable to the heliostat assembly, the relative cost behavior for each surrogate must be independent of ancillary conditions such as: 
- years of production,

- annual production rates, and changes in rates,

- absolute unit costs of surrogates,

- economic factors,

- production volume, lot sizes, and sequence numbers used, and

- extraneous factors that might distort the constant rate of reduction in unit cost.

Thus, it is assumed that cost reduction (or increase) is constant over time, and can be estimated from the observed slope parameter (b) for the surrogate products selected. If the raw cost/quantity data have been influenced in any way to distort the "true" slope in a substantive manner, these effects must be estimated and data adjustments made, or assumed negligible. An excellent example of this type of problem is illustrated at the conclusion of this section.

After an acceptable list of surrogates was constructed, the next step was to acquire meaningful production cost data. The original intent was to gather historical cost data for each surrogate product, broken down according to labor, materials, and overhead. Furthermore, sources of cost reduction and extraneous factors were to be determined in the manufacturing of surrogate products.

The data acquisition task proved to be a formidable one, so cost data presented in this section are of limited quality. For the surrogate approach to be credible, it is imperative that accurate and reliable cost data be used, and that the manufacturing history of each component be well understood. In view of unexpected and unavoidable difficulties encountered in acquiring reliable cost data for many surrogate products, it is recommended that the derived learning percentages be accepted with caution, and that absolute values and ranges be considered illustrative rather than definitive.

The data acquired for this study were provided by Arthur D. Jittle, Inc., and are summarized in the tables presented in Appendix A. Data sources are identified except when confidentiality was requested. Some comments concerning the data contained in those 20 tables are listed below.

- All dollar amounts given were normalized within each table, to account for inflation, and are in ternally consistent for each surrogate.

- Since cumulative production quantities are required, only sequential proriuction volumes are included; for example, plot points for the data in the first table are calculated from the true cumulative production figures since 1960 .

- In cases where production quantities were not available, plot pointa were calculated from normalized material costs. This technique assumes that observed differences in deflated materials costs reflect production level changes only and that materials unit costs remain constant.

- Prior cost/quantity history is ignored. Data are assumed to reflect "normal" learning even though mature industries such as motor vehicles might have behaved quite differently at the outset.

- Tabulated data given in this report have been summarized; more detailed raw data were extracted from most sources indicated.

- In all cases, total cost includes direct labor, materials, and overhead. 


\subsubsection{Surrogate Learning Curve Estimation}

After all relevant data had been accumulated, unit costs and corresponding cumulative production quantities were calculated according to the scheme presented in Appendix B. In most cases, the average cost of producing the nth unit was considered; however, a few cumulative cost curves were also generated primarily for comparative purposes. Cost/ quantity data pairs were subsequently coded for computer processing. A least-squares linear fit (on log-log scale) was then performed using the BMDP Biomedical Computer Program subroutine BMDP1R, Multiple Linear Regression. The complete output of this program is illustrated in Appendix B.

The output presents several summary statistics of interest, including the following:

- The estimated least-squares line; i.e., the intercept parameters $(\log a)$ and the slope (b);

- The standard error of the regression coefficient estimate (b); under certain assumptions, this term can be used to calculate confidence interval estimates for the slope;

- $\mathrm{R}$ (the sample correlation coefficient) and $\mathrm{R}^{2}$ (which measures the proportion of variation in log cost explained by the linear model);

- The standard error of estimate, which measures the dispersion of the observations about the estimated regression line; and

- The probability that a test statistic calculated from the data (the F-ratio) would be as large as observed if, in fact, the two variables were not linearly related; a small probability implies rejection of the hypothesis of no linear relationship.

A plot of observed $\log \operatorname{cost}(0)$ and predicted $\log$ cost from the least-squares equation $(P)$ is also given in $\log -\log$ units. The plot of residuals (observed minus predicted log costs) is also given for purposes of validating an important underlying assumption of regression theory. This assumption refers to the independence of observed $C$ values; that is, in regression theory it is assumed that successive observations are independent of one another. This assumption is clearly violated in cumulative cost curves, and is difficult to justify in unit cost data as well. Nevertheless, probability statements in the form of $95 \%$ confidence interval estimates are presented in Appendix A, Table A-21, which summarizes all regression runs performed. Therefore, if regression assumptions are accepted, the probability is 0.95 that the learning rate interval given includes the "true" (unknown) learning rate that we are attempting to estimate from these data.

The eff ect of variability in slope estimates, as well as overall precision in the estimation techniques, is demonstrated in Fig. B-3 (see Appendix B) using the Aircraft Canopy surrogate data. Three lines are drawn to indicate upper (80\%) and lower (58\%) bounds, and the regression estimate itself (68\%), since these estimators are subsequently applied in this study to actual heliostat components.

In the usual application of learning curve theory, this regression line would be used to predict the unit cost of producing additional canopies. Two different, and of ten misunderstood, interval estimates are also illustrated in Fig. B-3 for this situation. The narrower band depicts a $95 \%$ confidence interval estimate about a conditional mean cost value; the wider band represents the more commonly required prediction interval concern with the estimation of villy one individual unit cost. For example, it can be stated with $95 \%$ confidence that, on the average, the cost of producing the 200 th canopy would be 
between 4.7 and 13 hours; however, the data also indicate that the predicted cost of the 200 th canopy produced in this sequence can be expected to be between 2.9 and 22 hours, a much broader, less precise estimate. In addition to displaying this distinction between confidence and prediction intervals, this figure is intended to illustrate the following:

- Variation in slope can have dramatic effects on unit cost estimates;

- An apparent "reasonable good" linear fit $\left(\mathrm{R}^{2}=0.88\right)$ does not necessarily yield estimates or predictions of acceptable (i.e., useful) precision; and

- Regression theory, if appropriate at all, works best near the mean of the data; extrapolating beyond the observed data is risky and subject to large estimation errors.

There are additional limitations to applying historical learning trends to different, but related, components. For example, the following concerns are worth noting:

- Learning curve slope estimates are highly dependent on the particular surrogate oclccted; different surrngates intended to characterize the sallie liellostat component can yield vastly different estimates of learning effects.

- Identical surrogates, such as plywood, lead to widely varying estimates depending on the data source, age of industry, and other variables, such as geographical location.

- There is evidence that learning dampens out for mature industries and, therefore, may not represent expected patterns for similar components with different system configurations and/or requirements.

- Estimated slopes appear to depend on units of measure, even in situations that should be invariant; e.g., see Appendix A data on number of workers $(b=-0.59)$, hours worked $(b=-0.33)$, and standardized labor cost $(b=-0.65)$.

- Many of the surrogates used in this study indicated little or no measurable learning. This condition manifested itself in two ways: (1) the data did not appear to be linearly related as measured by standard goodness-of-fit test statistics, and/or (2) unit costs were constant, and apparently unrelated to quantity produced over the range of production units considered.

- Estimates for heliostat components are highly subjective, even if the surrogate cost/quantity data were reliable in all respects.

- Historical "raw" cost data can be, and frequently are, contaminated with hidden effects that only extraordinary and detailed investigation will uncover. Examples of this type of unusual cost/quantity behavior are given in Appendix A, in two sets of cost data. In Tables A-16 and A-19, one column, denoted as "actual" unit cost, reprcisnt.s ensts incurred to produce the corlesponding lot sizes. 'I'he other cost column, entitled "adjusted" unit cost, reflects the results of a comprehensive study conducted by Arthur D. Little, Inc., which yielded substantive evidence that "actual" costs were inflated and unusually high for early production units because of circumstances unique to a particular production program. Such uniqueness is not uncommon in the literature. 


\subsection{APPLICATION TO HELIOSTAT ASSEMBLY}

\subsubsection{Unit Cost Estimates for Relevant Components}

The prototype heliostat investment cost estimates for various annual production levels for MDAC and GE design configurations are presented in Subsection 7.3. Tables 8-4 (GE) and 8-5 (MDAC), provide the average investment cost per heliostat estimates for the baseline plant $(25,000$ units/yr). For the MDAC Prototype Heliostat Study (3) it was assumed that plants will initiate operations after 100,000 heliostats have been produced for pilot plants, demonstration plants, and the first commercial plants. However, the average investment cost per heliostat has been projected as that required at the start of the second year of rate production in the factory, or at unit 125,000 [3, pp. 9-21]

The 25,000 units/yr scenario, representing the plans associated with a well conceived, advanced design, has been developed as the baseline scenario. This rate represents a significant high-volume production situation and reflects conditions required to establish a steady-state production process. Also, it may be easily translated into both higher or lower productive capacity. Thus, this scenario lends visibility to the development of viable business constraints and at the same time supports a strategy for capturing an important share of eventual markets. As indicated before, the 25,000 heliostats/yr production rate represents only one of many possible scenarios.

\subsubsection{Development of Heliostat Component Cost Curves}

The procedures for using learning and cost curves to predict cost reduction in manufacturing solar technologies outlined previously show that learning and cost curves were to have been derived and aggregated over labor, materials, and overhead cost elements for each heliostat part. Since the data collected are not amenable to treatment at this level of detail, the conceptual framework will be illustrated with total cost data only.

Learning curve slope estimates observed for the surrogates were superimposed on the single point estimate assigned to the 25,000th unit. Again, the criterion for selecting a representative slope estimation from among two or more alternatives was essentially subjec tive. In each case, upper and lower bounds were also prescribed to emphasize the importance of using interval estimation; these bounds, however, are not purported to be confidence limits, and probability statements do not apply. The technique is illustrated for the GE design and the MDAC design in Appendix C.

\subsubsection{Aggregation of Costs}

A composite cost curve was then constructed for each heliostat design configuration by aggregating costs at similar production quantity levels over the 11 individual component parts. To illustrate the aggregation process, boundary value cost curves are generated by summing high and low costs, respectively, in addition to the "expected" value determined from the "most likely" learning slope. As before, these boundary values have no statistical (i.e., probabilistic) meaning, and are included for illustrative purposes only. The aggregate cost curves are given in Fig. 8-1 and 8-2 for the GE and MDAC designs, respectively. As these curves indicate, the conceptual estimation technique examined in this study would almost certainly yield a nonlinear cost/quantity relationship for the overall assembly since slopes are not additive over components in a log-log scale. 
Table 8-4. COST ESIIMATE-25,000th UNIT, GENERAL ELECTRIC DESIGN

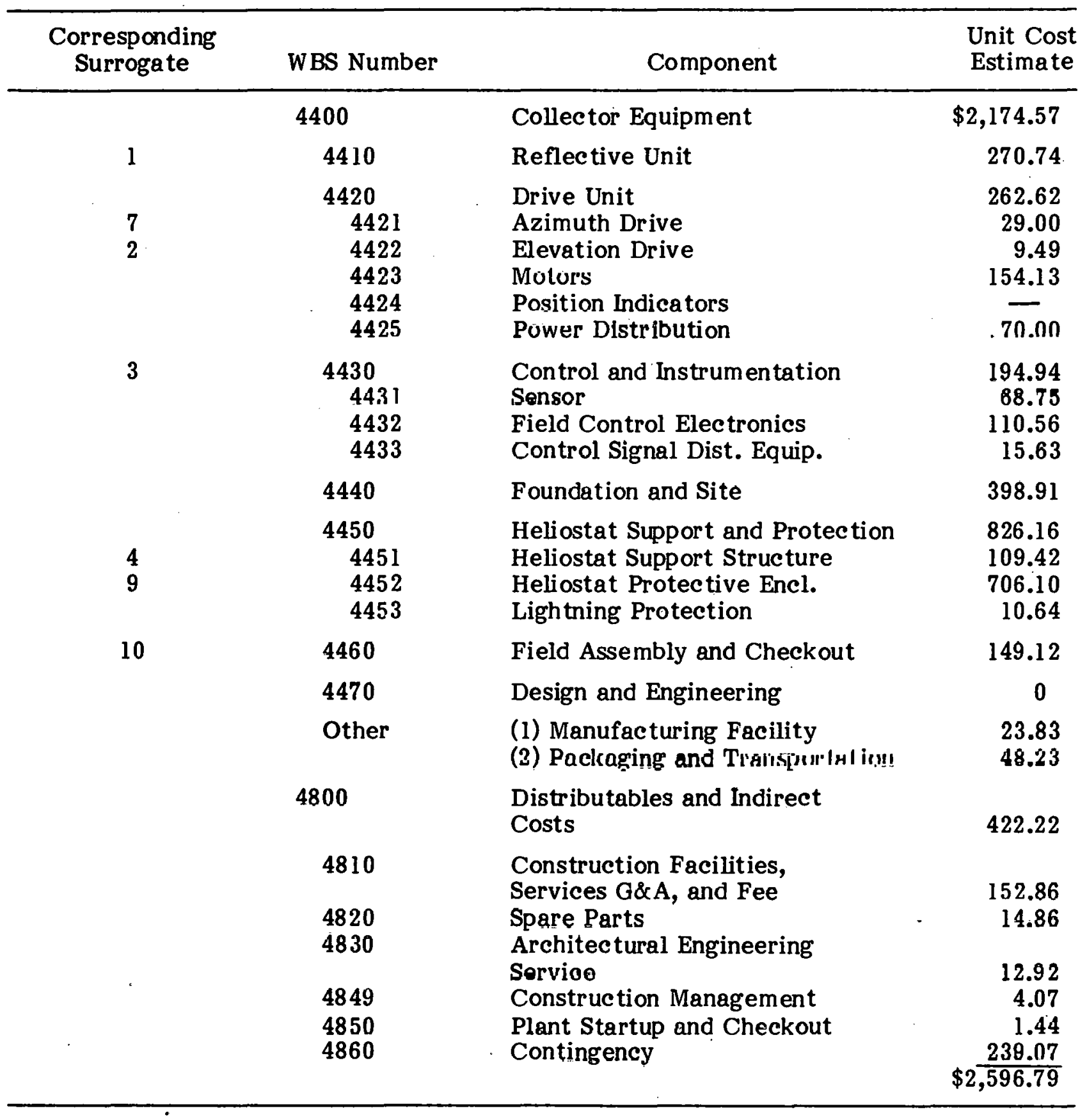


Table 8-5. COST ESTIMATE-25,000th UNIT, McDONNELL DOUGLAS DESIGN

\begin{tabular}{|c|c|c|c|c|c|c|c|}
\hline \multirow[b]{2}{*}{$\begin{array}{l}\text { Corresponding } \\
\text { Surrogate }\end{array}$} & \multirow[b]{2}{*}{ WBS Number } & \multirow[b]{2}{*}{ Component } & \multicolumn{4}{|c|}{ Capital Investment } & \multirow[b]{2}{*}{$\begin{array}{l}\text { Unit Cost } \\
\text { Estimate }\end{array}$} \\
\hline & & & \multicolumn{2}{|c|}{$\begin{array}{l}\text { Labor } \\
\text { Hours }\end{array}$} & \multicolumn{2}{|c|}{\begin{tabular}{c}
\multicolumn{2}{c}{ Matl. Dollars } \\
Pur. Pt. Raw Mtl. \\
$\$$.
\end{tabular}} & \\
\hline & & Grand Total-Heliostat & 39.3 & 748. & 1923. & 570. & 3,241 \\
\hline & 4410 & Reflective Unit & 4.3 & 60. & 735. & 88. & 883. \\
\hline 1 & 4411 & Reflective Surface & 1.3 & 18. & 407. & 46. & 471. \\
\hline 5 & 4412 & Mirror Back Struct & 1.5 & 22. & 328. & 13. & 363. \\
\hline & 4413 & Assy and Bond & 1.5 & 21. & 0. & 28. & 49. \\
\hline & 4420 & Drive Unit & 7.8 & 110 & 937. & 260. & 1306. \\
\hline 6 & 4421 & Azimuth & 4.0 & 56. & 141. & 156. & 354. \\
\hline 2 & 4422 & Elevation & 2.5 & 36. & 482. & 103. & 621. \\
\hline & 4423 & Motor Total & 0.0 & 0. & 164. & 0. & 164. \\
\hline & 4424 & Pos/Limit Indicato & .8 & 11 & 17. & 0. & 29. \\
\hline & 4425 & PWR SPLY Dist. & 0.0 & 0. & 131. & 0. & 131. \\
\hline & 4426 & Assy Dr./Ped./Elect & .5 & 7. & 1. & 0. & 8. \\
\hline 3 & 4430 & Control/Instrum. Eq. & 2.4 & 36. & 78. & 0. & 114. \\
\hline & 4431 & Sensor/Calib.Equip. & 0.0 & 0. & 1. & 0. & 1. \\
\hline & 4432 & Field Control & 0.0 & 0. & 1. & 0. & 1. \\
\hline & 4433 & Cntrl./Sig. Eq. & 2.4 & 33. & 68. & 0. & 102. \\
\hline & 44320101 & Collector Control & .1 & 2. & 8. & 0. & 9. \\
\hline & 4440 & Found/Site Prep & 14.5 & 336. & 172. & 102. & 609. \\
\hline & 4441 & Foundation & 10.5 & 243. & 172. & 102. & 517. \\
\hline & 4442 & Site Preparation & 4.0 & 93. & 0. & 0. & 93. \\
\hline & 4450 & Helio SPT ST/PR EN & 1.1 & 15. & 1. & 121. & 136. \\
\hline 4 & 4451 & Helio Supp. Struct & 1.1 & 15. & 1. & 121. & 136. \\
\hline & 4452 & Protection Encl. & 0.0 & 0. & 0. & 0. & 0 \\
\hline & 4453 & Lightning Prot. & 0.0 & 0. & 0. & 0. & 0. \\
\hline 10 & 4460 & Field Assy and C/O & 9.2 & 192. & 1. & 0. & 193. \\
\hline & 4461 & Heliostat & 3.2 & 74. & 0. & 0. & 74. \\
\hline & 4462 & Sensor/Calib. Eq. & 0.0 & 0. & 0. & 0. & 0. \\
\hline & 4463 & Elec trical/Distrib. & 1.8 & 42. & 0. & 0. & 42. \\
\hline & 4464 & Align Heliostats & .8 & 18. & 0. & 0. & 18. \\
\hline & 4465 & Field Support & 1.1 & 25. & 0. & 0. & 25. \\
\hline & 4466 & Pack and Transp. & 2.3 & 33. & 1. & 0. & 33. \\
\hline & 4100 & Site, Stru., M isc. Eq. & .2 & 3. & 34. & 1. & 38. \\
\hline & 4130 & Misc. Equip. & .2 & 3. & 34. & 1. & 38. \\
\hline & 4800 & Dist and Indir. & 0.0 & 0. & 2. & 0. & 2. \\
\hline & 4840 & Initial Spares & 0.0 & 0. & 2. & 0. & 2. \\
\hline
\end{tabular}




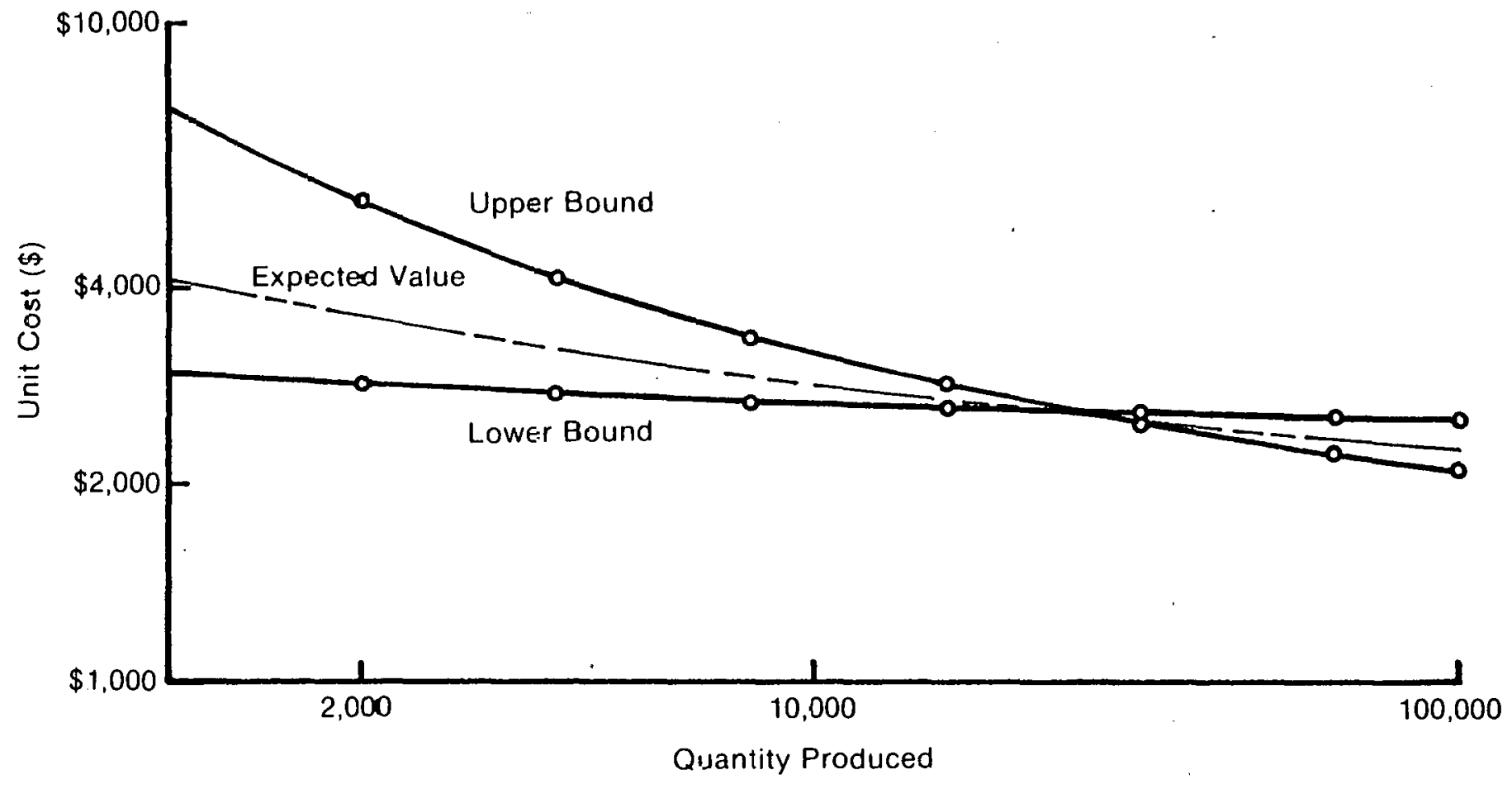

Figure 8-1. Heliostat Assembly Unit Cost Curve (GE) Design 


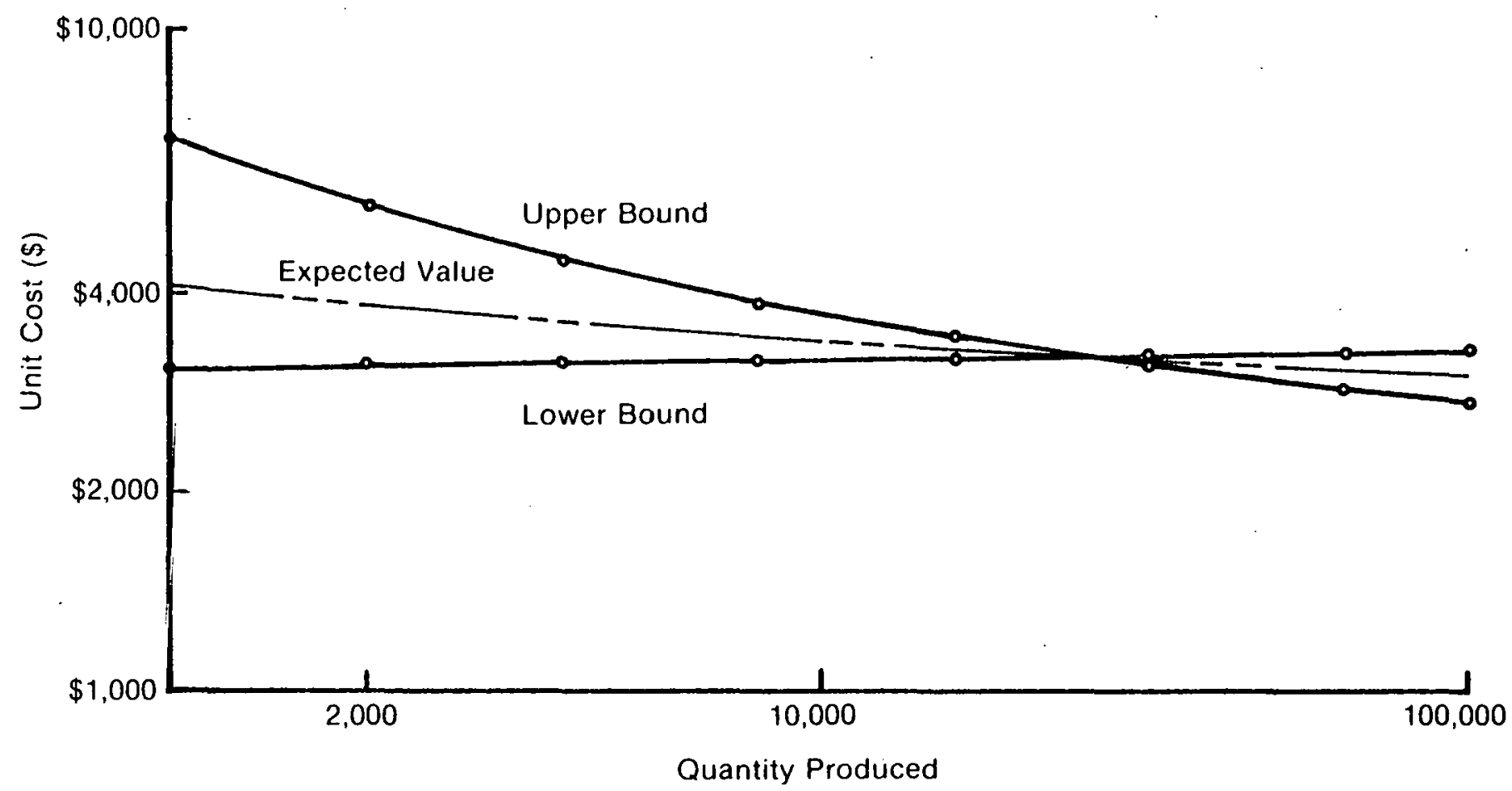

Figure 8-2. Heliostat Assembly Unit Cost Curve (MD) Design 
The MDAC heliostat assembly composite unit cost curve starts out at approximately $94 \%$, changes to $96 \%$, and finally reaches $97 \%$.

Table 8-6. ESTIMATED COSTS AND SLOPES FOR THE MDAC HELIOSTAT DESIGN

\begin{tabular}{ccc}
\hline $\begin{array}{c}\text { Quantity } \\
\text { Produced }\end{array}$ & $\begin{array}{c}\text { Heliostat Investment Cost } \\
\$ \text { Per Heliostat }\end{array}$ & $\begin{array}{c}\text { Composite Curve } \\
\text { Slope (\%) }\end{array}$ \\
\hline 1,000 & 4,128 & 93.8 \\
2,000 & 3,873 & 94.1 \\
4,000 & 3,645 & 95.1 \\
8,000 & 3,468 & 95.7 \\
16,000 & 3,319 & 96.1 \\
32,000 & 3,189 & 96.7 \\
64,000 & 3,085 & \\
100,000 & 3,017 & 97.3 \\
\hline
\end{tabular}

While, for the same production scenario, the GE heliostat assembly composite unit cost curve starts out at approximately $89 \%$ changes to $92 \%$ and $94 \%$, and finally reaches $99 \%$.

'I'able 8-7. ESTIMATED COSTS AND SLOPES FOR THE GE HELIOSTAT DESIGN

\begin{tabular}{ccc}
\hline $\begin{array}{c}\text { Quantity } \\
\text { Produced }\end{array}$ & $\begin{array}{c}\text { Heliostat Investment Cost } \\
\text { \$ Per Heliostat }\end{array}$ & $\begin{array}{c}\text { Composite Curve } \\
\text { Slope (\%) }\end{array}$ \\
\hline 1,000 & 4,100 & 88.7 \\
$2,0 n n$ & 3,640 & 89.5 \\
4,000 & 3.258 & 90.9 \\
8,000 & 2,962 & 92.0 \\
16,000 & 2,723 & 93.0 \\
32,000 & 2,533 & 94.0 \\
64,000 & 2,382 & \\
100,000 & 2,287 & 99.0 \\
\hline
\end{tabular}




\section{SECTION 9.0}

\section{REPERENCES}

1. Drumheller, K. Heliostat Manufacturing Analysis. EY-76-C-06-1830. Prepared for the United States Department of Energy. Richland, WA: Pacific Northwest Laboratory; Oct. 1978.

2. Electric Power Research Institute Heliostat Cost Study. Cambridge, MA: Arthur D. Little, Inc., et al.

3. McDonnell Douglas Astronautics Company, West. Solar Central Receiver Prototype Heliostat CDRL Item B.d Final Technical Report. Vol. I and II. MDCG7399. Hunting ton Beach, CA: McDonnell Douglas Astronautics Company; Aug. 1978.

$\because$

4. General Electric. Solar Central Receiver Prototype Heliostat Phase I. Final Technical Report. SAN-1468-1. Schenectady, N.Y.: General Electric; Oct. 1978.

5. Petruschel, R. L. The Derivation and Use of Estimating Relationship, Memorandum \#RM-3215-PPR. Santa Monica, CA: The Rand Corporation; Feb. 1962.

6. Fisher, G. H. Derivation of Estimating Relationships: An Ilustrative Example. Prepared for the United States Air Force Project Rand, Memorandum RM-3366PR. Santa Monica, CA: The Rand Corporation; Nov. 1962.

7. Walters, A. A. "Production and Cost Functions: An Econometric Survey." Econometrica. Vol. 31: Jan. 1963; pp. 1-66.

8. Conway, R. W.; Schultz, Andrew Ir. "The Manufacturing Progress Function." The Journal of Industrial Engineering. Vol. 10: .Jan.-Feb. 1959; pp. 39-54.

9. Krawiec, F.; Flaim, T. Solar Cost Reduction Through Technical Improvements: The Concepts of Learning and Experience. SERI/RR-52-173D. Prepared for the U.S. Department of Energy. Golden, CO: Solar Energy Research Institute; Feb. 1979.

10. Costello, Dennis; et al. Photovoltaic Venture Analysis; Progress Report. SERI23. Golden, CO: Solar Energy Research Institute; Apr. 1978.

11. Young, Samuel L. "Misapplications of the Learning Curve Concept". The Journal of Industrial Engineering. Vol. XVII (No. 8): pp. 410-415. 
12. Colasuonno, Vincent. An Analysis of Progress Curve Conceptual Advances and Progress Curve Uses Since 1956. M.S. thesis. Air University; 1970.

13. Orsini, Joseph A. An Analysis of Theoretical and Empirical Advances in Learning Curve Concepts Since 1966. M.S. thesis. Air University; 1970.

14. Hirsch, Werner F. "Manufacturing Progress Functions." Review of Economics and Statistics. Vol. 34: May 1952; pp. 143-155.

15. Andress, Frank J. "The Learning Curve As a Production Tool." Harvard Business Review. Vol. 32: Jan.-Feb. 1954; pp. 87-97.

16. Baloff, Nicholas. "Extensions of the Learning Curve: Some Empirical Results." Operational Research Quarterly. Vol. 22: Dec. 1971; pp. 329-340.

17. Wright, T. P. "Factors Affecting the Cost of Airplanes." Journal of Aeronautical Science. Vol. I: Feb. 1936; pp. 122-128.

18. Pegels, C. Carls. "Start Up or Learning Curves-Some New Approaches." Decision Sciences. Vol. 7: 1976; pp. 39-54.

19. Asher, Harold. Cost Quantity Relationships in the Airframe Industry. R-291. Santa Monica, CA: The Rand Corporation; July 1956.

20. Reguero, Miguel A. An Economic Study of the Military Airframe Industry. Ann Arbor, MI: University Microfilms International; 1957.

21. Billion, S. A. "Industrial Learning Curves and Forecasting." Management International Review. July 1965; pp. 65-96.

22. Harting, W. G. Cost Estimate Errors Resulting from the Use of Learning Curve Methods. L. G. Hanseem Field, MA: Fscer, Electronic Systems Division; Aug. 1969.

23. Ferguson, C. E. The Neoclassical Theory of Production and Distribution. London: Cambridge University Press; 1971.

24. Brewer, Glenn M. The Learning Curve in the Airframe Industry. M.S. thesis. Air University; 1965. 
25. Morse, Wayne J. "Learning Curve Cost Projections with Constant Unit Costs." Managerial Planning. Mar.-Apr. 1974; pp. 15-21.

26. Hirschmann, Winfred B. "Profit from the Learning Curve." Harvard Business Review. Vol. 42: Jan.-Feb. 1964; pp. 125-139.

27. Boston Consulting Group. Prospectives on Experience. Boston, MA: 1972.

28. Bodde, David L. "Riding the Experience Curve." Technology Review. Mar.-Apr. 1976; pp. 53-59.

29. Yelle, Louis E. "Estimating Learning Curves for Potential Products." Industrial Marketing Management. Vol. 5: 1976; pp. 147-154.

30. Seherer, F. M. Industrial Market Structure and Economic Performance. Chicago, IL: Rand McNally Publishing Co.; 1970.

31. Salter, W.E.G. Productivity and Technical Change. 2nd ed. London: Cambridge University Press; 1966.

32. Small Power Systems Study. Quarterly Report No. 1. SERI-36. Golden, CO: Solar Energy Research Institute; July 1978.

33. Recommendations for the Conceptual Designs of the Barstow, California, Solar Central Receiver Pilot Plant. Executive Summary. SAND-77-8035. Sandia Laboratories; Oct. 1977.

34. Solar Central Receiver Prototype Heliostat. Phase 1, Final Technical Report. SAND-1468-1. Schenectady, N.Y.: General Electric; Oct. 1978.

35. Conceptual Design of Advanced Central Receiver Power System. Phase 1, Executive Summary. Martin Marietta Corp.; Sept. 1978.

36. Prototype/Second-Generation Heliostat Evaluation and Recommendations. Executive Summary. SAND-78-8265. Sandia Laboratories; Oct. 1978.

37. Vant-Mull, L. L. "Development of Solar Tower Program in the United States." Optical Engineering. Vol. 16 (No. 6): Nov.-Dec. 1977. 
38. Marshall, B. W. "Operation of the Solar Thermal Test Facility." Department of Energy Large Solar Central Power Systems Semiannual Review. SAND-78-8511. Sandia Laboratories; Nov. 1978.

39. Wilson, W. G. "An Overview of the Heliostat Development Program." Proceedings of the 1978 DOE Workshop on System Studies for Central Solar Thermal Electric; Mar. 27-30, 1978. University of Houston Solar Energy Laboratory; Oct. 1978.

40. Schell, Allen C. Preliminary Design Study of a Flat Plate Reflector and Support Unit. Hughes Aircraft Co.; May 1964.

41. Nourse, J.H. Prototype Heliostat Costing Scenario. Final Report. Huntington Bearh, C.A: MeDonnell Douglas $\Lambda$ stronauties Company; July 1979.

42. Development of Surrogate Experience Curves for Costs Associated with the Production of Heliostats. Final Report. Cambridge, MA: Arthur D. Little, Inc.; Sept. 1979. 
APPENDIX A

SUMMARY OF DATA ACQUIRED FOR SELECTED SURROGATE PRODUCTS 


\section{SE라}


Table A-1. SURROGATE 1A-PLYWOOD (Total) ${ }^{a}$

\begin{tabular}{|c|c|c|c|c|c|}
\hline \multirow[b]{2}{*}{ Year } & \multicolumn{2}{|c|}{$\begin{array}{l}\text { Production } \\
\left(\text { feet } \times 10^{9}\right)\end{array}$} & \multirow{2}{*}{$\begin{array}{l}\text { No. of } \\
\text { Workers } \\
\text { (per m }\end{array}$} & $\begin{array}{c}\text { Hours } \\
\text { Worked }\end{array}$ & \multirow{2}{*}{$\begin{array}{c}\text { Labor } \\
\text { Cost } \\
\left(\begin{array}{ll}\text { ( 1 } \\
3\end{array}\right) \\
\text { etion) }\end{array}$} \\
\hline & Annual & Cumulative & & feet of $p$ & \\
\hline 1960 & 7.8 & 75.3 & $4.9^{b}$ & & \\
\hline 1965 & 12.6 & 127.7 & $3.5^{\mathrm{b}}$ & & \\
\hline 1970 & 14.1 & 195.4 & $2.8^{\mathrm{b}}$ & & \\
\hline 1972 & 17.8 & 229.6 & 2.2 & 5.04 & $\$ 12.64$ \\
\hline 1973 & 17.9 & 247.6 & 2.3 & 4.97 & 10.94 \\
\hline 1974 & 15.3 & 262.9 & 2.4 & 5.12 & 12.58 \\
\hline 1975 & 15.7 & 278.6 & 2.2 & 4.54 & 11.41 \\
\hline 1976 & 17.8 & 296.4 & 2.2 & 4.78 & 10.96 \\
\hline 1977 & 19.7 & 316.1 & 2.1 & 4.55 & 9.58 \\
\hline
\end{tabular}

asource: American Plywood Association.

${ }^{b}$ Estimates derived from employment figures for softwood plus hardwood plywood.

Table A-2. SURROGATE 1A-PLYWOOD (West) ${ }^{\text {a }}$

\begin{tabular}{|c|c|c|c|c|c|}
\hline \multirow[b]{2}{*}{ Year } & \multicolumn{2}{|c|}{$\begin{array}{l}\text { Production } \\
\left(\text { feet } \times 10^{9}\right)\end{array}$} & \multirow[t]{2}{*}{$\begin{array}{l}\text { Direct } \\
\text { Labor }\end{array}$} & \multirow{2}{*}{$\begin{array}{c}\text { Material } \\
\text { Cost } \\
\text { (per } 10^{3} \text { feet). }\end{array}$} & \multirow[t]{2}{*}{$\begin{array}{l}\text { Total } \\
\text { Cost }\end{array}$} \\
\hline & Annual & Cumulative & & & \\
\hline 1965 & 11.3 & 125.0 & $\$ 15.95$ & $\$ 30.58$ & $\$ 58.51$ \\
\hline 1970 & 10.1 & 177.4 & 17.12 & 35.06 & 65.90 \\
\hline 1975 & 9.3 & 231.3 & 15.27 & 33.27 & 60.80 \\
\hline 1977 & 10.7 & 263.3 & 12.97 & 29.39 & 51.74 \\
\hline
\end{tabular}

${ }^{8}$ American Plywood Association. 
Table A-3. SURROGATE 1A-PLYWOOD (South) ${ }^{a}$

\begin{tabular}{|c|c|c|c|c|c|}
\hline \multirow[b]{2}{*}{ Year } & \multicolumn{2}{|c|}{$\begin{array}{c}\text { Production } \\
\left(\text { feet } \times 10^{9}\right)\end{array}$} & \multirow[t]{2}{*}{$\begin{array}{l}\text { Direct } \\
\text { Labor }\end{array}$} & \multirow{2}{*}{$\begin{array}{c}\text { Material } \\
\text { Cost } \\
\text { (per } 10^{3} \text { feet) }\end{array}$} & \multirow[t]{2}{*}{$\begin{array}{l}\text { Total } \\
\text { Cost }\end{array}$} \\
\hline & Annual & Cumulative & & & \\
\hline $\begin{array}{l}1965 \\
1970 \\
1975 \\
1977\end{array}$ & $\begin{array}{l}1.14 \\
3.32 \\
5.68 \\
7.45\end{array}$ & $\begin{array}{r}1.62 \\
11.96 \\
38.06 \\
52.32\end{array}$ & $\begin{array}{r}\$ 10.23 \\
\cdot 6.69 \\
.6 .66 \\
6.02\end{array}$ & $\begin{array}{r}\$ 25.12 \\
27.17 \\
24.25 \\
20.95\end{array}$ & $\begin{array}{r}\$ 54.21 \\
55.00 \\
48.58 \\
40.30\end{array}$ \\
\hline
\end{tabular}

a American Plywood Association.

Trhle A-4. SUKKOGATE IA TLYWOOD CORPORATION ${ }^{\mathrm{a}}$

\begin{tabular}{ccr}
\hline Year & Production & Manhours \\
\hline 1966 & 8,299 & 55,019 \\
1967 & 34,393 & 290,439 \\
1968 & 46,945 & 262,377 \\
1969 & 46,679 & 239,186 \\
1970 & 48,208 & 248,176 \\
1971 & 59,063 & 291,685 \\
1972 & 55,345 & 301,430 \\
1973 & 48,729 & 271,029 \\
1974 & 47,247 & 276,036 \\
1975 & 50,678 & 293,496 \\
1976 & 55,146 & 308,789 \\
1977 & 57,230 & 317,840 \\
1978 & 59,559 & 324,830 \\
1979 & 34,914 & 168,044 \\
\hline
\end{tabular}

${ }^{a_{C}}$ Confidential source (plywood Corporation). 
Table A-5. SURROGATE 1A-PLYWOOD AND VENEER ${ }^{8}$

\begin{tabular}{ccrrr}
\hline Year & $\begin{array}{c}\text { Production } \\
\left(\text { tons } \times 10^{6}\right)\end{array}$ & $\begin{array}{c}\text { Direct } \\
\text { Labor } \\
\left(\times 10^{6}\right)\end{array}$ & $\begin{array}{r}\text { Material } \\
\text { Cost } \\
(\mathrm{x} \mathrm{10})\end{array}$ & $\begin{array}{r}\text { Total } \\
\text { Cost } \\
(\mathrm{x} \mathrm{106})\end{array}$ \\
\hline 1967 & 7.7 & $\$ 335.7$ & $\$ 931.4$ & $\$ 1,384.4$ \\
1968 & 8.6 & 322.1 & 946.4 & $1,377.9$ \\
1969 & 8.0 & 300.1 & 925.9 & $1,334.7$ \\
1970 & 8.3 & 332.7 & 990.1 & $1,446.4$ \\
1971 & 9.7 & 346.8 & $1,103.6$ & $1,579.4$ \\
1972 & 10.4 & 357.8 & $1,218.7$ & $1,702.9$ \\
1973 & 10.4 & 326.4 & $1,187.3$ & $1,628.7$ \\
1974 & 9.0 & $\mathrm{NA}$ & $\mathrm{NA}$ & $\mathrm{NA}$ \\
1975 & 8.7 & 386.8 & $1,132.9$ & $1,534.5$ \\
1976 & 9.9 & 295.4 & $1,230.4$ & $1,638.0$ \\
\hline
\end{tabular}

${ }^{a}$ Predicasts.

Table A-6. SURROGATE 1B-AIRCRAFT WINDSHIELD ${ }^{a}$

\begin{tabular}{ccc}
$\begin{array}{c}\text { No. of Units } \\
\text { Produced in Lot }\end{array}$ & $\begin{array}{c}\text { Geometric } \\
\text { Mean }^{\mathrm{b}}\end{array}$ & $\begin{array}{c}\text { Unit Cost } \\
\text { (Direct Labor Hours) }\end{array}$ \\
\hline 4 & 2.2 & 97 \\
4 & 6.4 & 79 \\
22 & 20.6 & 149 \\
4 & 31.3 & 181 \\
3 & 32.4 & 468 \\
9 & $\cdot 52.7$ & 190 \\
35 & 59.3 & 153 \\
42 & 137.0 & 94 \\
35 & 146.8 & 73 \\
15 & 203.0 & 182 \\
29 & 238.5 & 92 \\
18 & 241.4 & 141 \\
. &. &
\end{tabular}

${ }^{\mathrm{a}}$ Confidential source (aircraft manufacturer).

bunits were not produced sequentially within lots; plot points were calculated according to geometric mean of actual production sequence. 
Table A-7. SURROGATE 1C-LAMINATED MIRRORS ${ }^{\mathbf{a}}$

\begin{tabular}{cccc}
\hline Year & $\begin{array}{c}\text { Direct } \\
\text { Labor Cost } \\
\left(\times 10^{6}\right)\end{array}$ & $\begin{array}{c}\text { Material } \\
\text { Cost } \\
\left(\times 10^{6}\right)\end{array}$ & $\begin{array}{r}\text { Total } \\
\text { Cost } \\
\left(\times 10^{6}\right)\end{array}$ \\
\hline 1967 & $\$ 27.12$ & $\$ 81.97$ & $\$ 125.1$ \\
1968 & 28.09 & 86.72 & 131.3 \\
1969 & 30.54 & 97.54 & 146.9 \\
1970 & 29.08 & 84.26 & 132.7 \\
1971 & 30.70 & 97.55 & 148.1 \\
1972 & 42.67 & 135.69 & 205.6 \\
1973 & 14.69 & 138.69 & 211.7 \\
1974 & 46.47 & 135.08 & 211.7 \\
1975 & 49.94 & 141.82 & 241.6 \\
1970 & 52.80 & 162.32 & 253.9 \\
\hline
\end{tabular}

Q Predicasts.

Table A-8. SURROGATE 2A-AIRCRAFT LANDING GEAR ${ }^{2}$

\begin{tabular}{ccc}
\hline $\begin{array}{c}\text { No. of Units } \\
\text { Produced in Lot }\end{array}$ & $\begin{array}{c}\text { Geometric } \\
\text { Mean }^{\text {b }}\end{array}$ & $\begin{array}{c}\text { Unit Cost } \\
\text { (Direct Labor Hours) }\end{array}$ \\
\hline 4 & 3.9 & 238 \\
4 & 5.4 & 2.18 \\
32 & 18.8 & 124 \\
4 & 29.5 & 140 \\
3 & 31.2 & 100 \\
9 & 45.7 & 111 \\
35 & 60.5 & 97 \\
42 & 114.6 & 135 \\
35 & 121.5 & 107 \\
15 & 161.9 & 155 \\
29 & 196.0 & 157 \\
18 & 197.4 & 79 \\
\hline
\end{tabular}

${ }^{a}$ Confidential source (aircraft manufacturer).

bUnits were not produced sequentially within lots; plot points were calculated according to geometric mean of actual production sequence. 
Table A-9. SURROGATE 3A-PERSONAL ELECTRONIC CALCULATORS ${ }^{a}$

\begin{tabular}{lcccc}
\hline Year & $\begin{array}{c}\text { Production } \\
\left(\text { tons } \times 10^{6}\right)\end{array}$ & $\begin{array}{c}\text { Direct } \\
\text { Labor } \\
\left(\times 10^{6}\right)\end{array}$ & $\begin{array}{c}\text { Material } \\
\text { Cost } \\
\left(\times 10^{6}\right)\end{array}$ & $\begin{array}{r}\text { Total } \\
\text { Cost } \\
\left(\times 10^{6}\right)\end{array}$ \\
\hline 1974 & 12.0 & $\$ 130$ & $\$ 415$ & $\$ 603$ \\
1975 & 16.0 & 84 & 320 & 513 \\
1976 & 17.5 & 43 & 196 & 316 \\
1977 & 18.7 & 65 & 244 & 393 \\
\hline
\end{tabular}

${ }^{\text {a Predicasts. }}$

Table A-10. SURROGATES 4A AND 8C-STEEL PIPES AND TUBES ${ }^{a}$

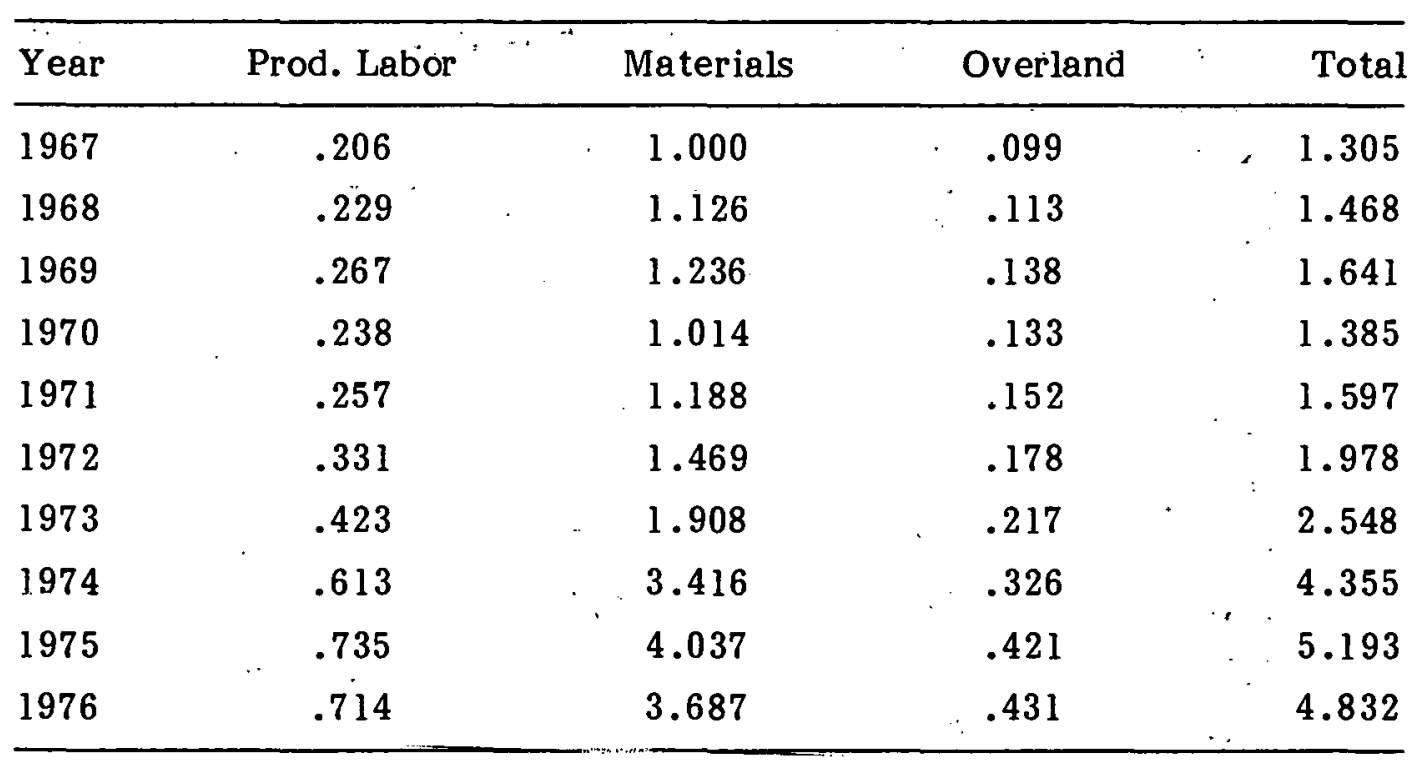

${ }^{\text {a }}$ Predicasts. 
Table A-11. SURROGATE 5A-STEEL STUDS ${ }^{2}$

\begin{tabular}{cccc}
\hline Year & $\begin{array}{c}\text { Production } \\
\left(\text { feet } \times 10^{3}\right)\end{array}$ & $\begin{array}{c}\text { Materials } \\
\text { Cost/Ft }\end{array}$ & $\begin{array}{c}\text { Other Cost/Ft } \\
\text { (incl. Profit Margin) }\end{array}$ \\
\hline 1975 & 150.1 & $\$ .116$ & $\$ .063$ \\
1976 & 506.0 & .126 & .059 \\
1977 & 1196.0 & .137 & .059 \\
1978 & 1176.0 & .149 & .058 \\
1979 & 1067.0 & .169 & .044 \\
\hline
\end{tabular}

${ }^{a}$ Confidential source (building component manufacturer).

Estimate from price data and wholesale price index for galvanized carbon steel sheets:

Table A-12. SURROGATES 5B-METAL DOOR SASH AND TRIM ${ }^{\mathrm{a}}$

\begin{tabular}{ccccc}
\hline Year & Prod. Labor & Materials & Overland & Total \\
\hline 1967 & .308 & 1.000 & .241 & 1.549 \\
1968 & .329 & 1.059 & .253 & 1.641 \\
1969 & .363 & 1.140 & .294 & 1.797 \\
1970 & .383 & 1.186 & .306 & 1.875 \\
1971 & .424 & 1.424 & .344 & 2.192 \\
1972 & .520 & 1.709 & .415 & 2.644 \\
1973 & .556 & 1.769 & .434 & 2.759 \\
1974 & .672 & 2.297 & .505 & 3.474 \\
1975 & .620 & 2.299 & .509 & 3.428 \\
1976 & .748 & 2.879 & .621 & 4.239 \\
\hline
\end{tabular}

${ }^{\text {B}}$ Predicasts. 
Table A-13. SURROGATES 5C AND 8B-METAL HOUSEHOLD FURNTUURE ${ }^{a}$

\begin{tabular}{lllll}
\hline Year & Prod. Labor & Materials & Overland & Total \\
\hline 1967 & .351 & 1.000 & .202 & 1.553 \\
1968 & .397 & 1.099 & .223 & 1.719 \\
1969 & .455 & 1.209 & .241 & 1.905 \\
1970 & .456 & 1.253 & .276 & 1.985 \\
1971 & .477 & 1.356 & .306 & 2.139 \\
1972 & .574 & 1.649 & .35 & 2.573 \\
1973 & .675 & 1.921 & .422 & 3.018 \\
1974 & .759 & 2.270 & .500 & 3.529 \\
1975 & .709 & 2.193 & .506 & 3.408 \\
1976 & .865 & 2.694 & .614 & 4.173 \\
\hline
\end{tabular}

${ }^{a}$ Predicasts.

Table A-14. SURROGATE 6A-DRIVE WHEEL TRANSMISSION ${ }^{\mathrm{a}}$

\begin{tabular}{ccccc}
\hline $\begin{array}{c}\text { Production } \\
\text { Year }\end{array}$ & Volume & Manufacturer & $\begin{array}{c}\text { Percent Change } \\
\text { Labor }\end{array}$ & Total \\
\hline $1975-76$ & 6,325 & $+2.3 \%$ & $-5.6 \%$ & $-2.1 \%$ \\
$1976-77$ & 11,431 & +6.2 & -3.7 & +2.1 \\
$1977-78$ & 14,303 & +0.4 & -7.1 & -2.9 \\
$1978-79$ & 12,448 & +0.6 & -1.7 & -0.3 \\
\hline
\end{tabular}

${ }^{a}$ Confidential source (vehicle manufacturer).

${ }^{b}$ Percentages are based on dollar change in standard cost exclusive of economics or accounting changes over the time period indicated; 1975 was the first full year of production. 
Table A-15. SURROGATES 8D-FABRICATED PIPES AND FITTINGS ${ }^{\circledR}$

\begin{tabular}{ccccc}
\hline Year & Prod. Labor & Materials & Overland & Total \\
\hline 1967 & .316 & 1.000 & .207 & 1.523 \\
1968 & .371 & 1.245 & .216 & 1.832 \\
1969 & .332 & 1.417 & .223 & 1.972 \\
1970 & .419 & 1.198 & .265 & 1.882 \\
1971 & .475 & 1.464 & .323 & 2.262 \\
1972 & .562 & 1.759 & .377 & 2.698 \\
1973 & .661 & 2.324 & .443 & 3.428 \\
1974 & 1.131 & 4.010 & .680 & 5.721 \\
1975 & 1.388 & 5.796 & .951 & 8.135 \\
1976 & 2.251 & 7.754 & 1.241 & 11.246 \\
\hline
\end{tabular}

${ }^{\text {a }}$ Predicasts.

Table A-16. SURROGATE 9B-AIRCRAPT CANOPY ${ }^{\mathrm{a}}$

\begin{tabular}{cccc}
\hline $\begin{array}{c}\text { No. of Units } \\
\text { Produced in Lot }\end{array}$ & $\begin{array}{c}\text { Geometric } \\
\text { Means }^{\mathrm{b}}\end{array}$ & $\begin{array}{c}\text { Actual Unit Cost } \\
\text { (Direct Labor Hours) }\end{array}$ & $\begin{array}{c}\text { Adjusted } \\
\text { Unit Cost }^{\mathrm{c}}\end{array}$ \\
\hline 4 & 2.6 & 1,134 & 646 \\
4 & 14.1 & 234 & 391 \\
35 & 25.1 & 239 & 331 \\
42 & 82.3 & 94 & 233 \\
35 & 89.9 & 192 & 226 \\
15 & 130.9 & 115 & 203 \\
29 & 156.8 & 89 & 192 \\
\hline
\end{tabular}

${ }^{a}$ Confidential source (aircraft manufacturer).

${ }^{b}$ Units were not produced sequentially within lots; plot points were calculated according to geometric mean of actual production sequence; e.g., first lot contained first, second, fourth, and sixth items produced.

${ }^{c}$ Actual costs were demonstrated to be excessive relative to experience of previous manufacturer; cost estimates were subsequently derived to ADL study to account for differences. 
Table A-17. SURROGATE 9E-HELICOPTER BLADE LNNERS

\begin{tabular}{|c|c|c|c|c|}
\hline Year & $\begin{array}{l}\text { No. of } \\
\text { Units }\end{array}$ & $\begin{array}{l}\text { Direct } \\
\text { Labor }\end{array}$ & Materials & Total \\
\hline 1969 & 10 & $\$ 1,132$ & $\$ 686$ & $\$ 4,422$ \\
\hline $\begin{array}{l}1970 \\
1971\end{array}$ & 509 & 34,788 & 24,008 & 129,241 \\
\hline $\begin{array}{l}1972 \\
1973\end{array}$ & $\begin{array}{r}705 \\
1161\end{array}$ & $\begin{array}{l}36,508 \\
59,908\end{array}$ & $\begin{array}{l}33,379 \\
57,901\end{array}$ & $\begin{array}{l}133,776 \\
189,698\end{array}$ \\
\hline 1974 & $909^{b}$ & & (data missing) & \\
\hline $\begin{array}{l}1975 \\
1976\end{array}$ & 657 & $\overline{22,299}$ & 29,304 & 74,437 \\
\hline $\begin{array}{l}1977 \\
1978\end{array}$ & 1200 & 35,252 & 49,840 & 114,986 \\
\hline 1979 & 1450 & 35,706 & 55,585 & 114,500 \\
\hline
\end{tabular}

${ }^{a}$ Confidential source (plastic components manufacturer).

${ }^{b}$ Estimated production used to determine plot point.

Table A-18. SURROGATES IOA-TRUCKS AND BUS BODIES ${ }^{\circledR}$

\begin{tabular}{ccccc}
\hline Year & Prod. Labor & Materials & Overland & Total \\
\hline 1967 & .368 & 1.000 & .199 & 1.567 \\
1968 & .427 & 1.181 & .223 & 1.831 \\
1969 & .468 & 1.274 & .259 & 2.001 \\
1970 & .509 & 1.440 & .319 & 2.268 \\
1971 & .541 & 1.757 & .357 & 2.655 \\
1972 & .769 & 2.950 & .495 & 4.214 \\
1973 & .844 & 2.910 & .520 & 4.274 \\
1974 & .836 & 2.940 & .508 & 4.284 \\
\hline
\end{tabular}

${ }^{\mathbf{a}}$ Predicasts. 
Table A-19. SURROGATE 10B-WING STRUCTURE ${ }^{2}$

\begin{tabular}{crcr}
\hline $\begin{array}{c}\text { No. of Units } \\
\text { Produced in Lot }\end{array}$ & $\begin{array}{c}\text { Geometric } \\
\text { Means }\end{array}$ & $\begin{array}{c}\text { Actual Unit Cost } \\
\text { (Direct Labor Hours) }\end{array}$ & $\begin{array}{r}\text { Adjusted } \\
\text { Unit Cost }^{c}\end{array}$ \\
\hline 4 & 4.4 & 6,538 & 4,707 \\
4 & 4.7 & 6,170 & 4,603 \\
22 & 20.3 & 2,895 & 2,984 \\
3 & 21.5 & 3,139 & 2,962 \\
4 & 28.8 & 3,178 & 3,213 \\
9 & 43.8 & 1,347 & 2,400 \\
35 & 60.4 & 1,671 & 2,165 \\
42 & 114.6 & 1,362 & 2,128 \\
35 & 121.4 & 1,185 & 1,759 \\
15 & 163.3 & 1,024 & 1,611 \\
29 & 194.8 & 1,091 & 1,818 \\
18 & 198.3 & 1,072 & 1,534 \\
\hline
\end{tabular}

${ }^{\mathrm{a}}$ Confidential source (aircraft manufacturer).

bunits were not produced sequentially within lots; plot points were calculated according to geometric mean of actual production sequence.

${ }^{c}$ Actual costs were demonstrated to be excessive relative to experience of previous manufacturer; cost estimates were subsequently derived to ADL study to account for differences.

Table A-20. SURROGATES 11 A-MOTOR VEHICLES ${ }^{\mathrm{a}}$

\begin{tabular}{lcccc}
\hline Year & Prod. Labor & Materials & Overland & Total \\
\hline 1967 & .105 & 1.000 & .045 & 1.150 \\
1968 & .136 & 1.249 & .055 & 1.440 \\
1969 & .138 & 1.309 & .059 & 1.507 \\
1970 & .126 & 1.194 & .061 & 1.321 \\
1971 & .178 & 1.651 & .075 & 1.904 \\
1972 & .202 & 1.853 & .086 & 2.141 \\
1973 & .246 & 2.203 & .106 & 2.555 \\
1974 & .232 & 2.159 & .109 & 2.500 \\
\hline
\end{tabular}

${ }^{\mathbf{a}}$ Predicasts. 
Table A-21. SUMMARY STATISTICS

\begin{tabular}{|c|c|c|c|c|c|c|c|c|c|}
\hline$\frac{\text { Component }}{\text { Reflectors }}$ & $\begin{array}{c}\begin{array}{c}\text { Data } \\
\text { Table }\end{array} \\
4\end{array}$ & \multicolumn{2}{|c|}{ Surrogate } & Cost Element & $\begin{array}{l}\text { Estimated } \\
\text { Learning } \%^{a}\end{array}$ & Slope & $\mathrm{R}^{2 \mathrm{~b}}$ & $\begin{array}{c}\text { No. of } \\
\text { Data } \\
\text { Points }\end{array}$ & $\begin{array}{c}95 \% \\
\text { Confidence } \\
\text { Interval } \\
\text { For Slope }\end{array}$ \\
\hline Reflec tors & 4 & $\begin{array}{c}\text { Ply wood } \\
" \\
" \\
" \\
" \\
" \\
" \\
" \\
"\end{array}$ & (South) & $\begin{array}{l}\text { No. of Workers } \\
\text { Production Labor } \$ \\
\text { Labor Hours } \\
\text { Total \$ } \\
\text { Labor \$ } \\
\text { Material \$ } \\
\text { Total \$ } \\
\text { Labor \$ } \\
\text { Material \$ }\end{array}$ & $\begin{array}{l}67 \% \\
64 \% \\
80 \% \\
92 \% \\
85 \% \\
99 \% \\
96 \% \\
92 \% \\
98 \%\end{array}$ & $\begin{array}{l}-0.59 \\
-0.57 \\
-0.33 \\
-0.12 \\
-0.23 \\
-0.02 \\
-0.06 \\
-0.13 \\
-0.03\end{array}$ & $\begin{array}{l}0.97 \\
0.57 \\
0.58 \\
0.16 \\
0.46 \\
0.01 \\
0.53 \\
0.92 \\
0.29\end{array}$ & $\begin{array}{l}9 \\
6 \\
6 \\
4 \\
4 \\
4 \\
4 \\
4 \\
4\end{array}$ & $\begin{array}{l}62.0-71.0 \\
37.0-109.0 \\
61.0-104.0 \\
52.1-162.8 \\
50.0-146.0 \\
60.3-161.3 \\
85.2-108.2 \\
87.0-96.0 \\
87.5-109.1\end{array}$ \\
\hline & 7 & \multicolumn{2}{|c|}{ Plywood Corp. } & Labor Hours & $76 \%$ & -0.39 & 0.99 & 4 & $70.0-82.8$ \\
\hline & 8 & \multicolumn{2}{|c|}{ Ply wood/Veneer } & Total \$ (CUM) & $98 \%$ & -0.03 & 0.79 & 7 & $96.6-99.0$ \\
\hline & - & $"$ & $"$ & Labor \$ (CUM) & $95 \%$ & -0.07 & 0.95 & 7 & $94.0-96.0$ \\
\hline & & $"$ & $"$ & Material \$ (CUM) & $99 \%$ & -0.02 & 0.47 & 7 & $97.7-100.1$ \\
\hline & & $"$ & $"$ & Total $\$$ & $99 \%$ & -0.02 & 0.13 & 9 & $96.3-101.5$ \\
\hline & & $"$ & in & Labor $\$$ & $93 \%$ & -0.11 & 0.79 & 9 & $90.0-96.0$ \\
\hline & 9 & \multicolumn{2}{|c|}{ Aircraft Windshield } & Labor Hours & $100 \%$ & 0.005 & 0 & .12 & $82.2-120.9$ \\
\hline & 10 & \multicolumn{2}{|c|}{$\underset{\|}{\text { Laminated Mirrors }}$} & $\begin{array}{l}\text { Total \$ (CUM) } \\
\text { Labor } \$(C U M) \\
\text { Labor } \$\end{array}$ & $\begin{array}{l}100 \% \\
100 \% \\
100 \%\end{array}$ & $\begin{array}{c}0.01 \\
-0.002 \\
-0.002\end{array}$ & $\begin{array}{l}0.41 \\
0.04 \\
0.06\end{array}$ & $\begin{array}{l}10 \\
10 \\
10\end{array}$ & $\begin{array}{r}100.0-101.0 \\
99.2-100.5 \\
99.3-100.3\end{array}$ \\
\hline
\end{tabular}

${ }^{a}$ Percent reduction in cost for each doubling of quantity.

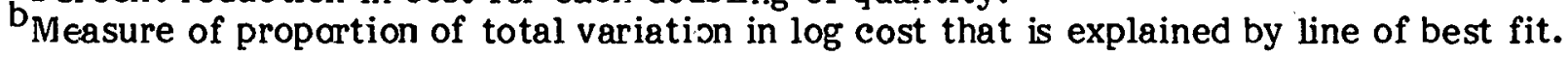


Table A-21. SUMMARY STATISTICS (continued)

\begin{tabular}{|c|c|c|c|c|c|c|c|c|}
\hline Component & $\begin{array}{l}\text { Data } \\
\text { Table }\end{array}$ & Surrogate & Cost Element & $\begin{array}{l}\text { Estimated } \\
\text { Learning } \%^{a}\end{array}$ & Slope & $\mathrm{R}^{2 \mathrm{~b}}$ & $\begin{array}{l}\text { No. of } \\
\text { Data } \\
\text { Points }\end{array}$ & $\begin{array}{c}95 \% \\
\text { Confidence } \\
\text { Interval } \\
\text { For Slope }\end{array}$ \\
\hline \multirow[t]{2}{*}{ Elevation } & 11 & Aircraft Landing Gear & Labors Hours & $90 \%$ & -0.15 & 0.38 & 12 & $81.9-98.9$ \\
\hline & -c $^{c}$ & $\begin{array}{l}\text { Sleeve and Plunger, } \\
\text { Aileron Power } \\
\text { Cont:ol Cylinder } \\
(\mathrm{F}=4 \mathrm{~A} / \mathrm{C})\end{array}$ & Man Hours & $88 \%$ & -0.19 & NA & 9 & NA \\
\hline \multirow[t]{3}{*}{$\begin{array}{l}\text { Drive } \\
\text { Controls }\end{array}$} & 12 & $\begin{array}{l}\text { Personnel Electronic } \\
\text { Calculators }\end{array}$ & Total $\$(C U M)$ & $76 \%$ & -0.39 & 0.99 & 4 & $70.6-82.4$ \\
\hline & & $\begin{array}{ll}" & " \\
" & " \\
n & " \\
n & "\end{array}$ & $\begin{array}{l}\text { Labor } \$(C U M) \\
\text { Material } \$(C U M) \\
\text { Total } \$ \\
\text { Labor } \$ \\
\text { Material } \$\end{array}$ & $\begin{array}{l}72 \% \\
76 \% \\
72 \% \\
67 \% \\
72 \%\end{array}$ & $\begin{array}{l}-0.47 \\
-0.39 \\
-0.48 \\
-0.58 \\
-0.47\end{array}$ & $\begin{array}{l}0.99 \\
0.99 \\
0.91 \\
0.86 \\
0.91\end{array}$ & $\begin{array}{l}4 \\
4 \\
4 \\
4 \\
4\end{array}$ & $\begin{array}{l}66.0-79.0 \\
70.7-82.6 \\
52.9-97.8 \\
41.0-111.0 \\
52.8-98.2\end{array}$ \\
\hline & $-\mathbf{c}$ & $\begin{array}{l}\text { Memory Unit-Saturn } \\
\text { Computer }\end{array}$ & Mfg. Hours & $78 \%$ & -0.36 & NA & 10 & NA \\
\hline
\end{tabular}

a Percent reduetion in cost for each doubling of quartity.

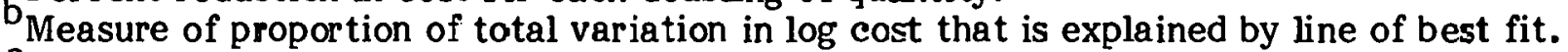

${ }^{c}$ Learning curve estimate summarized in "Report on Improvement Curve Experience," DCAAP 7641.14, April, 1970. 
Table A-21. SUMMARY STATISTICS (continued)

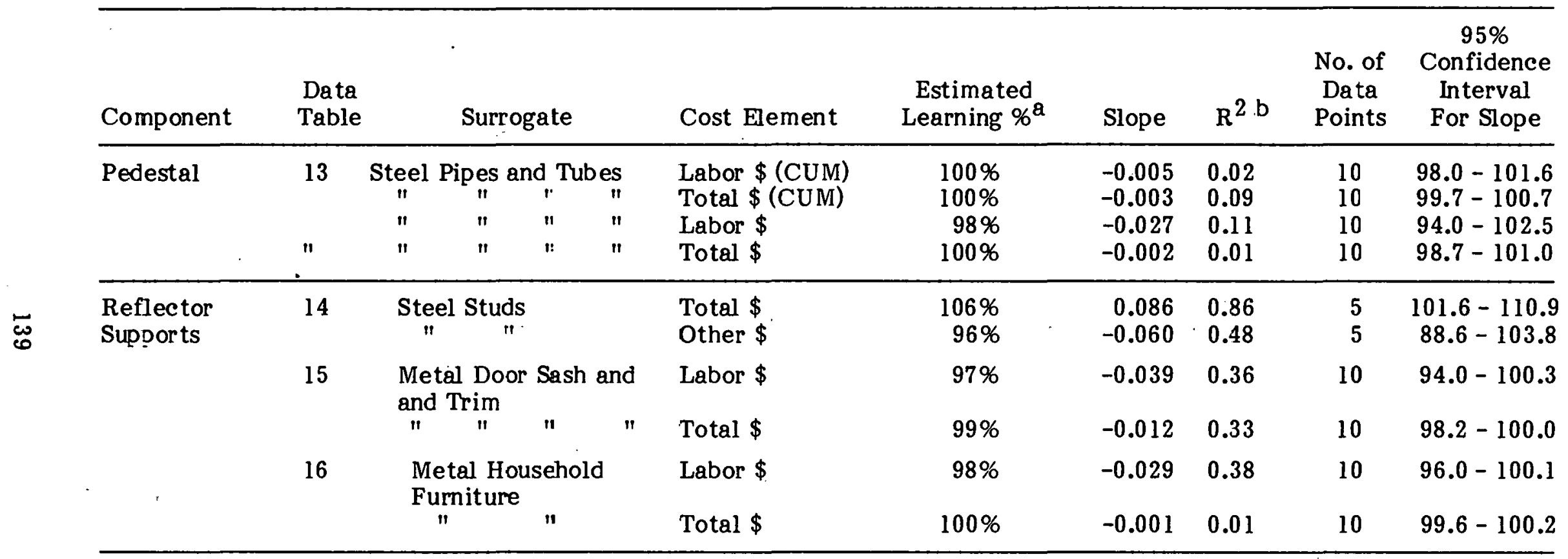

a Percent reduction in cost for each doubling of quantity.

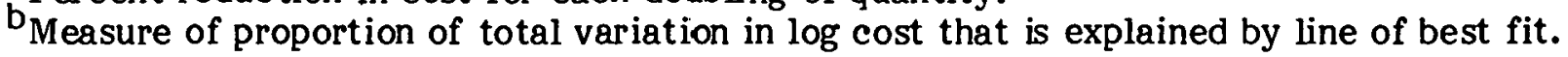


Table A-21. SUMMARY STATISTICS (contirued)

\begin{tabular}{|c|c|c|c|c|c|c|c|c|}
\hline Component & $\begin{array}{l}\text { Data } \\
\text { Table }\end{array}$ & Surrogate & Cost Element & $\begin{array}{l}\text { Estimated } \\
\text { Learning } \%^{\mathrm{g}}\end{array}$ & Slofe & $\mathrm{R}^{2 \mathrm{~b}}$ & $\begin{array}{c}\text { No. of } \\
\text { Data } \\
\text { Points }\end{array}$ & $\begin{array}{c}95 \% \\
\text { Confidence } \\
\text { Interval } \\
\text { For Slope }\end{array}$ \\
\hline \multirow[t]{7}{*}{$\begin{array}{l}\text { Azimuth } \\
\text { Gear } \\
\text { Box }\end{array}$} & 17 & $\begin{array}{c}\text { Drive Wheel Transmission } \\
" ~\end{array}$ & $\begin{array}{l}\text { Total (\%. Change) } \\
\text { Labor (\% Change) } \\
\text { Material (\% Change) }\end{array}$ & $\begin{array}{r}100 \% \\
96 \% \\
102 \%\end{array}$ & $\begin{array}{l}-0.015 \\
-3.052 \\
-0.027\end{array}$ & $\begin{array}{l}0.16 \\
0.92 \\
0.90\end{array}$ & $\begin{array}{l}4 \\
4 \\
4\end{array}$ & $\begin{array}{l}97.3-102.1 \\
93.0-99.7 \\
99.8-104.0\end{array}$ \\
\hline & $-{ }^{c}$ & $\begin{array}{l}\text { Constant Speed Drive } \\
\text { Transmission }\end{array}$ & Direct Labor Hours & $92 \%$ & -0.12 & NA & 26 & NA \\
\hline & $-c$ & $\begin{array}{l}\text { SM } \text {;05/737 Truck } \\
\text { Transmission }\end{array}$ & $\begin{array}{l}\text { Production Dir. } \\
\text { Labor Hrs. }\end{array}$ & $91 \%$ & -0.14 & NA & 5 & N/A \\
\hline & $-c$ & M551 Tank Transmission & Direct Labor Hours & $96 \%$ & -0.053 & NA & 16 & NA \\
\hline & -c & TX-100 Transmission & Direct Labor Hours & $87 \%$ & -0.20 & NA & 28 & NA \\
\hline & $-c$ & XTG-250 Transmission & Direct Labor Hours & $87 \%$ & -0.20 & NA & 12 & NA \\
\hline & $-c$ & XTGY112A Transmission & Direct Labor Hours & $83 \%$ & -0.25 & $\mathrm{NA}$ & 27 & NA \\
\hline
\end{tabular}

Azimuth No Data Available

Drive

Hub

${ }^{2}$ Percent reduction in cost for each doubling of quentity.

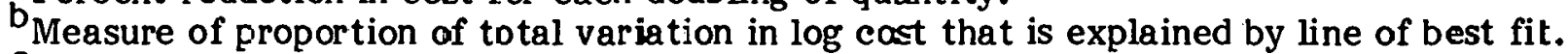

cearning curve estimate summarized in "Report on Improvement Curve Experience," DCAAP 7641.14, April, 1970. 
Table A-21. SUMMARY STATISTICS (continued)

\begin{tabular}{|c|c|c|c|c|c|c|c|c|}
\hline $\begin{array}{l}\text { Reflector } \\
\text { Yoke }\end{array}$ & 18 & $\begin{array}{cccc}\text { Fabricated Piping and Fittings } \\
" 1 & " 1 & " 1 & " \\
" & " & " 1 & "\end{array}$ & $\begin{array}{l}\text { Labor } \$(C U M) \\
\text { Total } \$(C U M) \\
\text { Labor } \$ \\
\text { Total } \$\end{array}$ & $\begin{array}{l}98 \% \\
99 \% \\
98 \% \\
99 \%\end{array}$ & $\begin{array}{l}-0.025 \\
-0.009 \\
-0.030 \\
-0.012\end{array}$ & $\begin{array}{l}0.37 \\
0.38 \\
0.08 \\
0.12\end{array}$ & $\begin{array}{l}10 \\
10 \\
10 \\
10\end{array}$ & $\begin{array}{l}96.0-100.1 \\
98.7-100.0 \\
92.0-103.9 \\
97.3-101.1\end{array}$ \\
\hline \multirow[t]{2}{*}{$\begin{array}{l}\text { Reflector } \\
\text { Enclosure }\end{array}$} & 19 & Aircraft Canopy & $\begin{array}{l}\text { Labor Hours } \\
\text { (Actual) }\end{array}$ & $68 \%$ & -0.56 & 0.88 & 7 & $58.0-79.9$ \\
\hline & & $"$ & $\begin{array}{l}\text { Labor Hours } \\
\text { (Adjusted) }\end{array}$ & $81 \%$ & -0.30 & 1.00 & 7 & $81.3-81.6$ \\
\hline
\end{tabular}

a Percent reduction in cost for each doubling of quantity.

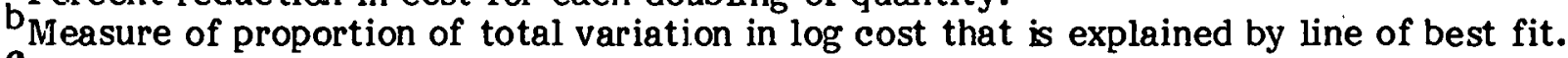

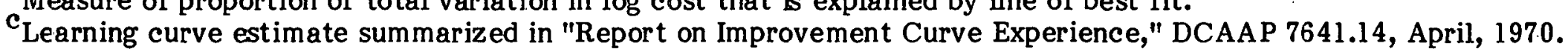


Table A-21. SUMMARY STATISTICS (concludeć)

\begin{tabular}{|c|c|c|c|c|c|c|c|c|}
\hline Component & $\begin{array}{l}\text { Data } \\
\text { Table }\end{array}$ & Surrogate & Cost Element & $\begin{array}{l}\text { Estimated } \\
\text { Learning } \%^{\mathrm{a}}\end{array}$ & Slope & $\mathrm{R}^{2 \mathrm{~b}}$ & $\begin{array}{l}\text { No. of } \\
\text { Data } \\
\text { Points }\end{array}$ & $\begin{array}{c}95 \% \\
\text { Confidence } \\
\text { Interval } \\
\text { For Slope }\end{array}$ \\
\hline \multirow[t]{6}{*}{ Assembly } & 21 & $\underset{7}{\text { Truaks and Bus Bodies }}$ & $\begin{array}{l}\text { Labor } \$ \\
\text { Total } \$\end{array}$ & $\begin{array}{l}94 \% \\
98 \%\end{array}$ & $\begin{array}{l}-[.097 \\
-0.025\end{array}$ & $\begin{array}{l}0.64 \\
0.55\end{array}$ & $\begin{array}{l}8 \\
8\end{array}$ & $\begin{array}{l}89.0-98.0 \\
96.8-99.8\end{array}$ \\
\hline & 22 & Wing Structure & $\begin{array}{l}\text { Labor Hours } \\
\text { (Actual) }\end{array}$ & $71 \%$ & $-\complement .49$ & 0.95 & 12 & $67.2-75.4$ \\
\hline & & $"$ & $\begin{array}{l}\text { Labor Hours } \\
\text { (Adjusted) }\end{array}$ & $82 \%$ & $-\complement .28$ & 0.96 & 12 & $80.0-85.0$ \\
\hline & $-^{c}$ & F-4 Wing-Slotted & Total Mfg. & $87 \%$ & -.020 & NA & 27 & NA \\
\hline & $-\mathbf{-}^{\mathrm{c}}$ & $\begin{array}{l}\text { Fuel Tank and } \\
\text { Afterbody Assy. for } \\
\text { MK46 Torpedo }\end{array}$ & $\begin{array}{l}\text { Direct Mfg. } \\
\text { Hours }\end{array}$ & $86 \%$ & -0.22 & NA & 7 & $\mathrm{NA}$ \\
\hline & $-c$ & $\begin{array}{l}\text { AN/MPQ-4A Trailer } \\
\text { Assemblies }\end{array}$ & $\begin{array}{l}\text { Direct Labor } \\
\text { Hours }\end{array}$ & $93 \%$ & -0.10 & NA & 10 & NA \\
\hline $\begin{array}{l}\text { Overall } \\
\text { Product }\end{array}$ & 23 & $\underset{" \text { Notor Vehicles }}{\|}$ & $\begin{array}{l}\text { Labor } \$ \\
\text { Total } \$\end{array}$ & $\begin{array}{l}101 \% \\
100 \%\end{array}$ & $\begin{array}{l}0.011 \\
0.002\end{array}$ & $\begin{array}{l}0.29 \\
0.33\end{array}$ & $\begin{array}{l}8 \\
8\end{array}$ & $\begin{array}{r}99.6-102.0 \\
100.0-100.3\end{array}$ \\
\hline
\end{tabular}

${ }^{a}$ Percent reduction in cost for each doubling of quantity.

$\mathrm{b}$ Measure of proportion of total variation in log cost that is explained by line of best fit.

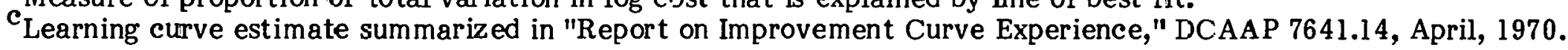


APPENDIX B

ESTIMATIONS OF THE SURROGATE LEARNING CURVE

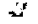




\section{SEPl}


Figure B-1. LEARNING CURVES ILLUSTRATIVE EXAMPLE: CALCULATOR

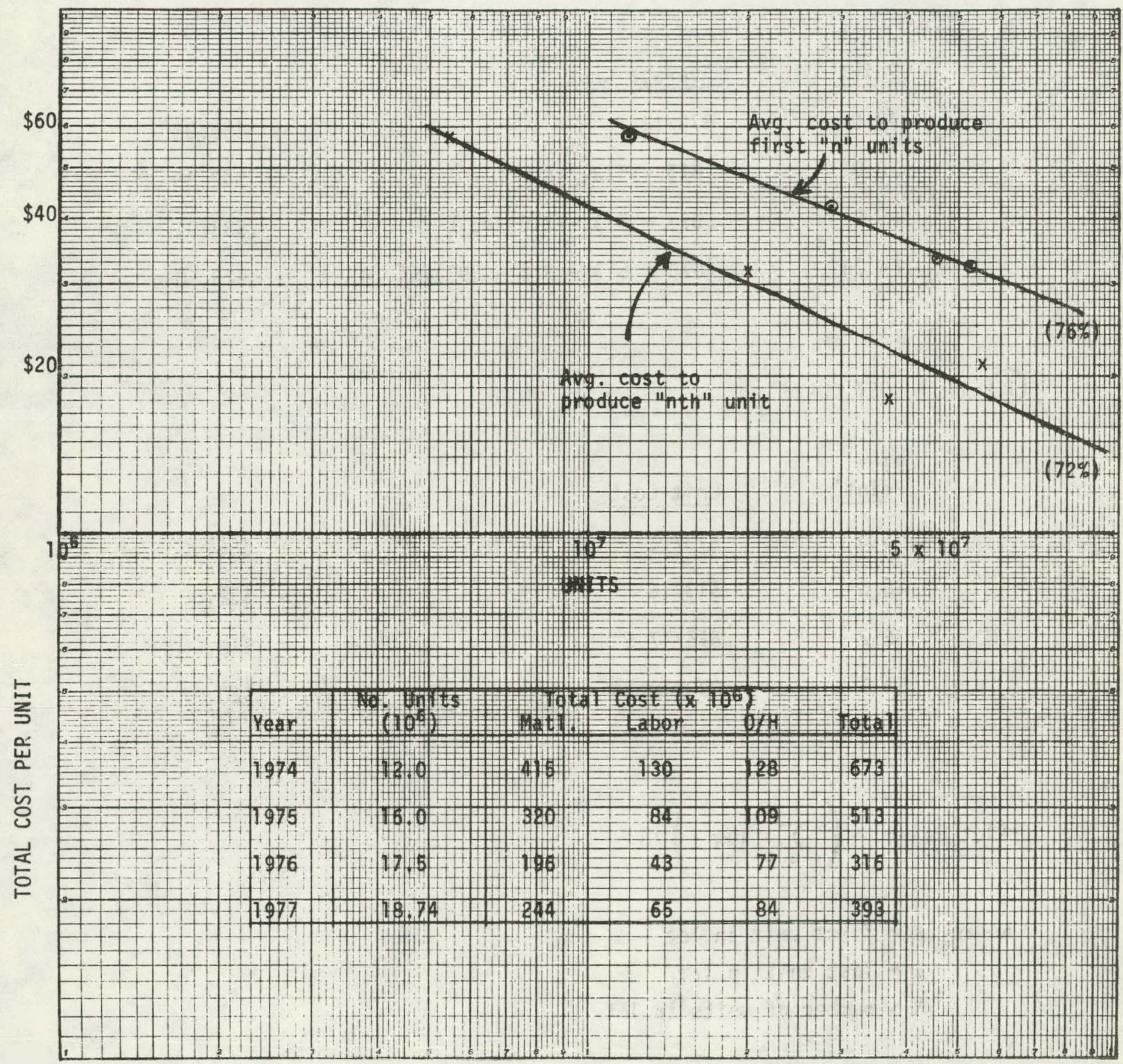


Figure B-1. LEARNING CURVES ILLUSTRATIVE EXAMPLE (continued)

(1) CUMULATIVE AVERAge CURVE

\begin{tabular}{lll}
$\begin{array}{ll}\text { Plot } \\
\text { Point }\end{array}$ & Average Cost & \\
\hline 12.0 & $673 / 12$ & $=\$ 56.08$ \\
28.0 & $(673+513) / 28$ & $=\$ 42.36$ \\
45.5 & $(673+513+316) / 45.5$ & $=\$ 33.01$ \\
64.24 & $(673+513+316+393) / 64.24$ & $=\$ 29.50$
\end{tabular}

(2) UNIT COST CURVE

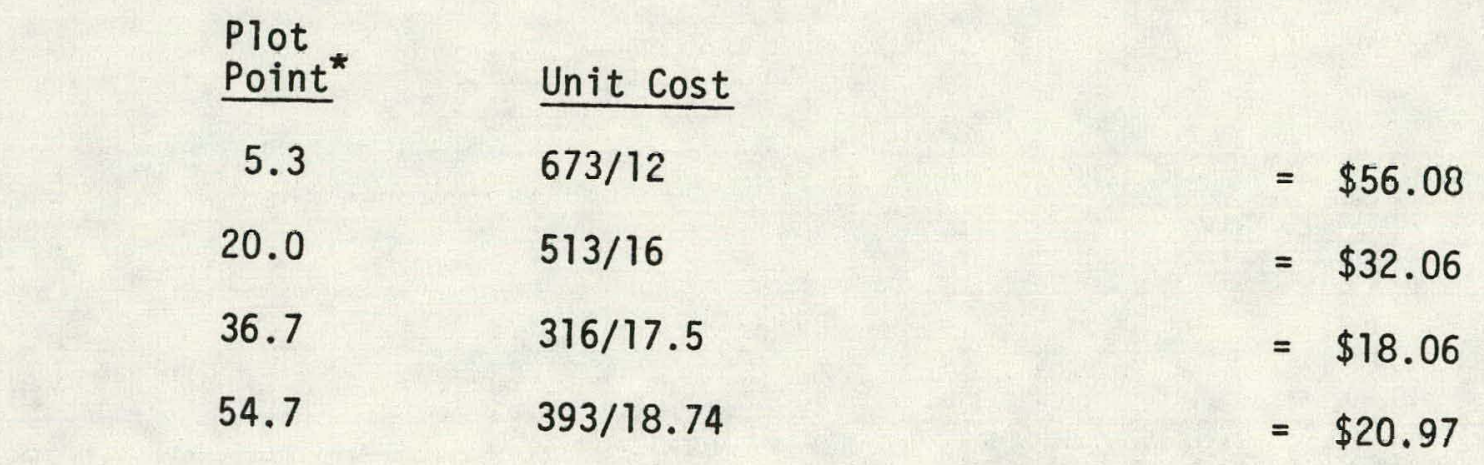

$\overline{\text { *Plot Point }}=\left(\sum_{i=F}^{L} \log 1\right) / N$

where $F=$ first unit in lot

$L=$ last unit in lot

$\mathrm{N}=$ number of units in lot 
IN THIS VERSION OF BMOPIR

- THREE VARIAGLES, RATHER THAN THO AS STATED IN THE MANUAL, ARE HRITTEN ON THE OUTPUT SAVE FILE AFTER THE DATA VARIABLES. THEY ARE RESIDUAL SOUARED, RESIDUAL. AND PREDICTEO VALUE IN THAT ORDER.

- WHEN THE CORRELATION MATRTX IS REQUESTED. THE CORRELATION OF THE REGRESSION. COEFFICIENTS IS ALSO PRINTED

IF MORE THAN ONE VARIABLE ENTERED THE EQUATION.

PROGRAM CONTROL INFORMATION

\begin{tabular}{|c|c|}
\hline $\begin{array}{l}\text { IPROBLEM } \\
\text { IINPUT }\end{array}$ & $\begin{array}{l}\text { TITLE IS 'CANOPY UCI ' } \\
\text { VARIABLES ARE } 20 \\
\text { CASES ARE } 7 \\
\text { FORMAT IS I } \\
\text { I2F5.11\% }\end{array}$ \\
\hline $\begin{array}{l}\text { JVARIABLE } \\
\text { ITRANSFORM }\end{array}$ & $\begin{array}{l}\text { NAMES ARE } C_{0} x_{0} \\
C=L O G(C) \\
x=L O G(x):\end{array}$ \\
\hline /REGRESS & $\begin{array}{l}\text { DEPENDENT IS } C_{0} \\
\text { INDEPENDENT Is } x_{\text {. }}\end{array}$ \\
\hline $\begin{array}{l}\text { APLOT } \\
\text { /END. }\end{array}$ & VARIABLE I5 $x_{0}$ \\
\hline
\end{tabular}

PROQLEM TITLE ............ANOPY (ACT)

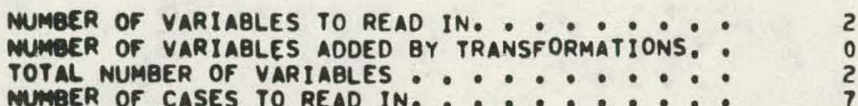
MUMBER OF CASES TO READ IN: $: \vdots: \vdots: \cdots$

CASE LABELING VARIABLES LIMITS AND MISSING VALUE CHECKED BEFORE TRANSF ORMATIONS BLANKS ARE
INPUT UNIT NUMBER
REMINO INPUT UNIT PRIOR TO READING. NO

INPUT FORMAT

(2F 5.11

INTERPRETIVE TRANSF ORMATIONS ARE

$\begin{array}{llll}c & =\operatorname{LOg} i c & 1\end{array}$

VARIABLES TO BE USED

REGRESSION INTERCEPT. ......... NON-ZERO

GROUPING VARIABLE $\ldots . . \ldots . . . .$.

MEIGHT VARIABLE.$\cdots \cdots$

PRINT COVARIANCE MATRIX $: \cdots . \cdots$

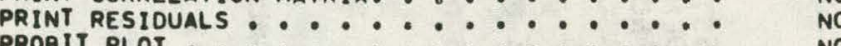

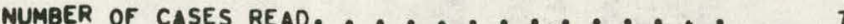



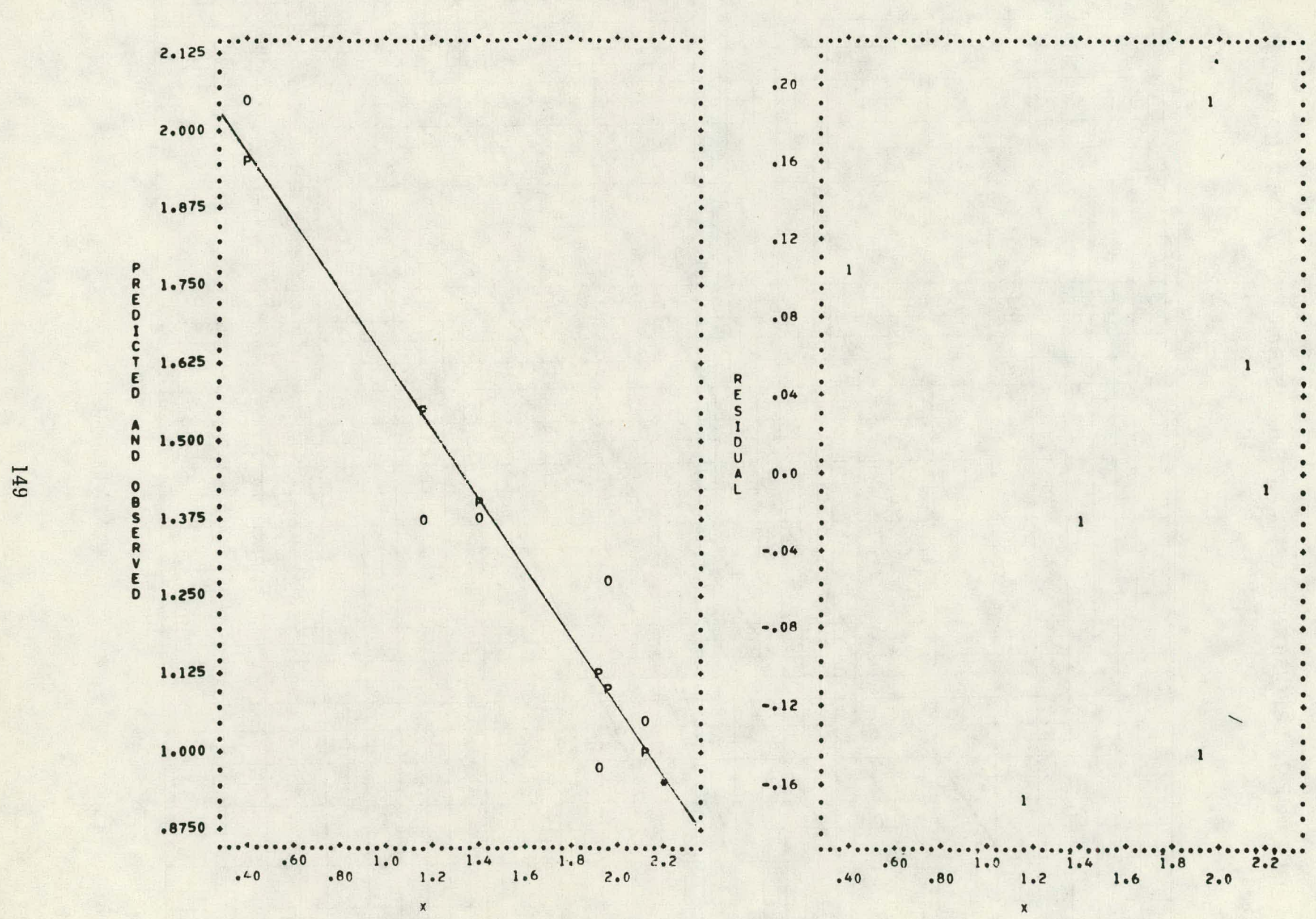

Figure B-2. REGRESSION OUTPUT (continued) 
Figure B-3. PRECISION OF ESTIMATES ILLUSTRATIVE EXAMPLE (CANOPY)

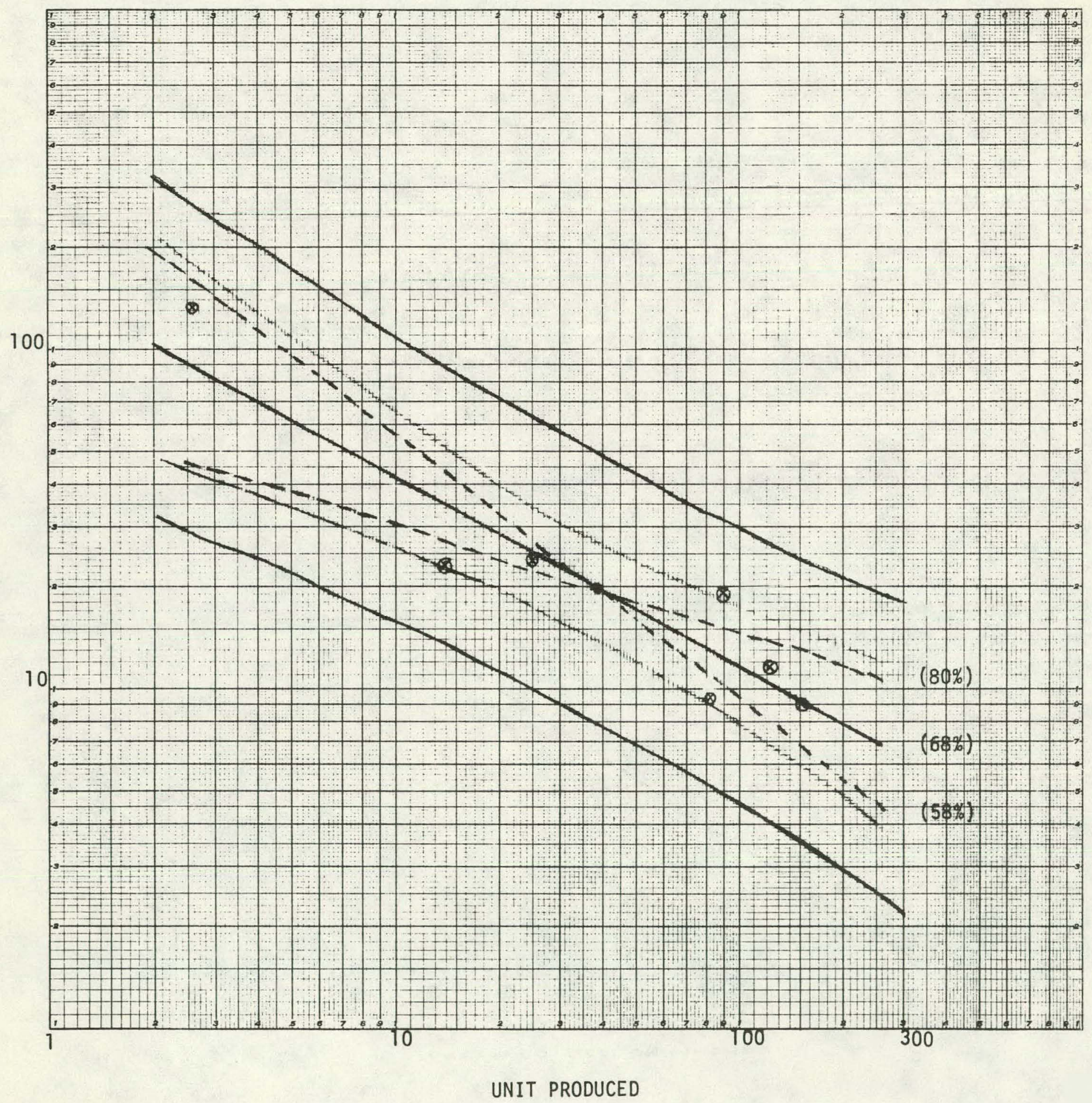


APPENDIX C

COST CURVES FOR THE MDAC AND GE HELIOSTAT DESIGNS 
(들 


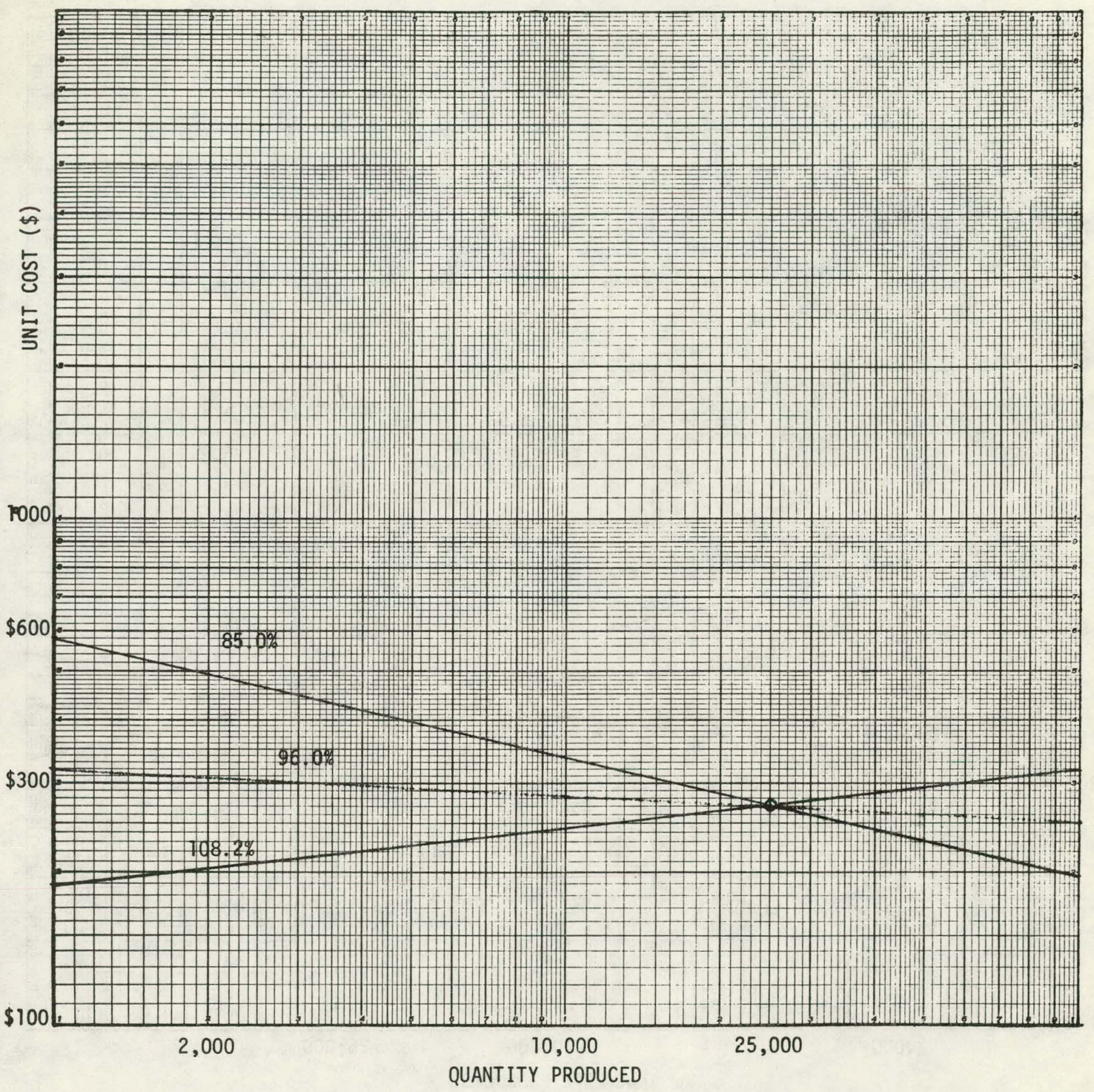

Figure C-1. REFLECTOR (GE) 


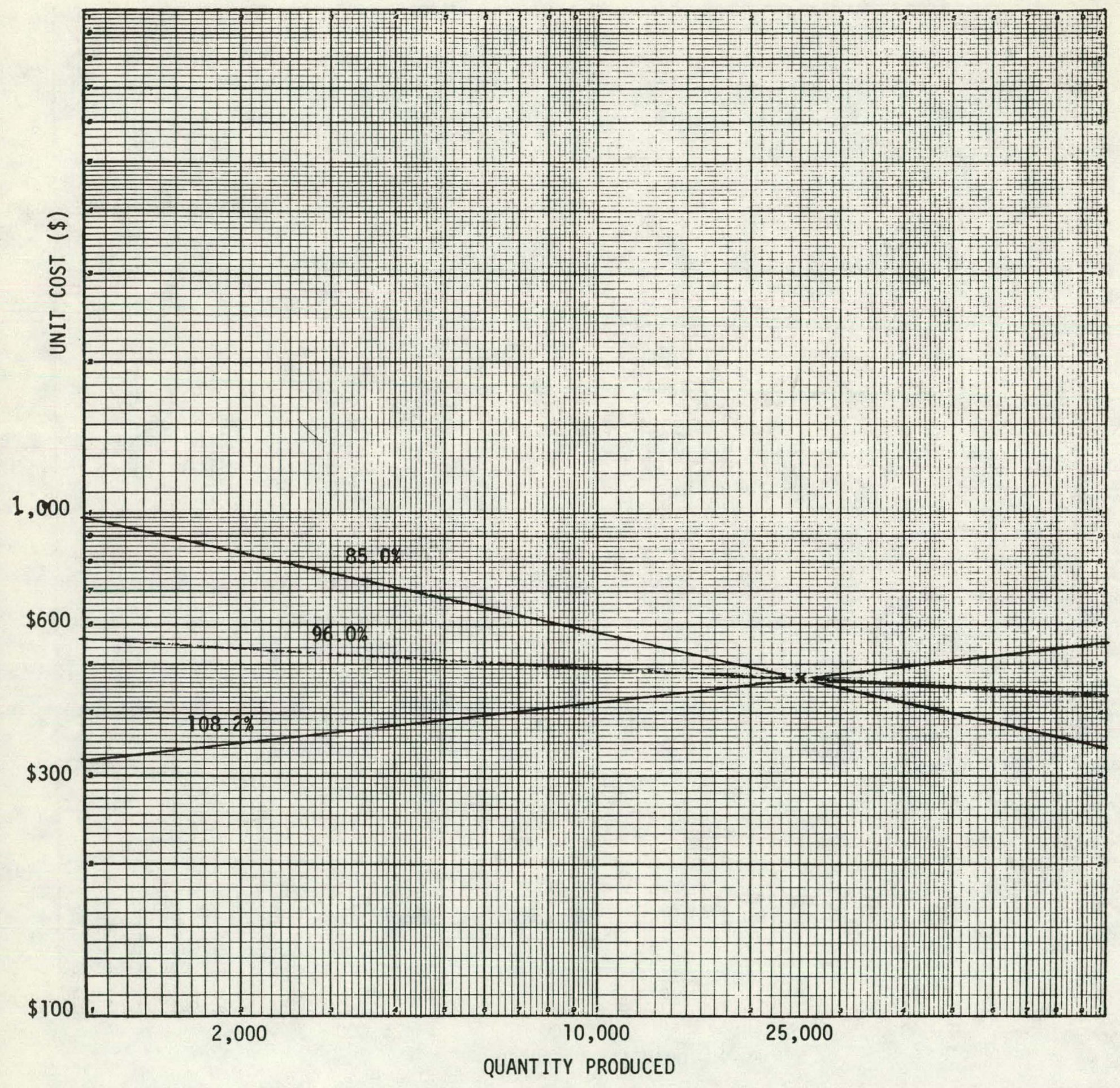

Figure C-2. REFLECTOR (MD) 


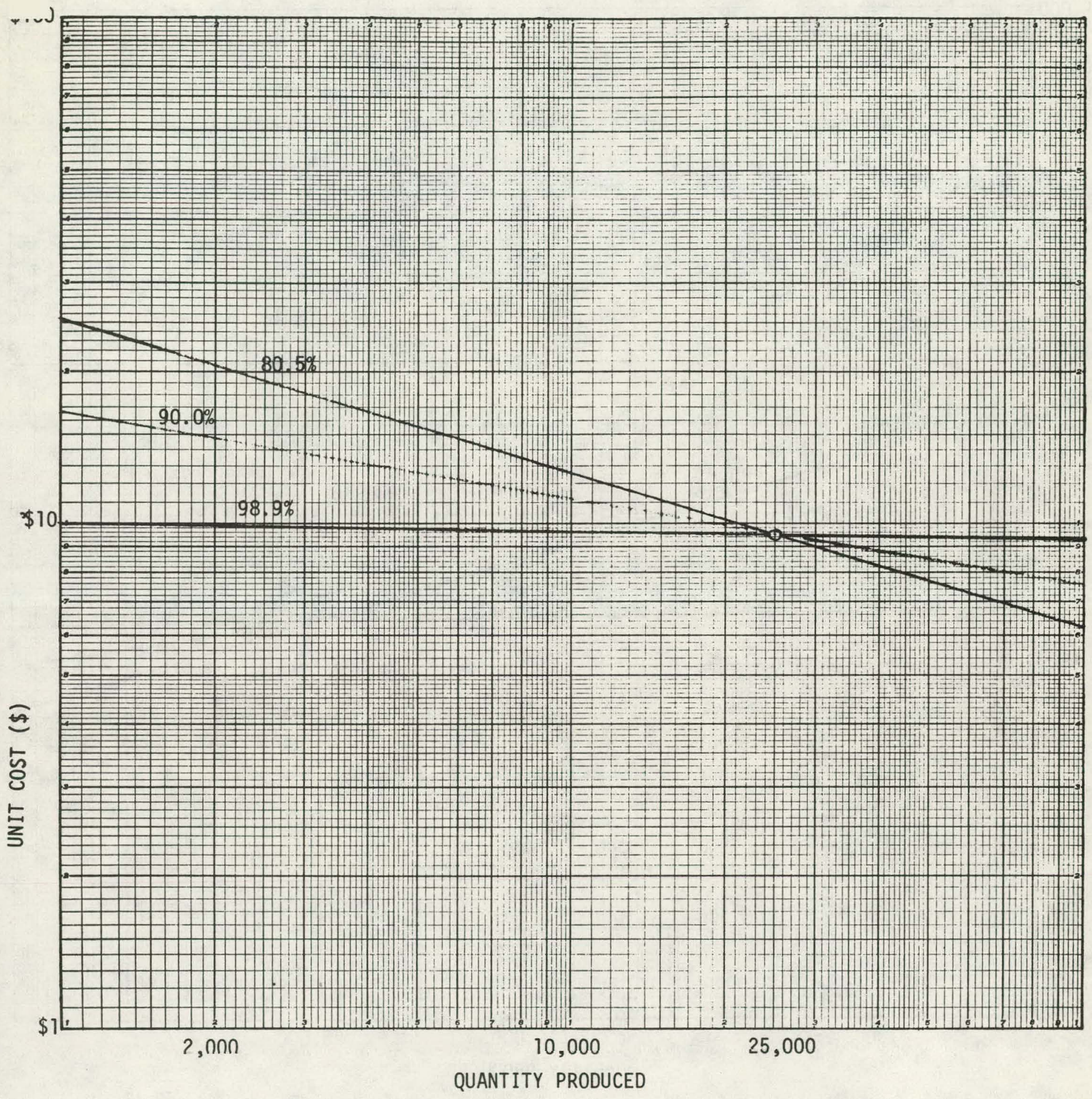

Figure C-3. ELEVATION ACTUATOR (GE) 


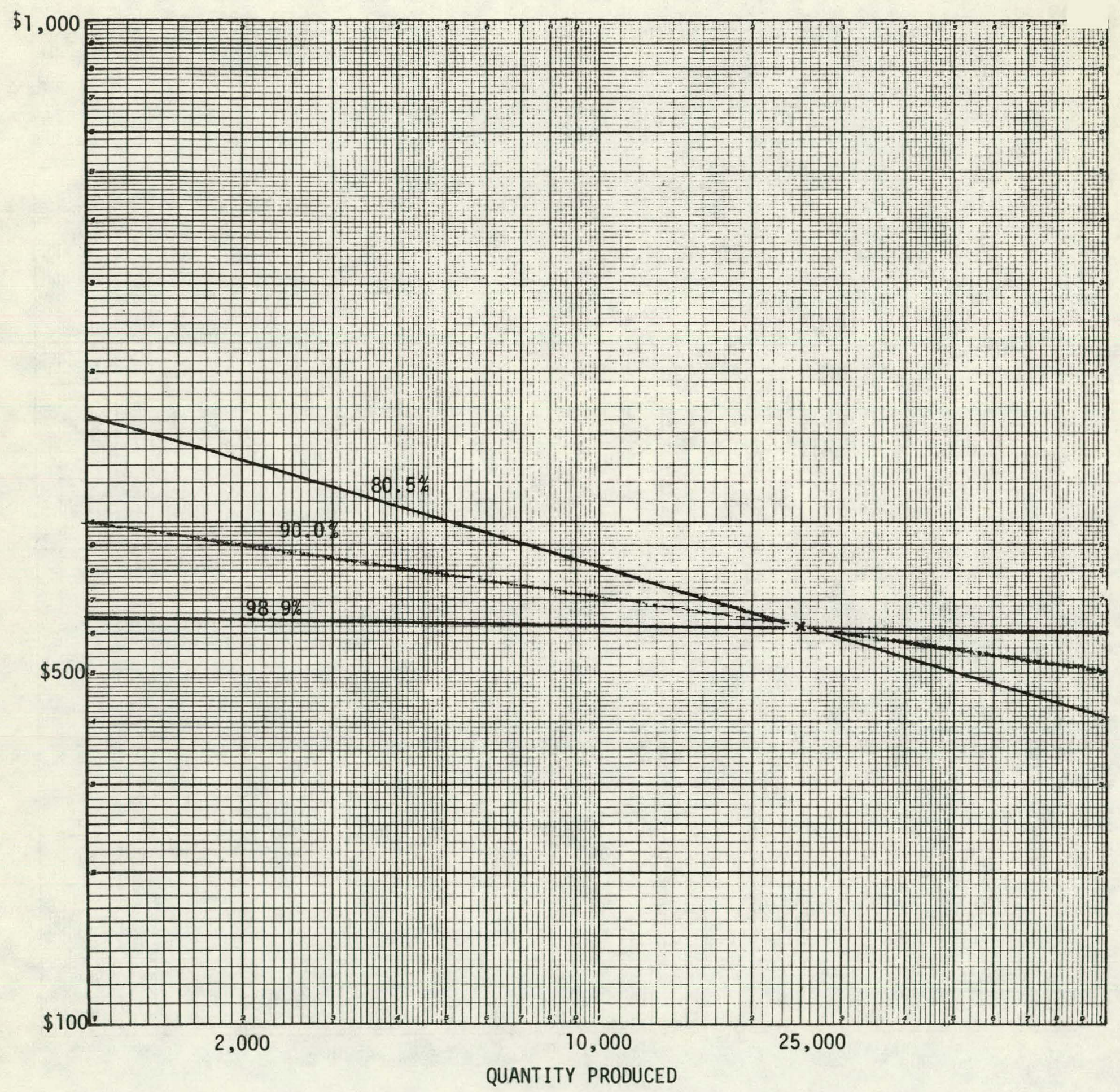

Figure C-4. ELEVATION ACTUATOR (MD) 


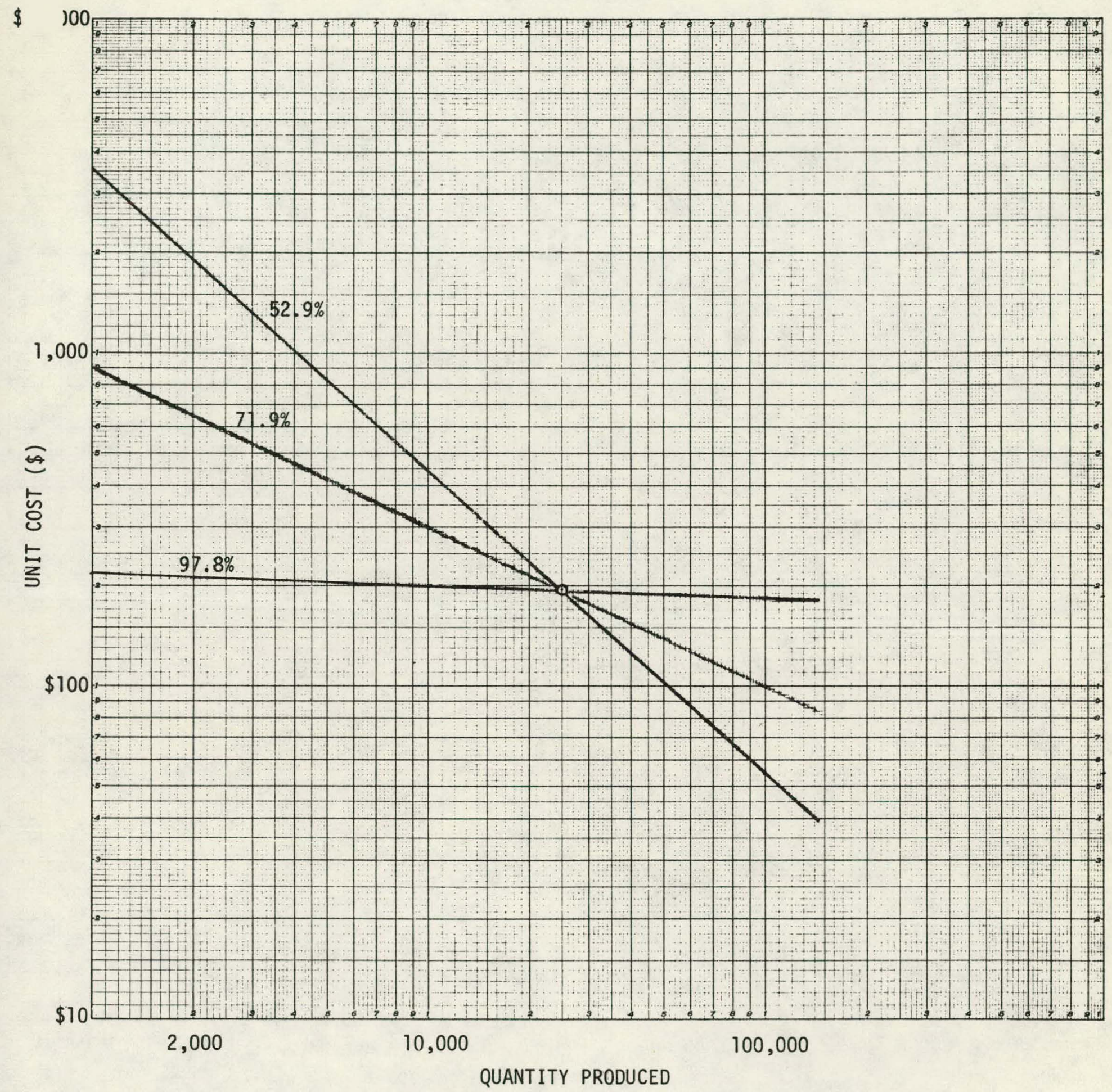

Figure C-5. DRIVE CONTROLS (GE) 


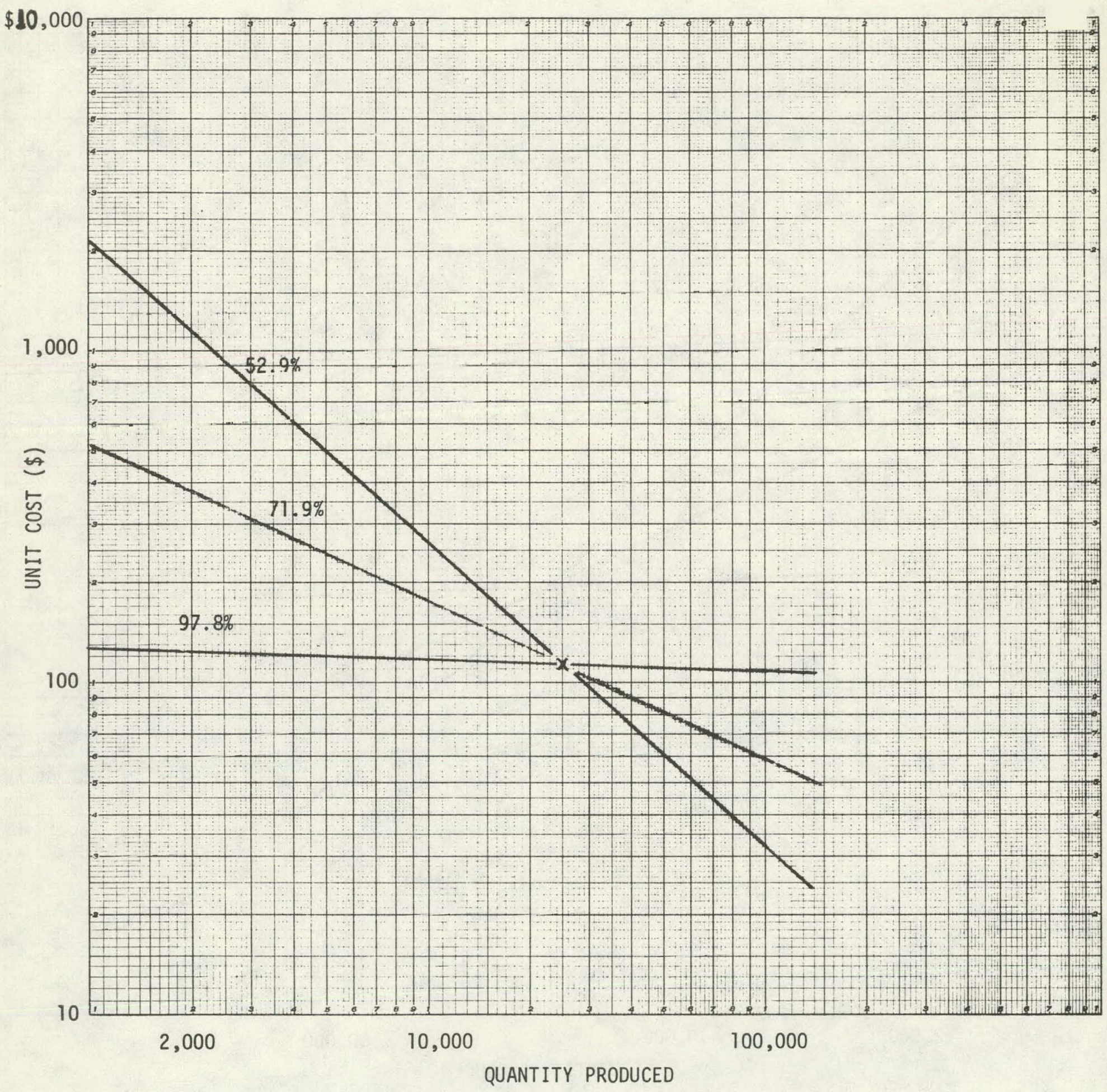

Figure C-6. DRIVE CONTROLS (MD) 


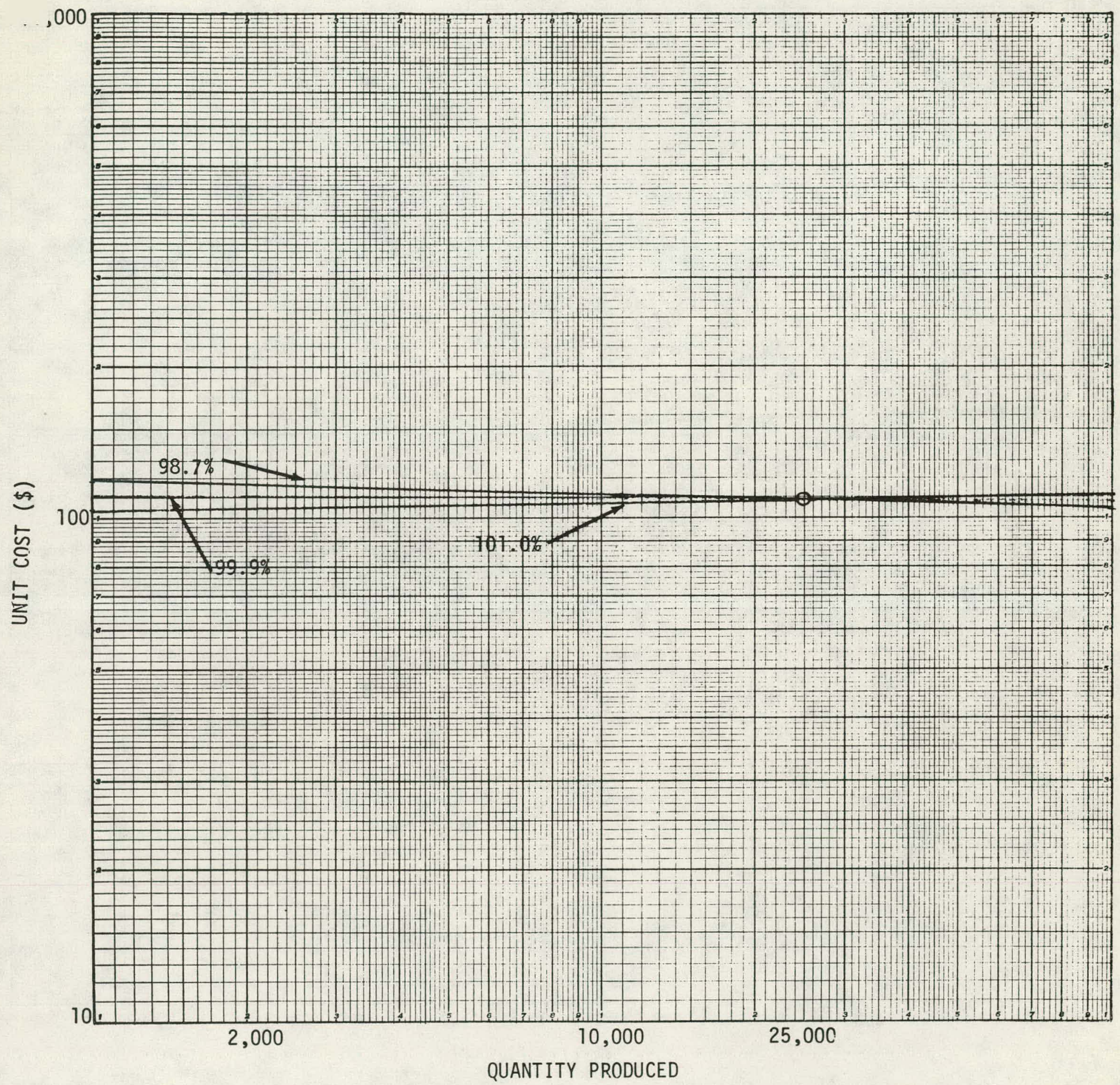

Figure C-7. PEDESTAL (GE) 


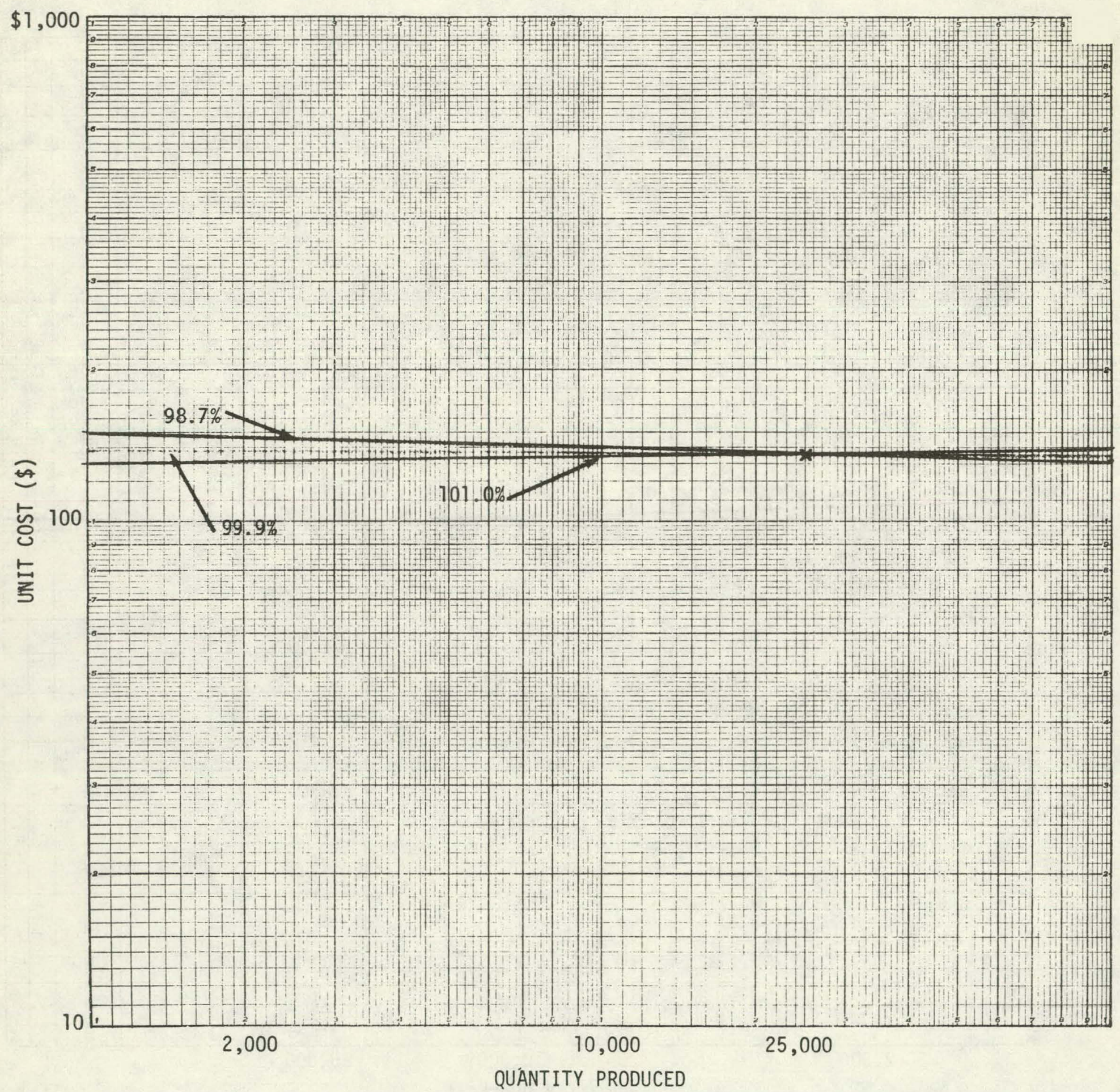

Figure C-8. PEDESTAL (MD) 


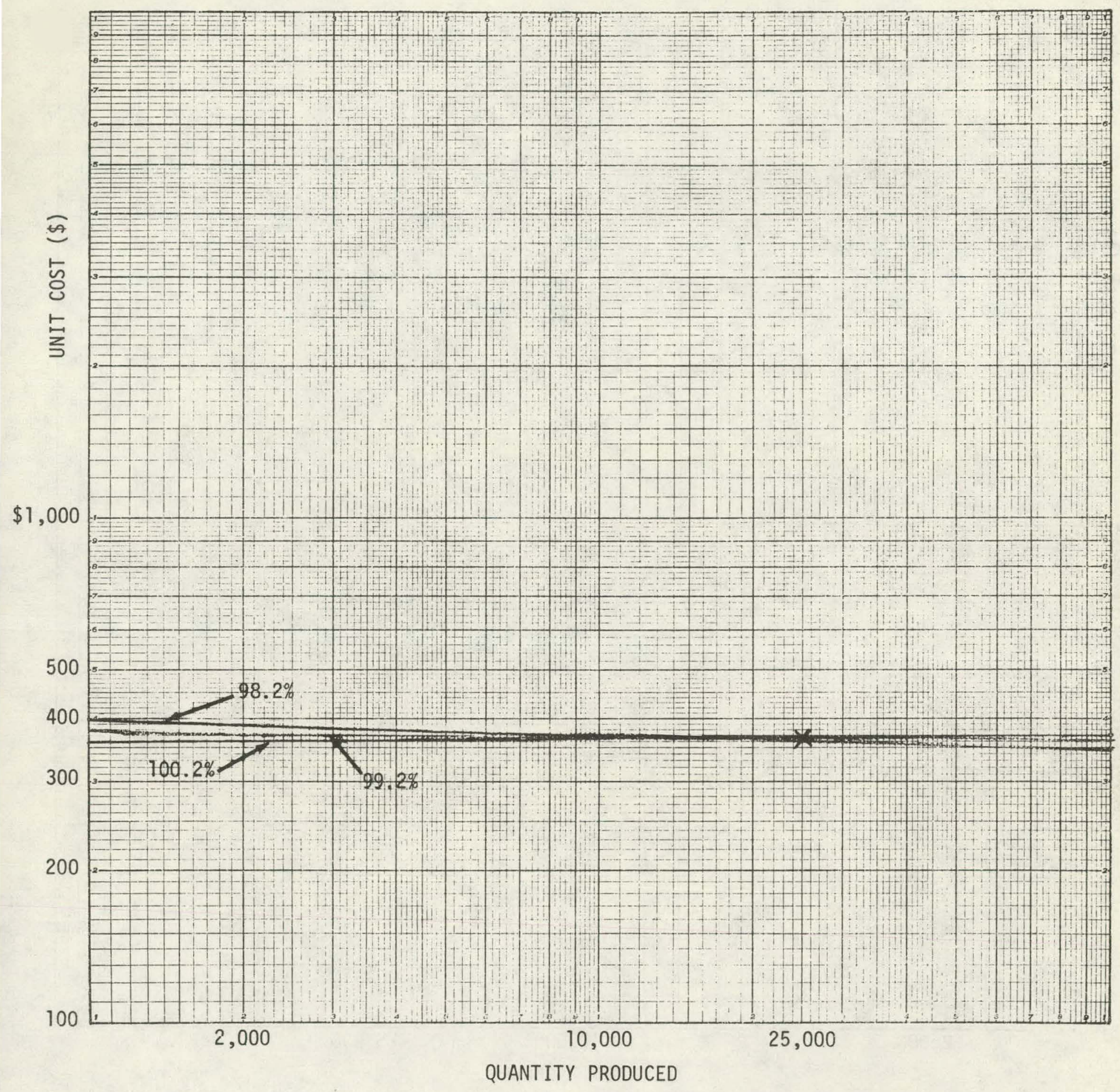

Figure C-9. REFLECTOR SUPPORTS (MD) 


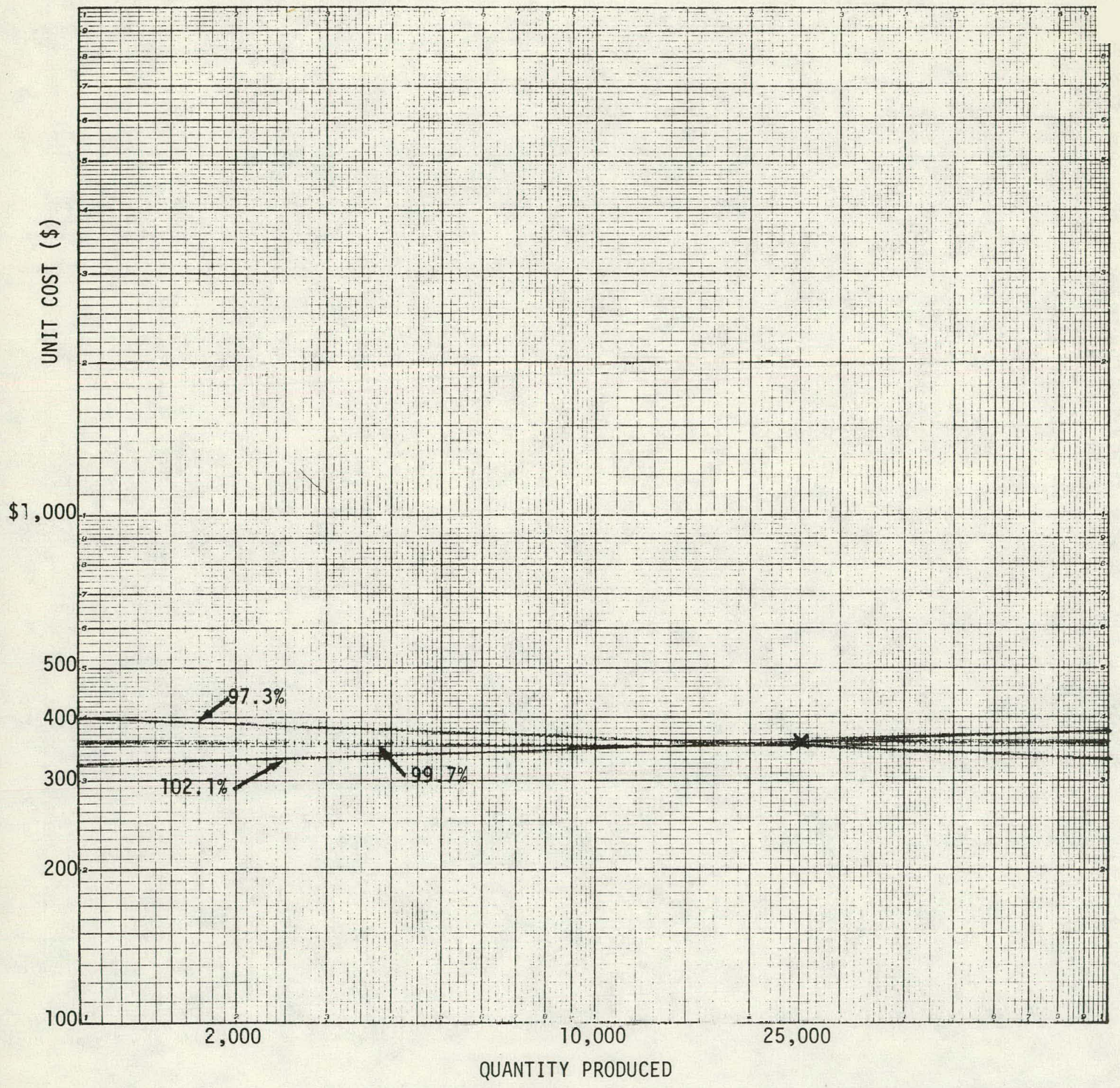

Figure C-10. AZIMUTH GEAR BOX (MD) 


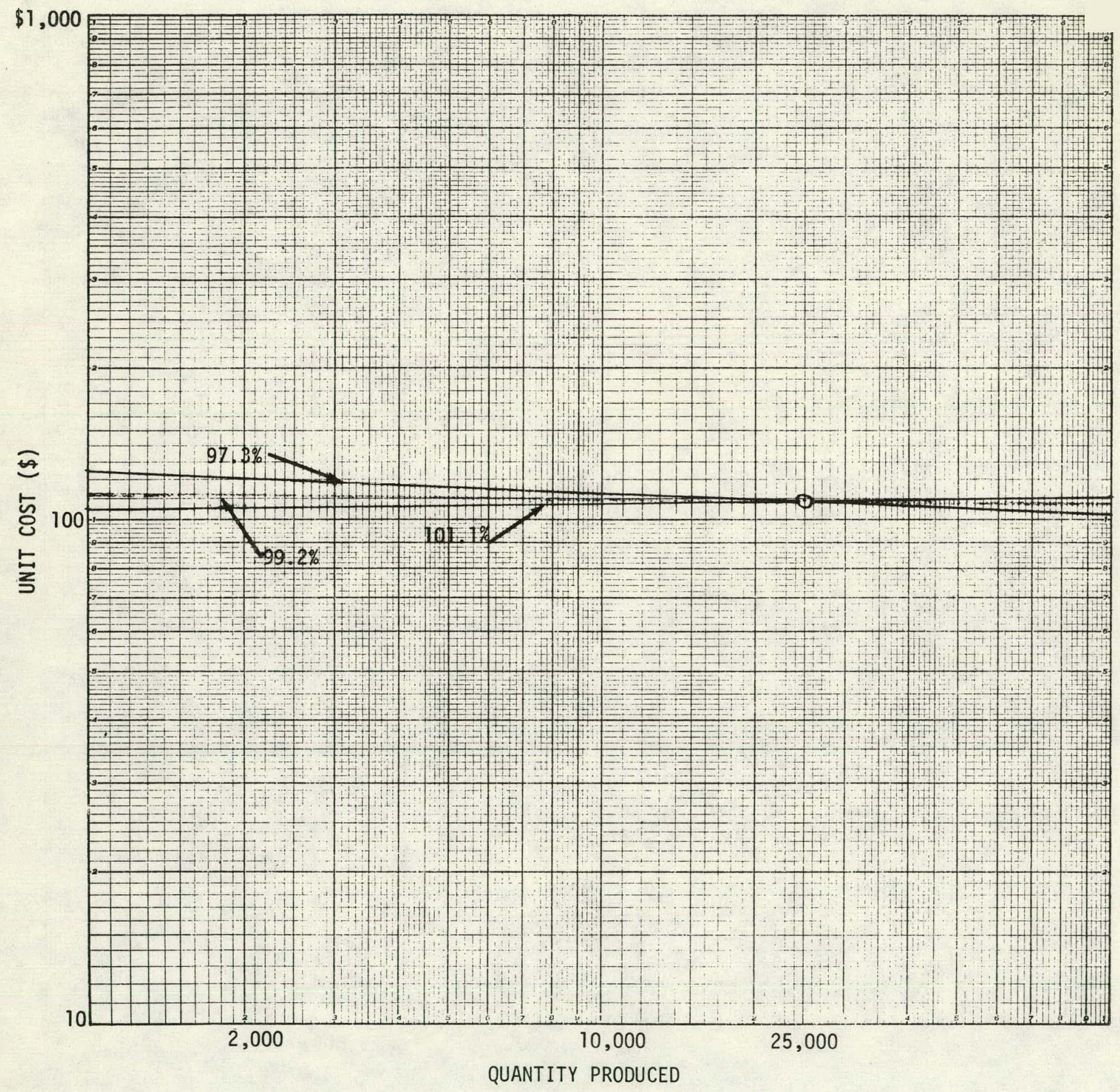

Figure C-12. REFLECTOR YOKE (GE) 


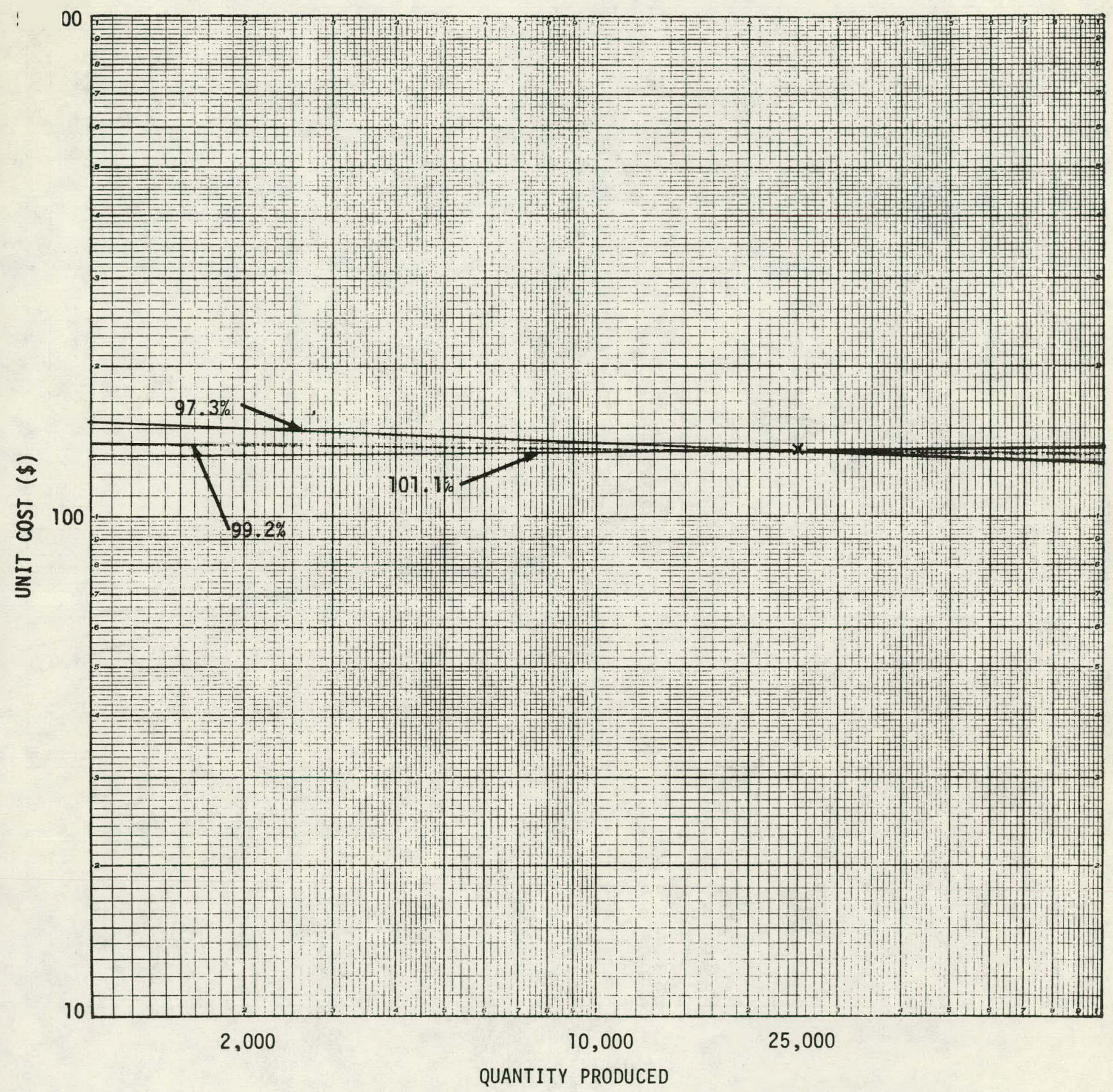

Figure C-13. REFLECTOR YOKE (MD) 


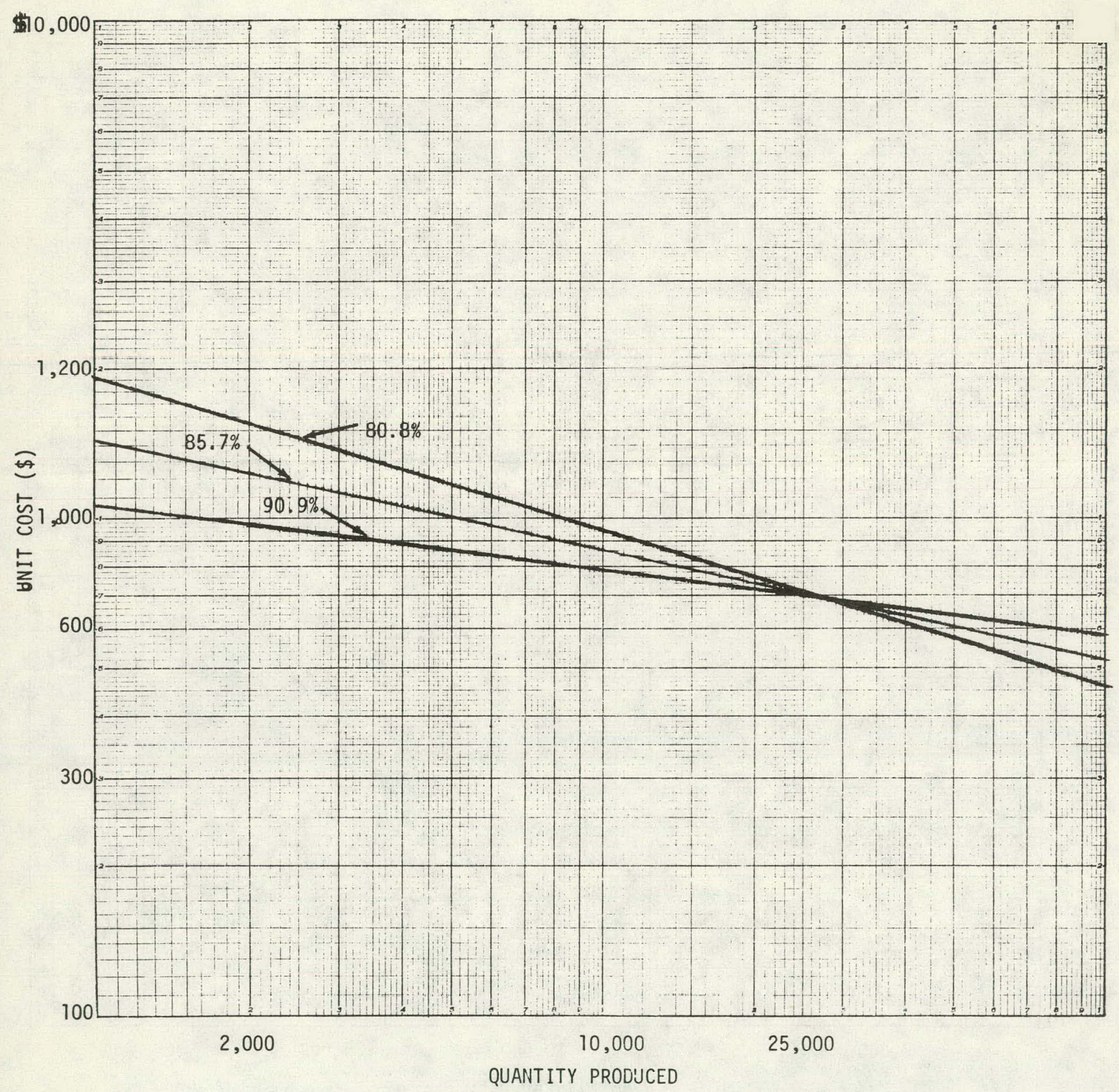

Figure C-14. REFLECTOR ENCLOSURE (GE) 


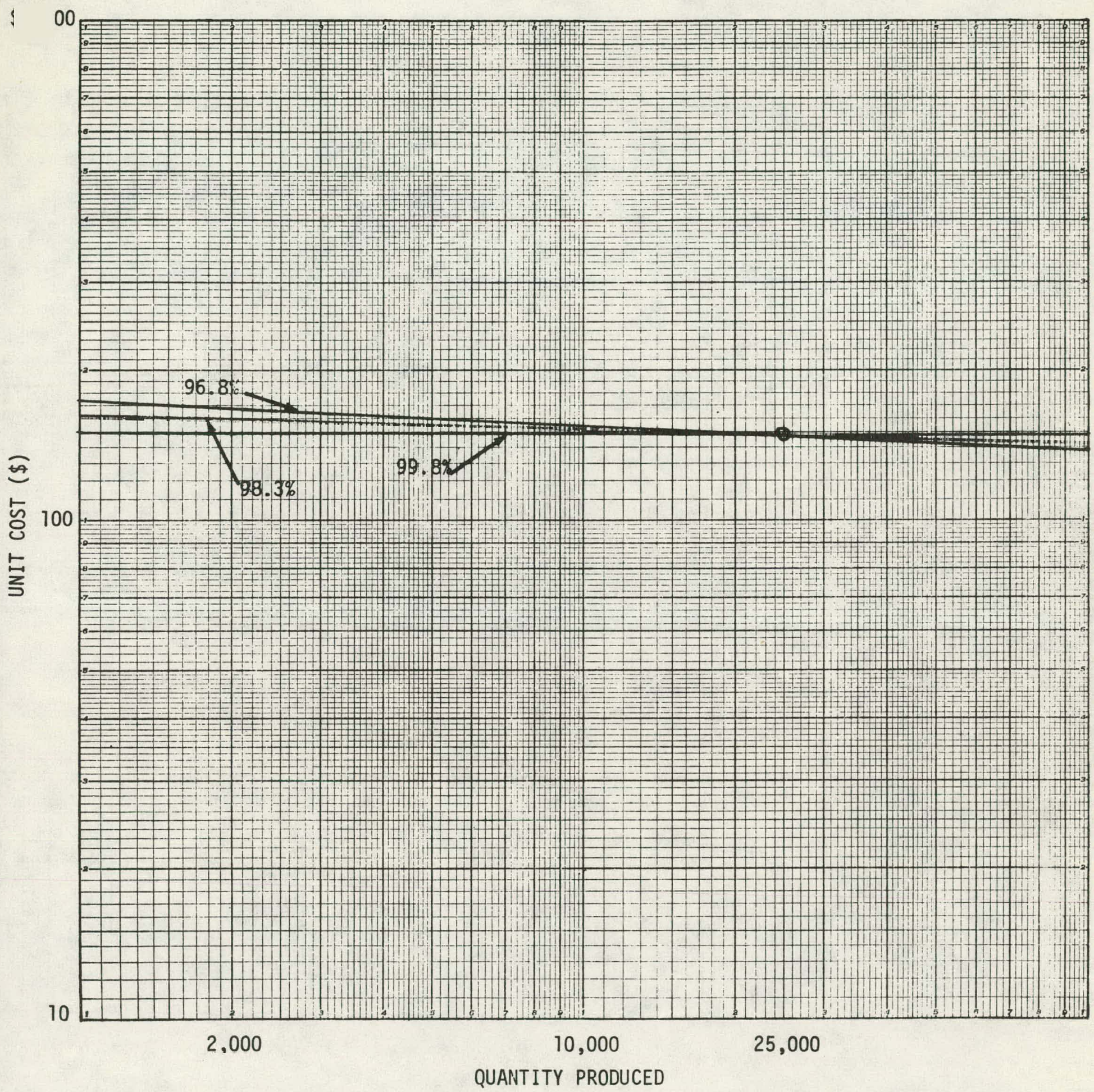

Figure C-15. ASSEMBLY (GE) 


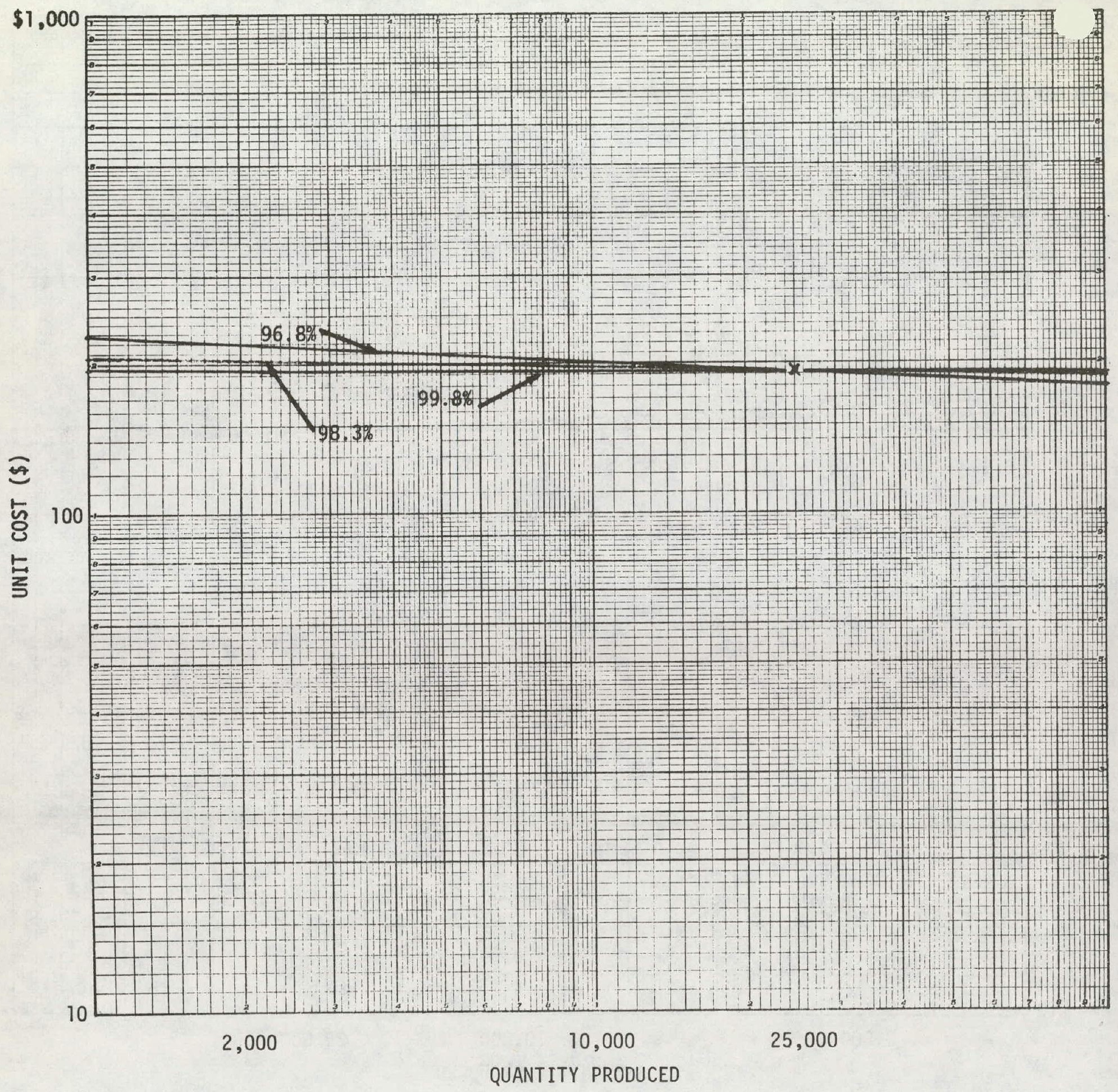

Figure C-16. ASSEMBLY (MD) 


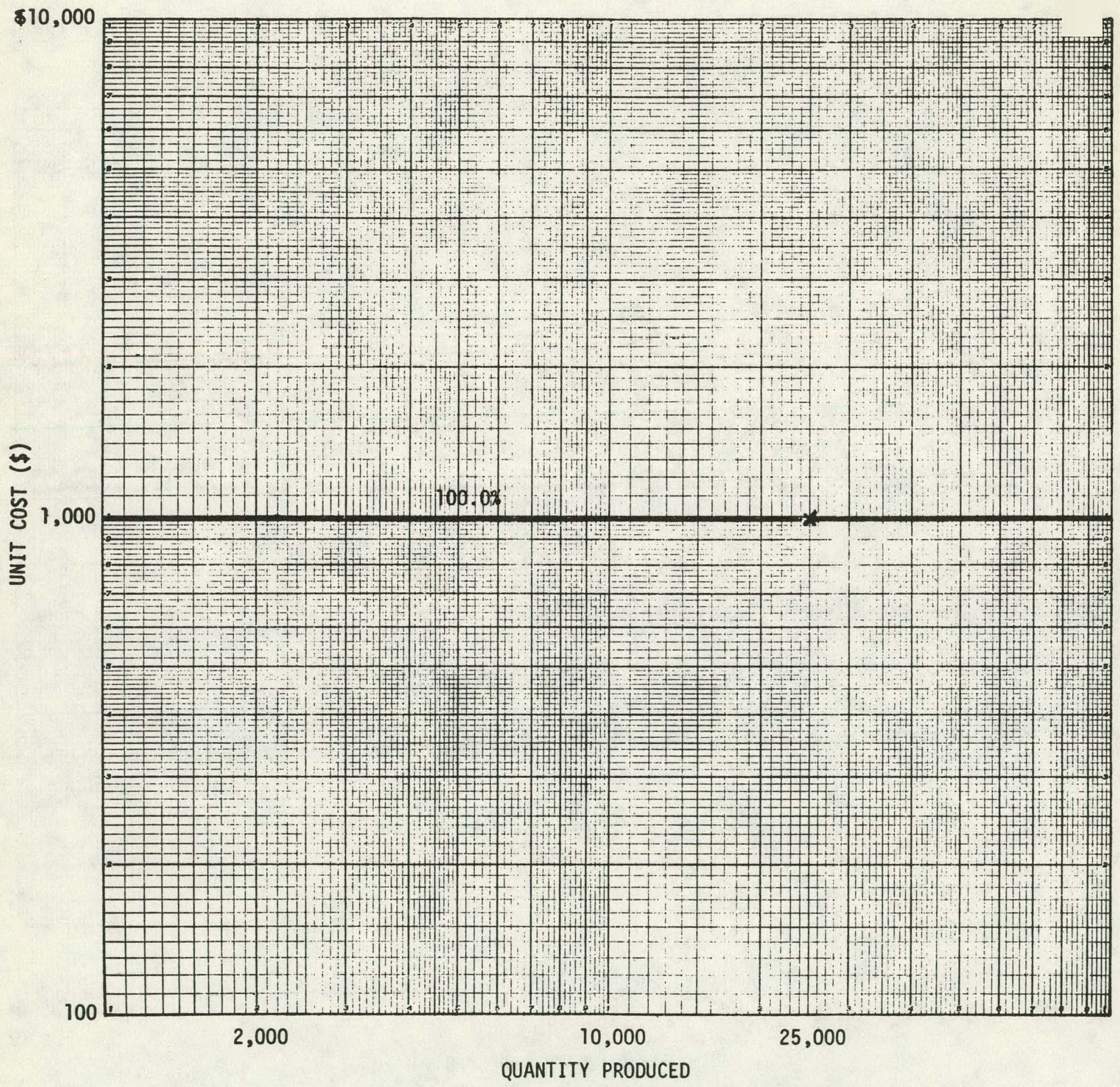

Figure C-18. ALL OTHER COMPONENTS (MD) 


\begin{tabular}{|c|c|c|}
\hline $\begin{array}{l}\text { Document Control } \\
\text { Page }\end{array}$ & $\begin{array}{l}\text { 1. SERI Report No. } \\
\text { TR-353-459 }\end{array}$ & 3. Recipient's Accession No. \\
\hline \multicolumn{2}{|l|}{ 4. Title and Subtitle } & $\begin{array}{r}\text { 5. Publication Date } \\
\text { April } 1980 \\
\end{array}$ \\
\hline \multicolumn{2}{|c|}{ An Investigation of Learning and Experience Curves } & 6. \\
\hline \multicolumn{2}{|l|}{ 7. Author(s) } & 8. Periorming Organization Rept. No. \\
\hline \multicolumn{2}{|c|}{ 9. Performing Organization Name and Address } & $\begin{array}{l}\text { 10. Project/Task/Work Unit No. } \\
5227\end{array}$ \\
\hline \multicolumn{2}{|c|}{$\begin{array}{l}\text { Solar Energy Research Institute } \\
1617 \text { Cole Boulevard } \\
\text { Golden, Colorado } 80401\end{array}$} & $\begin{array}{l}\text { 11. Contract (C) or Grant (G) No. } \\
\text { (C) } \\
\text { (G) }\end{array}$ \\
\hline \multirow{2}{*}{\multicolumn{2}{|c|}{ 12. Sponsoring Organization Name and Address }} & $\begin{array}{l}\text { 13. Type of Report \& Period Covered } \\
\text { Technical Report }\end{array}$ \\
\hline & & 14. \\
\hline
\end{tabular}

16. Abstract (Limit: 200 words)

This study assesses the applicability of learning and experience curves for predicting future costs of solar technologies, and the major test case is the production economics of heliostats. Alternative methods for estimating cost reductions in systems manufacture are discussed, and procedures for using learning and experience curves to predict costs are outlined. Because adequate production data often do not exist, production histories of analogous products/ processes are analyzed and learning and aggregated cost curves for these surrogates estimated. If the surrogate learning curves apply, they can be used to estimate solar technology costs. The steps involved in generating these cost estimates are given. Second-generation glass-steel and inflated-bubble heliostat design concepts, developed by $\mathrm{MDAC}$ and $\mathrm{GE}$, respectively, are described; a costing scenario for 25,000 units/yr is detailed; surrogates for cost analysis are chosen; learning and aggregate cost curves are estimated; and aggregate cost curves for the GE and MDAC designs are estimated. However, an approach that combines a neoclassical production function with a learning-by-doing hypothesis is needed to yield a cost relation compatible with the historical learning curve and the traditional cost function of economic theory.

17. Document Analysis

a. Descriptors Learning Curves ; Experience Curves ; Commercialization ; Design ; Production ; Cost : Learning : Heliostats ; Installation

b. Identifiers/Open-Ended Terms

c. UC Categories

18. Availability Statement

National Technical Information Service

U. S. Department of Commerce

5285 Port Royal Road

Springfield, Virginia 22161

19. No. of Pages

190

20. Price

$\$ 9.00$ 